Portland State University

PDXScholar

$1-1-1979$

\title{
Negotiating the guilty plea: a study of the process of felony case disposition in one urban court system
}

\author{
Kathryn Ann Farr \\ Portland State University
}

Follow this and additional works at: https://pdxscholar.library.pdx.edu/open_access_etds

\section{Let us know how access to this document benefits you.}

\section{Recommended Citation}

Farr, Kathryn Ann, "Negotiating the guilty plea: a study of the process of felony case disposition in one urban court system" (1979). Dissertations and Theses. Paper 875.

https://doi.org/10.15760/etd.875

This Dissertation is brought to you for free and open access. It has been accepted for inclusion in Dissertations and Theses by an authorized administrator of PDXScholar. Please contact us if we can make this document more accessible: pdxscholar@pdx.edu. 
NEGOTIATING THE GUILTY PLEA:

A STUDY OF THE PROCESS OF FELONY CASE DISPOSITION

IN ONE URBAN COURT SYSTEM

by

KATHRYN ANN FARR

A dissertation submitted in partial fulfillment of the requirements for the degree of

DOCTOR OF PHILOSOPHY

in

URBAN AFFAIRS

Portland State University

1979 
TO THE OFFICE OF GRADUATE STUDIES AND RESEARCH:

The members of the Committee approve the dissertation of

Kathryn Ann Farr presented April 24, 1979.
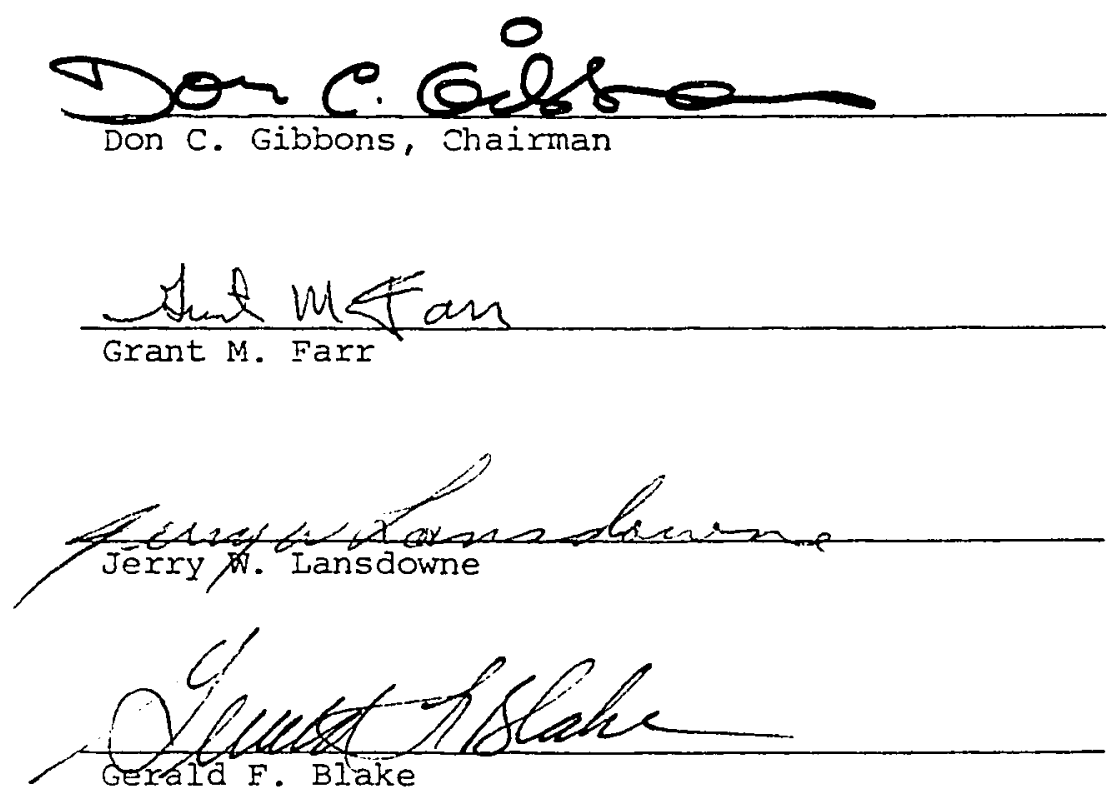

APPROVED:

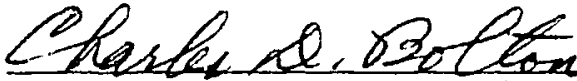

Charles D. Bolton, Acting Dean, School of Urban Affairs

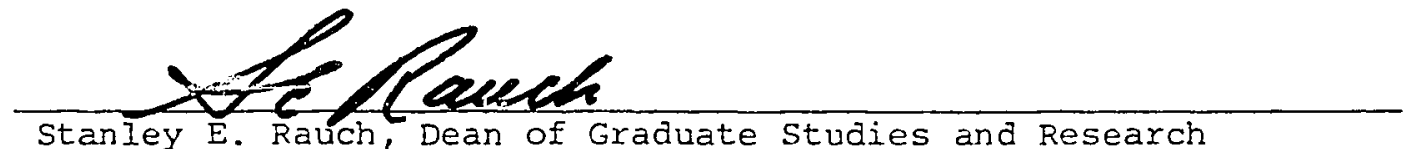


AN ABSTRACT OF THE DISSERTATION OF Kathryn Ann Farr for the Doctor of Philosophy in Urban Affairs presented April 24, 1979.

Title: Negotiating the Guilty Plea: A Study of the Process of Felony Case ijisposition in One Urban Court System

APPROVED BY MEMBERS OF THE DISSERTATION CONMITTEE:

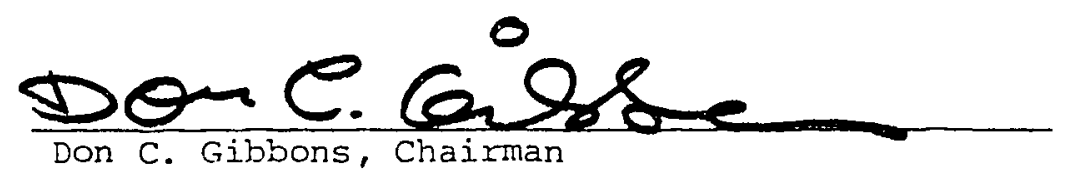
$\frac{\text { D.t } M . \tan }{\text { Grant M. Farr }}$
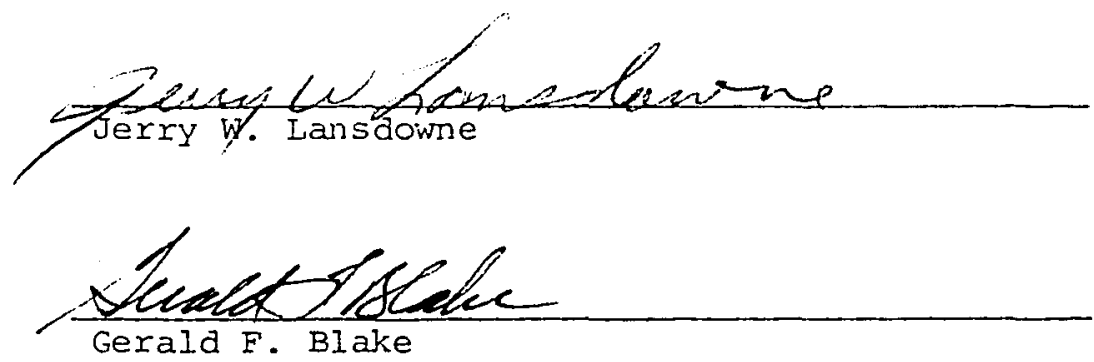

Recent research has led to a growing awareness that the dominant method of settling criminal cases in the United States involves disposition without trial. The overwhelming majority of criminal cases are settled by guilty pleas, and the majority of guilty plea dispositions involve some kind of bargain on the charge or sentence. The purpose of the present study was to 
examine and analyze the phenomenon of negotiating the guilty plea in terms of its relationship to the functional needs and ideal goals of the court system.

A basic assumption of this study was that case disposition through a bargaining process provides for both functional needs and ideal goals which are not clearly provided for in the trial system. A detailed examination of felony case disposition without trial in one Pacific Northwest urban court system was undertaken to ascertain the precise nature of the bargaining process. Records regarding the nature and outcomes of felony dispositions in 1976 and 1977 were researched, along with information on the formal structure, procedures and policies of the court organization. Interviews with prosecutors, public defenders and judges in the felony court system provided attitudinal data. Observations of guilty plea hearings and negotiation conferences allowed the researcher to record actual activities in the disposition process.

The data indicated that the majority of cases were settled by guilty pleas and that the majority of guilty pleas involved some kind of bargain. Plea negotiation in this court system was routinized, formalized and highly structured. The bargaining process was prosecutor-dominated, in part due to the District Attorney Office policy which was noticeably inflexible in terms of bargaining criteria. The one commodity of power held by the defense attomey was strength of case. If the defense could find legal "loopholes" in the state's case, the chances of the defendant getting a good deal improved. This emphasis on legal factors 
appeared to strengthen the professional orientation as well as the adversary perspective of the opposing attomeys.

Pleading guilty to a reduced charge resulted in the greatest likelihood of a defendant receiving a non-incarceration sentence. The majority of reductions were to offenses necessarily included in the initial charge. Conviction by trial resulted in the highest, proportion of incarceration sentences of all closing types. However, there was evidence that circumstances of the case and the defendant were influential regarding the likelihood of incarceration at the sentencing stage.

A balancing factor appeared to be at work according to comparisons of the 1976 and 1977 data. Changes in the District Attorney Office policy instituted in 1977 expanded the list of non-reducible offenses. While the proportion of trial closings consequently increased for these non-reducible offenses, this increase was offset by a decrease in the proportion of trials for offenses not included in the non-reducible category. Generally, the findings supported the theoretical assumption that disposition by guilty plea negotiation could fulfill functional needs of the court system within a legalistic framework. 
The resources utilized in a research undertaking include the contributions of individuals whose input helps sustain the researcher as well as the research project. This dissertation was completed with the help of a number of individuals. The members of my faculty committee--Don C. Gibbons, Grant M. Farr, Jerry w. Lansdowne and Gerald F. Blake--were continually available to offer advice and suggestions. In particular, I would like to express my deep appreciation to the committee chair, Don C. Gibbons, for his encouragement and support throughout my entire graduate experience. Kathy Grove is to be acknowledged for her efficiency in typing the manuscript in a short period of time and for her reassurances that we would (and we did) meet the graduation deadline. Additional sustenance was provided by Ivan Clark and by my children (Tori, Sheila and Erin Farr), who lived with me and thus with the research project from its inception to its conclusion. Finally, the study could not have been done at all without the cooperation of the members of the court system under study who willingly participated as subjects and as resource advisors. 
TABLE OF CONTENTS

PAGE

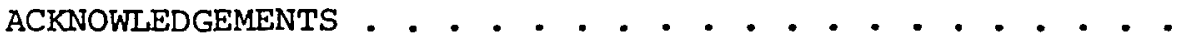

CHAPTER

I THE RESEARCH PROBLEM: SETTLING CASES THROUGH

Introduction ..............

Theoretical Framework .........

Production and Efficiency

Routinization

Cooperation

Compliance and Commitment

Prior Research and the Need for Further

Exploration . . . . . . . . .

Plea Bargaining: Relationships Between the Informal and Formal Process

Plea Bargaining and Goal Achievement

The Relationship Between Key Actors

in the Bargaining Process

The Research Problem . . . . . . . .

Propositions

Exploratory Areas

Summary

II RESEARCHING THE PROBLEM: DESIGN, SETTING, SOURCES AND TECHNIQUES . . . . . . . . . 30

The Research Design . . . . . . . . . 30

The Research Setting . . . . . . . . 32 
Data Collection: Sources and Techniques . . . . 34

Methods for Data Analysis . . . . . . . . . 39

Concluding Remarks . . . . . . . . . . . . 41

III THE FORMAL ORGANIZATION: STRUCTURES, PROCEDURES

AND POLICIES . . . . . . . . . . . . . . . 43

Introduction . . . . . . . . . . . . . . 43

Felony Court . . . . . . . . . . . . . . 44

Office of the District Attorney . . . . . . . . 47

Formal structure

Plea Bargaining: Formal Policy

Screening and Charging: Formal Policy

Office of the Public Defender . . . . . . . . 57

Concluding Remarks . . . . . . . . . . . 60

IV THE NATURE OF OFFENSES, OFFENDERS AND DISPOSITIONS:

CRIMINAL COURT FELONY CASES . . . . . . . . . . 62

Introduction . . . . . . . . . . . . . 62

A Profile of the Sample Populations . . . . . . . 64

The Nature of Offenses

The Nature of closings

The Nature of offenders

The Nature of Punishment

Relationships Between the Nature of offenses and offenders

Defendant Characteristics: Interrelationships

Profile Summary

Relationships Between Type Closing and Offense/

Offender Characteristic . . . . . . . . .

Offense Type

Offender Characteristics

Multiple counts

Summary 
The Issue of Punishment . . . . . . . .

Pre-Trial Detention and Offense/

offender Characteristics

Sentencing and offense/Offendex Characteristics

Variations in Sentencing

Bargains and Punishment

Summary

Pleading to a Lesser offense . . . . . . .

102

Case Disposition Without Trial and Efficient Production . . . . . . . . . . . .

Changes in Disposition Patterns: 1976 and 1977 Comparisons . . . . . . . . . .

Shifts in the Relationships Between Offense and Closing Types: Stability in the Overall Picture

Shifts in Relationships Between offenses, Closings and Punishment: Overall Increases in the Likelihood of Incarceration

Concluding Remarks . . . . . . . . . .

THE NATURE OF DISPOSITIONAL OUTCOMES: SUMMARY AND SELECTED STATISTICS ON CASES HANDLED BY THE OFFICE OF THE PUBLIC DEFENDER -. - . .

Introduction . . . . . . . . . . . . . .

Disposition Outcomes of Felony Cases Handled by Public Defenders: Summary Statistics

Burglary I and Forgery I Public Defender

Cases . . . . . . . . . . . . . . .

Burglary I

Forgery I

Concluding Remarks . . . . . . . . . . 
Consideration Given Various Factors

in the Handling of Cases

Summary: Question Number one

Getting Something in Exchange for a Guilty Plea

Knowledge of the Routinized Process: Anticipating Bargains

Satisfaction with Disposition Outcomes Presumption of Guilt .

The Number of Guilty Plea Cases Involving Bargains

Power Imbalance in the Exchange Process Concluding Remarks

Responses to Interview Questions . . . . .

Introduction

Question Number One: In Your Opinion, What is Plea Bargaining

Question Number Two: What Features of a Case Would Make it Most Likely that the Prosecutor Would be Willing to Plea Negotiate?

Question Number Three: What Features of a Case Would Make it Most Likely that the Defense Attorney Would be Inclined to Think the Defendant Should Plead Guilty?

Question Number Four: What Features Make a Case Most Problematic or Difficult in Terms of Deciding How to Charge/Plea?

Question Number Five: Are There Certain Kinds of Cases for Which Charge Reductions are Fairly Standard? If So, Could You Give Some Examples?

Question Number Six: What Do You See as Your Role as Prosecutor/Public Defender/ Judge?

Question Number Seven: What Makes You Feel Satisfied with the Disposition Outcome of a Case You Have Handled? 
Question Number Eight: How Would You Characterize the Relationship of the District Attorney's Office with the Public Defender's Office?

Question Number Nine: What Do You See as the Main Advantages and Disadvantages of Plea Bargaining?

Concluđing Remarks ..............

VII FELONY CASE DISPOSITION IN ACTION: OBSERVATION OF THE PROCESS ................

Introduction . . . . . . . . . . . 191

The Pre-Trial Conference . . . . . . . . 192
Conference 1
Conference 2
Conference 3
Conference 4
Conference 5
Concluding Remarks

Hearings in Chief Criminal Court . . . . . .

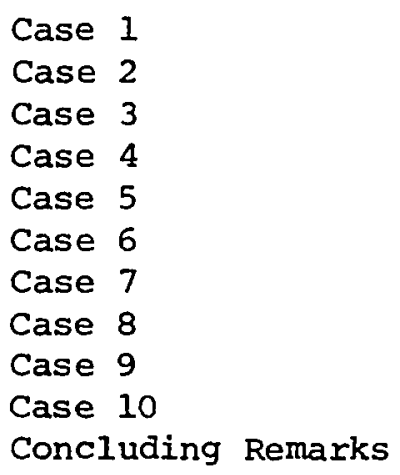

VIII FELONY CASE DISPOSITION THROUGH NEGOTCATION: A MODEL OF ONE URBAN COURT SYSTEM . . . . . . . 217

Negotiating the Guilty Plea as the Dominant

Method of Case Settlement . . . . . 218

Routinization Through Formalization . . . . 219 
Contained Cooperation Within an Adversary

Framework . . . . . . . . . . . .

Benefits and Costs in the Exchange Process .

Perceptions of Key Court Actors: Agreement and Disagreement Regarding the Social Reality of the Disposition Process . . .

Perceptions of Key Court Actors Regarding Plea Bargaining and System Needs and Goals

Plea Negotiation and Efficient Production . . 232

Plea Negotiation and Ideal Goals ...... 234

A Re-evaluation of the Theoretical Framework and the Propositions Resulting from that Framework ................

Previous Research and the Present Study:

Suggestions for Future Research . . . . . .

REFERENCES . . . . . . . . . . . . . . . . .

APPENDIX A . . . . . . . . . . . . . . . . . . 259

APPENDIX B . . . . . . . . . . . . . . . . 279

APPENDIX C . . . . . . . . . . . . . . . . . 281

APPENDIX D . . . . . . . . . . . . . . . . . 283

APPENDIX E . . . . . . . . . . . . . . . 287

APPENDIX F . . . . . . . . . . . . . . . . 289

APPENDIX G . . . . . . . . . . . . . . . . . 298

APPENDIX H . . . . . . . . . . . . . . . . 299

APPENDIX I . . . . . . . . . . . . . . . . . . 301

APPENDIX J . . . . . . . . . . . . . . 306 


\section{LIST OF TABLES}

I Persons 16 Years of Age and Over Employed in

Selected Occupational Categories, By

Percent: 1970 County Census Data . . . .

II Variables on Which Data Were Collected From

Criminal Court Felony Case Files . . . .

III Abbreviations for Offense Types . . . . . . .

IV Most Serious Initial Charge: 1976 and July

Through December of 1977, By Percent . . .

V Most Serious Settled Charge: 1976 and July

Through December of 1977, By Percent . . .

VI Initial Charge Categories: 1976 and July

Through December of 1977, By Percent . . .

VII Settled Charge Categories: 1976 and July

Through December of 1977, By Percent . . .

VIII Total Cases by Types of Multiple Counts: 1976

Through December of 1977, By Percent . . .

IX Closing Types: 1976 and July Through December

of 1977, By Percent........... .

$\mathrm{x}$ Total Convictions for Which Selected Sentence

Conditions Were Ordered: 1976 and July

Through December of 1977, By Percent . . . 
XI Multiple Initial Counts for Selected Offenses:

1976 and July Through December of 1977,

By Percent . . . . . . . . . . . .

XII Unemployed Defendants with Public and Private

Attorneys: 1976 and July Through December

of 1977, By Percent . . . . . . . . .

XIII Bargained Cases Closed with Multiple Counts and

No Felony Counts: 1976 and July Through

December of 1977, By Percent . . . . . .

86

XIV Public and Private Attorneys' Clients Held in

Pre-Trial Custody: 1976 and July Through

December of 1977, By Percent . . . . . .

89

XV Defendant Prior Record By Sentence: 1976 and

July Through December of 1977, By Percent..

91

XVI Education Levels By Incarceration Sentences: 1976

and July Through December of 1977,

By Percent . . . . . . . . . . . .

XVII Selected Sentencing Orders Given By Selected

Judges: 1976, By Percent .........

XVIII Selected Sentencing Orders Given By Selected

Judges: July Through December of 1977,

By Percent .................

XIX Type Closing By Pre-Trial Custody Status:

1976 and July Through December of 1977,

By Percent . . . . . . . . . . . • 
XX Type Closing By Sentence: 1976 and July Through December of 1977, By Percent . . . . . . . 98

XXI Type closing By Sentence on Selected Offesnes:

1976 and July Through December of 1977 . . . . 100

XXII Types of Plea Reductions: 1976 and July Through

December of 1977, By Percent ........ 103

XXIII Initial Charge/Settled Charge Reduced Pleas: 1976 . 104

XXIV Initial Charge/Settled Charge Reduced pleas:

July Through December of 1977 . . . . . . 105

XXV Type Closing By Total Disposition Time: July

Through December of 1977, By Percent... . . 107

XXVI Initial Charge By Type Closing: 1976, By Percent . . 110

xxVII Initial Charge By Type Closing: July Through

December of 1977, By Percent ......... 111

XXVIII Settled Charge by Type Closing: 1976, By Percent . . . 112

XxVIX Settled Charge By Type Closing: July Through

December of 1977, By Percent . . . . . . . 113

Xxx Settled Charge By Sentence: 1976, By Percent . . . . 116

XXXI Settled Charge By Sentence: July Through December

of 1977, By Percent .............. . 117

XXXII Felony Cases Closed By the Office of the Public

Defender: 1976 and July Through December of 1977 . . . . . . . . . . . . . . 122

XXXIII Closing Types for Non-Reducible offenses: Cases

Handled By the Public Defender's Office From July Through December of 1977 . . . . . . . 
XXxIV Total Convictions Resulting in Penitentiary, Jail and Non-Incarceration Sentences: Public Defender Felony Cases in 1976 and July Through December of 1977, By Percent .........

XXXV Incarceration Sentences for Selected offenses:

Public Defender Cases From July Through

December of 1977, By Percent . . . . . .

XXXVI Variables on Which Data Were Collected on Public Defender Burg I and Forg I Cases . . . . .

XXXVII Type Closing: Public Defender Burg I Cases From July Through December of 1977, Bi Percent . .

XXXVIII Type Closing: Public Defender Forg I Cases From

July Through December of 1977, By Percent . .

XXXIX Categories and Inclusive Variables on Which Analysis 
CHAPTER I

\section{THE RESEARCH PROBIEM: \\ SETTLING CASES THROUGH THE GUILTY PLEA}

\section{INTRODUCTION}

Concomitant with the growth of urbanism and industrialism in modern society was a growth in the social scientific study of formal organizations. Following Max Weber's early treatise delineating the characteristics of formal organizations, sociologists began to look at greater depth into the social reality of such organizations. The result has been an increasing awareness of the multi-faceted complexity which pervades these organizations in modern society. This complexity is still not fully understood, and thus there remains a need for exploratory studies of particular organizations. The present study offers an analysis of the social reality of the case disposition process in one type of formal organization--that of the criminal court system in American society. The social scientific study of legal organizations is relatively new within the larger field of formal organizations research. In particular, the structured activities of the ccurt system have received little in-depth study until quite recently. However, in the last decade, several major works on the American court system have opened up the way for further study (Newman, 1966; Skolnick, 1966; Neubauer, 1974). 
As a sub-system of the criminal justice system in the United states, the courts are responsible for achieving justice through formally charging alleged law violators, establishing the guilt or innocence of those individuals, and meting out legal punishment to persons found guilty. Both substantive and procedural laws provide the rules by which these activities are to be carried out. Rules regarding charges, pleas and punishments are delineated in substantive law. Substantive law attends to the criminal justice system's goals of crime control, protection of the public good and achieving justice by defining criminal acts and the appropriate punishments for such behaviors. Procedural law deals with another major criminal justice goal, i.e., insuring due process by guaranteeing alleged law violators the right to presumed innocence until guilt has been proved, the right to counsel, and the right to trial.

It would be a mistake, however, to view the court system solely in terms of its legal mandate to work toward these goals by means of the formal rules. The court is a formal organization which also responds to its own functional needs to maintain stability and viability. Since the ideal system, based upon substantive and procedural law, does not consider explicitly the functional needs of the organization it has created, the organization must develop its own processes through which stability and viability can be achieved. In order to maintain its legitimacy, however, the court must achieve these functional imperatives without forsaking its responsibility for achieving justice. In addition, legitimacy 
requires a commitment to the larger system's goals of crime control, protection of the public good, and due process.

The ideal process for criminal case disposition within the court system involves the following elements: formal charges are made based exclusively on substantive law; the guilt issue is resolved through adversary proceedings in a trial by jury or judge; for those adjudicated guilty, punishment is set based exclusively on substantive law. However, this is not the dominant method of case settlement in American courts. Rather, the overwhelming majority of cases are settled by guilty pleas prior to the trial stage. Although there are variations among jurisdictions, studies indicate that from 70 percent to 90 percent of criminal cases in which formal charges are filed are settled by guilty pleas rather than trials (Newman, 1956; Mather, 1973; Mulkey, 1974; Heumann, 1975). Moreover, many of the cases disposed of by guilty pleas involve some kind of bargain on the charge or sentence which may not be based exclusively on substantive law (Sudnow, 1965; Newnan, 1966). These findings have led to a social-scientific interest in examining the case disposition process within the court system.

The purpose of the present study was to explore and analyze the pirenomenon of negotiating the guilty plea and its relationship to the ideal and actual process of criminal case disposition within an organizational setting. The study involved a detailed examination of the felony case disposition process in one urban court system, located in a metropolitan area in the Pacific Northwest. Data were collected from several sources. Records and case files were used to 
gather data regarding the nature and outcomes of felony dispositions in 1976 and 1977. Official documents yielded information on the formal structure, procedures and policies of the court organization. Interviews with prosecutors, public defenders and judges in the felony court system provided attitudinal data from the key actors in the disposition process. Finally, observations of guilty plea hearings and plea negotiation conferences allowed the researcher to record actual activities relevant to the research focus.

Regarding the precise nature of the case disposition process through negotiation in this particular court system, the study can be appropriately described as exploratory. A preference for "exploring" rather than "testing" resulted from 1) the recognition that the acea of study is relatively new and thus lacks extensive research and 2) an awareness that the negotiation process in this court system has certain formal characteristics which differ from those in court systems previously researched. However, the research problem was approached from a specific theoretical perspective which has provided the framework for the analysis of the data. Based upon organizational and exchange theories, as well as prior studies of plea negotiation, a functional argument has been offered as an explanation of plea negotiation as the dominant method of case disposition in the American court system. The ultimate goal of the study then was three-fold: 1) to construct, based upon the data, a model of case disposition without trial in one urban court system; 2) to analyze this model from a theoretical perspective; 3) to compare the findings from this research with those from prior research. 
The theoretical framework of the study is introduced in the next section, followed by a discussion of the findings from prior studies in which case disposition through negotiation has been researched. The final part of the chapter is devoted to an explicit description of the research questions to be subjected to empirical examination.

THEORETICAI FRAMEWORK

A conceptualization of the court as a formal organization is useful in order to understand the case disposition process. One of the primary defining characteristics of an organization is its orientation to the achievement of formal goals (Parsons, 1956). Etzioni has suggested that organizations may be classified according to their orientation to one of three borad categories of goals: maintenance of social order; maintenance of cultural conditions; economic production.

Organizations with order goals attempt to control actors who are deviants in the eyes of some social unit the organization is serving (frequently society) by segregating them from society and by blocking them from further deviant activities.

Organizations that have culture goals institutionalize conditions needed for the creation and preservation of symbolic objects, their application, and the creation of reinforcement of commitments to such objects.

Organizations with economic goals produce commodities and services supplied to outsiders (Etzioni, 1975: 104105).

While some organizations may be easily placed into one or another of these categories, the court organization is difficult to classify in terms of its goal orientation. It appears that courts attempt to 
contend with all three categories of goals. First, there are the order and culture goals of the superordinate system which the courts must consider. The courts, as part of the superordinate system of criminal justice, must work toward the maintenance of rule by law, crime control, protection of the public good, and due process. Second, there are order and culture goals which are specifically assigned to the organization in terms of its role in the superordinate system. The courts are assigned the specific goal of achieving justice by formally charging the alleged violator, resolving the guilt/innocence issue, and meting out the appropriate punishment to the guilty. Although economic goals may not be construed as a major orientation of the court system, they are functionally important to the maintenance of the system; that is, efficient production of settled cases is imperative. Order and culture goals best describe the ideal goal orientation of the court system. There are also the functional goals of stability and viability which must be attained if the organization is to survive. Stability and viability are dependent on the satisfaction of the functional needs and requirements of the organization. Such needs often take priority over the ideal goals, for without the satisfaction of the former, the latter have little chance of being realized. According to one theorist:

\footnotetext{
- . a given empirical system is deemed to have basic needs, essentially related to self-maintenance; the system develops repetitive means of self-defense; and day-to-day activity is interpreted in terms of the functions served by that activity for the maintenance defense of the system (Selznick, 1948: 25).

In order to enhance its stability and viability, an organization
} 
must satisfy production and efficiency needs. Stability is further enhanced by routinization and cooperation within a system. Another functional necessity is that key actors exhibit compliance with and commitment to the system.

Production and Efficiency

An organization is a system which "produces an identifiable sonething which can be utilized in some way by another system" (Parsons, 1956: 64). The courts "produce" settled cases which reflect justice. The individual, as a component of the product, is either released to society or moved on into the correctional systern. Production must be efficient. To be efficient the court must conserve scarce resources (time, labor, money) by settling cases quickly and thus avoiding overload (Blumberg, 1967; Rosett and Cressey, 1976). Case dispositions through guilty pleas advance both production and efficiency goals. In fact, a high proporation of guilty pleas is essential to the survival of large, urban court systems, which are constantly threatened with collapse due to case overload (Newman, 1956). The importance of production and efficiency to the stability and viability of the court organization leads to the recognition that the utilitarian nature of this formal organization and its pursuit of economic goals cannot be overlooked.

\section{Routinization}

Routinization, which refers to the standardization, institutionalization and legitimation of processes and norms, is another functional requirement. First, routinization enhances production 
and efficiency. Second, it strengthens the security of system members by spelling out norms for interaction which can be learned and relied upon:

The security of all participants, and of the system as a whole, generates a persistent pressure for the institutionalization of relationships, which are thus removed from the uncertainties of individual fealty or sentiments (Selznick, 1948: 20).

Merton suggested that a formal, rationally organized social structure involved "clearly defined patterns of activity in which, ideally, every series of actions is functionally related to the purposes of the organization" (1957: 195). However, neither the formal rules of the criminal justice system, nor those of the court sub-system, provide adequately for the production and efficiency needs of the court. Nor do they provide for the security needs of system members. Therefore, it is understandable that an informal process for case disposition emerges and becomes routinized. Although the routinized process vai ..es with the needs of specific courts, prior empirical studies of court systems indicate that it centers around bargaining to achieve a guilty plea. It has been found that this routinized process includes:

1. A classification scheme of offenses/offenders and appropriate punishments which are deemed "just" (Sudnow, 1965; Newman, 1966; Mather, 1973; Neubauer, 1974).

2. Identifiable factors which guide decisions to charge, plea and bargain (Newman, 1956; Blumberg, 1967; Cole, 1970; Neubauer, 1974; Mulkey, 1974; Rosett and Cressey, 1976).

3. Procedural norms for interaction through a bargaining process (Blumberg, 1967; Rosett and Cressey, 1976). 
Cooperation

To attain its functional goals, an organization must operate

as a cooperative system. Organizational theory posits that a formal organization is made up of interdependent parts which must function as a unit to achieve organizational purposes (Selznick, 1948; Etzioni, 1961). However, the ideal rules for case disposition in the court system emphasize adversary proceedings, in which prosecuting and defense attorneys represent the opposing interests of their clients or publics. The bargaining process, on the other hand, allows prosecuting and defense attorneys to work in cooperation with one another with the goal of speedy case disposition through guilty pleas. Prior studies indicate that the routinized plea bargaining process includes norms for cooperation among key actors in the system (Feeley, 1973; Neubauex, 1974).

Sompliance and Commitment

The stability and viability of the organization also require that the needs of system members be taken into consideration. A functional organization relies upon the compliance ana commitment of its members (Etzioni, 1961). Compliance is facilitated when systein members are motivated to participate willingly in organizational activities and to be committed to organizational goals (March and Simon, 1958). Compliance thus motivated is, in turn, facilitated when an organization acknowledges its members' needs and provides incentives in accordance with those needs. The ideal system of criminal justice does not attend adequately to the provision of incentives for system members: 


\begin{abstract}
. . what one finds in the system of criminal justice is a highly formalized and defined set of rules, norms, and goals, but also an organization which possesses no corresponding set of incentives and sanctions which act systematically to enforce them (Feeley, 1973: 422).
\end{abstract}

Case disposition through bargaining can be seen as providing inducements for key court actors to comply with, willingly participate in, and be committed to the court system. The way in which this is accomplished can be understood by examining the case disposition process in the context of exchange theory. Exchange theory posits that interaction between persons consists of an exchange of material and non-material goods. The exchange process is functional for the organization because it meets system-member needs for cooperation, security, involvement and rewards. Bargaining is an exchange process which allows for frequent interaction between key court actors (particularly between prosecuting and defense attorneys). The reciprocity inherent in the exchange process also provides an atmosphere of cooperation and trust. Reciprocity may be defined as a cooperative, mutually gratifying pattern of exchanging goods and services (Gouldner, 1960). Coopecation and trust are also advanced through norms which routinize interaction, in that attitudes and behaviors can be anticipated. The bargaining process serves members' needs for security by reducing the risks and uncertainties of outcomes. Risks are reduced through the avoidance of trial, and uncertainties are reduced through the routinization of the process (Church, 1976). Bargaining also allows prosecuting and defense attorneys to play active roles in case disposition. This is important for several reasons: I) it allows 
actors to experience a sense of autonomy and control in the decisionmaking process; 2) it contributes to individual feelings of selfworth and usefulness; 3) it allows actors to consider ideal goals as they make decisions. Finally, the exchange process provides benefits for both prosecuting and defense attorneys. Unlike the adversary system, the outcomes are not zero-sum, i.e., there is not a total win for one side accompanied by a total loss for the other side.

The commodities exchanged in the bargaining process are charges, pleas and punishments. The defense attorney has command (through his or her client) of the plea commodity. Since the guilty plea is the desired outcome, this commodity gives the defense attorney considerable leverage. However, the prosecutor has command of the charge commodity. Since punishments are formally related to charges, the prosecutor also has some control over the punishment commodity. In addition to influencing punishment through the charge, the prosecutor also gains power through his or her right to recommend punishment to the judge. Prior studies indicate that the issue of punishment is of primary concern in the bargaining process (Rosett and Cressey, 1976; Sudnow, 1965). The threat of severe punishment, which is considerable under the law, may reduce the bargaining power of the defense attorney. Studies show that the balance of power is tipped in favor of the prosecutor in the exchange process (Newman, 1956; Mulkey, 1974; Neubauer, 1974). 
Bargains may be of several types: charge reduction, dismissal of one or more charges or counts, punishment reduction, or charge or punishment concurrency. This variety of possibilities leads to a number of benefits and costs. What is important to remember is that benefits and costs are not zero-sum; all actors can receive some of both. For example, the defense attorney may decide to exchange a guilty plea for a reduced charge. Although the defense attorney suffers some costs through this exchange (both in terms of the interests of his or her client and in terms of his or her professional role as advocate for the accused), he or she also gains a benefit in the form of the reduction of the severity of the charge (and most likely punishment) against the client. The prosecutor, on the other hand, suffers a cost in giving up the full potential of the charge and punishment commodities, but benefits in getting a convicition in the interests of the state. Blumberg (1967) has suggested that rewards in the form of prestige and approval are given attorneys who advance the instrumental goals of the court by settling cases quickly through the routinized bargaining process. These rewards may further personal and career concerns of attorneys and thus act as a further incentive for complying with the system.

Thus far, ways in which case disposition through bargaining contributes to the satisfaction of functional needs of the courts have been discussed. While functional theories go a long way toward explaining why plea bargaining is the dominant method of case disposition in American courts, examinations of the precise 
nature of the disposition process reveal that other elements are also involved in plea bargaining as well. The following section elaborates upon this point by reviewing the findings of prior research.

PRIOR RESEARCH AND THE NEED FOR FURTHER EXPLORATION

While the precise nature of the bargaining process varies among court systems, studies to date indicate that it exists in some form in virtually all systems. Since the actual process may not have formal status or may deviate from formal policy, considexable probing is required in order to capture the essence and implications of the actual process. Prior research points to several problems which are in need of further exploration. First, there is a need to examine the way in which the actual process does or does not reflect formal policies and laws. A second problem has to do with the way in which plea bargaining reflects functional and/or ideal goals. Finally, the nature of the exchange relationship between key court actors needs further clarification.

Plea Bargaining: Relationships Between the Informal and Formal Process

The extent to which plea bargaining is formally recognized varies among court systems. The recent acknowledgement of plea bargaining at the national level (President's Commission on Law Enforcement and Administration of Justice, 1968; Brady v. U.S., 397 U.S. 742,1970 ) is likely to lead to increased formal recognition at state and local levels. Since the widespread use of plea bargaining is conceded by most authorities, there has been 
a recent movement to see plea bargaining given uniform formal status. However, in court systems where formal policy does exist, there is little information regarding the way in which the informal process does or does not deviate from formal policy.

A related problem has to do with the way in which the plea bargaining process relates to substantive and procedural law. For example, consider Sudnow's study on charge reduction in plea bargaining. He argued that the classification scheme by which offenses and offenders along with appropriate punishments are delineated is not based upon substantive law: "

. . in searching an instant case to decide what to reduce it to, there is no analysis of the statutorily referable elements of the instant case; instead, its membership in a class of events, the features of which cannot be described by the penal code, must be decided (Sudnow, 1965: 259). The classification scheme, according to Sudnow, outlines categories of "normal" crimes. Normal crimes share certain features: a typical manner in which offenses are committed, social characteristics of persons who regularly commit them, typical setting in which they occur, and types of victims typicaliy involved. For example, Sudnow reported that public defenders view normal burglaries as involving repetitive violators, no weapons, inexpensive items, little property damage, lower class establishments, black defendants, and a non-professional orientation to the offense. Normal crimes, according to Sudnow, are easily settled by routinized bargains, legitimated by the belief that the bargain outcome is reasonable and just because of the typical nature of the crime. He also concluded that the bargained charge on a normal crime is often 
neither necessarily or situationally included in the original charge, i.e., neither statutorily included in the initial offense whereby the commission of one crime includes the commission of another, e.g., murder and attempted murder--nor situationally included as a part of the offense behavior, e.g., loitering and public indecency. Rather, normal crimes are often reduced on the basis of their typical features to lesser offenses not necessarily or situationally included in the original offense, e.g., burglary to petty theft. Such reductions are deemed reasonable, however, if the offense/offender fits the typical description. It is obvious that plea bargaining deviates from formal procedural law for case disposition. Through plea bargaining the trial process for resolution of guilt is circumvented. The issue of importance to the key actors in plea bargaining is not guilt/innocence, but rather punishment. For the bargaining process to work, some guilt must be presumed at the outset; the focus is on what will be done to the offender in terms of punishment (Heumann, 1975; Rosett and Cressey, 1976). By giving up the right to trial, the defendant gives up the right to presumed innocence, the protection against self-incrimination, and the right to confront his or her accusers. Recent court decisions have ruled that this is legal provided the defendant is advised of the rights he or she is waiving by pleading guilty (Boykin v. Alabama, 395 US 238, 1969). Thus, the shortened procedure is gaining legitimacy.. Mather (1973) has suggested that case disposition through bargaining deviates from the ideal process in another way. From 
his research, he concluded that the way in which a case is to be settled depends primarily on two factors--seriousness of offense and strength of case. "Dead-bang" cases--those in which the offense is not extremely serious, the punishment not extremely severe, and the case against the accused is strong--are routinely settled through a plea of guilty on the original charge, although the defense may receive some benefit (e.g., recommendation for punishment reduction or concurrency) in exchange for cooperation. "Reasonable doubt" cases, in which the offense is not extremely serious, the case for the original charge is weak, but the case is strong for guilt on a lesser charge, can be quickly settled by routinized bargain reductions. More troublesome cases are those in which the offense and/or punishment are considered to be extremely severe and in which there is reasonable doubt in terms of the strength of the case. Such cases, of which there are relatively few, are unlikely to be settled by a bargained guilty plea, for the costs to the defense attorney and her or her client outweigh the benefits of a guilty plea. These are the cases which most often go to trial.

The examination of relationships of the bargaining process to substantive and procedural law gives considerable insight into the way in which plea bargaining reflects functional and ideal goals. Yet there are other factors to be considered in examining the goals issue. 
Plea Bargaining and Goal Achievement

Case disposition through bargaining does not discount ideal justice goals. Although these goals may be modified in line with functional requirements for stability and viability, the notions of crime control, due process and justice are incorporated into the routinized process for case disposition (Mulkey, 1974; Rosett and Cressey, 1976). In fact, it has been suggested that the nature of routinized plea bargaining in American court systems provides for the achievement of ideal justice goals which are less likely to be achieved through strict adherence to the formal rules. Rosett and Cressey (1976) concluded that plea bargaining processes outline uniform standards of justice while allowing for a consideration of mitigating factors which are not included in the formal penal code. They also argued that the range of punishments provided by law is reduced, thus limiting the broad discretionary powers of judges in sentencing. Crime control is taken into account by separating serious from non-serious cases and delineating reasonable punishments for both types. Also, plea bargaining practices can be geared to the needs of particular jurisdictions regarding crime control and justice.

While it does appear that the goals of crime control and justice may be served by plea bargaining practices, serious questions have been raised regarding the due process goal. Legally a plea of guilty can only be entered if the defendant assures the judge that he or she is pleading guilty willingly and with full knowledge of the consequences of such a plea. Yet such formal assurances are 
of questionable value. The defendant most often does not have adequate knowledge of either the informal or the formal system. Lacking complete knowledge, lacking power, and threatened by severe punishment, the defendant may be at least implicitly coerced into compliance with the recommendations of his or her counsel. The evidence suggests that public defense attorneys are likely to advise clients to plead guilty if a bargain can be obtained (Newman, 1956, 1966; Blumberg, 1967). While there are obvious due process problems when the trial process is circumvented and guilt is presumed from the outset, participants in the bargaining process do endeavor to attend to justice norms of "appropriateness" and "fairness" in terms of punishment. Also, bargains usually do appear to reduce the severity of punishment allowable under maximum sentencing. Finally, the defense attorney does have a commitment to a professional role, i.e., representing the interests of the defendant (Mather, 1973). Thus, the defense attorney has an interest in "getting a good deal" for the client.

As was pointed out earlier, the achievement of ideal criminal justice goals is not the sole orientation of the court organization. Functional goals (perhaps more appropriately labeled needs and requirements) cannot be overlooked.

Conservation of limited resources is the most often cited advantage of plea bargaining (Mulkey, 1974). In their study, Rosett and Cressey (1976) found that prosecutors and defense attorneys consistently mentioned conservation of resources and 
administrative expediency when asked what purposes plea bargaining serves. Thus, it appears that, from the perspectives of key court actors, organizational needs are of paramount importance in case disposition. Conservation of resources is increasingly important to all three of the criminal justice sub-systems (law enforcement, courts, corrections). Since the activities of any of the three sub-systems have consequences for the others (e.g., limiting arrests reduces the load of the court; dismissing cases and reducing sentences in the court reduces the load of corrections), it seems Iikely that an important factor to be considered in the disposition process is the needs of law enforcement and corrections.

The police have considerable discretionary power in making arrest decisions and thus are influential in selecting offenses/ offenders to be handled by the courts (Skolnick, 1966; Wilson, 1968). Law enforcement helps curb court overload by not arresting all suspected offenders and by dismissing approximately one third of felony cases after arrest but prior to initial prosecutorial screening (Rosett and Cressey, 1976). The police also have come influence regarding the formal charge decision, for the report of the arresting officer is taken into consideration by the prosecutor. Findings on the extent of police influence in the charge decision are somewhat unclear, as influence varies among particular jurisdictions. However, prior studies indicate that the police experience some frustration in what they perceive as their inability to play a more active role in settling cases for which they are initially responsible (Banton, 1964; Wilson, 1968). Corrections plays a role 
in the case disposition process through the pre-sentence investigation conducted by the probation department. Like the police, the probation officer's role in case dispositions is essentially advisory. However, the court system needs the cooperation of law enforcement and corrections in order to coordinate activities in line with the functional stability and ideal goals of the superordinate criminal justice system. Thus, it is advisable for key court actors to take into account these sub-systems in the decisionmaking process.

There are also interests outside of the criminal justice system which must be attended to by the courts. Related systems, e.g., social work, mental health, are affected by and attempt to affect court activities. Community attitudes toward law, order and justice may also be influential in court activities. There is some evidence that special interest groups have and exercise the power to impinge on court operations in order to satisfy their own vested interests. In his study, Cole (1970) found that prosecutors invariably consider the demands of community influentials in making charge decisions. While more research is in order, it does appear that the needs and demands of extraorganizations are important in terms of the functional stability of the courts. Since these various needs are often conflicting, decisions pertaining to court structure and process may be continually problematic:

Each subculture [of a court] is thus a crystallized solution to the problems given courthouse workers by specific groups whose conflicting demands and conceptions of justice must all be somehow worked into the scheme of things. Each is a negotiated social order-a set of 
rules, understandings and customs--that has developed as courthouse workers have accommodated themselves to the demands of these various groups (Rosett and Cressey, 1976: 94).

The extent to which personal needs of key court actors influence charge, plea and bargain decisions has received little empirical attention. There are some indications that prosecuting and defense attorneys who settle cases quickly by obtaining guilty pleas and being clever bargainers are perceived by other actors in the system as "good" attorneys, thus enhancing career possibilities (Blumberg, 1967; Rosett and Cressey, 1976). It has also been suggested that attorneys who learn the routinized system quickly and proficiently are rewarded with approval from superiors within the system (Blumberg, 1967). Further research is needed to assess the way in which key court actors perceive the court system as neeting their own personal needs.

There is also a lack of agreement regarding whether or not other factors influencing charge, plea and bargain decisions are consistent with criminal justice goals. The strength of the state's case has been identified as the most important factor in the prosecutor's charge and bargain decisions (Alshuler, 1968; McIntyre, 1967; Mulkey, 1974). The strength of case factor can be perceived as reflecting criminal justice goals, for a strong case is likely to end in conviction, thus furthering crime control. However, strength of case is a variable which can also be used to facilitate speedy case settlement. With a strong case, the prosecutor has a good chance of getting defense counsel to agree to a guilty plea. 
In agreeing to a guilty plea, the defense may only receive a minimal concession, but avoid, however, the actual risks of trial. On the other hand, if the state's case is not strong, the state still gains from getting a quick and certain guilty plea conyiction; the defense--likely to be offered a good deal--also may opt for the speedy and sure guilty plea disposition. Since the overwhelming majority of cases are settled by guilty pleas, it can be speculated that strength of case factors are more often used as levers in the negotiation process than as mechanisms for achieving ideal justice goals. Although the data are conflicting, some studies suggest that prosecutors may overcharge, anticipating that charge reduction will be necessary to obtain a guilty plea (Newman, 1966; Blumberg, 1967; Alshuler, 1968; Cole, 1970). Such a move on the part of the prosecutor can be viewed as an attempt to further functional imperatives.

One category of factors which has been found to have substantial influence regarding charge, plea and bargain decisions at.tends (at least theoretically) to criminal justice goals. This category includes nature of offense and nature of offender factors. The seriousness of the offense has been found to be extremely influential in the disposition process. The most serious offenses are those jeast likely to be settled through the bargaining process; also, the most serious offenses are most likely to be subjected to the full charge potential (Mulkey, 1974). Additionally, cases which deviate from the norm (are not typical) are less likely to be settled through the bargaining process. Apparently the justice 
norms which have been informally established for typical cases cannot be easily applied to atypical cases, and thus trial is felt to be necessary in the interests of justice. The value of property losses and the costs (material and non-material) to victims are also important elements in the nature of the offense (Subin, 1966; McIntyre, 1968).

Previous research has indicated that attributes of the offender are influential in determining the nature of case dispositions. Prior criminal record of the defendant appears to be of particular importance. Like seriousness of the offense, prior record increases the likelihood of certainty and severity of punishment for the defendant and thus gives the prosecutor an advantage in the bargaining process. Severe treatment of criminal repeaters may be perceived by key court actors as furthering the crime control goal. Data also suggest that defendant characteristics such as appearance, demeanor, sex, race, education and socio-economic status influence case disposition (Piliavin and Briar, 1958; Chambliss and Seidman, 1971; Quinney, 1975; Gibbons, 1977; Chiricos and Waldo, 1970). Discriminatory treatment of defendants is difficult to rationalize on the basis of criminal justice goals. While there is general agreement that case disposition through p].ea bargaining meets functional needs and requirements of the system, there are conflicting opinions regarding the extent to which plea bargaining serves ideal criminal justice goals (Neubauer, 1974). Critics point out that defendants' rights to due process and equal treatment are threatened through the plea negotiation process. 
They also argue that functional needs take precedence in the bargaining process, thus subverting ideal goals:

In short, critics of plea bargaining maintain that reliance upon bargaining involves an emphasis upon administrative convenience which subverts achievement of criminal justice goals, including the suppression of crime, the rehabilitation of offenders, and the maintenance of procedural due process (Mulkey, 1974: 57).

The Relationship Between Key Actors in the Bargaining Process

Further research is in order regarding the nature of the relationship between key actors in the bargaining process, particularly the primary actors, i.e., the prosecutor and the defense attorney. As mentioned earlier, the relationship between the prosecutor and defense attorney is increasingly being described as a cooperative one, thus calling into question the ideal concept of case disposition through adversary proceedings. When the defense attorney is a member of the public court orjanization, i.e., a public defender, his or her role is paxticularly problematic. Ideally, the public defender represents the interests of the accused and thus stands in opposition to the attempts of the state to prosecute fully a given case. Yet the public defender is also part of an organization which requires coordination and cooperation in order to satisfy functional needs. Blumberg (1967) argued that the public defender acts as an agent-mediator who helps the accused "redefine the situation and restructure perceptions concomitant with a plea of guilty." According to Rosett and Cressey: - . it becomes a breach of etiquette for a lawyer to take a stance so adversary that it disturbes the conditions of peaceful co-existence (Rosett and Cressey, 1976: 105). 
In addition, both prosecutors and public defenders belong to the same professional system, thus promoting cooperation in the protection of shared professional norms (Sudnow, 1965). Another argument in favor of the cooperative model is that frequent interaction among members of the public court organization promotes cooperation (Mulkey, 1974). Many of these claims are based primarily on theory; further empirical data are needed to ascertain the extent to which prosecutors and public defenders share the same values and perspectives regarding plea bargaining as well as the functions and goals of the court system. Data are also needed to assess the extent to which key actors perceive of cooperation as functionally necessary. In addition to surveying the opinions of key court actors, the nature and extent of cooperation can be explored by observing the bargaining process in action, with attention to the content and frequency of interactions. While the relationship of the prosecutor and public defender is of paramount interest in examining the plea bargaining process, there are other court actors with whom the attorneys must interact. One obvious key actor in the process is the judge, who has the ultimate decision powex in setting of punishments. Although, as a result of the bargaining process, the prosecutor's charge may reduce the legal limits of punishment, within those limits the prosecutor can only make sentence recommendations. In addition to those recommendations, the judge receives inputs from the police, the probation department, and the defense attorney. Although in theory the final decision regarding punishment is guided by the neutrality of law, in actuality it is also guided by system needs. 
It is likely, therefore, that the judge will play a cooperative role in the routinized case disposition process. From their lengthy study, Rosett and Cressey concluded:

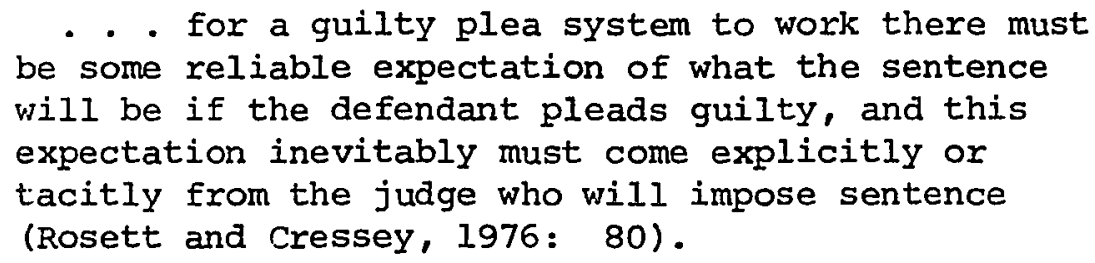

There is evidence that prosecutors and defense attorneys attempt to become familiar with attitudes and behaviors of individual judges, and that expectations of particular judges' actions is an influential factor in charge, plea and bargain decision (cole, 1970). Also, Church (1976) found in his study of a mid-western urban court system that when bargains on a charge are not allowed, bargains on punishment occur in which the judge becomes a focal actor in the exchange process.

There is also a need for further research on the nature of the role of the defendant in the negotiation process. Although it is the fate or future of the defendant which is being decided in the case disposition process, there is evidence that the accused plays a minor role in the bargaining process (Rosett and Cressey, 1976).

THE RESEARCH PROBLEM

\section{Propositions}

It was the assumption of this study that case disposition through a bargaining process in which commodities are exchanged (charges, pleas, punishments) by key court actors (prosecutors, defense attorneys, judges) with the goal of obtaining a guilty 
plea without trial has become the dominant "method of action" in American court systems due to its provisions for both functional and ideal goals which are not clearly provided for in the ideal system. This assumption, based upon organization and exchange theories, as well as prior studies of American court systems, was subjected to empirical examination through a research focus on the following four general propositions.

Proposition I. The majority of felony cases which result in formal charges are settled by guilty pleas, and the majority of guilty plea dispositions are the result of some kind of bargain which explicitly or implicitly invovles punishment reduction. Proposition II. Case disposition through negotiation is routinized, i.e., there are identifiable patterns both in the substance of the bargain and in the procedures for the exchange which are known to and accepted by key court actors.

Proposition III. Key actors in the negotiation process, the prosecutor and the defense attorney, work in cooperation with one another and interact frequently.

Proposition IV. The negotiation process provides for the needs of key actors to be active participants, to work toward ideal goals, and to receive rewards for their work.

\section{Exploratory Areas}

It has also been suggested that a thorough analysis of case disposition through negotiation requires further exploration of certain features of the process. By examining in detail the case disposition process in one urban court system, such an exploration 
was achieved. Based upon the findings, a model of the court system under study was constructed which was analyzed both in terms of its theoretical relevance and in terms of its similarities and dissinilarities to previously researched systems. Additionally, formal plea negotiation policies in the system under study underwent certain changes between 1976 and 1977 which allowed for the incorporation of intra-system comparisons into the analytical model. The following aspects of court operations and plea negotiations have been explored and the findings included in the model of felony disposition in one court system:

The formal organization.

Structure, procedure, policy. Intra-organization comparisons.

The nature of the process of case disposition through negotiation.

Relationship between the formal and actual process. Routinization in the process.

The nature of the exchange relationship. Cooperative and adversary roles. Facilitation of compliance and commitment.

The nature of the substance of case disposition.

Characteristics of offenses, offenders and dispositions. Relationships between offenses, offenders and dispositions. Types of bargains.

Relationship of bargains to substantive law. Routinization of bargains. Factors which influence disposition decisions. Relationships between bargains and punishment. other factors which influence punishment.

Relationship between beliefs about and actualities of the process and substance of case disposition through negotiation.

Policy changes aimed at restricting bargaining.

Effects on production and efficiency. Effects on disposition outcomes. Effects on the exchange relationship. 
The way in which case disposition without trial satisfies functional needs and ideal goals.

Attitudes and actualities.

Summary

Chapter I has introduced the research problem, set forth the theoretical framework, and discussed prior research. Additionally, the research problem has been explicitly defined in the form of four general propositions and an outline of the exploratory areas which have been subjected to empirical investigation. The research methodology of the study is described in detail in the next chapter. 
CHAPTER II

RESEARCHING THE PROBLEM:

DESIGN, SETTING, SOURCES AND TECHNIQUES

THE RESEARCH DESIGN

The purpose of this study was to examine a particular process, i.e., case disposition without trial, within an organizational context, i.e., the public court system. Although the study had an explicit theoretical focus as well as a set of initial propositions based upon theory and previous research, the general orientation of the study was exploratory. In order to grasp fully the nature and meaning of the case disposition process, a decision was made to do an in-depth study of the social reality of this phenomenon in one urban court system. The intent of the study was not purely descriptive; rather, description was used to facilitate interpretative and explanatory analyses of the topic under study. Comparisons of the findings with those from similar studies as well as assessments of the theoretical relevance of the data further facilitated such analyses. Considering the purpose and the nature of the study, it seemed appropriate to adopt field research as the methodological model.

Field research is a broad label which covers a variety of scientific endeavors utilizing a number of specific methodological techniques. The field research design deemed to be appropriate for 
the present study has the following characteristics. First, it attempts to comprehend the social reality of a total field area. The research design must incorporate techniques for examining the "total picture," for the focus is not on isolated parts of the whole, but rather on the way in which the parts fit into a model of the whole. In the present study, the "total picture" referred to case disposition within a formal organization. The component parts which formed the whole were: the formal and informal structures, procedures and norms of the organization; the formal and informal process of case disposition without trial; the substance and outcomes of case disposition; the attitudes and behaviors of key actors in the disposition process.

A second characteristic of this methodological model is that it is non-experimental. Neither the setting nor the other variables under study are controlled or manipulated. Whereas an experimental study tests relationships by comparing data on experimental and control groups, the field study examines relationships as they occur naturally. Without an experimental design, the testing of pre-determined hypotheses is at the least problematic. When the orientation of the study is exploratory, the testing of hypotheses is even less appropriate.

Although direct observation is the data-collection technique most often associated with field research, a growing number of field studies combine observations with other techniques in order to strengthen the likelihood of accurately depicting the total reality of the field of study. The use of multiple data sources 
(often referred to as triangulation) is thus another characteristic of the model used in the present study. The use of multiple methods for data collection lends itself to a mixture of qualitative and quantitative methods of data analysis. This mixture is another component of the methodology utilized in the current study. For a further elaboration of the advantages of the field research model in an exploratory study see Appendix A.

THE RESEARCH SETTING

The research took place in an urban county in the Pacific Northwest. The 1970 Census data provided a general description of the population of the county (although the actual statistics obviously have changed since 1970, the overall profile remains the same). The total population of the county numbered 556,667 . Slightly over half of the population was female, and 30 percent of the population was under age 35. The overwhelining majority of the residents were white. Blacks made up only 4 percent of the population, and those defined as "persons of Spanish language" made up another 2 percent. There was a small percentage ( 5 percent) of foreign born individuals.

The population was also relatively stable. Fifty percent had not changed residences between 1965 and 1970. Another 28 percent had changed residences, but remained in the same SMSA. Of all housing units, 58 percent were owner-occupied.

The population also showed relative stability regarding income and employment. Only 8 percent of families had an income below the 
poverty level. Seventy-six percent of males over 16 were employed, as were 45 percent of females over 16 years of age. Table I indicates the distribution of employee groups.

TABLE I

PERSONS 16 YEARS OF AGE AND OVER EMPLOYED IN SELECTED OCCUPATIONAL CATEGORIES, BY PERCENT: 1970 COUNTY CENSUS DATA

\section{Occupational Category}

$\begin{array}{lr}\text { Professional, technical and kindred workers } & 158 \\ \text { Manager and administrators, except farm } & 98 \\ \text { Sales workers } & 98 \\ \text { Clerical and kindred workers } & 228 \\ \text { Craftsmen, formen and kindred workers } & 138 \\ \text { Operatives, except transport } & 108 \\ \text { Transport equipment operatives } & 48 \\ \text { Laborers, except farm } & 58 \\ \text { Farm workers } & 18 \\ \text { Service workers } & 138 \\ \text { Private household workers } & 18\end{array}$

Finally, the education level of the population further suggested stability. Only 10 percent of the people between the ages of 16 and 21 were not high school graduates or not enrolled in school. Over 24,000 of the residents under age 35 were enrolled in college.

The general population of the county in which the research took place, then, did not appear to suffer overall from the deprivations indicated in the statistics on many other urban jurisdictions in the country. 
DATA COLLECTION: SOURCES AND TECHNIQUES

Four types of data were collected, two from secondary sources and two from primary sources. The first secondary source was official documents. Information regarding the formal structures, procedures and policies of case disposition within the court organization was collected from official documents produced within the system. The Offices of the District Attorney and Public Defender provided information about the formal organization of their offices. Information about the formal organization was also collected from state statutes.

The other secondary source was records kept by the organization on felony cases settled in 1976 and 1977. Two random samples were taken from the Criminal Court records of cases settled in 1976 and 1977. Ten percent samples (one for 1976 and one for 1977) were drawn from a master list of felony cases alphabetized by defendants' last names. The drawing of every tenth case for which an arrest and closing took place in 1976 yielded a sample of 306 cases for this year. The method for drawing a sample of 1977 was the same; however, only cases for which there was an arrest and closing from June through December were included in the 1977 sample. The decision to use only the population from July through December in 1977 was based on the fact that new policies instituted by the office of the District Attorney expanding the list of non-negotiable felonies went into effect in July of 1977 (see Chapter III). Although this decision meant that the sample size for 1977 would be considerably smaller $(n=163)$, it was felt that comparisons would more accurately reflect 
the case settlement process before and after the policy changes. Data were collected on 33 variables (see Appendix B for a list of variables and codings). Not all case files contained information on all the variables. There are no apparent reasons to suspect, however, that these omissions were not randomly distributed. In addition to these random samples, summary statistics compiled by Criminal Court on the number and type of closings for the total populations of felony cases in 1976 and 1977 were used as a check on the reliability of the samples. These summary statistics did indicate that the samples were indeed representative of the total populations. The researcher attempted to collect data from the case files of the Office of the Public Defender of the county on 17 variables (see Appendix $C$ for a list of variables and codings) for the total populations of initial charge Burglary I and Forgery I cases which were closed by the Public Defender's Office between July and December of 1977. Since a number of these files were in use by attorneys and thus not available for researching, the total population goal was not reached. Of the population of 46 Burglary I cases, dacia were collected on 33. Of the population of 59 Forgery I cases, data were collected on 47 . In addition, data were not available on type closing, judge or sentence for the 10 Burglary I cases and the 8 Forgery I cases in which there was a change of attorney after assignment (and thus a public defender did not handle the case through to closing). Data were also missing on other variables for these latter cases, particularly when the change of attorney took place early in the process. Summary statistics were also taken 
from Public Defender records on type offense and type closing for the July to December period in 1977.

The selection of the variables on which data were collected from case files was based on the research problem as outlined in the propositions and the areas for exploration. The choice of variables was also determined in part by the findings from other studies of case disposition in which relevant relationships were indicated. Finally, of course, the selection was limited by the information provided in the case files. For example, the researcher had hoped to collect data on the race of the defendant; however, race was not recorded in the Criminal court files. While race was recorded in the Public Defender files, the small number of cases investigated in this data set rendered conclusions regarding race tenuous at best.

Interviews were the source of the third type of data. Three groups of court actors were interviewed by the researcher: public defenders, prosecutors and judges. These three groups were selected because of their roles as key actors in the disposition process in general and in the negotiation process in particular. Although it is recognized that both private and public attorneys are key actors in the bargaining process, the focus of this study was on the way in which members of the public court system perceived this system. In addition, it was necessary to set some limits on the number of people interviewed. Since nearly half of all felony cases in this county were handled by the public defender system, the decision was made to interview only this group of public defense 
attorneys. The intent was to interview all public defenders, prosecutors and judges who handled felony cases in this county. All felony public defenders in the county (plus five who had recently left the office) were interviewed, resulting in a total population of 15. Due to time constraints on their office, the District Attorney decided that only five full interviews could be granted. The interviewees, all high-level deputy district attorneys, were selected by the D.A.'s Office. In addition to these five complete interviews, nine prosecutors from the county office responded to the questionnaire segment of the interview form. These latter respondents were also selected by the D.A.'s Office. Eleven of the 13 Circuit court judges who handled felony cases agreed to be and were interviewed, but only 8 of them agreed to fill out the questionnaire.

The interviews consisted of two parts. At the beginning of the interview, respondents were given a questionnaire which called for written responses to questions using a five-point rating scale. With the exception of the nine prosecutors who filled out this form on their own, respondents completed the questionnaire in the presence of the researcher. This afforded an opportunity to make written notes on comments made by the interviewees as they filled out the form. The second part of the interview called for open-ended verbal responses to a standard set of questions asked of the respondent by the interviewer. The questions calling for verbal responses are stated in full in Chapter VI. A copy of the questionnaire form is found in Appendix $D$. 
The construction of the interview instrument was accomplished by identifying the key concepts outlined in the propositions and exploratory areas and then operationalizing these concepts with the aid of instruments used in previous studies of the same concepts. The interview was pre-tested by giving it to three attorneys who work or have worked in the court system of this county. Their suggestions (as well as those of academic experts in the field) led to some modifications in the interview form. In spite of these checks, it became clear as the interviews proceeded that certain questions were consistently problematic, in that the meaning or wording was unclear or unfamiliar to the respondents. A discussion of these problematic questions is included in Chapter VI.

Overall, the data-collection process took the researcher (working alone) five months. During this five-month period (from November, 1976 through March, 1977), the investigation included continual observations of the case disposition process within the court system. Casual conversations with court actors yielded various pieces of information which have been incorporated into the analysis of the findings. Also, a variety of general impressions were recorded from the direct observation of a number of trials, hearings and informal exchanges between court actors.

In addition to these exploratory observations, standardized schedules were constructed and used for recording data on observations of two activities in the case disposition process. The first was for the observations of pre-trial conferences. These conferences, mandatory for all felony cases, represent the setting in which the 
formal negotiation process takes place. Although generally the only people allowed in the room during a pre-trial conference were the attorneys and the defendant, the investigator was granted permission by the attorneys and defendants involved in five different cases to sit in as an observer. The observation schedule (see Appendix E) called for the recording of each comment in the sequence in which it took place. Recorded for each comment were the following: the speaker; the content, coded as one of 16 categories; whether the verbalization was a statement or a question. Additional notations were made regarding the conversations as time allowed, and finally, the duration time of each conference was recorded.

The second set of observations made with a pre-determined schedule was of guilty plea hearings and sentencings in Chief Criminal Court. Recordings were made as the observer sat as a spectator in the courtroom. Since these hearings were open to anyone, permission to observe was not necessary, nor was invasion of privacy a concern. The great majority of hearings were completed within five minutes, with several more minutes elapsing prior to the next hearing. The entire conversation of each hearing was recorded (either by a summary of each comment or by a direct quotation). Observations of 25 hearings were made in this manner.

METHODS FOR DATA ANALYSIS

Data collected from written documents describing the formal structures, procedures and policies of case disposition within the court system were analyzed qualitatively. This information was 
used to describe the formal organization and to point out the way in which the formal organization (as depicted by the organization itself) did or did not differ from the informal organization. Data from the case files on settled felony cases were subjected to quantitative analysis. First, the frequency distributions of the coded variables were prepared. Second, relationships between variables were ascertained through cross tabulations and computation of chi square values. Some relationships, while not reaching statistical significance, nevertheless indicated trends or patterns which were described with the use of percentage statistics. Throughout the analysis of the findings from the case files data, percentage descriptions were used generously, based upon the belief that this kind of numerical description had the distinct advantage of presenting the data in a manner which could be clearly communicated to the court actors and to the public in general. Since a major goal of this research undertaking was to provide system members and the general public with information about the reality of the case disposition process, easy communication was a methodological priority. In addition to frequencies, percentages and tests of statistical significance, relationships were described qualitatively in order to analyze the meaning of the findings in terms of the total picture of case disposition.

The questionnaire part of the interview yielded interval level data. However, the use of inferential sample statistics for analysis of these data was inappropriate since the respondent groups were not random or representative samples (in fact, one group 
was a total population and another group was just short of a total population). Thus, these data were presented with the use of descriptive statistics: means, modes, ranges and standard deviations. Inferential analysis was done qualitatively.

For the open-ended, conversational part of the interview, each question was separately analyzed. Between and within group differences were pointed out by noting the numbers of respondents who held similar or opposing views. The content of the responses was qualitatively described and relationships were noted between attitudes of the interviewees and the data on case disposition collected from other sources. Again, the ultimate purpose was to show the way in which the parts fit into a picture of the whole.

While the analysis of the pre-trial observations included numerical accounts of the frequency and oxder of comments, the major analytical focus of the observational data was on the content of the activities. The content of the observations was analyzed qualitatively, again with an eye toward relationships to data from the other sources and toward the overall picture of the case disposition process. Particular care was taken to distinguish between the description of events and observer impressions or interpretations of those events.

\section{CONCLUDING REMARKS}

The preceding discussions of the field research model and the specific methodology for this study indicate that this type of research is no small undertaking. It is not surprising, 
therefore, that a number of questions have been raised regarding the "methodological soundness" of the field research model on which this study was based. Appendix $A$ is devoted to a discussion of these questions and reflects the author's confidence in the appropriatenesss of this methodology for the present study.

In this chapter, the research design, setting and methods for data collection and analysis have been described. Beginning with the next chapter, the remainder of the dissertation is given over to a presentation and analysis of the research findings. The formal organization is described in Chapter II. The findings from records and case files are presented in Chapters IV and V. Chapter VI deals with the interview data, and Chapter VII focuses on the observational data. In the final chapter, a model of the case disposition process in the court system under study is set forth. Accompanying the model is a detailed analysis of the findings in terms of their relationship to theory and previous research. 
CHAPTER III

THE FORMAL ORGANIZATION:

STRUCTURES, PROCEDURES AND POLICIES

INTRODUCTION

The formal organization under study was the felony court system in one urban county. The specific research focus was on three parts of the formal organization: (1) felony court, in which accused felons were processed from initial charge to final disposition; (2) the office of the District Attorney, through which the prosecution process took place; (3) the Office of the Public Defender, through which the defense process for approximately half of accused felons took place. Although all three were interdependent parts of the overall public court system, the formal organization of each was independently examined in order to assess the relationship of the parts to the whole.

The court system which had as its jurisdiction the county under study was located in the central city of the county. The building which housed the courtrooms, judges' chambers, records divisions and District Attorney's Office (plus a number of other county offices) was the County Courthouse. The top floor of this building was a jail, used primarily as a temporary holding center for accused offenders at various stages of the court process. The county office of the public defender system was located in a separate 
office building several blocks away from the cuurthouse. Also, a separate building in the immediate area provided a second office site for the district attorney system. Following is a description of the formal organization of felony court, the Office of the District Attorney and the Office of the Public Defender.

\section{FELONY COURT}

Felony defendants moved in and out of various locations within the courthouse as their cases proceeded toward final disposition. The first appearance of the defendant took place in a courtroom (with easy access to the jail) over which different District Court judges presided on assignment. This appearance--at which time the formal charge was gone over, the defendant was assured of an attorney, and the date for a preliminary hearing was set--was required by law to take place within 24 hours of the defendant's arrest. The second appearance was at the preliminary hearing (held in a different courtroom), the purpose of which was to determine whether or not the evidence warranted a formal arraignment on the charge. If the decision was affirmative, the defendant appeared in the Chief Criminal courtroom for the formal arraignment. At the arraignment, the defendant entered a not-guilty plea (if he or she refused to enter such a plea, one was automatically entered), and the dates for the pre-trial conference (the plea negotiation session) and the actual trial were set. The pre-trial conference date must be within 15 days of the formal arraignment. After the pre-trial conference, the defendant could enter a petition to change the plea of guilty 
either to a plea of not-guilty or to a plea to a bargained charge. If the accused had entered a plea to a misdemeanor rather than to the original felony (or if the judge decided to grant misdemeanor status at the plea hearing), he or she could waive sentence postponement and be sentenced at the same time that the plea was entered and accepted by the judge. The guilty plea hearing did not, of course, take place if the defendant maintained the notguilty position. If the individual plead guilty to a felony, a pre-sentence investigation was required prior to sentencing. Such an investigation then took from foux to six weeks. Following the completion of the pre-sentence report, the offender either returned to Chief Criminal Court for sentencing or had his or her case assigned out to one of the other felony judges for sentencing. After the initial court appearance in front of a District Court judge, felony cases was handled by 13 felony court judges who held the Circuit Court positions (an additional Circuit Ccurt position was created after the research had been completed). At all times one of these 13 juages was sitting on the bench in Chief Criminal Court. Through a rotation system, the judges were assigned to this latter position for a duration of from two to three months. The result of this system was that the majority of cases was heard and settled by only a few judges in any given year. Another Circuit Court judge was elected to serve as Presiding Judge; his or her responsibilities were the handling of civil cases, administrative activities, and the assignment of trials to judges. 
The judges as a group played an active role in the structuring of the case disposition process. Through this administrative role, they had set up the mandatory pre-trial conference, the mandatory pre-sentence investigation for convicted felons, and the guidelines for speedy disposition of cases. State statutes gave further formal recognition to the procedures for plea bargaining and speedy case disposition. In addition to the procedures for plea negotiation, policl on plea bargaining is outlined in the state statutes (see Appendix F). The Speedy Trial Act passed by the legislature states that cases must be disposed of within 60 days or dismissed. The courtrooms were physically designed in such a way as to create an aura of awe and respect. The rooms were very large; the ceilings were high; the decor was austere. The juage sat at the back of the room, set off from others by a raised platform and podium--both effective boundaries. The hard-back spectator benches were similar to those found in churches. All court authorities were formally dressed, but the dress of the judge indicated the highest status. Beginning with the entrance of the judge into the courtroom, a number of verbal rituals followed which further added to the atmosphere of austerity and formality. The only courtroom which deviated from the above description was the Chief Criminal Court. This room was considerably smaller than the other courtrooms. The spectator section was very small, and thus the spectators were situated quite close to the juage. The pre-trial conference rooms could only be entered from the inside of this courtroom, and the entrance was located between the spectator 
section and the judge's podium. There was continual traffic in and out of these rooms while cases were being heard. The enormous amount of continual activity provided for an atmosphere which was much less austere than in the other courtrooms.

Overall, then, the organization of felony court was highly formalized and structured. The judges played an active administrative role (formalizing and structuring the disposition process) as well as the traditional judicial role. The formal organization was backed up by state statutes which provide not only procedural rules but also policy guidelines for case disposition through guilty pleas.

$$
\text { OFFICE OF THE DISTRICT ATTORNEY }
$$

\section{Formal Structure}

The Office of the District Attorney is responsible for prosecuting all criminal cases. With the aid of federal monies, the office had expanded its operations considerably in recent years. Two separate buildings in the central city provided office sites. Headed by the elected District Attorney, the office staff consisted of 152 deputy district attorneys, investigators, and other professional and clerical staff. The staff size had increased noticeably over the last 20 years. In 1956, the office had a staff of 27, consisting only of deputy district attorneys and clerical personnel.

Along with the increase in size, the Office had become specialized in its division of labor. Seventeen deputy attorneys handled felony cases. Additionally, two attorneys were assigned to the Intake Office, their task being to review all misdemeanor cases and 
decide whether or not to proceed with prosecution. The professional staff were also assigned to special units and divisions within the Office. There were six units handling different offense types. Unit A handled arson, felony driving and some burglary cases; Unit B was assigned drug, pornography and prostitution cases; Unit C handled burglary, robbery, weapon offenses and negligent homicide; sex crimes and assaults were assigned to Unit $D$; and finally cases handled by Unit $\mathrm{E}$ were described as fraud and white collar offenses. Unit U was the Career Criminal Unit, which handled a variety of offenses in which the defendant had been declared by the office to be a career criminal.

Two special divisions within the Office were Child Support and Juvenile Justice. The Child Support Unit was responsible for the enforcement of child support obligations and for trying paternity suits in the county. The Juvenile Justice Division handled cases against juvenile defendants and acted as an advocate for children involved in abuse, neglect and termination of parental rights cases.

There were two relatively new programs in which office personnel expressed particular pride. The first was a victims' aid program which included three projects: Victim's Assistance Project; Rape Victim Assistance Project; Project Repay (all established in the last five years). The other program was composed of three special prosecution units, aimed at "taking a hard line" against certain offenses/offenders. The No Plea Bargaining Unit initiated in 1973 directed its efforts toward the reduction or elimination of plea 
bargaining on certain cases. Initially, this unit focused on burglary and robbery cases, but recently expanded its operations to include other offenses (see following section on plea bargaining policy). The Career Criminal Unit discussed above was funded by the Law Enforcement Assistance Administration in 1976 and was another of the "hard line" programs aimed at controlling crime. This program was carried out by five deputy attorneys and support staff who, according to the office manual

\footnotetext{
- . devote their full energies and special prosecution techniques toward building solid cases and securing substantial sentences for those offenders whose criminal career poses, and continues to pose, a threat to the lives and property of the citizens in our community.
}

The Negligent Homicide Unit, funded by the state Traffic Safety Commission, was the responsibility of specially trained deputy attorneys whose duty was to aid in investigation and prosecution of cases in which traffic accidents resulted in fatalities. Recent re-organization of the D.A.'s office emphasized a team approach to the handling of cases. The manual stated:

The felony attorneys are divided into crimespecific teams that correspond to and work with crime-specific police investigative units. With this reorganization, the team which makes the initial decision to file charges also tries the case.

There are two ways in which felony cases may be initiated. The first is to present a case to a Grand Jury, which decides whether or not the facts suggest that there is enough evidence for issuing a charge against a defendant. The second method is the filing of charges through the District Attorney's Information of Felony, which gives 
the formal decision-making power to the District Attorney. The majority of felony cases were initiated by Information, and the use of the Information was increasing (in 1976, initiation by Information increased by 53 percent, whereas Grand Jury initiations decreased by 28 percent).

It was clear that the District Attorney's Office in this county had a complex social structure characterized by specialization. Documents compiled by the office clearly depicted the formal organization by delineating statuses, roles and procedures within the structure. Additionally, care had been taken by the office to set down in writing lengthy descriptions of office policy. Of relevance to the present study was the office's description of plea bargaining policy.

Plea Bargaining: Formal Policy

The Office of the District Attorney had formally recognized plea bargaining as a method in case disposition. The policy manual included a section entitled "Plea Negotiation Policy--Adult Felony Charges," in which the philosophy and guidelines for plea bargaining were explicitly stated. In the first paragraph of this section, plea bargaining was given formal recognition:

As a part of its professional responsibilities, the office is ethically required to make known its general policy of a willingness to consult with the defense concerning disposition of charges by a plea and to establish criteria for those discussions and potential agreements. It has been recognized, of course, that during these discussions bargaining concerning criminal charges between defense and prosecution takes several forms. Sentence bargaining and the dropping of indicted and unindicted counts (many of which may merge into one offense regardless) are but two methods of bargaining. 
of interest is the fact that bargaining by charge reduction was not mentioned in this paragraph. This omission reflected current efforts by the office to limit and in some cases eliminate charge reduction bargains. Initially, these efforts were formalized by policy which disallowed bargaining for charge reduction on robbery and burglary offenses, but the restrictions have been expanded. As of June 1, 1977, charge reduction bargains were prohibited for the following felonies: (1) Robbery I; (2) Robbery II (committed with simulated weapon; (3) Burglary I; (4) Burglary II; (5) Theft I; (6) Furnishing heroin or cocaine; (7) Supplying contraband; (8) Forgery I; (9) Escape I; (10) Escape II; (11) Ex-convict in possession of a firearm; (12) All cases where the defendant had been designated as a career criminal by the District Attorney's Career Criminal Project's staff. The formal policy did, however, include a clause which made charge reduction permissible for special cases of these offenses. This clause read:

This policy recognizes that there will be times when it is in the interest of justice for a reduction of a non-reducible charge to occur. It is anticipated that this will not occur in more than five percent of the cases in the non-bargainable categories. These reductions may only occur with the written consent of the District Attorney or his designate.

The ultimate decision on charge reduction, then, lay with the District Attorney himself.

The target offenses for the "campaign" to reduce plea bargaining were either property offenses or victimless crimes. The rationale for not including crimes against persons in the nonreducible category had to do with the needs and interests of victims. 
The office perceived of itself as playing a major role in

victim advocacy:

Because of the District Attorney's policy of total victim involvement and the consideration of the victim's needs in the cases of violent cximes against persons such as rape, sodomy, sex abuses and assault, the prosecutor shall retain the discretion in these cases to plea negotiate. The prosecutor is required, however, to have contact with the victim and take into consideration the victim's needs and desires in the exercise of the prosecutor's discretion to negotiate.

In addition to charge reduction bargaining, formal policy

allowed for the following sentence and charge dismissal bargains

for all felonies:

To make or not oppose favorable recommendations concerning the sentence which may be imposed if the accused enters a plea of guilty.

To seek or not to oppose dismissal of the offense charged if the accused enters a plea of guilty to another offense reasonably related to the accused conduct.

To seek or not oppose dismissal of other charges or potential charges against the accused if the defendant enters a plea of guilty.

The selection of the words "reasonably related" in the second type of bargain implied a recognition that not all guilty pleas would be to a charge necessarily included in the initial charge.

There were also explicit statements concerning criteria which were not to be considered in deciding to negotiate for a plea. It was strongly stated that plea negotiation should not be undertaken to meet production needs:

Plea negotiations, however, shall never be used to reduce case backlogs or reallocate manpower. This would constitute a flagrant abuse of the process and the inherent responsibility and discretionary powers of the prosecutor. 
However, there were other policy statements which implied a concern for organizational needs. For example, it was stated that one criterion to be used in deciding whether or not to bargain was the advancement of other prosecution goals through non-prosecution of certain charges. It was also stated that plea bargaining could be undertaken in cases where it appeared that the interests of effective administration of criminal justice would be served. These rather vague statements would appear to allow for considerable flexibility in the decision-making process.

Another criterion which was not to guide plea negotiation decisions referred to the relationship between the prosecutor and defense attorney handling a given case:

The choice of defense counsel shall not be a factor in a deputy district attorney's decision to negotiate or not negotiate with a defendant. A defendant shall not receive favorable advantages or unfavorable treatment in negotiations based upon past or present relationships between defense counsel and the District Attorney's Office.

This statement implied a concern for equal treatment of cases. An equal treatment approach was emphasized in another policy statement:

Similarly situated defendants shall be afforded equal plea agreement opportunities.

Yet, in still another section, individual ratehr than equal treatment was emphasized:

The deputy district attorney shall be certain that all cases are determined individually and on their own unique facts and circumstances.

In fact, formal policy outlined criteria which were to be considered in determining the "availability and acceptance of a guilty plea" for each individual case. These criteria included: seriousness of offense; 
mitigating circumstances; age; background; prior record, attitude and mental state of the defendant; nature and needs of victims; attitudes of witnesses; strength of case; arrest circumstances and attitudes of the arresting officer.

In addition to criteria for deciding whether or not to plea bargain, formal policy also outlined procedure for plea bargaining. In line with state law, Office policy was that plea negotiations were to be carried on only in the presence of defense counsel. A bargain could not be offered a defendant without defense counsel's approval. While this policy was seen by its makers as a due process safeguard, it did lend support to the contention that the prosecutor and defense attorney were formally viewed as the key actors in the bargaining process. It was the interaction between these two parties which was essential in order for a bargain to eventually take place.

Procedural policy also stated that the deputy district attorneys should make known to defense counsel the generai policy and willingness of the Office to plea negotiate and to set aside times and places for negotiation discussions. Policy statements warned deupty district attorneys that they were not to make any promises regarding sentence. Sentence bargaining could only take the form of a recommendation. Again in line with state law, policy stated that if the prosecutor was unable to fulfill an understanding previously agreed upon in a plea negotiation, the defense could withdraw the guilty plea. It must be assumed that this included sentence agreements; however, since sentence bargains were only recommendations, the meaning of the plea withdrawal policy for sentence bargains was unclear. 
This detailed description of plea bargaining policy issued by the Office of the District Attorney was indicative of the importance which was attached to the role of plea negotiation in the case disposition process. Although they were given lesser space in the policy manual, guidelines for screening and charging criminal cases were also explicitly outlined. These guiddlines are described in the following section.

\section{Screening and Charging: Formal Policy}

Screening refers to a decision not to charge or to dismiss a charge(s) early in the process. The policy manual defines screening as a "process by which a person is removed from the criminal justice system prior to trial or plea." Screening was alleged to meet two prosecution goals. The first had to do with efficiency needs of the system:

The first is to eliminate cases which the prosecution knows are futile-futile due to lack of evidence or other case necessities--and a continuation of prosecution process would be fruitless and result in wasted economic resources.

The second goal was to stop action against people who were found to be falsely accused. If either of these criteria applied to a given case, it would be screened out of the system. A case might also be screened out for the following reason:

Specific laws and elements that constitute crime are legislative responsibilities, but prosecutorial discretion must be applied in granting "immunity" by screening special individuals due to extenuating circumstances, i.e., individuals who aid law enforcement in the apprehension of criminals and who participate in certain crimes in doing so. 
This description is ambiguous. The suggested reference was to individuals who had been asked to aid law enforcement and in so doing had to be involved in a criminal offense. However, it is unlikely that individuals acting under the auspices of law enforcement will be subsequently charged with a crime which is part of an assistance plan. Whether or not this clause applied to individuals who first committed an offense and then aggred to assist the system in exchange for immunity was unclear.

Formal policy emphasized the discretionary power of the prosecutor in making charge decisions (although a list of factors to be considered in charge decisions similar to factors to be considered in bargaining decisions was given). The following statements were indicative of the formal policy of discretion:

Within his discretion, the prosecutor shall determine what charges shall be filed, how many charges shall be filed, and how charges shall be presented.

The prosecutor is not obligated to file all possible charges which available evidence might support. The prosecutor may properly exercise his discretion to present only those charges which he considers to be consistent and in the best interest of justice.

While the charging policy was much less restrictive than the plea bargaining policy, there were two charging restrictions which were relevant to the present study. The first implied a concern for getting convictions:

The prosecutor shall file only those charges which he believes can be reasonably substantiated by admissible evidence at trial.

The second referred to the ethical issue of overcharging in anticipation of plea bargaining: 
The prosecutor shall not attempt to utilize charging decisions only as a leverage device in obtaining guilty pleas to lesser charges.

The policies of the District Attorney's Office concerning plea bargaining, charging and screening were numerous and well-delineated. They attended to a variety of needs and goals of the criminal justice system. The complexity of the formal policies complemented the complexity of the formal structure of the office.

OFFICE OF THE PUBLIC DEFENDER

While the Office of the District Attorney was a part of the county court system and was allocated funding as a part of the system, the Office of the Public Defender was a non-profit private corporation operating under contract with the county. As such, the Public Defender's Office was an independent organization and not vunerable to changes in funding allocations in the same way as was the District Attorney's Office. Under contract, the Public Defender's Office agreed to handle a certain number of civil and criminal cases in a given year for a set fee. Thus, the office knew in advance what its caseload would be for the year and could plan accordingly. From June 30, 1977 to June 30, 1978, the designated caseload for the office in this county was 1,520 felonies, 1,200 misdemeanors and up to 1,000 civil commitments.

The formal title of the office was the Metropolitan Public Defender office, and the office under study was actually a branch (although it was the central and largest branch) of the metropolitan organization. The individual who headed the entire Metropolitan 
Office was called the Public Defender (his office was in the central Office under study). Staff attorneys were not called public defenders, but rather were referred to as attorneys who work for the Public Defender's office (in the text of this paper, however, they are referred to as public defenders for the purpose of role identification). The Public Defender's Office of the county under study was located in an office building several blocks away from the County Courthouse. Offices were located on two floors in this building. In addition to the Public Defender, there were 13 attorneys in this Office, 8 af whom worked specifically on felony cases. In addition, there were investigators, attorney assistants and clerical staff-the entire staff consisting of approximately 80 individuals.

The eight felony attorneys, working in teams of two, were responsible for a designated number of cases on a weekly basis. Case assignment was randomly carried out through a rotation system. A team appeared in District Court for two weeks, during which time it picked up 18 cases. The third week, the team appeared in Circuit Court and picked up another eight cases. The fourth week was known as "free week," and during this time the team picked up no new cases. In any given week, then, there were two teams in District court and one team in Circuit court for case assignment. The only cases which were not randomly picked up through this sytem were those declared as "major cases," i.e., homicides or others so declared due to their need for greater time and effort than routinely expected. Major cases were assigned only to senior attorneys; however, within this group, assignment was done on a rotation basis. The Public 
Defender himself did not have a caseload; his role was administrative (he also appeared to be counted on quite heavily as an advisor to the staff attorneys).

It was the researcher's impression that the Public Defender's Office operated under an atmosphere of informality and intimacy (particularly in comparison to the Courthouse or the District Attorney's Office). All levels of staff referred to one another on a first-name basis, and interactions suggested no feelings of superiority/inferiority. In fact, this lack of hierarchical structure apparent to the observer was promoted by the Public Defender and was an integral part of formal office policy.

The underlying philosophy of the Public Defender's Office was that attorneys and their professional assistants were independently responsible for the entire handling of a case once it was assigned to them. The way in which the case was to be handled from start to finish was decided by the attorney and assistants to which it had been assigned. Beyond the legal rules, the attorneys were free to make their own judgments as to the way in which the case would be handled. This philosophy, then, was really the office policy. Unlike the Office of the District Attorney, the Office of the Public Defender had no policy manual. What it did have was a brief statement of purposes and goals. According to this statement, the Public Defender's office was concerned with the following:

Providing the best possible legal defense services to indigents as determined and appointed by the courts.

Providing those services at a savings to governmental units entering into service contracts with the Metropolitan Public Defender Services. 


\author{
Extending specialized knowledge of defense counseling \\ to the benefit of clients, judicial system and the \\ private bar. \\ The philosophy of independence and individual responsibility was \\ formalized in these words: \\ - . that which best serves the client and office \\ is what is expected of every employee, limited only by \\ a commitment to working within and improving the criminal \\ justice system.
}

\title{
CONCLUDING REMARKS
}

A description of the formal organization of the public court system indicated both similarities and differences between the subparts. Both Felonly Court and the Office of the District Attorney were highly formalized and structured. By comparison, the Office of the Publi.c Defender appeared informal. Role specialization was dominant in the structure of the office of the District Attorney. Role generalization better characterized the activities of Circuit Court judges and attorneys in the Office of the Public Defender. It was clear that the Offices of the District Attorney and Public Defender in this county differed both in structure and policy. The larger District Attorney's Office had a noticeably more complex structure which was basically hierarchical. Formal policy statements were detailed and lengthy, allowing for little decision-making at the lower staff levels. Both the structure and the philosophy which guided the Public Defender's Office emphasized individual responsibility for decision-making; policy guidelines were general and brief. Whereas plea bargaining was given specific attention in the policy 
manual of the District Attorney's office (and showed a close relationship to the statutory guidelines), it was not directed by formal policy in the Public Defender's Office.

The formal organization provides the setting in which felony cases are processed and settled. The substance of the disposition process, i.e., characteristics of offenses, offenders and outcomes, is the subject of the next two chapters, in which the findings from case records and files are discussed. 
CHAPTER IV

THE NATURE OF OFFENSES, OFFENDERS AND DISPOSITIONS:

CRIMINAL COURT FELONY CASES

\section{INTRODUCTION}

Essential to the understanding of the totality of the case settlement process in a given court system is a statistical description of the nature of offenses, offenders and dispositions processed through the system during the time of the research undertaking. A descriptive profile of the populations of offenses, offenders and dispositions--presented in the first part of this chapter-was constructed on the basis of frequency distributions of the variables listed in Table I.T.

The next task was an analytical examination of the descriptive data relevant to the specific inquiries of the research endeavor. This examination was done by identifying statistical relationships between certain variables which were meaningful for the analytical purpose of this study. The findings from this examination are discussed under five headings--each of which attends directly to the form and/or outcome of case disposition through negotiation. These areas are: (1) the relationships between closing types (straight guilty pleas, bargained guilty pleas, trials and dismissals) and offense/offender characteristics; (2) the relationships between closing types, offense/offender characteristics and punishment; (3) the relationship of original charges to reduced charges; (4) the 
TABLE II

VARIABLES ON WHICH DATA WERE COLLECTED

FROM CRIMINAI COURT FELONY CASE FIIES

1. Initial most serious charge

2. Initial charge: 2nd count

3. Initial charge: 3rd count

4. Initial charge: 4th count

5. Number initial counts

6. Number initial felony counts

7. Settled most serious charge

8. Settled charge: 2nd count

9. Settled charge: 3rd count

10. Settled charge: 4th count

11. Number settled counts

12. Number settled felony counts

13. No contest plea

14. Type closing

15. Number setovers

16. Type attorney

17. Judge
18. Pre-trial custody status

19. Sentence: incarceration

20. Fine

21. Drug or alcohol program

22. Mental health program

23. Restitution

24. Community services

25. Month arrest

26. Total disposition time

27. Sex of defendant

28. Age of defendant

29. Prior record of defendant

30. Education of defendant

31. Employment of defendant

32. Residence of defendant

33. D.A. unit (1977 only)

relationship between closing types and efficient production; (5) changes in patterns from 1976 to 1977.

Ultimately, these findings from the Criminal Court case files were interwoven with the findings from other data sources to form the model of case disposition in one urban court system which is presented in the final chapter.

Data discussed in this chapter were collected from individual case files fxom the County Criminal Court Records Division. Two 10 percent samples (one for 1976 and one for the latter half of 1977) were drawn from a master list of felony cases settled in these years (see Chapter II). Data were collected on the 33 variables listed in Table II. Not all case files contained information on all the variables, and, in particular, the number of cases with missing 
data on defendant characteristics was relatively high. There is no reason to suspect, however, that missing data were not random.

In the following pages, certain offense types are referred to by an abbreviated label. These labels, described in Table III, not only serve the interests of brevity, but also were used commonly within the court system.

TABLE III

ABBREVIATIONS FOR OFFENSE TYPES

$\begin{array}{ll}\text { CAID: } & \text { Criminal Activity in Drugs } \\ \text { CDP: } & \text { Criminal Drug Promotion } \\ \text { Burg: } & \text { Burglary } \\ \text { Forg: } & \text { Forgery } \\ \text { Rob: } & \text { Robbery } \\ \text { UUV: } & \text { Unauthorized Use of a Motor Vehicle } \\ \text { ECPFA: } & \text { Ex-Con in Possession of a Firearm } \\ \text { DUIL: } & \text { Driving Under the Influence of Liquor } \\ \text { DWS: } & \text { Driving While Suspended } \\ \text { Sod: } & \text { Sodomy } \\ \text { Att: } & \text { Attempted }\end{array}$

A PROFILE OF THE SAMPLE POPULATIONS

The Nature of Offenses

Drug and petty property offenses accounted for the majority of initial charge offenses and the overwhelming majority of settled charge offenses in both years. Tables IV and $V$ present the frequency distributions of most serious initial and settled charges for both years. Due to the small number of cases in 1977, robberies and other property crimes were not broken down further as they were for 1976. Crimes against the person were divided for 1976 into homicides, kidnaps, assaults and sex crimes. For 1977, sex crimes were coded separately, but homicides, kidnaps and assaults were placed into one category. 


\section{TABLE IV}

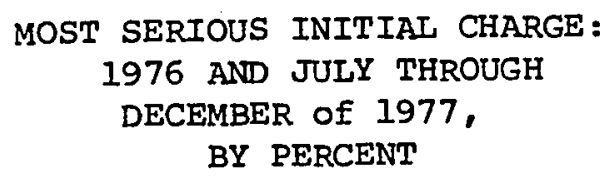

1976

1977

\begin{tabular}{|c|c|c|c|}
\hline CAID & 198 & CAID & 198 \\
\hline Theft I & 128 & Burg I & 228 \\
\hline Burg I & 88 & Forg I & 108 \\
\hline Other Burg & 88 & Traffic & 108 \\
\hline UUV & 78 & Other Property & 98 \\
\hline Rob I & 78 & Theft I & 78 \\
\hline Assaults & 78 & Rob & 78 \\
\hline Forg I & 58 & $\begin{array}{l}\text { Homicides/ } \\
\text { Assaults/ }\end{array}$ & \\
\hline Misc. & 58 & Kidnaps & 78 \\
\hline Other Rob & 58 & Misc. & 68 \\
\hline Escape/ECPFA & 48 & Escape/ECPFA & 48 \\
\hline Sex Crimes & 48 & Other Burg & 48 \\
\hline Traffic & 38 & Sex Crimes & 38 \\
\hline Homicides & 38 & Other Drug & 18 \\
\hline Other Property & 28 & TOTAL & $1008 \quad(163)$ \\
\hline Kidnaps & 28 & & \\
\hline Other Drug & 18 & & \\
\hline TOTAL & $1008 \quad(306)$ & & \\
\hline
\end{tabular}


TABLE V

MOST SERIOUS SETTLED CHARGE:

1976 AND JULY THROUGH

DECEMBER OF 1977,

BY PERCENT

$\underline{1976}$

1977

Other Drug

$11 \%$

118

Theft I

98

Traffic

118

Other Burg

98

CAID

118

UUV

88

Forg

118

Misc.

$7 \%$

Theft I

108

Rob I

$7 \%$

Other Drug

98

Assaults

78

Burg I

88

CAID

78

Misc.

$8 \%$

Other Property

68

Other Rob

68

Homicides/

Assaults/

Kidnaps

78

68

Other Burg

78

48

Sex Crimes

48

48

Rob

48

48

Escape/ECPFA

18

Traffic

48

TOTAL

1008 (141)

Homicides

28

TOTAL

1008 (253) 
As these tables indicate, CAID was the most common initial charge, accounting for 19 percent of the total initial charges in both years. From Tables VI and VII it can be seen that the majority of cases were property offenses. Crimes against the person made up a small minority of the offense types. Noticeable was the increase in the proportion of traffic offenses from 1976 to 1977, largely due to a legislative change making some traffic offenses felonies rather than misdemeanors. Relatively uncommon as settled charges were the most serious, Class A felonies (for a listing of the felony and misdemeanor levels of different offenses see Appendix G).

TABLE VI

INITIAI CHARGE CATEGORIES:

1976 AND JULY THROUGH

DECEMBER OF 1977,

BY PERCENT

1976

1977

Property (include Rob) $52 \% \quad$ Property (include Rob) 508

Crimes Against Person $14 \% \quad$ Crimes Against Person $10 \%$

$\begin{array}{lll}\text { Drugs } & 208 & \text { Drugs }\end{array}$

$\begin{array}{llll}\text { Traffic } & 38 & \text { Trafic } & 108\end{array}$

$\begin{array}{lll}\text { Other } & 118 & \text { Other }\end{array}$

TOTAL 1008 (306) TOTAL 1008 (163)

The great majority of cases in both years were single count rather than multiple count cases. As indicated in Table VIII, however, there was a slight increase in settled multiple count cases in 
TABLE VII

SETTLED CHARGE CATEGORIES:

1976 AND JULY THROUGH

DECEMBER OF 1977 ,

BY PERCENT

$\begin{array}{lcll}\text { Property (include Rob) } & 548 & \text { Property (include Rob) } & 498 \\ \text { Crimes Against Person } & 138 & \text { Crimes Against Person } & 118 \\ \text { Drugs } & 188 & \text { Drugs } & 208 \\ \text { Traffic } & 48 & \text { Traffic } & 118 \\ \text { Other } & 118 & \text { Other } & 98 \\ & & & 1008 \text { (14I) } \\ \text { TOTAL } & 1008 \text { (253) } & \text { TOTAL } & \end{array}$

TABLE VIII

TOTAL CASES BY TYPES OF MULTIPLE COUNTS:

1976 AND JULY THROUGH

DECEMBER OF 1977,

BY PERCENT

$\begin{array}{lcc} & 1976 & 1977 \\ \text { TOTAL CASES } & 306 & 163 \\ \text { Percent multiple initial counts } & 26 & 25 \\ \text { Percent multiple initial felony counts } & 20 & 19 \\ \text { Percent multiple settled counts } & 6 & 13 \\ \text { Percent multiple settled felony counts } & 4 & 8\end{array}$


1977. While the number of multiple count initial charges was small, the number of multiple count settled charges was even less. The number of cases settled with more than one felony count was miniscule. About a quarter of the cases $(27$ percent in 1976 and 25 percent in 1977) which resulted in conviction ended up with no felony counts. Thus, a reduction in offense severity was notable as cases moved from initial charge to settled charge.

\section{The Nature of Closings}

Nine categories of closing types were coded. The labels given the closing types, which are used in subsequent references, symbolize the following. PG refers to those cases in which the defendant entered a straight guilty plea to the initial charge(s). PG + Dis symbolizes those cases in which the defendant plead guilty to the initial charge but had a count(s) and/or other charges(s) dismissed. PGTL indicates those cases in which the defendant plead guilty to a less serious charge (a lower class offense) than the initial one. PGTL + Dis refers to cases in which the defendant plead guilty to a lesser charge and also had a count(s) and/or other charge (s) dismissed. $C B J$ means convicted at trial by jury; ABJ means acquitted at trial by jury. $C B C$ refers to those cases in which the defendant waived the right to trial by jury and was convicted by the court (judge); $A B C$ means acquitted by txial heard by the judge. DIS refers to cases which were dismissed subsequent to formal arraignment. The categories are mutually exclusive. However, at times the following narrative refers to all PGTLS (which includes PGTL 
and PGTL + Dis), all PG bargains (which includes PGTL, PGTL + Dis and PG + Dis), or all PG's (which includes PG, PGTL, PGTL + Dis and PG + Dis). Table IX gives the percentage distributions of closing types in 1976 and the latter half of 1977.

TABLE IX

CLOSING TYPES: 1976 AND JULY THROUGH

DECEMBER OF 1977, BY PERCENT

$\underline{1976} \quad \underline{1977}$

$\begin{array}{lcc}\text { Type Closing } & & \\ \text { PG } & 268 & 238 \\ \text { PG + Dis } & 128 & 13 \% \\ \text { PGTL } & 248 & 298 \\ \text { PGTL + Dis } & 98 & 78 \\ \text { CBJ } & 88 & 98 \\ \text { CBC } & 38 & 78 \\ \text { ABJ } & 28 & 18 \\ \text { ABC } & 18 & 0 \\ \text { Dis } & 158 & 128 \\ \text { TOTAL } & & \\ & 1008 & 1008 \\ & (306) & (163)\end{array}$

Variations in the distribution of closing types between 1976 and 1977 were slight. There was a small decrease in the proportion of PG closings and a small increase in the proportion of trial closings. Charge reduction closings (PGTL and PGTL + Dis) were the most common type closing in both years. Only a small percentage of cases went to trial, and an extremely small number ended in 
acquittal. It should be noted that the number of dismissals was actually higher than here indicated (see Chapter VI) since Criminal Court statistics include only dismissals after formal arraignment. Over half of all cases which did not end in dismissal were settled with a bargained guilty plea. It should also be noted that data on two other types of bargains--agreements not to file on other known charges and sentence agreements--were not available from this data source. However, data from the Public Defender files (see Chapter V) indicated that if these two types of bargains were included, the number of bargained closings would account for the great majority of convictions.

The Nature of Offenders

The defendants were not representative of the general population; rather, they were characterized by high rates of undereducation, unemployment and underemployment, and recidivism. Also, young people and men were over-represented in the offender population. Finally, the great majority were defended by public attorneys. Reflecting national patterns, the overwhelming majority of defendants were male ( 83 percent in 1976 and 88 percent in 1977). Also in line with national statistics, defendants were relatively young. In 1976, the mean age of defendants was 29, and in 1977 it was 28. The mode statistics was even lower (20 in 1976 and 19 in 1977).

Compared to the general county population, defendants were considerably undereducated. Thirty-eight percent in 1976 and 42 percent in 1977 had completed less than four years of high school. 
Seventeen percent in both years had some college, but only 1 percent in 1976 and 2 percent in 1977 were college graduates. The statistics indicated that about half of the defendants in both years were unemployed. Although high, the unemployment statistic only partially reflected the extent of employment instability which characterized the offender population. First, employment status was often a self-report measure, and as such was subject to bias. Since attorneys interviewed expressed the belief that a defendant with employment increased his or her chances of receiving a light sentence (an opinion likely passed on to the client), the bias may have been in favor of underreported unemployment. Also, it is likely that anything that could qualify as employment was reported as such, e.g., part-time yard maintenance or off-and-on janitorial work. Additionally, an unemployed defendant who was not in jail custody may have been urged to find some employment in order to increase the chances of light sentencing. An attempt was made to take these points into account by coding defendants who had been employed less than six months in a separate category. However, data on length of employment were not available for all cases. Also, the data on part-time and off-and-on employment were too sketchy to record with any confidence (although these descriptions appeared frequently enough to suggest that there was likely a substantial number of these kinds of employment). However, a profile of job instability was definitely indicated by the statistics on defendants who had been employed for over six months, as only 20 percent in 1976 and 26 percent in 1977 fell into this category. 
An attempt was also made to get some idea of the nature of jobs held by those accused offenders who were employed. Many of the case files only gave the name of the defendant's employer, and thus it was not possible to ascertain the nature of the job in these cases. However, job descriptions were obtained for 72 defendants from the 1976 sample (a complete description of these jobs is given in Appendix $\mathrm{H}$ ). The great majority of these persons either had labor or low-level service jobs. Only three individuals held jobs which could be classified as administrative types. It should be remembered that most defendants were relatively young, and therefore it would not be expected that they would have a significant rate of high-level employment. Nevertheless, the complete picture indicated by the data was one of employment instability. The people who got in trouble with the law tended to be unemployed, only partially employed, or have employment which society characterizes as working or lower class.

Prior record, like employment, was a problematic variable. Some of the files from which the data were drawn included only the sheet on which self-reported prior record was recorded. Others only included a form which called for prior felony convictions. Arrests not resulting in convictions were not uniformly recorded, and thus were not included in the prior record category. Even so, the great majority of defendants were recorded as repeaters. Seventy percent had prior felony convictions in 1976, as did 72 percent in 1977 . When the only prior record information available was for prior felony convictions, the researcher coded no prior 
felony convictions as a separate category. This latter category is really an unknown, since it included those with misdemeanor convictions as well as those with no prior record of any kind. However, there was a clear indication of no prior record of convictions of any type for only a small percentage of individuals (10 percent in 1976 and 14 percent in 1977). offenders were highly likely to be defended by a public attorney. In only 15 percent of the cases in 1976 and 20 percent of the cases in 1977 was an attorney privately retained. Almost half of the cases (49 percent in 1976 and 41 percent in 1977) were handled by public defenders, while the remaindex were handled by court-appointed attorneys from the private bar. These findings point to the low economic status of the offender population, for in order to be assigned either a public defender or a court-appointed attorney from the private bar, the defendant had to sign a statement saying that he or she was indigent and unable to afford to retain an attorney.

The Nature of Punishment

Over half of the charged offenders (53 percent in both years) spent their pre-trial time in jail custody. Release on own recognizance was granted in 31 percent of the cases in 1976 and 35 percent of the cases in 1977. Bail release was obviously the least common of the three possible pre-trial custody statuses. While these gross distributions likely reflected reality, it should be noted that for individual cases, the type of pre-trial custody 
recorded may have only represented a portion of pre-trial time, as changes in custody status can occur during the course of case settlement.

The largest number of convictions resulted in a non-incarceration sentence in both years, although non-incarceration sentences decreased from 54 percent in 1976 to 47 percent in 1977 . Of those who were not incarcerated, 89 percent in 1976 and 86 percent in 1977 were placed on probation. The remainder either received no punishment at all or were punished through a fine, restitution, or participation in a special program. The proportion of defendants who received jail sentences increased from 23 percent in 1976 to 33 percent in 1977. The percentage of defendants sent to the penitentiary was about the same for both years $(23$ percent in 1976 and 20 percent in 1977).

Table $\mathrm{X}$ shows the distributions of convicted cases in which the sentences included a fine, restitution, or participation in a special program. While the variations between the years were slight, the use of special programs did increase in 1977. It should be noted that these conditions were usually not alternatives to incarceration or probation, but rather, in almost all cases, were accompanied by a jail or probation sentence.

Since all felony charges carry a potential penitentiary placement, it is clear that sentencing was much less severe than allowed for by law. While charge reductions pxior to conviction accounted for some of the reduction in punishment severity, maximum sentencing even on non-reduced felonies was under-utilized. of those 
TABLE X

TOTAL CONVICTIONS FOR WHICH SELECTED SENTENCE CONDITIONS WERE ORDERED: 1976 AND JULY THROUGH DECEMBER OF 1977, BY PERCENT*

$\begin{array}{lcc} & 1976 & 1977 \\ \text { TOTAL CONVICTIONS } & 253 & 142 \\ \text { Percent restitution } & 23 & 22 \\ \text { Percent fine } & 13 & 16 \\ \text { Percend arug or alcohol program } & 17 & 16 \\ \begin{array}{l}\text { Percent mental health program } \\ \text { Percent community service }\end{array} & 5 & 10 \\ \begin{array}{l}\text { *These are not mutually exclusive conditions. Multiple sentence } \\ \text { conditions could be ordered for a single case. }\end{array} & 2\end{array}$

who were sent to the penitentiary, however, the majority $(66$ percent in 1976 and 72 percent in 1977) were given sentences of five years or more. Thus, if one was sent to the penitentiary, he or she was likely to have received a long sentence.

Relationships Between the Nature of offenses and offenders

As an addition to the population profile presented thus far, relationships between offense and offender characteristics are presented in this section. Relationships involving the type offense variable refer to settled rather than initial charge unless otherwise specified.

The relationship between initial charge and multiple counts was highly significant (at the .001 level in both years). As indicated in Table XI, Drugs and Crimes Against Person (along with 
TABLE XI

MULTIPLE INITIAL COUNTS FOR SELECTED OFFENSES:

1976 AND JULY THROUGH DECEMBER OF 1977,

BY PERCENT

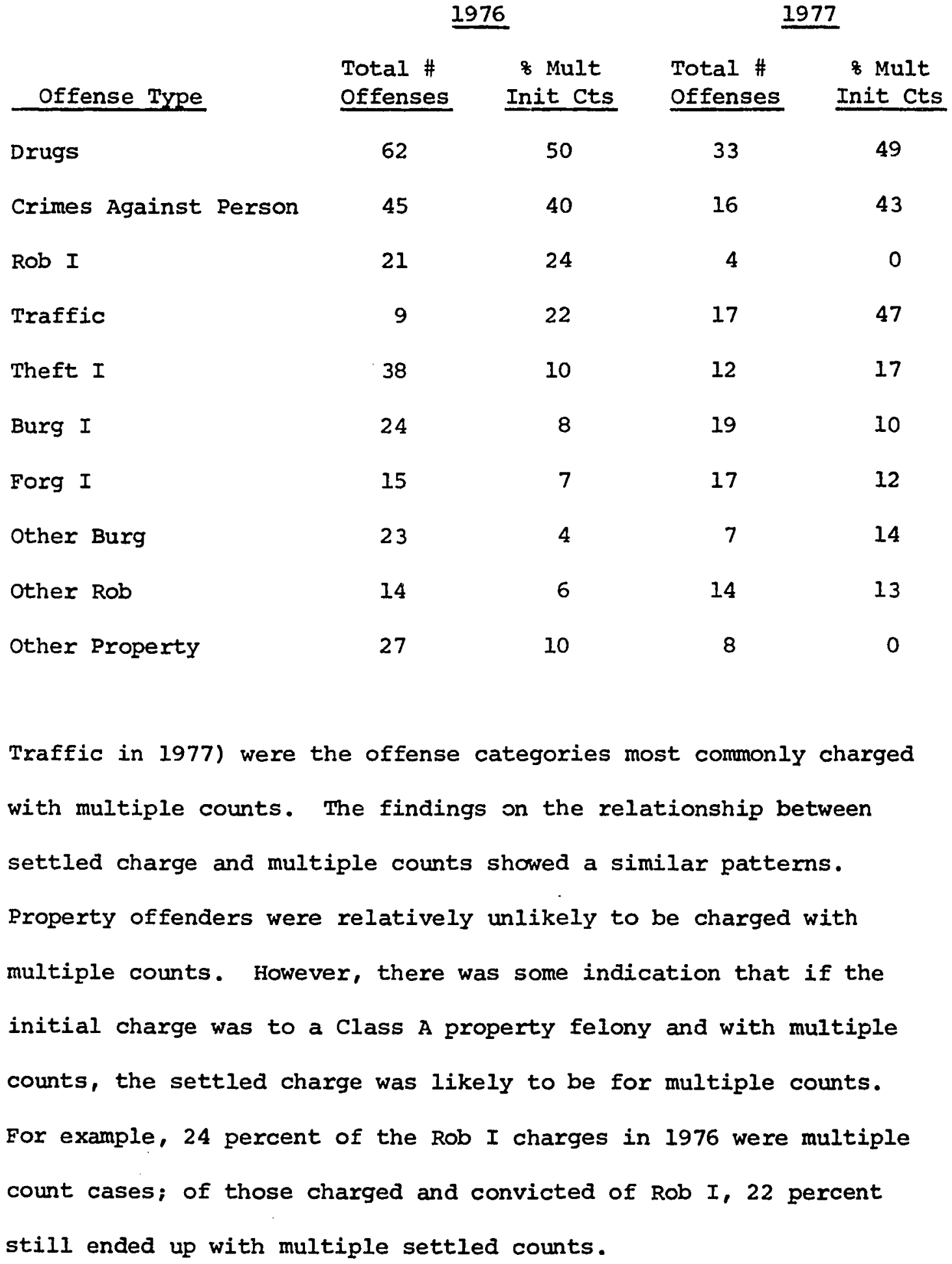


Offense types were differentially distributed on the basis of the sex and age of offenders. The relationship between sex and type offense (significant at the .01 level of 1976 and the .001 level in 1977) indicated that females were most likely to commit offenses which could be categorized as petty property crimes, e.g., Forg I, Theft I, Other Rob and other Property. The relationship between age and type offense was also significant at the .01 level in 1976 and the .001 level in 1977. Crimes with particularly high numbers of youthful offenders in both years were: Burg I (60 percent in 1976 and 67 percent in 1977 were 17 to 20 years old); UUV (60 percent in 1976 and 75 percent in 1977 were 17 to 20 years old); Other Burg (35 percent in 1976 and 40 percent in 1977 were 17 to 20 years old). These relationships between type offense and sex and age of offender are in line with official national statistics. Statistically significant relationships were not found between the type offense variable and prior record, education or employment of the defendant. However, there were patterns worth noting which were consistent for both years. Of all offenses, the Rob, Burg and Traffic categories had the highest proportions of offenders with prior felony records. Drug offenders much less frequently had prior felony records. The less serious property offenses (Other Rob, Other Burg and Other Property) involved the highest proportions of defendants with less than four years of high school. Drug offenses showed the lowest proportion of defendants with less than four years of high school. Unemployment was most frequent among petty property offenders. Traffic and Crimes Against Person offenders were the most likely to have been employed for over six months. 
The only relationship which was significant for both years between type attorney and the offense/offender characteristics was that between type attorney and employment status of the defendant (significant at the .05 level in 1976 and the .001 level in 1977). As shown in Table XII, the differences were more dramatic in 1977, but the patterns were consistent for both years. As would be expected, those who retained attorneys were less likely to be unemployed than those who had public attorneys. Of all offense types,

\section{TABLE XII}

UNEMPLOYED DEFENDANTS WITH PUBLIC AND PRIVATE ATTORNEYS: 1976 AND JULY THROUGH DECEMBER OF 1977, BY PERCENT

1976 1977

\begin{tabular}{|c|c|c|c|c|}
\hline Type Attorney & $\begin{array}{c}\text { Total \# } \\
\text { Defendants } \\
\end{array}$ & $\begin{array}{l}\text { \% Defendants } \\
\text { Unemployed }\end{array}$ & $\begin{array}{c}\text { Total \# } \\
\text { Defendants }\end{array}$ & $\begin{array}{l}8 \text { Defendants } \\
\text { Unemployed }\end{array}$ \\
\hline Public defender & 102 & 56 & 44 & 61 \\
\hline $\begin{array}{l}\text { Court-appointed/ } \\
\text { private bar }\end{array}$ & 66 & 56 & 34 & 63 \\
\hline Privately retained & 26 & 31 & 19 & 16 \\
\hline
\end{tabular}

Traffic cases were the most likely to be handled by retained attorneys in both years (38 percent in 1976 and 43 percent in 1977 were handled by retained attorneys). The offenses with the next highest proportion of retained attorneys was Theft I for both years (35 percent in 1976 and 29 percent in 1977). In 1976, the relationship between attorney and prior record of defendant was significant at the .01 level, with those defendants who retained attorneys much less likely to have prior felony reocrds. The fact that this relationship was 
not significant in 1977 was likely due in part to the rise in Traffic offenses in 1977 (since Traffic offenders were likely to retain attorneys and also likely to have prior felony reocrds).

Defendant Characteristics: Inter-Relationships

A final piece of information entered into the population profile is on the inter-relationships between defendant characteristics. The only relationship which was statistically significant for both years was that between age and education. Over half of the youngest (17 to 20) and oldest (over 30) defendants had not completed four years of high school. Patterns were similar in 1976 and 1977 in the relationship between age and employment. The 17 to 20 age group included a high proportion of unemployed individuals; younger defendants had infrequently been employed for more than six months. As one moves up the age scale, the proportion of defendants with prior felony records increased steadily in both years. Almost all defendants over 40 years old had prior felony records.

Of males, 50 percent were unemployed in 1976 and 51 percent in 1977. Of females, 70 percent were unemployed in 1976 and 78 percent were unemployed in 1977. If females were financially supported by an employed male, they were counted as employed; thus, the differences in employment were not due to the housewife status of women. Males were much more likely than females to have a prior record in both years. However, a greater proportion of females than males in both years reported having no prior felony record. As explained earlier, the no prior felony category was an ambiguous one; it could include a number of women with prior misdemeanor records. 


\section{Profile Summary}

The descriptive data from the 1976 and 1977 samples indicated overall stable patterns in terms of the nature of offenses, offenders and dispositions of felony cases processed through this urban court system. In this section, these consistent patterns are summarized.

Property offenses accounted for about half of both initial and settled charges. Drug offenses made up another fifth of the offense types. The most serious offenses (Class A felonies) constituted a minority of all initial charges and an even smaller minority of all settled charges. The great majority of cases began as single count cases; very few cases ended up with more than one settled count, and the number of cases settled with multiple felony counts was extremely small.

The overwhelming majority of cases were settled by guilty pleas. Guilty pleas with reductions and/or dismissals were more common than straight guilty pleas as charged. About half of the accused felons spent their pre-settlement time in jail custody, and approximately half of the convicted offenders were incarcerated at sentencing. Compared to the general population, accused felons were undereducated and underemployed. The great majority were defended by public attorneys, and attorneys from the Public Defender's Office defended almost half of all accused felons. The offenders were predominantly male, tended to be young, and were highly likely to have prior criminal records. 
Offenders accused of Traffic and Theft offenses were the most likely of all offenders to privately retain attorneys. Those who retained attorneys were more likely than those who had public attorneys to be employed and (with the exception of Traffic offenders) less likley to have prior felony records.

Offenses in the Drugs, Crimes Against Person and Traffic categories were the most likely to be charged with multiple counts. Women were most likely to commit offenses which fall into the petty property category. Individuals in the 17 to 20 age group accounted for the great majority of Burg I and UUV offenses. Crimes Against Person and Traffic offenses were categories with relatively high numbers of over age 30 offenders. The data indicated patterns suggesting that prior felony records were most common in the Rob, Burg and Traffic offender populations. Undereducation and unemployment were most common for petty property offenders.

There were also indications of inter-relationships between defendant characteristics. The youngest and oldest defendants were the most likely to be undereducated. The youngest offenders were the most likely to be unemployed and underemployed. From young to old, the proportion of offenders with prior felony records increased steadily. The women were more likely than the men to be unemployed, but the men were more likely than the women to have prior felony records.

What emerges, then, is a profile of felony offenders who bear a number of negative labels upon entrance into the court system. 
Their most common offenses are drugs and property violations. Most are convicted through guilty pleas, and very few are acquitted in any manner. Only about half, however, go to jail or the penitentiary upon conviction. Having presented this population profile, the discussion now moves to a description and analysis of relationships which are specifically relevant for an assessment of the nature and outcome of case disposition through negotiation. The first two of the remaining five sections in this chapter attend to relationships which showed consistent patterns between 1976. The final three sections are concerned with comparisons of the 1976 and 1977 data.

\section{RELATIONSHIPS BETWEEN TYPE CLOSING AND OFEENSE/OFFENDER CHARACTERISTICS}

\section{Offense Type}

The data on type closing and offense type indicated some relationships which were consistent in both the 1976 and 1977 samples. Offenses which were most likely to be closed with charge reduction bargains fell into the Drugs, Assaults, Traffic, Other Rob and other Property categories. Straight guilty plea closings without reductions or dismissals were most common for the offense categories of Rob I, Burg I, Other Burg, Theft I and Forg I (all of which were included in the non-reducible classification scheme of the District Attorney's Office). With the exception of Sex Crimes, no Crimes Against Person were closed with a straight plea of guilty as charged in either year. There were no consistent patterns between 1976 and 1977 in the proportions of offense types closed either by PG + Dis or by trial. In 1976, the highest proportion of 
PG + Dis closings were in the Homicide, Kidnap and Other Property categories; in 1977, Theft I and Traffic offenses had the highest proportions of PG + Dis closings. The data showed little variation in the type offense/closing by trial relationship in 1976 (although Forg I and Other Property offenses had a noticeable lack of trial closings). In 1977, however, the non-reducible offenses had high proportions of trial closings.

Offender Characteristics

Cross tabulations were carried out between type closing and offender characteristic variables. Ideally, these relationships could best be analyzed by controlling for the type offense variable. However, when offense types were broken down into as many categories as they were, the small number of cases made this type of analysis unfeasible. On the other hand, lumping offenses into a few broad categories covered up important differences. The decision to retain the more precise categories of offenses meant, therefore, that it was impossible to make statements about the relative importance of other variables on type closing independent of offense type. Despite this methodological impediment, the data did indicate the existence of patterns which would appear to warrant future, more precise testing.

The findings suggested that sex, age, prior record, employement and education were not influential factors in terms of whether or not a defendant was offered and accepted a bargain in exchange for a guilty plea. 
In 1976, women accounted for 10 percent of PG closings and 30 percent of PGTL closings. However, women were likely to be charged with offenses which were likely to close by PGTL. Of the 19 women in the 1977 sample, 8 closed by PG, and 6 closed by PGTL. The larger proportion of female PG closings in 1977 was likely due to the larger number of Forg I convictions for females in the 1977 sample.

Age did not appear to be an important factor regarding straight versus bargained guilty pleas. However, age did make a difference in the trial closings. The statistics were particularly dramatic in 1977. Only 13 percent of 17 to 20 age offenders went to trial in 1977. Offenders over the age of 30 , on the other hand, accounted for 53 percent of the trial closings in the same year. These statistics are even more meaningful when one takes into account that offenses common to young people had a relatively high proportion of trial closings in 1977, and offenses common to older people had a relatively low proportion of trial closings in 1977. Prior felony record did not appear to be related to type closing independent of offense type. In both years, of those offenders with prior felony records, the highest proportion of bargained closings was PG + Dis, followed in order by PGTL + Dis and PGTL. However, offenses which commonly closed by PGTL were also those with relatively low numbers of offenders with prior felony records.

No significant relationships or interesting patterns were found between education and type closing or between employement and 
type closing with the exception of one interesting piece of information. Of all closing types, trials had the lowest percentage of unemployed for both years (38 percent in 1976 and 47 percent in 1977).

\section{Multiple Counts}

Significant relationships were found for both years between number of initial counts and type closing. Over 90 percent of those who PG and PGTL in both years were initially charged with only one count. In fact, 100 percent of PG in 1977 had only one count. Of trials, however, 76 percent in 1976 and 79 percent in 1977 had only one initial count. The fact that the offenses that were most likely to have multiple initial counts (Drugs, Crimes Against Person, Traffic) were not offenses with high trial rates suggests that multiple counts may be an important variable in terms of the defense's decision as to whether or not to go to trial. Table XIII gives the percentages of bargained closings which had multiple

TABLE XIII

BARGAINED CASES CLOSED WITH MULTIPLE COUNTS AND NO FELONY COUNTS: 1976 AND JULY THROUGH DECEMBER OF 1977,

BY PERCENT

\begin{tabular}{|c|c|c|c|c|c|c|}
\hline \multirow[b]{2}{*}{ Type Bargain } & \multicolumn{3}{|c|}{1976} & \multicolumn{3}{|c|}{1977} \\
\hline & $\begin{array}{c}\text { Total \# } \\
\text { Cases } \\
\end{array}$ & $\begin{array}{l}8 \text { Mult } \\
\text { Counts }\end{array}$ & $\begin{array}{l}8 \text { No Fel } \\
\text { Counts }\end{array}$ & $\begin{array}{c}\text { Total \# } \\
\text { Cases }\end{array}$ & $\begin{array}{l}8 \text { Mult } \\
\text { Counts }\end{array}$ & $\begin{array}{l}8 \text { No Fel } \\
\text { Counts }\end{array}$ \\
\hline PGTI & 73 & 1 & 70 & 47 & 0 & 62 \\
\hline PGTL + Dis & 28 & 3 & 47 & 12 & 27 & 46 \\
\hline$P G+D i s$ & 37 & 3 & 0 & 21 & 14 & 0 \\
\hline
\end{tabular}


settled felony counts and which had no settled felony counts. A particularly relevant piece of information was that the majority of PGTL bargains ended up with no settled felony (but rather only misdemeanor) counts.

Summary

The findings from the cross tabulations on type closing and offense/offender variables indicated several patterns which were consistent in the 1976 and 1977 samples. Charge reduced guilty plea closings were most common for Drugs, Assaults, Traffic, Other Rob and Other Property offenses and least common for Rob I, Burg I, Other Burg, Theft I and Forg I offenses. Being charged with multiple counts, being older and being employed showed a positive relationship to disposition by trial. However, none of the defendant characteristic variables appeared to be independently related to whether or not cases were closed by straight as opposed to bargained guilty pleas. Finally, the great majority of PGTL closings ended up with no settled felony counts.

THE ISSUE OF PUNISHMENT

Two areas of punishment were considered in the collection and analysis of data from the case files: pre-disposition detention and sentencing. The researcher endeavored to uncover relationships between punishment and offense/offender characteristics and to examine the way in which punishment was related to type closing. Again, in this section, the focus is on findings which were consistent in both years. 
Pre-Trial Detention and offense/Offender Characteristics

The relationship between pre-trial custody status and type offense was significant at the .001 level in 1976 but not significant in 1977. However, the patterns were similar for both years. The most serious property offenses--Burg I, Rob I--along with Escape and ECPFA had the highest proportions of jail custodies in both years (70 percent and over). Over half of those convicted of Crimes Against Person had also been in jail custody in both years. offenders who were least likely to be placed in jail custody were Drug and Traffic offenders; over half of defendants in these two categories were released on their own recogniznace. While the total number of bail releases was small in both years, Forg I and Other Property offenders had higher proportions of bail releases than any other offenses.

The only statistically significant relationship between custody status and the defendant characteristic variables was between custody status and prior record. The findings (significant at the .001 level in both years) were that of those placed in jail custody, 84 percent in 1976 and 85 percent in 1977 had prior felony records. In contrast, of those released on recognizance, 53 percent in 1976 and 59 percent in 1977 had prior felony records. Of bail releases, 65 percent had prior felony records in 1976 as did 50 percent in 1977.

Males were more likely than females to be placed in jail custody in both years (56 percent in 1976 and 53 percent in 1977 as opposed to 38 percent in 1976 and 37 percent in 1977). However, 
because females werc commonly charged with crimes which were less likely than others to be accompanied by pre-disposition custody, it appears that sex may indeed be an influential variable in predisposition custody. Similarly, although no differences were found in the relationship between age and pre-disposition custody, in view of the finding that youthful offenders cormonly committed offenses with a high likelihood of jail custody, the no-differences relationship becomes meaningful: If age were not an influential factor in pre-disposition custody, one would expect to find an inverse relationship between age of offenders and jail custody. No patterns were indicated in the relationships between custody status and education or employment.

The relationship between attorney type and pre-disposition custody status was significant at the .01 level in both years. As shown in Table XIV, those who retained attorneys were much less

TABLE XIV

PUBLIC AND PRIVATE ATTORNEYS' CLIENTS HELD IN PRE-TRIAL CUSTODY: 1976 AND JULY THROUGH DECEMBER OF 1977, BY PERCENT

\begin{tabular}{|c|c|c|c|c|c|}
\hline \multirow[b]{2}{*}{ Type Attorney } & \multicolumn{2}{|c|}{1976} & \multicolumn{3}{|c|}{1977} \\
\hline & $\begin{array}{l}\text { Total \# } \\
\text { Clients }\end{array}$ & $\begin{array}{l}\text { \%re-Trial } \\
\text { Custody } \\
\end{array}$ & $\begin{array}{l}\text { Total \# } \\
\text { Clients }\end{array}$ & $\%$ & $\begin{array}{l}\text { Pre-Trial } \\
\text { Custody }\end{array}$ \\
\hline $\begin{array}{l}\text { Court-appointed/ } \\
\text { private bar }\end{array}$ & 99 & 61 & 58 & & 67 \\
\hline Public defender & 144 & 47 & 65 & & 55 \\
\hline Privately retained & 36 & 22 & 30 & & 23 \\
\hline
\end{tabular}


likely to receive jail custody. This finding may be accounted for in great part by the category of Traffic offenders, who were highly likely to retain their own attorneys but not likely to receive jail custody. In both years, a larger percentage of defendants with court-appointed attorneys from the private bar than those with public defenders were placed in pre-trial jail custody. This relationship appeared to be independent of offense type.

Sentencing and offense/Offender Characteristics

As would be expected, the most serious crimes of violence (Homicide, Kidnap) as well as Rob I, Escape and ECPFA had the highest proportions of incarceration sentences in both years. Incarceration was highly unlikely for those convicted of other Property and Other Drug offenses in both years. Sentencing on Burg I, Theft I and Forg I convictions showed considerable variations in 1976 and 1977. These variations are discussed in the section on 1976/1977 comparisons.

Since the relationships between sentencing and defendant characteristics were not examined controlling for offense type, their interpretations are only suggestive. However, the consistent findings strongly indicated that sex, age, prior record, employment and education were influential variables in terms of sentencing. Seventy-one percent of females were not incarcerated in 1976 , and 62 percent were not incarcerated in 1977. In comparison, 51 percent of males were not incarcerated in 1976, and 45 percent were 
incarcerated in 1977. However, the fact that females were overwhelmingly convicted of petty property offenses (which had relatively low incarceration rates) suggests that sex may have been influential in terms of sentence severity.

No significant differences were found in the relationship between age and sentence. However, this does not mean that age was an unimportant variable in sentence severity, for young people were most likely to be convicted of crimes for which incarceration sentences were common. Thus, if age were not an influential variable, one would expect to find a high proportion of young people receiving incarceration sentences. The findings do suggest, then, that being young may work in favor of sentencing leniency. The relationship between sentence and prior record was significant for both years, and in both years the patterns were consistent. Table XV depicts this relationship. Those defendants

TABLE XV

DEFENDANT PRIOR RECORD BY SENTENCE: 1976 AND JULY THROUGH DECEMBER OF 1977, BY PERCENT

\begin{tabular}{|c|c|c|c|c|c|c|}
\hline \multirow[b]{2}{*}{ Sentence } & \multicolumn{3}{|c|}{1976} & \multicolumn{3}{|c|}{1977} \\
\hline & $\begin{array}{r}\text { Fel } \\
\text { Record } \\
\end{array}$ & $\begin{array}{l}\text { No Fel } \\
\text { Record }\end{array}$ & $\begin{array}{c}\text { No } \\
\text { Record } \\
\end{array}$ & $\begin{array}{r}\text { Fel } \\
\text { Record } \\
\end{array}$ & $\begin{array}{l}\text { No Fel } \\
\text { Record }\end{array}$ & $\begin{array}{c}\text { No } \\
\text { Record } \\
\end{array}$ \\
\hline Pen & 298 & 68 & 98 & 268 & 0 & 0 \\
\hline Jail & 288 & 138 & 148 & 358 & 308 & 278 \\
\hline No Incarc & 438 & $81 \%$ & 778 & 398 & 708 & 738 \\
\hline TOTAL & $\begin{array}{l}1008 \\
(163)\end{array}$ & $\begin{array}{l}100 \% \\
(47)\end{array}$ & $\begin{array}{l}1008 \\
(22)\end{array}$ & $\begin{array}{l}100 \% \\
(81)\end{array}$ & $\begin{array}{l}1008 \\
(20)\end{array}$ & $\begin{array}{l}100 \% \\
(15)\end{array}$ \\
\hline
\end{tabular}


with prior felony records were much more likely than those with no prior felony records to receive incarceration sentences.

Table XVI presents the distributions of persons in the various education categories along with incarceration sentences. As can be seen, those offenders with less than four years of high school had the

TABLE XVI

EDUCATIONAL LEVELS BY INCARCERATION SENTENCES:

1976 AND JULY THROUGH DECEMBER OF 1977,

BY PERCENT

$\underline{1976}$

1977

Total \# $;$ Incarceration Total \# \& Incarceration

Educational Level Defendants .Sentence Defendants Sentence

Less four years

high school

78

55

43

53

Four years

high school

90

36

40

49

College

36

35

19

31

highest proportions of incarceration sentences for both years. Yet, offenders with less than four years of high school were most likely to be convicted of petty property crimes--offenses which overall had a relatively low proportion of incarceration sentences. Thus, the findings do suggest that the education variable may be influential in terms of sentence severity.

The data on employment and sentence suggested the same possibility as did those on education and sentence. Of unemployed defendants, 46 percent were incarcerated in 1976 and 44 percent were 
incarcerated in 1977, even though unemployed defendants had high proportions of convictions for petty property crimes.

The data were also examined regarding the relationship between offense type and sentencing conditions other than incarceration. Of those offenses in which fines were ordered as a sentencing condition, in both years almost half were Drug offenses. Traffic offenses accounted for the second highest proportion of fines in both years (13 percent in 1976 and 16 percent in 1977). Restitution was most commonly ordered for Assault in both years (over half of Assault convictions received restitution orders). Taken as a single category, the less serious property offenses (Theft I, Other Property, Forg I) received restitution order in about one third of the cases. Participation in drug or alcohol programs was most commonly ordered for Traffic Homicides and Traffic offenses in general. Only a small minority of Drug offenders (13 percent in 1976 and 14 percent in 1977) were ordered at sentencing to participate in a drug or alcohol program. The number of offenders ordered to participate in a mental health program was extremely small in both years. However, in both years, sex offenders were more likely than any other offender types to receive an order to participate in a mental health program as a condition of their sentence. The number of community service orders was also extremely small but did not appear to be related to offense type.

\section{Variations in Sentencing}

In this county a rotation system was used in which one judge sat on the bench of Chief Criminal Court for several months hearing 
all guilty pleas and sentencing the overwhelming majority of defendants who had plead guilty. The result of this system was that a small number of Circuit court judges closed the great majority of felony cases in any given year. Data were collected on the four judges in each year who settled the largest number of cases. No noticeable differences appeared between judges by offense type or between judges by closing type. Some differences did appear between judges and sentence which could not, thus, be accounted for by type offense or type closing.

Tables XVII and XVIII show the percentages of various sentences ordered by respective judges. Judges have been labeled anonymously as $\mathrm{A}, \mathrm{B}, \mathrm{C}$ and $\mathrm{D}$ (these are different individuals in each year). In 1976, Judge $C$ gave a much higher proportion of incarceration sentences than any other judge. He also ordered a relatively high proportion of fines. Judge $A$, who handed out the lowest proportion of incarceration sentences, gave the highest proportion of drug/alcohol, mental health, and community service orders.

In 1977, Judges $A$ and $C$ gave higher numbers of incarceration sentences than did the other two judges. Here, the judge who gave the highest proportion of incarceration sentences also ordered the highest percentage of drug/alcohol, mental health, and community service participations. Judge $C$, who also gave a larger number of incarceration sentences, gave no drug/alcohol, mental health or community service orders; yet he ordered the highest percentage of restitution of all four judges, 
TABLE XVII

SELECTED SENTENCING ORDERS GIVEN BY SELECTED JUDGES: 1976, BY PERCENT*

Selected Sentencing Orders

8

Total \& Incar- \& \& Resti- \& Drug/ \& Mental Community Judge \#Cases ceration Fine tution Alcohol Health Service

$\begin{array}{lrrrrrrr}\text { A } & 42 & 33 & 14 & 25 & 27 & 15 & 10 \\ \text { B } & 79 & 39 & 5 & 17 & 16 & 3 & 3 \\ \text { C } & 35 & 63 & 25 & 14 & 9 & 6 & 6 \\ \text { D } & 49 & 39 & 10 & 22 & 14 & 4 & 4\end{array}$

*The selected sentencing orders are not mutually exclusive categories; multiple orders could be given for one case, e.g., incarceration, fine and participation in drug program. Thus, the percentages of total cases resulting in selected sentencing orders (computed across rows) total to oves 100 percent.

TABLE XVIII

SELECTED SENTENCING ORDERS GIVEN BY SELECTED JUDGES: JULY THROUGH DECEMBER OF 1977, BY PERCENT*

\section{Selected Sentencing orders}

8

Total \& Incar- \& \& Resti- \& Drug/ \& Mental Community Judge \#Cases ceration Fine tution Alcohol Health Service

$\begin{array}{lrrrrrrr}\text { A } & 28 & 68 & 19 & 26 & 23 & 16 & 10 \\ \text { B } & 25 & 32 & 21 & 21 & 18 & 5 & 21 \\ \text { C } & 18 & 61 & 6 & 35 & 0 & 0 & 0 \\ \text { D } & 19 & 42 & 6 & 3 & 6 & 6 & 6\end{array}$

*The selected sentencing orders are not mutually exclusive categories; multiple orders could be given for one case, e.g., incarceration, fine and participation in drug program. Thus, the percentages of total cases resulting in selected sentencing orders (computed across rows) total to over 100 percent. 
The patterns between judge and sentencing lead to no clear interpretations. What the statistics did show was that there were clearly variations in sentencing patterns of different judges which were not related to variations in type offense or type closing.

Bargains and Punishment

Pre-Disposition Punishment. The relationship between pre-trial custody status and type closing was significant at the .01 level in 1976 and at the .05 level in 1977. Table XIX presents the percentages of type closings with jail custody. Noticeable were the high percentages of PG + Dis closings with jail custody, again suggesting that the multiple count variable (regardless of whether or not multiple counts were dismissed) may be accompanied by harsh punishment. In contrast, PGTL had a low percentage of jail custodies in both years. Although the offenses which were likely to be closed by PGTL were the same offenses which were likely to be granted pretrial release, the PGTL percentages of pre-trial release were higher than the Drug and Traffic percentages of pre-trial release. Again while inconclusive, the findings do suggest a possible positive relationship between pre-trial release and PGTL independent of offense type.

Sentence Punishment. The relationship between sentence and type closing is depicted in Table $\mathrm{xx}$. As indicated, those who were convicted at trial had by far the greatest proportion of penitentiary sentences for both years. Those who PGTL were almost never sent to the penitentiary and were highly unlikely to be incarcerated at all. The findings suggest that PG + Dis was not an advantageous bargain. 
TABLE XIX

TYPE CIOSING BY PRE-TRIAL CUSTODY STATUS:

1976 AND JULY THROUGH DECEMBER OF 1977, BY PERCENT

\section{Type Closing}

1976 PG PGTL + Dis Dis $\underline{C B J} \underline{A B J}$ Dis

Custody Status

\begin{tabular}{|c|c|c|c|c|c|c|c|}
\hline Recognizance & $28 \%$ & 548 & 388 & $18 \%$ & 198 & 0 & 248 \\
\hline Bail & $15 \%$ & 138 & 108 & $12 \%$ & $25 \%$ & $38 \%$ & 178 \\
\hline Jail & 578 & 338 & 528 & 718 & 568 & 638 & 598 \\
\hline TOTAL & $\begin{array}{l}1008 \\
(75)\end{array}$ & $\begin{array}{l}1008 \\
(67)\end{array}$ & $\begin{array}{l}100 \% \\
(29)\end{array}$ & $\begin{array}{l}1008 \\
(34)\end{array}$ & $\begin{array}{c}100 \% \\
(32)\end{array}$ & $\begin{array}{c}100 \% \\
(8)\end{array}$ & $\begin{array}{l}100 \\
(4]\end{array}$ \\
\hline
\end{tabular}

1977

Custody Status

$\begin{array}{lccccccc}\text { Recognizance } & 28 \% & 50 \% & 50 \% & 248 & 17 \% & 338 & 37 \% \\ \text { Bail } & 148 & 22 \% & 0 & 10 \% & 4 \% & 0 & 11 \% \\ \text { Jail } & 58 \% & 28 \% & 50 \% & 67 \% & 78 \% & 67 \% & 538 \\ & & & & & & & \\ \text { TO'TAL } & 100 \% & 100 \% & 100 \% & 100 \% & 100 \% & 100 \% & 1008 \\ & (36) & (46) & (10) & (21) & (23) & (3) & (19)\end{array}$


TABLE XX

TYPE CLOSING BY SENTENCE: 1976 AND JULY THROUGH DECEMBER OF 1977, BY PERCENT

\begin{tabular}{|c|c|c|c|c|c|c|c|c|c|c|}
\hline \multirow[b]{3}{*}{ Sentence } & \multicolumn{5}{|c|}{1976} & \multicolumn{5}{|c|}{1977} \\
\hline & \multicolumn{5}{|c|}{ Type Closing } & \multicolumn{5}{|c|}{ Type Closing } \\
\hline & PG & $\begin{array}{l}\mathrm{PG}+ \\
\text { Dis }\end{array}$ & $\begin{array}{c}\text { PGTL + } \\
\text { Dis }\end{array}$ & PGTL & $\begin{array}{c}\mathrm{CBC/} \\
\mathrm{CBJ}\end{array}$ & PG & $\begin{array}{c}\text { PG }+ \\
\text { Dis }\end{array}$ & $\begin{array}{c}\text { PGTL + } \\
\text { Dis }\end{array}$ & PGTL & $\begin{array}{l}\mathrm{CBC/} / \\
\mathrm{CBJ}\end{array}$ \\
\hline Penitentiary & $28 \%$ & $33 \%$ & $20 \%$ & 0 & $53 \%$ & $28 \%$ & 298 & $9 \%$ & $2 \%$ & $48 \%$ \\
\hline Jail & $25 \%$ & $28 \%$ & $23 \%$ & $21 \%$ & $18 \%$ & $34 \%$ & $29 \%$ & $36 \%$ & $32 \%$ & 338 \\
\hline No Incarceration & $48 \%$ & $39 \%$ & $57 \%$ & $79 \%$ & $29 \%$ & $38 \%$ & 418 & 558 & $66 \%$ & $19 \%$ \\
\hline TOTAL & $\begin{array}{l}100 \% \\
(80)\end{array}$ & $\begin{array}{l}1008 \\
(36)\end{array}$ & $\begin{array}{l}100 \% \\
(30)\end{array}$ & $\begin{array}{l}100 \% \\
(73)\end{array}$ & $\begin{array}{l}100 \% \\
(34)\end{array}$ & $\begin{array}{l}100 \% \\
(29)\end{array}$ & $\begin{array}{l}100 \% \\
(17)\end{array}$ & $\begin{array}{l}100 \% \\
(11)\end{array}$ & $\begin{array}{l}100 \% \\
(44)\end{array}$ & $\begin{array}{l}100 \% \\
(21)\end{array}$ \\
\hline
\end{tabular}


Similarly, PGTL + Dis was more disadvantageous than PGTL in terms of sentencing. It appears that those charged with multiple counts do not gain much in terms of sentence leniency by having counts dismissed.

In order to get a better idea of the importance of type closing regarding sentence, this relationship was analyzed controlling for four offense types. Again, the small number of cases in several categories made it unwise to form any unequivocal conclusions, but the data did indicate patterns. Table XXI gives the frequency distributions of type closing by sentence for initial charges of Burg I, Theft I, Forg I and CAID.

Although the proportion of PG to the initial charge of Burg I was about the same in 1976 as in 1977, those who did PG to Burg I in 1977 were more likely not to be incarcerated than those in 1976. In both years, all defendants initially charged with Burg I who either were convicted by $P G+$ Dis or by trial received penitentiary sentences. Of those who were initially charged with Burg I but closed with PGTL or PGTL + Dis, the tendency was toward nonincarceration. Thus, for initial charges of Burg I, pleading guilty to a lesser offense did appear to be an advantageous bargain in terms of sentencing. On the other hand, PG was more advantageous than PG + Dis (again indicating the negative influence of multiple count charges). Of all four offenses discussed here, only Burg I had trials in which defendants were convicted of lesser offenses. Actually, those initially charged with Burg I who were convicted at trial appeared to have a good chance of being found guilty of a lesser offense and a non-incarceration sentence. 
TABLE XXI

TYPE CLOSING BY SENTENCE ON SELECTED OFFENSES: 1976 AND JULY THROUGH DECEMBER OF 1977

BURG I

1976

Sentence

Pen Jail No Jail
1977

Sentence

$\frac{\text { Sentence }}{\text { Pen Jail No Jail }}$

Type Closing

\begin{tabular}{|c|c|c|c|c|c|}
\hline PGTL & 1 & 0 & 4 & 0 & 0 \\
\hline$P G+D i s$ & 2 & 0 & c & 2 & 0 \\
\hline PG & 5 & 4 & 2 & 1 & 1 \\
\hline $\begin{array}{l}\text { Trial/reduced } \\
\text { offense } \\
\text { Trial/same }\end{array}$ & 0 & 0 & 2 & 0 & 1 \\
\hline offense & 1 & 0 & 0 & 3 & 0 \\
\hline
\end{tabular}

THEFT I

Type Closing

PGTL

$P G+D i s$

PG

Trial/same

offense

CAID

Type Closing
04

03

30

13

1

FORG I

Type Closing

PGTL

$\mathrm{PG}+\mathrm{Dis}$

PG

Trial/same offense
01

11

$0 \quad 0$

0

0
1

8

1

10

1

15

8

3

0

2
3

0

6

0

\section{0}

2

2

0

2

3

0

0

1

1 
The decrease in the number of initial Theft I charges which resulted in non-incarceration was due in part to the absence of PGTL in 1977. However, of those who PG to an initial charge of Theft I in 1976,63 percent were not incarcerated in 1976, as compared to only 17 percent in 1977. Similarly, harsher sentences were received by those who PG + Dis in 1977 than in 1976.

In 1976, regardless of whether an initial charge of Forg I was closed by PG or PGTL, defendants were not likely to be incarcerated. Harsher sentencing was indicated for those who PG to an initial charge of Forg I in 1977. Although the number of Forg I PGTLs was small in 1977, PGTL did appear to be a good bargain in this year in terms of sentencing.

In both years, the overwhelming majority of those initially charged with CAID who PGTL were not incarcerated. PGTL + Dis was a slightly less advantageous bargain, and PG + Dis even less advantageous. Those who PG to an initial charge of CAID were sentenced less harshly in 1977 than in 1976.

Summary

The findings on relationships between closing types and punishment indicated some patterns relevant to the study which were consistent in 1976 and 1977. Overall, pleading guilty to a lesser charge appeared to be related to leniency regarding both pre- and post-disposition incarceration. The great majority of offenders who PGTL were not incarcerated upon conviction. Pleading guilty to a reduced charge with counts and/or charges dismissed was the next most advantageous closing in terms of sentencing. A straight guilty 
plea as charged was slightly more advantageous than a guilty plea as charged with dismissal of counts and/or charges in 1976, but the former was slightly less advantageous than the latter in 1977: Conviction by trial resulted in the harshest sentencing of all closing types. Approximately half of offenders convicted by trial were sentenced to the penitentiary, and only about a quarter of these offenders were not incarcerated at sentencing.

PLEADING TO A LESSER OFFENSE

Contrary to other studies in which it has been suggested that bargains often result in pleas to charges which are not necessarily or situationally included in the original charge (Sudnow, 1965), the data from this study indicated that 69 percent of the 1976 cases and 74 percent of the 1977 cases involving reduced charges were to the initial offense at a lower level. Table XXII gives the distributions of different types of plea reductions. Although the overall percentages of those who plead guilty to a lesser charge were almost the same for both years, the nature of reductions underwent certain changes between 1976 and 1977. The most noticeable change was in the increased percentage of offenses in which a guilty plea was entered to the same charge, but at a misdemeanor rather than a felony status. Even omitting Traffic offenses from these statistics, the increase of bargains to a misdemeanor of the same charge went from 7 percent to 27 percent. These statistics did not take into account those cases in which either immediate or deferred felony status was granted by the judge 
TABLE XXII

TYPES OF PLEA REDUCTIONS: 1976 AND JULY THROUGH DECEMBER OF 1977, BY PERCENT

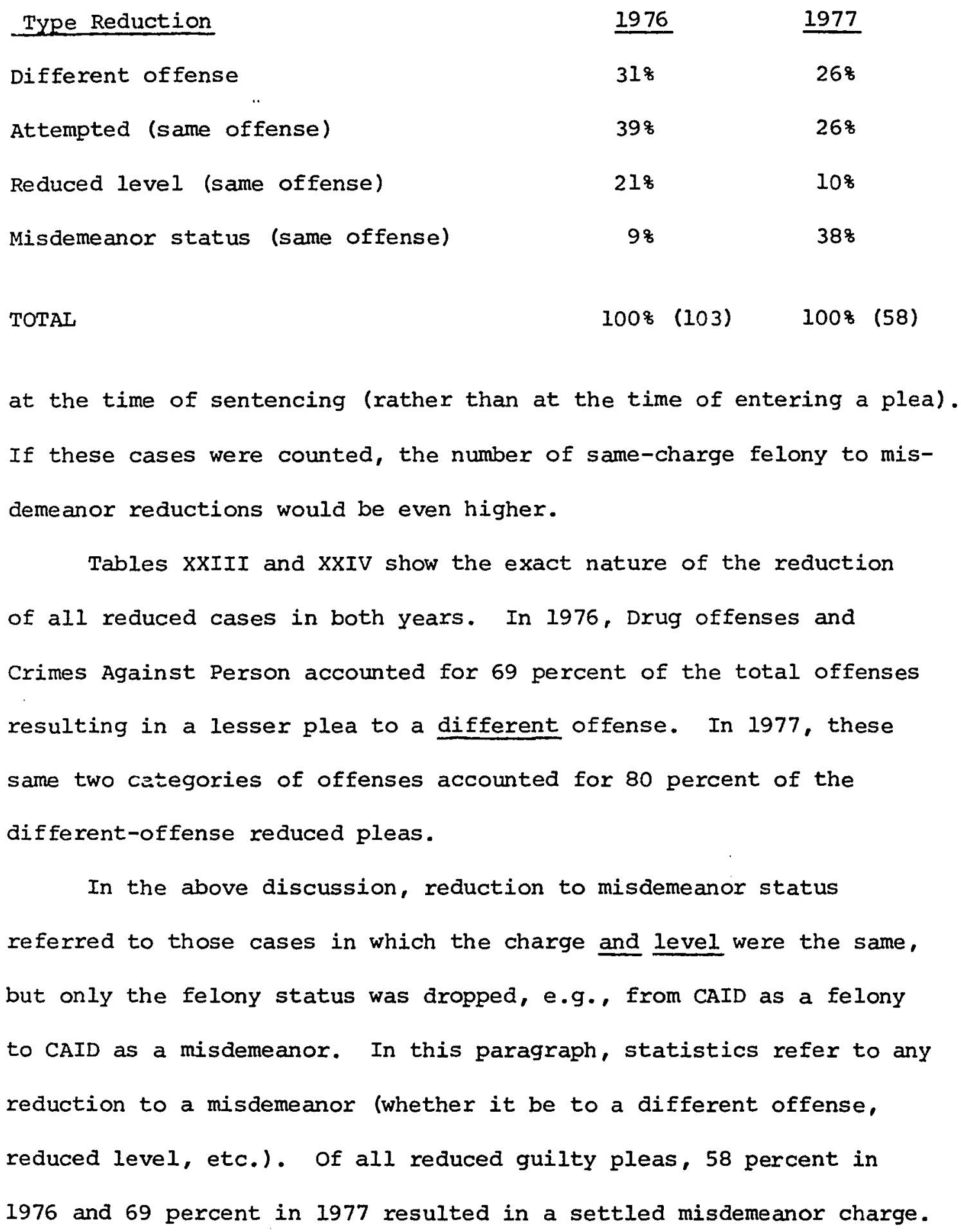


TABIE XXIII

INITIAL CHARGE/SETTLED CHARGE REDUCED PLEAS: 1976

Initial Charge/Settled Charge

$\begin{array}{lr}\text { CAID/Att CAID } & 16 \\ \text { CAID/CDP } & 9 \\ \text { Att CAID/Other Drugs } & 1 \\ \text { CAID/Other Drugs } & 1 \\ \text { CAID/MisJemeanor } & 4\end{array}$

Att Murder/Assault II 1

Mansltr I/Mansltr II $I$

Mansltr I/Crim Neg Homicide I

Att Assault I/Menacing 1

Asslt II/Att Asslt II 6

Assit II/Assit III 6

Assit II/Menacing 1

Asslt II/Resist Arrest $\quad 1$

Att Asslt II/Harrassment 1

Kidnap I/Rob II

Kidnap II/Att UUV

Rape I/Sex Abuse I

Att Rape I/Sex Abuse I

Sod I/Sex Abuse I

Sex Abuse I/Sex Abuse II

Rob I/Rob II

Rob II/Rob III

Rob II/Theft I

Rob III/Att Rob III

Rob III/Misdemeanor

DWS/Other Traffic

Other Traffic/Misdemeanor
Initial Charge/Settled Charge

Burg I/Burg II 2

Burg I/Att Burg I I

Burg I/Crim Trespass I 1

Burg I/Theft I I

Att Burg I/Crim Trespass I 1

Att Burg I/Burg II 1

Burg II/Att Burg II 3

Burg II/Theft II 1

Theft I/Theft II 5

Theft I/Att Theft I 2

Theft I/Misdemeanor 1

UUV/Att UUV 5

Other Prop/Att Other Prop 2

Arson I/Arson II 1

Arson I/Reckless Burning 1

Forg I/Att Forg I 2

Forg I/Att UOPA 1

Forg I/Misdemeanor 1

Escape I/Escape II 1

Escape II/Att Escape II 1

ECPFA/Weapons 1

Prostitution/Att

Prostitution

1 
TABLE XXIV

INITIAL CHARGE/SETTLED CHARGE REDUCED PLEAS:

JULY THROUGH DECEMBER OF 1977

Initial Charge/Settled Charge

CAID/Att CAID

CAID/CDP

CAID/Other Drugs

Other Drugs/Att Other Drugs I

Other Drugs/Misdemeanor 7

Att Murder/Assault II 1

Mansltr/Crim Neg Homicide 1

Crim Neg Homicide/Misdemnr I

Assault II/Assault III 1

Assault II/Att Assault II 1

Kidnap II/Att Coercion 2

Sod I/Sod III

Sod I/Sex Abuse II

Sex Abuse I/Sex Abuse II 1
Initial Charge/Settled Charge

Rob II/Theft II 1

Rob III/Theft II 2

Rob III/Misdemeanor 1

Burg I/Burg II 2

Forg I/Misdemeanor $\quad 2$

UUV/Att UUV 4

Arson I/Arson II 1

Other Prop/Att Other Prop 2

Other Prop/Misdemeanor 3

Traffic/Misdemeanor 9

Escape II/Misdemeanor $\quad 1$

At first glance, this may seem as though defendants were getting better bargains in 1977 than in 1976. However, this was actually not the situation, since more of the bargained cases were on original charges of Class C as opposed to Class A or B felonies in 1977 than in 1976 (43 percent compared to 32 percent). Additionally, the data indicated that in terms of sentencing, guilty pleas to lesser charges resulted in a higher proportion of incarceration sentences in 1977 than in 1976.

In both years, then, the overwhelming majority of charge reduction please were to lesser offenses which were necessarily included in the initial charge. In fact, the great majority were to the initial offense at a less serious level. Almost all the 
reductions to different offenses were to crimes which were reasonably related (or situationally included, to use Sudnow's term) to the initial charge.

\section{CASE DISPOSITION WITHOUT TRIAL} AND EFFICIENT PRODUCTION

The case disposition process in the county under study was extremely efficient in terms of time elapsed from initial charge to final settlement of cases. In 1976,62 percent of cases were settled within 60 days, and only a very few took over 90 days to settle. Of particular interest, however, was the fact that in the latter half of 1977, 81 percent of cases were settled within 60 days. A new state law called the Speedy Trial Act, which states that barring unusual circumstances, cases must be settled within 60 days from time of arrest or else dismissed, went into effect in 1977, and it appears that this Act has been effective. Concomitantly, there was a decrease in the percentage of cases with setovers or continuances during the settlement process. In 1976, 35 percent of the cases had one or more setovers, compared to 26 percent in 1977. There was also a decrease in the percentage of cases which had more than one setover. Of those cases which had setovers, 45 percent had more than one in 1976, but only 30 percent had more than one in 1977.

Total disposition time was not significantly related to type closing in 1976, but a significant relationship (at the .001 level) between these two variables was found in 1977. One finding was 
clear from the data for both years: trials were the least efficient of all closing types in terms of total disposition time. As indicated in Table Xxv, no trials were completed within 30 days, and 39 percent of the trials took over 60 days to complete (in 1976, 55 percent of trials took more than 60 days to settle). The

TABLE XXV

TYPE CLOSING BY TOTAL DISPOSITION TIME: JULY THROUGH DECEMBER OF 1977, BY PERCENT

\section{Type Closing}

\begin{tabular}{|c|c|c|c|c|c|c|}
\hline Total Time & $\underline{\mathrm{PG}}$ & $\begin{array}{l}\text { PG + } \\
\text { Dis } \\
\end{array}$ & $\begin{array}{l}\text { PGTL + } \\
\text { Dis } \\
\end{array}$ & PGTL & Trials & Dis \\
\hline 1 - 30 days & $35 \%$ & 148 & 188 & $9 \%$ & 0 & 288 \\
\hline 31 - 60 days & 498 & $81 \%$ & $64 \%$ & $76 \%$ & 618 & 508 \\
\hline Over 60 days & 268 & 58 & $18 \%$ & $15 \%$ & 398 & 228 \\
\hline TOTAL & $\begin{array}{l}1008 \\
(37)\end{array}$ & $\begin{array}{l}1008 \\
(21)\end{array}$ & $\begin{array}{l}1008 \\
\text { (1I) }\end{array}$ & $\begin{array}{l}100 \% \\
(46)\end{array}$ & $\begin{array}{l}100 \% \\
(28)\end{array}$ & $\begin{array}{l}100 \% \\
(18)\end{array}$ \\
\hline
\end{tabular}

only clear finding from the 1977 data on time differences between straight guilty plea and bargained guilty plea closing was that the former had a much higher percentage than the latter of cases closed within 30 days. However, straight guilty pleas had a higher proportion of over-60-day closings than did the bargained pleas. Thus, an assessment of the relationship of bargained vs. non-bargained guilty pleas to efficient production is problematic. The absence of any patterns in this relationship in the 1976 sample further clouded this issue. However, the findings were conclusive that any 
kind of disposition without trial was more efficient than disposition by trial. Finally, it is of interest that even those defendants whose cases were ultimately dismissed had a high likelihood of spending over 30 days in the court system.

The findings on the relationship between total disposition time and the D.A. unit which handled the case were in line with other data. Unit $C$, which handled serious felonies (Burg, Rob, Weapons and Negligent Homicide cases) and settled 62 percent of their cases with straight guilty pleas, had a relatively high proportion (39 percent) of cases settled within 30 days. Unit D, which handled primarily Crimes Against Person cases and had a high proportion of bargained closings, settled only 6 percent of their cases within 30 days. The Career Criminal Unit, which settled 60 percent of its cases by trial, had the highest proportion of over60-day trials (30 percent) of any of the D.A. units. In summary, then, case disposition in this county, in comparison with national trends, was time-efficient. An efficiency component had been built into the structure by administrative and legislative mandate. However, there were variations in efficiency which were related to the way in which cases were closed. Guilty plea dispositions were more efficient than trial dispositions. Finally, there was no clear evidence that bargaining for a guilty plea was less time-efficient than getting a straight guilty plea. 
CHANGES IN DISPOSITION PATTERNS:

1976 AND 1977 COMPARISONS

A noticeably stable picture of offenses and offender populations processed through the felony court system was indicated by the data from the 1976 and 1977 samples. Additionally, there was very little variation in the overall closing type proportions between the two years. However, diffexences did appear between the two years in certain relationships regarding offense types, closing types and punishments. These differences are particularly relevant in view of the fact that plea bargaining policies of the District Attorney's office underwent certain changes between 1976 and the last half of 1977. The list of non-reducible offenses was expanded, and the curb-plea-bargaining position was generally solidified. A hard-line approach was taken toward the treatment of the guilty offender.

Shifts in the Relationships Between offense and Closing Types: Stability in the Overall Picture

Although the data indicated only slight variations in the overall proportions of type closings between 1976 and 1977, when type closings were examined within offense categories, noticeable differences did appear between the two years. Tables XXVI and XXVII present the statistical breakdowns of closing types for different initial charges for both years, and Tables XXVIII and XXVIX shows the breakdowns of closing types for different settled charges for both years. 
TABLE XXVI

INITIAI CHARGE BY TYPE CLOSING:

1976, BY PERCENT

Type Closing

\begin{tabular}{|c|c|c|c|c|c|c|}
\hline Initial Charge & $\underline{\mathrm{PG}}$ & $\begin{array}{l}\text { PGTL/ } \\
\text { PGTL } \\
+\quad \text { Dis } \\
\end{array}$ & $\begin{array}{l}\mathrm{PG}+ \\
\text { Dis } \\
\end{array}$ & Trials & Dis & Total \\
\hline Homicides & 0 & 388 & $25 \%$ & 138 & $25 \%$ & $1008(8)$ \\
\hline Assaults & 0 & $80 \%$ & 0 & $20 \%$ & 0 & $100 \%(20)$ \\
\hline Kidnaps & 0 & $40 \%$ & 208 & $40 \%$ & 0 & $100 \%(5)$ \\
\hline Rob I & 488 & $5 \%$ & $10 \%$ & $29 \%$ & $10 \%$ & $100 \%(21)$ \\
\hline Other Rob & $14 \%$ & $50 \%$ & $14 \%$ & $21 \%$ & 0 & $100 \% \quad(14)$ \\
\hline Sex Crimes & $17 \%$ & $33 \%$ & $8 \%$ & $17 \%$ & $25 \%$ & $1008 \quad(12)$ \\
\hline Burg I & $46 \%$ & 218 & $8 \%$ & $17 \%$ & $8 \%$ & $1008 \quad(24)$ \\
\hline Other Burg & $35 \%$ & $26 \%$ & $13 \%$ & $17 \%$ & $9 \%$ & $1008 \quad(23)$ \\
\hline Theft I & $42 \%$ & $21 \%$ & $11 \%$ & $13 \%$ & $13 \%$ & $100 \%(38)$ \\
\hline UUV & $32 \%$ & $23 \%$ & 238 & 0 & $23 \%$ & $100 \% \quad(22)$ \\
\hline Forg I & 408 & $27 \%$ & $13 \%$ & 0 & $20 \%$ & 1008 (15) \\
\hline Other Property & $40 \%$ & $40 \%$ & $20 \%$ & 0 & 0 & $100 \%(5)$ \\
\hline CAID & $7 \frac{8}{8}$ & 518 & $10 \%$ & $7 \frac{2}{6}$ & $25 \%$ & $1008 \quad(59)$ \\
\hline Other Drug & 0 & 338 & 0 & $33 \%$ & 338 & $100 \%(3)$ \\
\hline Traffic & $44 \%$ & 338 & 0 & $22 \%$ & 0 & $100 \%(9)$ \\
\hline Escape/ECPFA & $46 \%$ & $23 \%$ & 88 & $15 \%$ & $8 \%$ & $1008 \quad(13)$ \\
\hline
\end{tabular}


TABLE XXVII

INITIAL CHARGE BY TYPE CLOSING: JULY THROUGH DECEMBER OF 1977 , BY PERCENT

Type Closing

\begin{tabular}{|c|c|c|c|c|c|c|}
\hline Initial Charge & $\underline{\mathrm{PG}}$ & $\begin{array}{l}\text { PGTL/ } \\
\text { PGTL } \\
+ \text { Dis } \\
\end{array}$ & $\begin{array}{l}\text { PG + } \\
\text { Dis }\end{array}$ & Trials & Dis & Total \\
\hline $\begin{array}{l}\text { Homicides/ } \\
\text { Assaults/ } \\
\text { Kidnap }\end{array}$ & 0 & 648 & 0 & 368 & 0 & 1008 (11) \\
\hline Rob I & 258 & 0 & 0 & 508 & 258 & $1008(4)$ \\
\hline Other Rob & 0 & 508 & $13 \%$ & 138 & $25 \%$ & $1008 \quad(8)$ \\
\hline Sex Crimes & 0 & 808 & 0 & $20 \%$ & 0 & $1008(5)$ \\
\hline Burg I & 478 & 118 & 118 & 328 & 0 & 1008 (19) \\
\hline Other Burg & 438 & 0 & 148 & 298 & $14 \%$ & $1008(7)$ \\
\hline Theft I & 588 & 0 & 338 & 298 & 0 & 1008 (12) \\
\hline Forg I & 538 & 128 & $18 \%$ & 68 & $12 \%$ & 1008 (17) \\
\hline Other Property & 78 & 648 & 0 & 148 & $14 \%$ & 1008 (14) \\
\hline CAID/Other Drug & 93 & 588 & $15 \%$ & 38 & 158 & $1008(33)$ \\
\hline Traffic & 68 & 538 & 248 & 68 & 128 & 1008 (17) \\
\hline Escape/ECPFA & 148 & 148 & 148 & 298 & 298 & $1008(7)$ \\
\hline
\end{tabular}


TABLE XXVIII

SETTLED CHARGE BY TYPE CLOSING: 1976, BY PERCENT

Type Closing

\begin{tabular}{|c|c|c|c|c|c|}
\hline Settled Charge & $\underline{P G}$ & $\begin{array}{l}\text { PGTL/ } \\
\text { PGTL } \\
+ \text { Dis } \\
\end{array}$ & $\begin{array}{l}\text { PG + } \\
\text { Dis } \\
\end{array}$ & $\mathrm{CBC} / \mathrm{CBJ}$ & Total \\
\hline $\begin{array}{l}\text { Homicides/ } \\
\text { Kidnaps }\end{array}$ & 0 & $40 \%$ & $40 \%$ & 208 & $1008(5)$ \\
\hline Assaults & 0 & 768 & $6 \%$ & $18 \%$ & 1008 (17) \\
\hline Rob I & 598 & 0 & $12 \%$ & 298 & 1008 (17) \\
\hline Other Rob & 148 & $50 \%$ & $14 \%$ & 218 & 1008 (14) \\
\hline Sex Crimes & 208 & 408 & $20 \%$ & $20 \%$ & $100 \%(10)$ \\
\hline Burg I & 298 & 0 & $148:$ & 78 & $1008 \quad(14)$ \\
\hline Other Burg & 368 & 328 & $9 \%$ & 238 & 1008 (22) \\
\hline Theft I & 708 & 98 & $13 \%$ & 98 & $1008 \quad(23)$ \\
\hline UUV & 358 & $30 \%$ & $35 \%$ & 0 & $1008(20)$ \\
\hline Forg & 558 & 278 & 188 & 0 & 1008 (11) \\
\hline Other Property & 138 & $81 \%$ & $6 \%$ & 0 & $1008 \quad(16)$ \\
\hline CAID & 248 & $18 \%$ & $35 \%$ & 248 & 1008 (17) \\
\hline Att CAID & 0 & 1008 & 0 & 0 & 1008 (16) \\
\hline Other Drug & 0 & $92 \%$ & 0 & 88 & 1008 (13) \\
\hline Traffic & 448 & 338 & 0 & 228 & $1008(9)$ \\
\hline Escape/ECPFA & $55 \%$ & 188 & 98 & 188 & 1008 (11) \\
\hline
\end{tabular}


TABLE XXVIX

SETTLED CHARGE BY TYPE CLOSING: JULY THROUGH DECEMBER OF 1977,

BY PERCENT

\section{Type Closing}

\begin{tabular}{|c|c|c|c|c|c|}
\hline Settled Charge & PG & $\begin{array}{l}\text { PGTL/ } \\
\text { PGTL } \\
+ \text { Dis } \\
\end{array}$ & $\begin{array}{l}\mathrm{PG}+ \\
\mathrm{Dis}\end{array}$ & $\mathrm{CBC} / \mathrm{CBJ}$ & Total \\
\hline $\begin{array}{l}\text { Homicides/ } \\
\text { Kidnaps/ }\end{array}$ & & & & & \\
\hline Assaults & 0 & 708 & 0 & $30 \%$ & $1008(10)$ \\
\hline All Rob & 208 & 208 & $20 \%$ & 408 & $1008(5)$ \\
\hline Sex Crimes & 0 & $67 \%$ & $17 \%$ & 178 & $100 \%(6)$ \\
\hline Burg I & 738 & 0 & $9 \%$ & 188 & 1008 (11) \\
\hline Other Burg & $30 \%$ & $20 \%$ & $10 \%$ & 408 & $1008 \quad(10)$ \\
\hline Theft I & $50 \%$ & 0 & 298 & $21 \%$ & $1008(14)$ \\
\hline Forg & $60 \%$ & 138 & $20 \%$ & 78 & 1008 (15) \\
\hline Other Property & 78 & $80 \%$ & 0 & $13 \%$ & 1008 (15) \\
\hline CAID & $20 \%$ & 478 & $27 \%$ & 78 & $100 \%$ (15) \\
\hline Other Drug & 0 & $92 \%$ & $8 \%$ & 0 & 1008 (13) \\
\hline Traffic & 78 & $60 \%$ & 278 & 78 & $100 \%$ (15) \\
\hline Escape/ECPFA & 338 & 0 & 338 & 338 & $1008(3)$ \\
\hline
\end{tabular}


There was a slight increase in the proportions of PG closings for initial charges of Rob I, Burg I, Other Burg, Theft I and Forg I. The proportions of these same initial-charge offenses which went to trial showed substantial increases between 1976 and the latter half of 1977. For bargained closings, these offenses showed decreases in PGTL but increases in PG + Dis. All of the above offenses are (or in the case of Other Burg include) crimes on which the non-reducible policy was strengthened as of June, 1977. It is clear that these policies have been accompanied by an increase in trials for non-reducible crimes. However, as if in compensation for this increase, the proportions of trials decreased for initial charges of Other Rob, Other Property, Drug and Traffic offenses. The number of PGTLs for these latter offenses, while relatively high for both years, showed increases in 1977.

The findings, then, supported theoretically-based arguments set forth in this study and in previous research. First, it appears that restricting one kind of bargain leads to an increase in other kinds of bargains. Similarly, restricting bargains for certain offenses leads to an increase in bargains for other offenses. Finally, restricting bargaining on certain offenses leads to an increase in trials for these offenses (not only was there an increase in trials for the non-reducible offenses, but also 60 percent of the non-negotiable Career Criminal cases were closed by trial in 1977). The result is that smooth movement of cases through the criminal justice system is insured, thus fulfilling the court's need for efficient production. 
Shifts in Relationships Between Offenses, Closings and Punishment: Overall Increases in the Likelihood of Incarceration

Proportionately more convicted offenders were incarcerated in 1977 than in 1976. Overall, 54 percent of offenders were not incarcerated in 1976; this percentage dropped to 47 percent in 1977. This drop was accompanied by a parallel increase in the proportion of offenders sentenced to jail; penitentiary sentences remained stable over the two years.

Approximately the same proportions of PG + Dis and PGTL + Dis closings resulted in sentences of incarceration in both years. However, there were increases in the proportions of PG and trial convictions (10 percent in both categories) incarcerated in 1977. The most dramatic shift was in the PGTL category; 21 percent resulted in incarceration in 1976 , but 34 percent resulted in incarceration in 1977.

As depicted in Tables $\mathrm{XXX}$ and $\mathrm{XXXI}$, there were shifts in punishment severity for different offense types. The most dramatic drop in incarceration sentences was for those convicted of CAID; 53 percent were incarcerated in 1976 while only 20 percent were incarcerated in 1977. There also appeared to be a decrease in punishment severity for convicted burglars. While a relatively high proportion of those convicted of Burg I in both years received penitentiary sentences, there was an increase in the proportion of those convicted of Burg I not receiving incarceration sentences. A considerable increase in the proportion of Other Burg convictions which resulted in non-incarceration was indicated by the data. These findings could be due in part to the fact that Burg trials 
TABLE XXX

SETTLED CHARGE BY SENTENCE:

1976 , BY PERCENT

Sentence

Settled Charge Penitentiary Jail No Incarceration Total

Homicide/

Kidnaps

$40 \%$

$40 \%$

$20 \%$

$100 \%(5)$

Assaults

$12 \%$

$29 \%$

$59 \%$

$100 \%$ (17)

Rob I

71 응

0

298

100\% (17)

Other Rob

$36 \%$

$7 \%$

$57 \%$

$100 \%(14)$

Sex Crimes

$30 \%$

$30 \%$

$40 \%$

1008 (10)

Burg I

$57 \%$

$29 \%$

148

$100 \%$ (14)

Other Burg

$45 \%$

$16 \%$

368

1008 (22)

Theft I

$17 \%$

22 웅

618

$100 \%(23)$

UUV

5 웅

25 웅

$70 \%$

$100 \%(20)$

Forg

98

$18 \%$

$73 \%$

$100 \%$ (11)

Other Property

$19 \%$

81 웅

$100 \%(16)$

CAID

$29 \%$

248

$47 \%$

$100 \%$ (17)

Other Drug

$28 \%$

$72 \%$

$100 \%(29)$

Traffic

$11 \%$

$89 \%$

$100 \%$ ( 9)

Escape/ECPFA

$36 \%$

$45 \%$

$18 \%$

$100 \%$ (11) 
TABLE XXXI

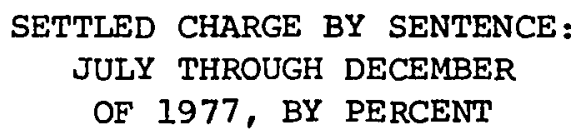

\section{Sentence}

\begin{tabular}{|c|c|c|c|c|c|}
\hline Settled Charge & Penitentiary & Jail & No Incarceration & \multicolumn{2}{|c|}{ Total } \\
\hline $\begin{array}{l}\text { Homicide/ } \\
\text { Kidnap/ }\end{array}$ & & & & & \\
\hline Assault & 258 & 638 & $13 \%$ & 1008 & $(8)$ \\
\hline AlI Rob & 408 & 208 & 408 & $100 \%$ & $(5)$ \\
\hline Sex Crimes & $50 \%$ & 178 & 338 & 1008 & $(6)$ \\
\hline Burg I & 438 & $14 \%$ & 438 & 1008 & $(7)$ \\
\hline Other Burg & $17 \%$ & 178 & 678 & 1008 & $(6)$ \\
\hline Theft I & 318 & $54 \%$ & 158 & 1008 & (13) \\
\hline Forg & $18 \%$ & 278 & 558 & 1008 & (11) \\
\hline Other Property & 158 & $15 \%$ & 708 & 1008 & (13) \\
\hline CAID & 78 & 138 & $80 \%$ & $100 \%$ & (15) \\
\hline Other Drug & 0 & 338 & 678 & 1008 & (12) \\
\hline Traffic & 0 & 578 & 438 & 1008 & (14) \\
\hline Escape/ECPFA & $33 \%$ & 678 & 0 & 1008 & ( 3 ) \\
\hline
\end{tabular}


(which increased in 1977) appeared to have a relatively good chance of resulting in non-incarceration sentences.

On the other hand, incarceration sentences for those convicted of Theft I increased substantially in 1977. Although not as dramatically as for Theft $I$, incarceration sentences also increased for those convicted of Forg $I$. The findings also indicated an increase in the likelihood of incarceration for the less serious property offenses not in the D.A.'s non-reducible cateogry. Thus, while incarceration increased overall from 1976 to 1977 , increases in incarceration for certain offenses were offset by decreases for other offenses, again maintaining a balance necessary to the stability of the criminal justice system.

Sentence severity also increased in 1977 for those defendants who had been granted pre-trial release. Whereas in 1976, only 19 percent of those individuals who had been released on their own recognizance were incarcerated upon sentencing, 38 percent of the recog releases were incarcerated at sentencing in 1977. A similar pattern emerged for those granted bail pre-trail release; incarceration sentences were given to 31 percent of bail releases in 1976, but to 58 percent of them in 1977. Thus, while pre-trial custody status was a good predictor of sentence severity (incarceration versus no incarceration) in both years, pre-trial release was much less likely to be accompanied by post-conviction release in 1977 than in 1976.

The importance of the multiple count variable in terms of dispositional outcomes has been previously documented. The 1976-1977 
comparisons yielded another piece of information in support of the contention that it is multiple initial counts as opposed to multiple settled counts that work toward punishment severity. While there was an increase in 1977 in the proportion of PGTL + Dis and PG + Dis closings with multiple settled counts, there was virtually no change in the proprotions of these closing types which resulted in incarceration sentences. In other words, regardless of whether an initial multiple count charge was settled with multiple or single counts, the likelihood of incarceration was the same.

\section{CONCLUDING REMARKS}

The findings on the nature of offenses, offenders and dispositions processed in felony court were examined for 1976 and the latter half of 1977 in this chapter. The data indicated a stable picture of the offenders and offenses processed through the system in both years. However, there were differences in dispositional outcomes which accompanied policy changes on bargaining. In the next chapter, data from the case files of the Public Defender's office are examined for their relevancy to the research topic of case disposition without trial. 
CHAPTER V

THE NATURE OF DISPOSITIONAL OUTCOMES: SUMMARY AND SELECTED STATISTICS ON

CASES HANDLED BY THE OFFICE OF

THE PUBLIC DEFENDER

\section{INTRODUCTION}

From data in the records of the office of the Public Defender in this county, the researcher endeavored to add to the body of information about the nature of cases settled in felony court in the system under study. The summary statistics on dispositional outcomes of all felony cases handled by the Public Defender's office served as an independent source of information similar to that collected from the Criminal Court random samples. Additionally, these population statistics could be analyzed in terms of their consistency with the sample statistics collected from the Criminal Court case files. For this latter purpose of comparison, sumary statistics from the Public Defender records are presented for the same time periods covered in the Criminal Court research (all of 1976 and the latter half of 1977).

In addition to the summary statistics, two offenses were selected for a more in-depth examination. Files on Burg $I$ and Forg I cases closed by the Public Defender's Office in the last six months of 1977 provided data relevant to the research topic. 


\section{DISPOSITION OUTCOMES OF FELONY CASES HANDLED BY PUBLIC DEFENDERS: SUMMARY STATISTICS}

Statistics on the closings of the total population of felony cases handled by the Public Defender's Office in all of 1976 and from July to December of 1977 are given in Table XXXII. These data confirmed the findings from the Criminal court data that the great majority of cases were closed by guilty plea dispositions and that the number of acquittals at trial was extremely small. However, there were some differences between these statistics and those from the Criminal court samples.

The most noticeable difference was in the percentages of dismissals. The proportion of dismissals reported in the Public Defender records was nearly double that found in the Criminal Court records. Variations in record-keeping practices appear to account for this difference. Whereas about half of the Public Defender dismissals came about at the preliminary hearing, only dismissals after the preliminary hearing were recorded in the Criminal Court statistics. The way in which the dismissal category was handled also affected the conviction rates. If dismissals were excluded, the conviction rate was much higher than if dismissals were included in the non-conviction statistics. The importance of taking into account these methodological variations in an analysis of the data is obvious.

Another difference between these data and those from Criminal Court was in the lower percentage of pleas to lesser offenses recorded in the Public Defender statistics. It is likely that the 
TABLE XXXII

FELONY CASES CLOSED BY THE OFFICE OF THE PUBLIC DEFENDER: 1976 AND JULY THROUGH DECEMBER OF 1977

\begin{tabular}{|c|c|c|c|}
\hline & & 1976 & 1977 \\
\hline Total & closed & 1,972 & 812 \\
\hline Total & adjudicated & 1,325 & 444 \\
\hline & Percent pleas & $58 \%$ & 608 \\
\hline & Percent trials & 108 & 148 \\
\hline & Percent dismissals & 328 & $25 \%$ \\
\hline & Percent guilty & 668 & 728 \\
\hline & Percent not guilty/dismissed & 348 & 288 \\
\hline Probat: & ion/extradition cases & 405 & 258 \\
\hline Change & of type attorney cases & 172 & 73 \\
\hline Bench & warrant cases & 68 & 37 \\
\hline Total & pleas and trials & 907 & 331 \\
\hline & Percent plea to charge & 498 & $52 \%$ \\
\hline & Percent plea to lesser & 368 & 298 \\
\hline & Percent trials & 158 & 198 \\
\hline & Percent guilty & $96 \%$ & $96 \$$ \\
\hline & Percent not guilty & 48 & 48 \\
\hline
\end{tabular}

fact that certain offenses, e.g., Traffic, which had high proportions of PGTLS, also had relatively high proportions of privately-retained attorneys accounted for some of this difference.

The data on type closing of the various non-reducible offenses were consistent with the data from Criminal Court. With the exception of CAID lonly some CAID charges are included in the nonreducible category), very few of these offenses were closed by PGTL. On the other hand, Burg I, Rob I, Rob II and Theft I had relatively 


\begin{abstract}
high proportions of closings by trial in 1977 . The frequency distribution of closing types for the non-reducible offenses is depicted in Table XXXIII.
\end{abstract}

TABLE XXXIII

CLOSING TYPES FOR NON-REDUCIBLE OFFENSES: CASES HANDLED BY THE PUBLIC DEFENDER'S OFFICE FROM JULY THROUGH DECEMBER

OF 1977

\begin{tabular}{|c|c|c|c|c|c|}
\hline \multirow[b]{2}{*}{ Type Offense } & \multicolumn{5}{|c|}{ Type closing } \\
\hline & $\underline{\text { Dis }}$ & $\underline{\mathrm{PG}}$ & PGTL & Trial & $\begin{array}{l}\text { Percent Trial of } \\
\text { Pleas and Trials }\end{array}$ \\
\hline Burg I & 1 & 19 & 1 & 12 & $38 \%$ \\
\hline Burg II & 9 & 15 & 2 & 4 & 198 \\
\hline Escape II & 1 & 9 & 0 & 1 & 108 \\
\hline Forg I & 12 & 33 & 0 & 5 & 138 \\
\hline Rob I & 0 & 9 & 0 & 5 & 368 \\
\hline Rob II & 5 & 2 & 3 & 2 & 298 \\
\hline Supp Contraband & 1 & 7 & 0 & 1 & 128 \\
\hline Theft I & 22 & 22 & 3 & 9 & 268 \\
\hline CAID & 24 & 19 & 45 & 5 & $7 \%$ \\
\hline ECPFA & 1 & 0 & 0 & 1 & \\
\hline TOTAL & 76 & 135 & 54 & 45 & \\
\hline
\end{tabular}

The findings on incarceration sentences were also generally consistent with those from Criminal court. As can be seen in Table XXXIV, the proportion of total incarceration sentences increased between 1976 and the latter half of 1977. The percentages of offenses 
TABLE XXXIV

TOTAL CONVICTIONS RESULTING IN PENITENTIARY, JAIL AND NON-INCARCERATION SENTENCES: PUBLIC DEFENDER FELONY CASES IN 1976 AND JULY THROUGH DECEMBER OF 1977, BY PERCENT

\section{Sentence \\ Penitentiary}

Jail

No Incarceration

TOTAL $\underline{1976}$

218

218

$58 \%$

$1008(872)$ $\underline{1977}$

248

248

528

which resulted in incarceration sentences (Table XXXV) showed the same patterns as in the Criminal Court data with the exception of Theft I. There were two factors which may have in part accounted

TABLE XXXV

INCARCERATION SENTENCES FOR SELECTED OFFENSES: PUBLIC DEFENDER CASES FROM JULY THROUGH DECEMBER OF 1977, BY PERCENT

Offense

CAID

Theft I

Forg I

Burg I

Burg II

UUV

Assault II

Rob I

Rape I

Rob II
Percent Incarceration

268

338

$46 \%$

668

$52 \%$

468

$64 \%$

868

508

$67 \%$ 
for this difference regarding Theft I. First, closings of Theft I cases handled by the Public Defender were characterized by an inordinately high proportion of dismissals. Second, Theft I offenders had a high proportion of privately-retained attorneys. Both factors suggest the possibility that public defenders had a higher success rate (in terms of getting a non-incarceration sentence) with Theft I cases than did other types of attorneys. BURGLARY I AND FORGERY I PUBLIC DEFENDER CASES

Data were collected from all of the available files of Burg I and Forg I cases closed by the Public Defender's Office from July through December of 1977. In addition to providing some new information, these findings generally supported the findings from the Criminal Court data. The list of variables on which data were collected is presented in Tabie XXXVI.

TABLE XXXVI

VARIABLES ON WHICH DATA WERE COLLECTED ON PUBLIC DEFENDER BURG I AND FORG I CASES

1. Number initial counts

2. Number initial felony counts

3. Most serious settled charge

4. Number settled counts

5. Number settled felony counts

6. Type Closing

7. Judge

8. Sentence recommendation by prosecutor

9. Sentence
10. Sex of defendant

11. Age of defendant

12. Prior record of defendant

13. Education of defendant

14. Employment of defendant

15. Race of defendant

16. Defendant drug/alcohol problem

17. Offense in dwelling (Burg I only) 


\section{Burglary I}

The closing type frequencies for Burg I cases closed by the Public Defender's Office in the last half of 1977 are given in Table XXXVII. As can be seen, the trial percentage was relatively high;

TABLE XXXVII

TYPE CLOSING: PUBLIC DEFENDER BURG I CASES FROM JULY THROUGH DECEMBER OF 1977, BY PERCENT

$\begin{array}{lc}\text { Type Closing } & \text { Percent } \\ \text { PG } & 31 \\ \text { PG + Dis } & 13 \\ \text { PG + Not File } & 17 \\ \text { PGTL } & 4 \\ \text { CBC/CBJ } & 26 \\ \text { ABC/ABJ } & 4 \\ \text { Dis } & 4 \\ \text { TOTAL } & 100(23)\end{array}$

Burg I cases were as likely to be closed by trial as by a straight guilty plea. In contrast, pleading guilty to a lesser offense was highly unlikely for Burg I offenders (the one offender in this category plead guiltĭ to Burg II). However, other kinds of bargains were not uncommon. Of the five cases with initial multiple counts, three were closed with PG + Dis. In this data set, a new type of bargain was coded as a separate category. This category, labeled $P G+$ Not File refers to a closing in which the defendant plead guilty to the initial charge in return for an agreement by the 
prosecutor not to file on other known charges. The statistics suggested that this was a fairly comon bargain for Burg $I$. Of all guilty plea convictions, then, some kind of bargain occurred in 64 percent of the cases.

A bargain agreement may also take the form of a sentence recommendation. Procedure in this court system required that prosecutors fill out a written form in which they are specifically to state their sentence recommendation. The data indicated that sentence recommendation was a powerful commodity held by the prosecutor, as the relationship between the recommendation and the actual sentence was significant at the .05 level. Prosecutors made an outright recommendation of incarceration in 43 percent of the cases; for another 35 percent, prosecutors stated that they would make a sentence recommendation subsequent to conviction and/or the completion of the pre-sentence investigation. They recommended no incarceration in 22 percent of the cases. Actual sentencing tended to be either quite severe or quite light. Fifty-three precent of the convicted were sentenced to the penitentiary (and of those 90 percent were sentenced to five years or more), and 11 percent were sentenced to jail. Thirty-seven percent received a non-incarceration sentence. Thus, when prosecutors withheld a recommendation until after conviction, there was a greater chance that the actual sentence would be for incarceration than for non-incarceration.

Specific evidence of the positive relationship between sentence recommendation and actual sentence includes the following. Of those cases for which a penitentiary sentence was recommended, all were: 
sentenced to the penitentiary. Misdemeanor status was not recommended for any case, nor was it ever granted at sentencing. There was one recommendation for a concurrent sentence which was granted at sentencing. There were no recommendations for consecutive sentences, and none were given at sentencing. Neither fines nor community service were recommended, and no such orders were given. Of four recommendations for participation in a drug or alcohol program, three were sentenced to participate in such a program. Restitution, however, was recommended in eleven cases but only ordered at sentencing in six cases.

In terms of sentencing, PG bargains were "no bargain" compared to straight PG closings. Of all PG bargains, 50 percent resulted in penitentiary sentences, and 33 percent resulted in non-incarceration sentences. In contrast, only 29 percent of PG closings resulted in penitentiary sentences, and 57 percent were not incarcerated at sentencing. However, the harshest sentencing was received by those convicted at trial; 83 percent of the Burg I offenders convicted at trial were sentenced to the penitentiary.

Further support was also found for the previously-discussed finding that certain defendant characteristics were related to sentence severity. Of those defendants who received incarceration sentences, 92 percent had prior felony records, whereas of those who received non-incarceration sentences, only 71 percent had prior felony records. Similarly, employment status appeared to be influential in sentencing. Of those who were incarcerated, 73 percent were unemployed, and of those who were not incarcerated, only 43 percent were unemployed. 
Another important factor in bargaining and sentencing decisions in Burg cases was whether or not the burglary took place in a dwelling. Non-dwelling burglaries appeared to be the most "bargainable." Eighty-three percent of the trial convictions were for dwelling burglaries; 71 percent of the PG closings were for dwelling burglaries, but only 38 percent of the PG bargain closings were for dwelling burglaries. Overall, non-dwelling burglaries had an advantage at sentencing. Only 43 percent of non-dwelling burglars (compared to 75 percent of dwelling burglars) received incarceration sentences. However, again the data indicated that PG bargain closings were not advantageous in terms of sentencing. While bargained closings included a relatively high proportion of non-dwelling burglaries, they also had a relatively high proportion of incarceration sentences. Thus, it seems that the advantage gained by committing a non-dwelling burglary is offset by pleading guilty with a dismissal or not file agreement as opposed to pleading guilty without such a bargain. Here it should be recalled that only one of the PG bargains was a charge reduction bargain. All others were pleas to the original charge with an agreement to drop other filed or known charges or counts. In line with the Criminal Court data, the Public Defender data on Burg I cases strongly suggested that the filing or knowledge of multiple counts or charges worked against the defendant at sentencing regardless of whether or not counts or charges were dropped in exchange for a guilty plea. of course, it is possible that sentencing would have been even harsher if these extra counts or charges had not been dropped. 
Nevertheless, compared to straight PG closings (almost all of which were single count cases), PG + Dis and PG + Not File had a sentencing disadvantage.

The people charged with (and for the most part convicted of) Burg I wore a number of negative labels. Compared to the general population, they showed a high proportion of undereducation, unemployment or underemployment, prior criminal records, and drug or alcohol problems. Fifty-eight percent had less than four years of high school, and none had any college education. Fifty-four percent of the defendants were unemployed; 36 percent had only tenuous employment (had been employed less than six months and/or were employed either part-time or intermittently. Only Il percent showed stable employment. Prior felony records were reported for 77 percent of the charged felons. Finally, the files indicated that 52 percent of the accused offenders had a drug or alcohol problem; for another 30 percent there was no information on whether or not such a problem existed, and in only 18 percent of the cases was it stated in the file that there was no indication of a drug or alcohol problem. Additionally, the Burg I offenders defended by public defenders were predominantly male, young and white. Fifty-nine percent were between 17 and 20 years old, and almost all ( 91 percent) were 27 or younger. Males comprised 94 percent of the group, and 84 percent were white. However, blacks were over-represented compared to their representation in the county population (13 percent of the defendants were black, whereas blacks account for only 4 percent of the total county population). 
Forgery I

Forg I cases handled by the public defender system in the latter half of 1977 were most likely to be settled by a bargained guilty plea conviction. While there was only one charge reduction plea (the defendant plead guilty to Att Theft II and had a second count dismissed), pleas to the initial charge accompanied by some agreement to dismiss or not file other counts or charges were extremely common. Of all convictions, 58 percent were settled by bargained guilty pleas, and 32 percent were settled by straight guilty pleas. Table XXXVIII gives the frequency distribution of closing types for the Forg I cases. Nine of the ten cases with initial multiple counts ended in conviction on only one count. Thus, initial multiple count cases were highly likely to receive a dismissal offer in exchange for a guilty plea.

TABLE XXXVIII

TYPE CLOSING: PUBLIC DEFENDER FORG I CASES FROM JULY THROUGH DECEMBER OF 1977, BY PERCENT

\section{Type Closing}

PG

$P G+D i s$

PG + Not File

$P G+$ Not File + Dis

PGTL + Dis

$\mathrm{CBC} / \mathrm{CBJ}$

$A B C$

Dis

\section{Percent}

26

8

23

13

2

8

2

18

TOTAL

$100 \quad(39)$ 
The majority of Forg I convictions (6I percent) resulted in non-incarceration sentences. Likewise, a sentence recommendation of non-incarceration was given in 61 percent of the cases. A positive relationship (significant at the .01 level) was found between recommendations of incarceration/non-incarceration and actual sentences of incarceration/non-incarceration.

Only three types of incarceration recommendations were made: (1) no incarceration and probation; (2) no position or no opposition to non-incarceration; (3) withhold until after conviction and/or pretrial investigation. Of those cases in which there was a recommendation of non-incarceration, non-incarceration was given in 90 percent of the cases. Of cases which received one of the two other types of recommendations, 42 percent were sentenced to the penitentiary; 42 percent were sentenced to jail, and only 17 percent were not incarcerated upon sentencing. Thus, when the prosecution took no position or withheld a position, the chances were high that the defendant would be incarcerated. In fact, of those cases in which the recommendation was withheld until after conviction and pre-trial investigation, all received incarceration sentences.

Actual sentencing was a little harsher than the recommendations regarding misdemeanor status. Although all 14 recommendations for immediate misdemeanor treatment were granted, only $I$ of the 7 recommendations for deferred misdemeanor treatment was granted. Fourteen of the 15 recommendations for restitution were ordered by the judge. 
PG bargains appeared to be "better deals" for Forg I

offenders than for Burg I offenders in terms of sentencing. Seventy-two percent of defendants who plead guilty with a bargain compared to 50 percent of defendants who plead guilty as charged were not incarcerated upon sentencing. The number of trials was small, but sentencing was the harshest for those defendants who were convicted at trial.

Defendant characteristic variables were also influential in terms of sentencing. Those who received incarceration sentences were more likely to have prior felony records, to have less than four years of high school education, and to be unemployed. Race was of noticeable importance. Whereas 70 percent of white defendants were not incarcerated upon conviction, only 38 percent of black defendants were not incarcerated at sentencing. Sex was also of considerable importance in the sentencing statistics for the Forg I offenders; 80 percent of females compared to 44 percent of males were not incarcerated upon conviction.

As was the case for Burg I, Forg I offenders had a number of strikes against them from the outset. Eighty-four percent had prior felony records; 44 percent had completed less than four years of high school. Unemployment was high (77 pexcent), and only 5 percent showed stable employemnt. Also, 22 percent were black (again a considerably higher proportion than the 4 percent of blacks found in the county population). Thus, the findings suggested that individuals charged with Forg I entered the system with a number of disadvantageous characteristics, and that these same characteristics worked against defendants as they moved through the system. 
The Forg I defendants tended to be older than the Burg I defendants. Only 33 percent of the former were 20 or younger. Also, the Forg I offenders were more likely to be female than were other types of offenders. Almost half (43 percent) of these public defender cases involved female offenders.

\section{CONCLUDING REMARKS}

The findings from the Public Defender records supported many of the findings from the Criminal Court data. The proportions of cases settled with the different closing types were similar, as were the proportions of incarceration and non-incarceration sentences. Both sources indicated a relatively high proportion of trial closings for Burg I, Rob I and Theft I in the latter half of 1977. Burg I and Forg I offenders were characterized similaxly in both data sets.

New information was also offered. Another type of bargain, i.e., pleading guilty with an agreement not to file on other known charges, was found to be common for both Burg I and Forg I cases (although more common for the latter than the former). It is possible that the agreement-not-to-file bargain is more advantageous than the agreement-to-dismiss bargain, since PG bargains were more advantageous in terms of incarceration sentences for Forg I than for Burg I offenders. Also, a positive relationship was found between sentence recommendation and actual sentence for both Burg I and Forg I. Finally, the data on race (not available from the Criminal Court records) indicated that blacks were proportionately more likely than whites to be incarcerated at sentencing. 
The present and preceding chapters have yielded a detailed picture of the nature and outcome of felony cases processed through the court system in this county. In the next chapter, the focus is on the atittudes and opinions of key actors in the disposition process regarding both the substance and the process of case disposition without trial. The data source was the interviews with prosecutors, public defenders and judges working in the court system under study. 


\section{CHAPTER VI \\ ATTITUDES AND OPINIONS OF KEY COURT ACTORS: \\ THE INTERVIEWS}

\section{INTRODUCTION}

An integral part of the total picture of the case disposition process within the court organization is the attitudes and opinions of participating key actors. As noted earlier, attitudes and behaviors regarding the workings of a system may be inconsistent. However, the reality of the total system can only be fully understood by including both attitudes and actions as component parts of the same system. The way in which system members perceive the system is likely to affect and be affected by the way in which they play their respective system roles. In similar dialectical fashion, attitudes and role behaviors are related to the overall operation of the system.

Because the interviewees, i.e., prosecutors, public defenders and judges, play major roles in the case disposition process, their attitudes and opinions are of primary importance. Analysis of the interview data was directed toward an assessment of (1) attitudes and opinions as independent as well as component parts of the system; (2) relationships between attitudes and actions; (3) relationships between and within the responses of the three different groups of key court actors. 
The interviews yielded two data sets. The source of the first set was a questionnaire which called for written closed-end responses. The second source was a set of questions calling for verbal open-ended responses. The questionnaire form is found in Appendix D. In this chapter, the findings from the questionnaire are discussed first, followed by a discussion of the findings from the open-ended part of the interview.

FINDINGS FROM THE QUESTIONNAIRE DATA

Consideration Given Various Factors in the Handling of Cases

The first question was a multi-part one in which the respondents were asked to rate on a five-point scale the amount of consideration given to 24 separate factors by the Public Defender's Office and the District Attorney's Office when handling a given case. The response categories moved from very much consideration (coded as five) to no consideration (coded as one). The question read:

In deciding how to handle a given case, how much consideration do you think the following factors are given by

a) the Public Defender's Office;

b) the District Attorney's Office?

For analytical purposes, the 24 factors or variables have been placed in one of 6 categories as shown in Table XXXIX.

The findings from the responses to this first question are discussed in narrative form in this chapter. For a statistical picture of these data, see Appendix J, in which the means, modes, ranges and standard deviations are presented. 
TABLE XXXIX

CATEGORIES AND INCLUSIVE VARIABLES ON WHICH ANALYSIS OF DATA FROM QUESTION NUMBER ONE WAS BASED

\author{
Nature of Case \\ Strength of Prosecutor's Case \\ Seriousness of offense \\ Typicality of offense \\ Nature of Defendant \\ Prior Record \\ General Character \\ Attitude \\ Criminal Justice Goals \\ Due Process \\ Actual Guilt \\ Crime Control \\ victim Needs \\ Defendant's Wishes \\ Functional Court Needs \\ Avoidance of Court Overload \\ Conservation of Staff Resources \\ Speedy Case Settlement \\ Maintenance of Good Relations \\ Within-System Input \\ Report of Arresting officer \\ Tendencies of Juries \\ Tendencies of Judges \\ Relationship with Opposing Attorney \\ Office Policy \\ Career Advancement Concerns \\ Outside-System Input \\ Community Attitudes \\ Political Concerns \\ Special Interest Groups
}

Nature of Case. Strength of prosecutor's case was the only variable on which there was high within and between group agreement that it was of extreme importance to both offices. There was also high within and between group agreement that seriousness of offense was given very much consideration by the D.A.'s office. While judges and public defenders also agreed that this variable was given a great deal of consideration by the P.D.'s Office, prosecutors felt that it 
was only of medium importance to the P.D.'s Office. All groups did give seriousness of offense a higher rating in terms of its importance to the D.A.'s Office than to the P.D.'s Office. Relative to other factors, strength and seriousness of case appeared to be perceived as very important in case disposition decisions. Here the opinions of key court actors were consistent with plea bargaining policy as well as observations of case disposition in action.

Typicality of offense turned out to be a problematic variable. The majority of respondents asked for further explanation of the meaning of this variable. Even after it was explained, three prosecutors and four judges said that they did not know how to respond to this question and therefore chose not to respond at all. The explanation given by the researcher was that typicality of the offense referred to whether or not the patterns of a particular case, e.g., characteristics of the defendant, the manner in which the offense was committed, the place in which the offense took place, were typical or fit an overall pattern generally seen for that type offense (see Chapter I for a description of Sudnow's conceptualization of normal or typical crimes). The interviewer's impression was that the great majority of respondents were not able to grasp clearly the meaning of this notion, and thus any interpretation of the ratings is questionable. The ratings themselves offered very little information; means fell at the middle of the scale, and the response ranges were high. It is possible that the concept of "typical offenses" (or to use Sudnow's label, "normal crimes") did exist in reality but that the researcher was simply unable to communicate the meaning of this concept 
to the respondents. However, it is also quite possible that sudnow's widely-cited claims that case disposition decisions are made based on the typicality of the offense do not reflect the reality of case disposition in this court system. This latter possibility was supported by the observational data, which were notable in their lack of reference to the concept of "typical" or "normal" crimes. Nature of Defendant. All groups agreed that prior record was given medium consideration by the P.D.'s Office and somewhat more consideration by the D.A.'s office. Interestingly, the group means indicated that prosecutors and public defenders thought that prior record was given more consideration by their own offices than did the other groups.

The data indicated that judges did not think either general character or attitude of the defendant was given much consideration by either Office. Prosecutors believed that general character of the defendant was given very little consideration by their office. Other than that, prosecutors and public defenders gave these two variables medium ratings in terms of its importance to both offices. All groups gave higher ratings on general character and attitude of the defendant to the P.D.'s Office than to the D.A.'s Office. The nature of the defendant (in terms of prior record, general character and attitude) was generally seen to be only of medium importance in deciding how to handle a given case (although prior record was perceived as of above average importance to the D.A.'s Office). Public defenders and prosecutors did attach slightly more importance to character and attitude of the defendant than did judges. 
Several public defenders commented that while the nature of the defendant was not particularly important in terms of type closing, it was important in terms of sentencing decisions. These findings were consistent with the findings from the Criminal Court case file data, indicating that the perceptions of key court actors reflected reality.

Criminal Justice Goals. Judges believed that due process was given a great deal of consideration by both Offices. Public defenders and prosecutors also believed that due process was given a great deal of consideration by the P.D.'s Office, but both groups agreed that it was of somewhat lesser importance to the D.A.'s Office. Prosecutors, however, gave due process a higher rating for their own Office than did public defenders. In subsequent comments by attorneys on both sides, it was indicated that while due process was a criminal justice goal for all, in fact it was public defenders who had the major responsibility for insuring due process.

While idealistically the actual guilt of the defendant should be a very important factor in case disposition decisions, the data suggested some ambiguity over this variable. For all groups, there was fair within-group agreement regarding the amount of consideration given to actual guilt by both offices. There was, however, considerable between-group disagreement. The data reflected a belief on the part of judges that the ideal was in fact reality, i.e., actual guilt was given a great deal of consideration by both Offices. Public defenders and prosecutors, on the other hand, believed that actual guilt was only of medium importance to the P.D.'s Office. Prosecutors 
thought that actual guilt was given a great deal of consideration by their own office. Public defenders, however, gave this variable a higher rating for their Office than for the D.A.'s Office. Looking at other data, it appeared that two factors were influential regarding these opinions on the importance of actual guilt. First, the great majority of accused offenders were believed to be actually guilty of something by attorneys and judges. This presumption of guilt must certainly lessen the amount of consideration given this variable in the case disposition process. Second, public defenders reported that a major goal for them was to defend a client to the best of their ability regardless of actual guilt. On the other hand, if a client maintained a position of total innocence (not guilty of the charge or of a related charge), trial was deemed by public defenders to be essential. Generally, however, the defense goal appeared to take precedence over the determination of guilt goal--one of several indications that the adversary system prevailed in this particular court system.

Another ideal goal of the criminal justice system is crime control. It was generally felt that crime control was important to the D.A.'s office but not so important to the P.D.'s office. of all groups, prosecutors gave crime control the highest rating in terms of its importance to their office. On the other hand, public defenders thought that crime control was more important to their Office than did the prosecutors or judges.

Like crime control, all groups believed that victim needs were not given much consideration by the P.D.'s Office. Prosecutors 
maintained that victim needs were of great importance to their office. However, public defenders and judges were inclined to think that victim needs were of only medium importance to the D.A.'s Office.

Finally, as would be expected, all groups believed that the P.D.'s Office gave a great deal of consideration to the defendant's wishes regarding the way in which his or her case be handled. There was high within-group agreement among public defenders about the importance of this variable to their own office, but considerable within-group disagreement between judges and prosecutors as to the amount of consideration the P.D.'s Office gave to defendant's wishes. All groups agreed that defendant's wishes were not very important to the D.A.'s office. However, prosecutors expressed the belief that it was more important to their own Office than did public defenders or judges.

The findings on the importance of criminal justice goals in the case disposition process, then, indicated that overall, public defenders and prosecutors believed that criminal justice goals were given more consideration by their own office (either more consideration than by the other office or more consideration than the other respondent groups thought). Judges were the most inclined to believe in the reality of the importance of the ideal goal of due process and the consideration given actual guilt. Functional Court Needs. All groups were of the opinion that court overload was not given much consideration by either office. However, public defenders and judges gave court overload a higher 
rating for the D.A.'s Office than for the P.D.'s Office, whereas prosecutors saw it as equally unimportant to both offices.

Judges believed that conserving staff resources was of medium importance to both offices, but public defenders and prosecutors reported that it was not very important to either office. The public defender group gave court overload the lowest rating for their own office, and the prosecutor group rated it the lowest for their Office.

Judges thought that speedy case settlement was of some importance to the P.D.'s office but of greater importance to the D.A.'s Office. Public defenders felt it was of some importance to the D.A.'s Office but of very little importance to their own Office. Prosecutors did not think that speedy case settlement was given much consideration by either office.

A similar pattern was found in the ratings on the need to maintain good relations with others in the court system. Judges were of the opinion that this factor was given some consideration by both Offices. Public defenders also rated it of medium importance to the D.A.'s Office, but of little importance to their own office. Prosecutors responded that it was of little importance to either Office.

The patterns for this category of variables were quite consistent. Judges tended to think that these functional court needs were given greater consideration by the attorneys than did the attorneys. There was overall agreement that these variables were more important to the D.A.'s Office than to the P.D.'s Office. However, prosecutors' ratings showed only slight variations for the two offices. None 
of the respondent groups viewed functional court needs as playing a particularly important role in case disposition decisions.

Two points should be noted. First, there was considerable within-group disagreement among judges regarding the importance of court overload, conservation of staff resources and speedy case settlement to either office. Thus, individual judges perceived the role of functional court needs quite differently. Second, comments by attorneys indicated a belief that these variables need not be given much consideration by them because the court structure provided for these needs, e.g., resources were administratively distributed; case settlement was mandated to take place within 60 days. The attorneys openly recognized the importance of functional court needs, but maintained that they were not influential in their decisions as to how to handle a given case.

Within-System Input. All groups believed that the report of the arresting officer was of slightly above average importance to the P.D.'s Office. Public defenders and judges felt that it was of somewhat greater importance to the D.A.'s office. Prosecutors, however, gave it only a slightly above average rating for their own Office. This is a finding of some interest since prosecutors are generally expected by other court actors to rely heavily on police reports.

Public defenders and judges thought that tendencies of juries were given a great deal of consideration by both offices, whereas prosecutors felt that it was given medium consideration by both Offices. All, however, felt that tendencies of juries were more important to the P.D.'s than the D.A.'s Offj.ce. 
Public defenders and judges believed that tendencies of judges were given over average consideration by both offices (public defenders reported that tendencies of judges were extremely important to them). While prosecutors rated tendencies of judges slightly above average for the P.D.'s office, they gave it a low rating for their own office.

Again public defenders and judges were in agreement over the amount of consideration given to the relationship between the two opposing attorneys handling a case, both groups giving it a slightly below average rating for both offices. Prosecutors, however, believed that this variable was of little importance to either office. The patterns for these four variables were also quite consistent. Overall, public defenders and judges were inclined to think that these within-system input factors were given more consideration in case disposition decisions than did prosecutors. All groups felt that report of the arresting officer was more important to the D.A.'s than the P.D.'s office, and all thought that tendencies of juries and judges were of greater importance to the P.D.'s than the D.A.'s Office.

The consideration given office policy by the D.A.'s office was rated high by all groups (means were 4.6 from the public defender ratings, 4.4 from the judge ratings, and 4.1 from the prosecutor ratings). Public defenders were in strong agreement that office policy (their own, not that of the D.A.) was of no importance to them in terms of decisions on how to handle a given case. Prosecutors believed that office policy was not very important to the P.D.'s office, but judges rated it high in importance 
(mean was 4.0 ) to the P.D.'s office. Again it should be noted that within-group disagreement was high among prosecutors and judges regarding the amount of consideration given this variable by the P.D.'s Office.

The factor of career advancement concerns rated very low in terms of its importance to the P.D.'s Office in making case disposition decisions. Prosecutors also gave this variable a very low rating in terms of its importance to their own office. Public defenders, however, thought that career advancement was given above average consideration (mean was 3.4 ) by the D.A.'s Office. Judges also thought that it was of some importance to the D.A.'s office (mean was 2.9). Both office policy and career advancement, then, were seen by public defenders and judges as being of greater importance to the D.A.'s Office than by the prosecutors themselves. Outside-System Input. All groups agreed that community attitudes were not given much consideration by the P.D.'s Office (of all groups, prosecutors gave the P.D.'s office the lowest rating on community attitudes). However, all groups felt that community attitudes were given above average consideration by the D.A.'s Office lof all groups, prosecutors gave community attitudes the lowest rating for their own office).

The patterns were similar regarding the importance of political concerns. All groups agreed that political concerns were given almost no consideration by the P.D.'s Office. Public defenders gave political concerns a high rating for the D.A.'s Office, and judges gave this variable an above average rating for the D.A.'s 
However, prosecutors believed that political concerns were of little consideration in their decisions about how to handle a case.

Special interest group demands indicated similar patterns. All groups agreed that demands of special interest groups were of very little importance to the P.D.'s Office. Public defenders and judges thought that this factor was given above average consideration by the D.A.'s Office (the public defender group gave it the highest rating for the D.A.'s Office). Prosecutors, however, viewed special interest group demands as being of very little importance to them (actually, they thought it was slightly less important to them than to the P.D.'s office).

The data on this category of variables were clear and consistent. Everybody agreed that none of these variables was given much consideration by the P.D.'s office. Public defenders thought that they were of considerable importance to the D.A.'s office, but the prosecutors thought they were of little importance to their own office. Judges fell somewhere in the middle of these two extremes regarding the importance of these factors to the D.A.'s office.

\section{Summary: Question Number One}

In the opinion of the respondents, strength of case and seriousness of offense were indisputedly the most important variables to both offices in terms of decisions as to how to handle a given case. The nature of defendants was seen as of lesser importance than the nature of the case. Judges were inclined to view due process, actual guilt and functional court needs as being of greater importance than did public defenders or prosecutors. Judges and public defenders tended to think that within-system inputs were 
given greater consideration than did prosecutors. All groups agreed that outside-system inputs were of little importance to the P.D.'s Office, but only prosecutors felt that they were of little concern to their own Office. Each group of attorneys tended to play up the importance of criminal justice goals to their respective offices, and to play down the importance of functional court needs and outsidesystem inputs to their own Offices.

Getting Something in Exchange for a Guilty Plea

Public defenders were asked to respond to the second question, which read:

If your client decides to plead guilty, how important is it to you that he/she receive some benefit in exchange for a guilty plea?

As for all the questions, a five-point rating scale was used; the possible responses were: very important (coded as five); important (four); somewhat important (three); not very important (two); not at all important (one).

The responses strongly indicated that a benefit in exchange for a guilty plea was considered by the public defenders to be quite important. This finding supported the theoretical assumption that an exchange or negotiation process is functional for meeting participants' needs only if there is a real exchange, in which all parties believe they have received some tangible benefit. Knowledge of the Routinized Process: Anticipating Bargains The third question, asked of public defenders and prosecutors, had two parts: 
After having studied a case assigned to you, how often do you feel that you can reasonably anticipate

a) whether or not the case will be plea negotiated;

b) what kind of a bargain will be made?

The five possible responses to both parts of the question were: always (coded as five); usually (four); sometimes (three); not usually (two); never (one).

The responses indicated that bargaining was routinized in this court system. Overall, attorneys believed that they could usually tell from the outset whether or not a case would be plea negotiated and what kind of a bargain would result. As groups, public defenders expressed greater certainty than did prosecutors. None of the public defenders or prosecutors gave a "not usually" or "never" response to either part of the question. All public defenders and 10 of the 14 prosecutors responded that they could usually tell whether or not a given case would be plea negotiated after they had looked it over. The attorneys were only slightly less sure of what kind of a bargain would be made. Thirteen of the 15 public defenders responded that they usually could anticipate what kind of a bargain would be made, and 9 of the 14 prosecutors also said that they could usually anticipate the bargain. Although no one gave an "always" responses to either part of this question, the predominance of the "usually" response was a strong indication of the existence of a routinized classification scheme which was understood by the key actors. 
Satisfaction with Disposition Outcomes

Again, only public defenders and prosecutors were asked to respond to the fourth question:

How often would you say you are satisfied with the disposition outcome of cases you handle?

The same response categories were offered as for the preceding question.

The majority of both groups of attorneys responded that they were usually satisfied with the disposition outcome. However, only 60 percent of the public defenders compared to 86 percent of the prosecutors reported that they were usually satisfied. This difference was consistent with other interview data, in which public defenders lamented their weaker position in the disposition process. Nevertheless, although no one reported that they were always satisfied, satisfaction with outcomes was more common than uncommon. There were no "never satisfied" responses, and only one "not usually satisfied" response.

Presumption of Guilt

The next two questions, asked of public defenders, prosecutors and judges, attended to the presumption of guilt issue:

Approximately how many accused felons do you think are actually guilty, either of the formal charge or of some related charge?

Approximately how many accused felons assigned to the Public Defender's office do you think are actually guilty, either of the formal charge or of some related charge?

The possible responses to these two questions (again coded from a high of five to a low of one for statistical purposes) were: over 
80 percent; 80 percent to 60 percent; 60 percent to 40 percent; 40 percent to 20 percent; less than 20 percent.

The findings confirmed previous research which has suggested that key actors in the disposition process assume that charged offenders are guilty of something prior to a legal finding of guilt or innocence. No differences were found regarding accused felons in general as opposed to accused felons defended by the public defender system.

All judges and prosecutors were of the opinion that over 80 percent of all accused felons (as well as those assigned to the P.D.'s office) were actually guilty, either of the formal charge or of some related charge. While 12 public defenders believed that over 80 percent of all accused felons as well as their own clients were actually guilty of something, the remaining 3 felt that only from 60 percent to 40 percent of all those charged were guilty. Thus, a minority of the public defenders were not so likely to presume guilt. Also, from comments made while responding to this question, it appeared that if the question had been limited to "guilty as charged," the ratings of public defenders would have been considerably lower.

The Number of Guilty Plea Cases Involving Bargains

Using the same percentage categories as for the preceding question, public defenders, prosecutors and judges were asked for their opinion regarding the percentage of guilty plea cases which were accompanied by some kind of bargain:

of cases which are settled by guilty pleas, how many do you think involve some kind of bargain, however minimal? 
All public defenders and judges believed that the majority of guilty plea dispositions involved some kind of bargain. sixtyseven percent of the public defenders responded that over 80 percent involved some kind of bargain, and the remaining 33 percent marked the 80 percent to 60 percent category. While only 38 percent of the judges thought that over 80 percent involved bargains, the other 62 percent felt that the percentage was in the 80 percent to 60 percent category. The estimates of public defenders and judges were consistent with the findings from the Criminal court data.

The responses of prosecutors showed greater variation on this question than did those of public defenders and judges. On the one hand, 50 percent of the prosecutors interviewed were of the opinion that over 80 percent of guilty plea cases involved some kind of bargain. Five marked the 80 percent to 60 percent category. Yet one checked the 60 percent to 40 percent category, and another marked the 40 percent to 20 percent category. Some of the differences between the three groups (and within the prosecutor group) could have been due to differences in definitions of "bargains." However, taking into account other interview responses, it seems likely that some of the differences are real, i.e., public defenders were the most inclined of the three groups to view guilty plea cases as accompanied by some kind of bargain.

\section{Power Imbalance in the Exchange Process}

In an attempt to uncover opinions regarding the balance of power in the exchange process, all three groups of interviewees 
were questioned about their agreement/disagreement with the following statement:

The district attorney has the "upper hand" in the plea negotiation process.

The possible responses were: strongly agree, agree, neutral, disagree, strongly disagree (again coded from strongly agree [five]. to strongly disagree [one]).

This question was purposely stated in very general terms in order to get at an overall feeling that respondents might have about the balance of power in the negotiation process. As a result of this rather ambiguous phrasing, the researcher had anticipated some requests for explanations of the meaning of this statement. None, however, was forthcoming. Respondents were able to give an opinion with no apparent discomfort or hesitation (although it should be recalled that 9 of the 14 prosecutors filled out the questionnaire not in my presence, rendering an assessment of their feelings about the question impossible).

Public defenders, as might be expected, showed the strongest agreement with this statement (mean was 4.2 ). None of the public defenders disagreed or strongly disagreed, and only one gave a "neutral" response. As a group, however, prosecutors also indicated agreement with this statement (mean was 4.1 ). One prosecutor did express disagreement. Judges, on the other hand, were less inclined to perceive of a power imbalance (mean was 3.3 ). Only one judge reported that he strongly agreed, and three judges said that they disagreed. From the conversational interview responses, it was apparent that judges tended to view plea negotiation in this court 
system as an opportunity for attorneys and the defendant to discuss objectively the facts of a case in an attempt to make mutual and rational decisions regarding resolution. Within this context, power was not seen as a major factor.

\section{Concluding Remarks}

The questionnaire data provided a great deal of insight into the attitudes and opinions of the interviewees, all of whom play key roles in the case disposition process. Generally, these attitudinal data were consistent with the behavioral data collected from records and observation, indicating an understanding on the part of the key actors of the reality of the disposition process. There were between-group differences regarding the amount of consideration given certain factors by the P.D.'s and D.A.'s Offices, implying that perspectives do vary in accordance with one's status and role within the system. However, the responses showed that all groups shared beliefs that most accused felons were guilty of something and that the majority of guilty pleas were accompanied by some kind of bargain. Public defenders and prosecutors also agreed that bargains could usually be anticipated at the outset and that the negotiation process was prosecutor-dominated.

\section{RESPONSES TO INTERVIEW QUESTIONS}

\section{Introduction}

The interviewees were asked to give open-ended responses to nine questions in terms of their own beliefs about plea bargaining and their respective roles in the case disposition process. In this 
section, the findings are discussed for each question separately. However, as is the case with the questionnaire data, these openended responses are also presented in the final chapter as part of the overall picture of case disposition in one urban court system. While all of the public defenders in this county and 11 of the 13 judges in the county felony court were interviewed, it should be recalled that only 5 (a small minority) of the county prosecutors responded to this verbal part of the interview. The bias which could result from this under-representation of the prosecutor group was compounded by the fact that the interviewed prosecutors were selected by the D.A.'s office and were all in positions at the upper level of the hierarchical structure of the office. Thus, the prosecutor staff was not only under-represented but also nonrepresentative. On the other hand, the argument could be made that the responses of high-level prosecutors reflect most closely the attitudes and opinions which in turn reflect the operations of the D.A.'s Office. In the hierarchical structure of the D.A.'s Office, policies (which are generally carried out in actual operations) are set by top-level staff. With these considerations in mind, let us now turn to a discussion of the conversational responses.

Question Number One: In Your Opinion, What is Plea Bargaining? The responses of the three groups to this question indicated a fair amount of definitional agreement. A description often given initially by individuals in all groups was of plea bargaining as a negotiation between prosecution and defense whereby cases were 
resolved through a guilty plea rather than a trial. Another common thread was that plea bargaining involved some sort of concession on the part of the prosecution in exchange for a guilty plea. Finally, there was general agreement that plea bargaining could take many different forms, e.g., charge reduction, dismissal of or not filing other counts or charges, sentence recommendations. Two prosecutors, however, pointed out that from the perspective of their office, plea bargains referred to charge reduction bargains. Public defenders expressed the belief that for prosecutors, plea bargains were charge reduction bargains.

Each group did tend to emphasize different aspects of plea bargaining. Judges were inclined to point out that plea bargaining was better labeled plea negotiation conference. Six judges explicitly stated that in this state, plea negotiation was a process structured by the courts for the purpose of allowing prosecution and defense to discuss the facts of the case and to work toward a mutual agreement as to the proper resolution of the case. The definition of one judge was illustrative:

The examination of the issues concerning the commission of a particular crime and the circumstances of the person charged with the crime--that's an examination conducted by the prosecution and the defense attorney and the defendant. Their determination, that is their agreement, as to what would be a proper disposition of the particular charge.

Whereas the mutual examination of issues was emphasized by the judges as a group, implications of strategical game plans for bargaining were absent. From one judge: 
In the criminal justice system now [in this state], for example, we have open discovery. Everything essentially that the state has is an open file to the defendant. In other words, they're trying to take out the games involved...

Although public defenders agreed with judges that plea bargaining in this court system was presently a formally structured process, they were less inclined to view it as a fair exchange. Eleven of the 15 public defenders interviewed emphasized that plea bargaining should be a negotiation process in which benefits were exchanged and concessions granted by both sides. The attorneys, as adversaries, were to try to get the best deal for their client. From the perspective of one public defender:

- . you have a basic charge that your client is charged with and you negotiate with the D.A. to achieve some kind of end result that's favorable to your client.

Under the present formalized system, however, it was felt that the bargaining position of the defense attorney had been severely reduced, resulting in an off-balance exchange:

Plea bargaining is largely where we--the defendant and his attorney--hope that the state is going to offer us something. What the state can bargain in this county is so carefully described by rules in the D.A.'s Office that they in most cases have very little flexibility. And so there are few things that you can offer as an inducement that would be sufficient to break the rules.

This belief may in part explain why public defenders also emphasized in their definitions that plea bargaining included any benefit, however minimal, that the defense attorney was able to get for his or her client:

[Plea bargaining is] gaining anything of value in return for entering a plea... 
As might be expected, prosecutors emphasized in their definitions of plea bargaining the fact that it included concessions by the state:

An agreement between prosecutor and defense which calls for some limitation on the part of the state other than those required by statute.

The prosecutor has given up something he or she wouldn't have to.

An incentive offered by the D.A. to encourage a plea.

In their responses to this first question, different emphases were noticeable between the three respondent groups. These emphases reflected their respective roles in the court system. Judges viewed plea bargaining as ideally a neutral, objective and cooperative process with the goal of arriving at a just decision. Public defenders saw it, again in ideal terms, as an adversary exchange in which both sides had some bargaining power. Prosecutors placed their emphasis on their belief that bargaining meant the state suffered some cost.

Question Number Two: What Features of a Case Would Make it Most Likely that the Prosecutor Would be Willing to Plea Negotiate?

Judges, prosecutors and public defenders were all most likely to cite strength of case as the most important factor in a prosecutor's willingness to plea negotiate. This finding was consistent with the responses on the questionnaire form. Following the strength of case factor, economy was most often referred to by the judges. The comments of two judges were illustrative: 
- . prostitution, drugs, marijuana offenses and things like that, you just haven't got the time. It isn't worth it. So you plea negotiate.

Even though the state has iron-clad cases, if they get 12 burglary cases against the same defendant, ordinarily, just for the purposes of economy, they're not going to try the same person 12 times.

This emphasis by the judges on functional needs was also seen in their responses on the questionnaire form.

Prosecutors noted that bargaining decisions were guided by their office policy. However, of all three groups, public defenders were the most vocal regarding the importance of D.A.'s Office policy. Rather than viewing it as a guiding factor, public defenders described it as a limiting factor in the prosecutors' ability to plea negotiate. However, the defense attorneys also suggested that policy could enhance the chances of plea negotiation when prosecutors had a weak case. This was due to their belief that the D.A.'s Office had an overriding concern with getting convictions. One public defender stated:

Also, they certainly do evaluate cases in terms of can they win. I think from my perception it's accurate to say that the D.A.'s office is much more concerned about winning and losing, for whatever purpose... I believe they're much more supervised there than we are; people are watched, and statistics are kept on wins and losses. I think we're also concerned with wins and losses; however, we don't expect to win. The cases that I have that are good to go to trial with, they give me offers that are just incredible.

A related factor mentioned by several public defenders and one judge was that policy not to negotiate on certain kinds of cases had to be enforced in order for the D.A.'s office to keep federal monies which had been given for the purpose of the reduction of plea bargaining. The judge stated: 
You wouldn't negotiate out your career criminal cases where you are rewarded monetarily for not negotiating.

Question Number Three: What Features of a Case Would Make It Most Likely that the Defense Attorney would be Inclined to Think the Defendant Should Plead Guilty?

Only judges and public defenders were asked to respond to this question. The majority (7 of the 11) judges interviewed said that guilt of the defendant was the most important factor. One judge actually stated that there were no other factors than actual guilt which should be considered in plea decisions. Another judge believed that plea decisions should be the result of the objective assessment of the facts of the case by all parties at the pre-trial conference. The responses of these judges indicated that they were talking about "what should be" rather than "what was." However, even with further probing, these judges held to their initial responses and were reluctant to attend to the interviewer's queries about differences between the ideal and the actual. The three remaining judges emphasized strength of case factors as influential in plea decisions on the part of the defense.

Public defenders also said that the guilt of the defendant was an important factor in plea decisions. However, they tended to elaborate on this factor in the following way. Guilt of the defendant, in the majority view, was important in that the defense attorney could not allow a client to plead guilty if he or she was not able to say that he or she was guilty. On the other hand, an admission of guilt by the defendant did not necessarily lead public defenders to a belief that pleading guilty was the only or best choice. 
Twelve of the 15 public defenders said that a primary concern for them regarding plea decisions was that their client get the most favorable outcome possible. The following statements of three public defenders reflect this point of view.

The only circumstance in which I don't think it's appropriate for a client to plead guilty is when in fact they can't say that they are in fact guilty. My role is simply to get people through the criminal justice system as expeditiously as possible for them with the least impact possible upon their lives, the least adverse effect possible. Generally, plea negotiation results in that.

A condition is that he acknowledge that he's guilty. But it's not a factor in deciding whether to go that route. I don't care how guilty they are, or how contrite or non-contrite they are; if I think that I can beat the case, the thing to do is to beat the case. But on the other hand, if I can't beat the case and I know it, I still have to try the case if my client says that he's not guilty.

As defense attorneys, we want to limit the exposure of the defendant to the authority of the state as much as possible.

Again, what came through clearly was a commitment on the part of the public defenders to their professional roles as advocates for the accused.

Public defenders generally agreed that the defendant was the one who had to make the plea decision, and that their job was only to present to their client the facts of the case along with a description of the possible options and outcomes. One public defender did admit that it was not always easy for the defendant to make a plea decision without some advice from the attorney:

To be truthful about that, the defendant often is not in a position to make the legal evaluations that are necessary to make decisions, and relies heavily on his lawyer's advice as to what the odds are of winning or losing, and in that sense it is false I think to say that the defendant is making an unfettered decision. 
Question Number Four: What Features Make a Case Most Problematic or Difficult in Terms of Deciding How to Charge/Plea?

Prosecutors were asked about problematic features in terms of charge decisions, and public defenders were asked about problematic features in terms of plea decisions.

Three of the five prosecutors interviewed said that the charge decision was not problematic in that the laws were quite straightforward in defining offenses. Another prosecutor responded that, although "problematic" was probably too strong a word, careful consideration was required in order to make sure that the facts of the case did fit the statute. The fifth prosecutor admitted to a problematic or difficult situation which occurred "when the credibility of witnesses is difficult to ascertain or you can't get enough information." All of these responses relied on a legalistic framework for making charge decisions.

Two of the prosecutors who said that the charge decision was not problematic did say that sometimes murder was problematic since it could be difficult to prove the defendant's mental state. One stated:

Murder can be difficult because you have to prove what's in a guy's head. That's probably why we plea bargain murder.

Problematic features mentioned by defenders, although expressed in slightly different ways, all had to do with the ultimate outcome for the defendant. All but one public defender referred to cases in which either there were possible defenses or the guilt of the defendant was unclear, but in which the likelihood of conviction and severe punishment were high if they went to trial. Expressing 
a concern for the least possible exposure for their client, the defense attorneys said that it was difficult to turn down "good offers" in such cases.

There are cases obviously where there is a great deal of pressure to enter a guilty plea. For example, if an individual is charged with murder which bears a mandatory life sentence, and they're offered some attractive charge with basically a guarantee of probation, that's a difficult plea to turn down, and we agonize over those a great deal.

Seven public defenders specifically stated that unpredictability of outcome was a problematic feature, adding that plea bargaining injected some certainty into the disposition outcome.

Four public defenders said that plea decisions were particularly difficult when there was uncertainty about the mental or emotional state of the defendant. One of these commented:

Maybe I think they're mentally ill, but it's nothing that I can demonstrate in court that would make them not responsible.

Another pointed out that a defendant's state of mind was sometimes such that the individual was unsure about what actually happened. Again, the overall concern was over the consequences for the defendant of entering a guilty plea as opposed to going to trial; that is, are the risks of going to trial too great for the defendant, even though a guilty plea may not be strictly appropriate?

Question Number Five: Are There Certain Kinds of Cases for Which Charge Reductions are Fairly Standard? If So, Could You Give Some Examples?

Although judges and prosecutors were especially inclined to object to the term "standard" (stating that no reductions were standard), all groups most commonly gave as examples of common 
reductions certain offense types. Drug offenses (particularly marijuana possession) were most often cited as examples of reduction cases. Sex crimes, non-premediated murders and assaults were the other classes of offenses most frequently cited by the respondents. Here, the beliefs of the key actors were consistent with reality, as it was these classes of offenses which were most likely to be settled with bargained, reduced-charge pleas. The respondents expressed the belief (again in line with reality) that cases were usually reduced to attempts or lower levels of the initial offense. Further probing with the purpose of getting respondents to talk about case features (other than general offense types) which enhanced the likelihood of charge reduction yielded some information. For instance, two prosecutors said that homicides resulting from traffic violations were commonly reduced from Manslaughter to Criminally Negligent Homicide. Another prosecutor said that sex cases in which the victim was unwilling or reluctant to testify were commonly reduced.

There was agreement among public defenders that reducible Homicide and Assault cases usually were non-premeditated and often involved domestic quarrels or arguments between non-strangers. In the case of Assaults, it was pointed out, complainant and defendant might not be easily distinguished:

In an assault case, there's often something that's happened between two individuals which provoked one of the individuals to strike the other, and it's usually the guy who gets hurt most who ends up running down to the courthouse and filing a complaint... 
Several public defenders talked about the importance of getting cases reduced to misdemeanors or at least to Class C felonies, both allowing in some instances for eventual expungement:

of course, we're always trying hard, especially on a first offender, for reductions to a Class $C$ felony for purposes of expungement.

Another remarked that if it was not possible to get a reduction to a Class $C$ felony or a misdemeanor, it was better to plead to an attempt (which reduces the offense one level) than to a lesser degree, e.g., Assault I to Assault II, because an attempt looked better on the defendant's record.

Public defenders agreed that charge reductions were less common than they had been prior to new policies instituted by the D.A.'s office. Generally, however, they agreed that for nonreducible offenses, bargains to dismiss, not file, or give favorable sentence recommendations were common.

A complaint often expressed by public defenders was that the uniform and rigid charge reduction policies adhered to by the D.A.'s office worked against the first offender but in favor of the more long-term criminal. Other kinds of bargains, uniformly applied, had the same effect.

It is in fact true that in most Burg I in a dwelling and Rob I they have quit charge reduction. However, what they have done instead is--they have continued to offer people the chance to plead guilty to one charge in exchange for an agreement not to bring other charges. Of course that has the effect of taking the truly professional criminal--the one who has committed many crimes, and giving them one Class A felony; however, it takes the 18 year old who has committed his first offense, and he gets the same conviction as the more hardened criminal. 
Another complaint of the defense attorneys was that the placement of an individual in the Career Criminal Unit (where all offenses are non-negotiable) was arbitrary, and depended in great part on whether or not the state had a strong case:

I get appointed on cases every day that the client clearly qualifies as a career criminal--it's a felony, and it was committed while he was on probation or parole, where he has a significant prior record, has been to the pen before--all their criteria--but you look at the case, and it stinks, either in terms of the facts or there's just a glaring search and seizure problem, a clear psychiatric defense, or something like that where-you know, they won't touch them. I suspect they're concerned because their funding depends on their statistics, and if they come back getting a lot of not guiltys, or it it's thrown out because of a motion to suppress, or there are psychiatric defenses, it's going to hurt their statistics.

Indeed, one public defender filed a motion intent upon proving that the Career Criminal Unit was unconstitutional in that it violated

the individual's due process rights. The motion was not upheld, however, and the Career Criminal unit remains active.

Eight of the 11 judges responded to the question about routine charge reductions with essentially "don't know" answers. The following statements were illustrative:

That's a hard question. I'm not sure that I can answer that very well. I don't know enough of their statistics.

Well, I don't know. I'm really not prepared to give an answer to that.

You'd have to look at the handbook with guidelines and the framework as to when they will do a plea reduction.

My understanding is that they won't bargain on major crimes now. But I've seen it done.

I do not believe there are any kinds of cases for which pleas to reduced charges are standard, nor do I think there should be. 
In spite of these initial responses, further probing yielded examples of commonly reduced offense types from all but two judges. The examples were the same as those given by prosecutors and public defenders, i.e., drugs, certain homicides and assaults, and sex crimes.

Five judges made references to the fact that agreements to dismiss or not file appeared to be common bargains at present. However, none of the judges talked about sentence bargaining, although one judge did comment on his own role in sentence reduction:

I reduce many cases--pure and simple shoplifts in which the shoplifter would try to run or something like that, they're charged with robbery, and although technically the facts might fit the statutory definition of robbery, it was still just a shoplift. In that situation, in that type of case, even though the conviction was for robbery, I don't reduce the charge--I reduce the penalty; I consider it as a misdemeanor instead of a felony.

The interviewer's impression of the judges' responses to this question, as to others, was that they were reluctant to give opinions about anything that was going on in the system in which they were not formally involved or for which they did not have statistics. Another impression was that they were inclined to respond to questions in terms of how the system was formally structured and how it was to function ideally. Some judges seemed to think that what was wanted from the interview was a description of the court system similar to what one might get in a political science or law course. One judge, for example, asked why it was necessary to talk to so many judges, expressing the belif that one could get all the information from talking to just one judge. Another frequent comment was that one should talk to someone from 
the D.A.'s or P.D.'s office in order to get information about those Offices. On the other hand, when the question was clearly an opinion question, e.g., what do you think are the main advantages and disadvantages of plea bargaining, the judges were more willing to give their opinions.

Question Number Six: What Do You See as Your Primary Responsibilities or Goals in Your Role as Prosecutor/Public Defender/Judge?

The responses of all three groups included references to the primary task or goal of handling cases as well as possible. As would be expected, the meaning of handling a case well varied in accordance with their respective roles. For judges, the general theme had to do with seeing that a fair trial was conducted from the standpoint of both the state and the defendant. For the prosecutors, handling a case well referred to convicting the guilty and thus protecting the community from crime. Public defenders were concerned with giving their clients the best possible legal representation and with reducing their exposure to the system.

As advocates for the state, prosecutors believed that it was their duty to prepare their cases well and get convictions: Charge right. Prepare right. Present correctly and win. Convict all the guilty people you can find.

They also spoke of their role in crime control:

To try to help solve the crime problem--either by putting people in jail or scaring them about going to jail, or maybe just warehousing.

Orderly process of holding people responsible for their anti-social acts; this serves rehabilitation and deterrence. 
All public defenders interviewed stressed first and foremost their responsibility to provide good legal defense for their clients and to see that their clients got the best disposition possible--the best disposition being defined as that which resulted in the least severe exposure or punishment. Three public defenders made an interesting point when they said that their responsibilities were sometimes incompatible. On the one hand, they felt obliged to see that due process and other legal rights were upheld; on the other hand, they were committed to seeing that the individual client suffered the least severe consequences from the disposition. The incompatability surfaced when an attorney felt that a legal issue should be tested but that such a test might result in a less favorable disposition for the client should the attorney lose the case. Additionally, testing the legal issue could mean a longer period of pre-disposition incarceration (or at the least a longer period of exposure to the system) for the defendant.

Six public defenders specifically stated that a major responsibility was to see that the system worked properly and honestly. One of these expressed the belief that although they (public defenders) did not have any overwhelming impact on the outcome of the case, the fact that they were there as advocates for the defendants kept the system in line.

Service to the client was seen by public defenders as including more than providing them with solid, proper defenses. All of the defense attorneys referred to their duty to make sure that their clients were totally informed about their case, their 
rights, and the options available. Five of the respondents talked at length about their social role in relation to their clients:

Beyond that [legal representation] I think we're also involved with dealing with human beings--our clients, our clients' families, even victims. And we try to help people out. I'm very much concerned about the particular life problems that my client might have, above and beyond and apart from the particular crime that he may or may not have committed.

But going beyond the legal issues, I think we play a big social role to the client--probably a social worker role, because a lot of what we're doing is taking somebody who's off the track and trying to get them back on the track, going into the reasons as to why they're involved in criminal activity and trying to prevent them from re-involving themselves.

I think we do more than that [legal representation]; we handle the people too. I think we really contribute to keeping crime down in this community because of the good relationships that we try to foster with our clients.

In their responses, judges referred to their responsibility of making sure that cases were resolved fairly from the standpoint of all involved. Six judges emphasized their responsibility to insure a "fair trial." Three judges, however, noted the fact that since many cases did not go to trial, their main job was to insure fair guilty pleas and accompanying negotiations. As one of these judges stated:

I prefer to think of the judge's primary role as just presiding over the means of resolving the controversy, which in the criminal justice system, as in the civil system, means mostly by negotiation, because only a small part of either kind of case is ever tried.

Another of these three judges, again noting the great number of guilty pleas, said that a primary responsibility was to make sure that guilty pleas were valid and to see that once it had been decided that a case should go to trial, it was not negotiated at the trial level. 
Several judges cited administrative tasks as an important part of their role, and seven judges talked about sentencing duties. Finally, two judges discussed the enormity of the job in relation to the time available. One of these said:

Unfortunately, under this present system, my main function is just to turn the business over. I'm not allowed the luxury of giving as much thought or time or effort to a particular case as I would prefer to give.

Question Number Seven: What Makes You Feel Satisfied with the Disposition Outcome of a Case You Have Handled?

Only prosecutors and public defenders were asked about satisfactions with cases they handled. Again, concomitant with their respective roles, prosecutors said they felt best about getting convictions, whereas public defenders felt most satisfied when they could get their clients off with as little exposure to the system as possible.

Four of the five prosecutors said that they felt satisfied when they got a conviction. One of these said "when the defendant is convicted of the crime that represents what he actually did." Another mentioned "conviction on particularly heinous crimes." Two prosecutors said they felt good when dangerous offenders were incarcerated. The fifth prosecutor gave a more general response, saying that he was satisfied when "I've done the best I can."

The responses of the prosecutors indicated that there was a distinction between deserving and underserving offenders. Two prosecutors commented that they got satisfaction from helping deserving offenders get into alternative programs, although one remarked that usually there was little feedback from this: 
At times people just get caught up in the system, and they show remorse. When you can divert these people, it's also satisfying.

Usually there's no follow-up on what happens say to a youthful first-time offender whom you've helped get into some rehabilitative program.

Eleven of the 15 public defenders said that a not guilty verdict was extremely satisfying. Of these 11, 8 responded with this answer practically before the question could be asked. In a particularly candid response, one public defender said:

There's nothing that even compares to the feeling of a not guilty verdict from the jury. There's just no emotion in the job that compares with it. And it's truly an ego-satisfying one in the sense of exhuberance you get from it; the sense of elation is, at least speaking for myself, totally unrelated to whether the man is innocent or guilty. It is purely a matter of them against me, and I won.

In addition to a not guilty verdict, public defenders stated that dismissals, fair sentences, and keeping people out of jail/ penitentiary were all very satisfying. Ten of the defense attorneys specifically mentioned that they felt very good when they could have some affect on their client's life, e.g., helping solve a problem, get into a rehabilitative program, stay out of the system in the future. Seven public defenders talked about the satisfaction from having a creative sentencing alternative accepted by the judge.

In all of these responses, however, public defenders indicated that many of these things rarely happened, and that when they did, they were happily surprised. Some comments illustrate:

The most satisfying thing of course is the acquittal or dismissal of a factually, legally innocent client. Not a terribly frequent occurrence, but that's the most satisfying.

Actually I think the most honest answer is the few occasions when three years after the case was over, the 
defendant came back by and was doing fine, and had really made some changes. That doesn't happen too often; if that was all you had to sustain you, you'd be in trouble.

Getting positive feedback from the clients--that's satisfying, although that's not a major part of the satisfaction of the job. You can't expect a lot of gratitude from the clients.

Winning is nice, but it happens very seldom, so that's not much of a source of gratification.

I think the thing that's most rewarding for me is feeling that somebody who is not a hardened criminal gets a break a person deserves. Now whether that's by going to trial and getting a not guilty verdict--even though he may be guilty--or whether it's by entering a plea and having the good fortune of having the judge understand the point of view which you're presenting about that person--having the judge go along with that against all odds, and having this person come out of it with a second chance...

Perhaps due to the perceived infrequency of some of the most rewarding occurrences, public defenders were also inclined to state that it was very satisfying just to know that they had done as good a job as possible in representing their client, and that others (e.g., clients, attorneys, judges) gave them recognition for a job well done:

When my clients feel good about how I've handled their case. When I know I did something well and that other people see it.

Knowing that I've done all that I can do and that at least the client has been represented as well as he can expect to be represented.

When you come up with something really creative, and the judge sees that... 
Question Number Eight: How Would You Characterize the Relationship of the District Attorney's Office with the Public Defender's Office?

All three groups of respondents were asked how they would characterize the relationship between the D.A.'s and P.D.'s Offices. After their initial response, the interviewer probed by asking whether or not they thought there was cooperation between the two Offices. A further probe attempted to ascertain whether or not the respondents thought that the prosecutors and public defenders had divergent belief systems or world views which went beyond what was inherent in the adversary system.

Generally, all three groups expressed the belief that relationships between attorneys in the two offices were good, and that although there were at times conflicts between some individual attorneys, for the most part they got along quite well at the staff level. It was pointed out by many that although there was cooperation in the working relationship, cooperation was limited by the nature of the adversary roles of the attorneys. The responses to the question about belief systems were mixed, with some interviewees believing that they were similar and others believing that they were dissimilar.

Prosecutors characterized the relationship between the two Offices with such phrases as "congenial," "good rapport," and "overall quite good." One prosecutor said that the relationship was "good in that we can communicate and healthy in that we're not the best of friends," suggesting that a certain distance should be maintained due to their divergent responsibilities within the criminal 
justice system. Prosecutors' comments about cooperation were similarly qualified. One said, for example, that there was cooperation in that "we share what we're required to share," but that the adversary system was inherently not a cooperative one. Another prosecutor said that there was cooperation in the sense that both sides worked toward making the system run properly and effectively. Public defenders agreed with prosecutors that overall the relationship was good, using phrases similar to those of the prosecutors, e.g., cordial, respectful, generally pretty good. However, 12 of the 15 defense attorneys stressed that it was difficult to generalize and that relationships varied with different attorneys. Here, as in other responses, public defenders were more inclined than prosecutors or judges to take an individualistic rather than a systemic approach.

They have so many people, and they run the gamut of personalities and abilities, that it gets complicated to generalize.

There's respect for individuals on both sides, but it's selective.

It's really a matter of individual relationships as a felony attorney.

There is cooperation between individual attorneys. Eleven public defenders expressed the belief that there were strains in the relationship due to certain policies of the D.A.'s office which severely limited the freedom of staff attorneys to make their own decisions.

There's less to cooperate about because of the directives from the top it seems to me, and that is part of what the strains are. 
Deputies have very little independence, exercise very little judgment on their own, because they're not allowed to. And frequently then you find that you're dealing with some guideline, or some office policy that there's really no way for us to attack.

Particularly frustrating to public defenders were the policies which disallowed or severely limited plea negotiation. Specifically singled out by three public defenders was the Career criminal unit:

There's some strain between attorneys in our office and attorneys in the Career Criminal Unit, and it's not because some of the attorneys in our office don't like those attorneys; it's because it's very hard to deal with the way they're handling cases. They have to follow their rules.

That [working with the Career Criminal Unit] is just like beating your head against the wall. I mean they cannot negotiate the charge; they cannot give any sentence recommendation prior to sentencing; so it's just a difficult situation...

Like prosecutors, public defenders were inclined to qualify their responses to the question about cooperation:

There's not a great deal of cooperation because we do represent differing points of view. Within that framework we cooperate to the extent that we don't cause each other unnecessary trouble, and we attempt to make the system work.

We work together on an ongoing basis, and I think more than cooperation I would be inclined to describe it as familiarity. You know the kinds of things this person is likely to do or think.

Three public defenders expressed the belief that because it was an adversary system, it was not a good idea for the two sides to become too cordial. However, these same respondents also felt that it was necessary for them to have a good working relationship with the deputies in order to benefit their clients.

I think there should always be a barrier between the defense and the prosecution. I think it's dangerous-and you see this in small counties--for the D.A.'s and the defense attorneys to be all buddy-buddy. I think that 
takes away part of your fighting spirit. I try to be very pleasant to all of them, even at great strain, because I think that's part of the job.

It's extremely cordial, and at times I think perhaps too cordial . . Obviously we work together constantly, and it's necessary to benefit my client that I have a relatively good working relationship with the D.A.s and the courts because you get more play out of the system.

Judges also expressed the belief that the relationship between the two offices was good, while reiterating that nevertheless they remained adversaries. The following coments illustrate:

A lot of compatability without compromise.

I think they get along very well, although they maintain an adversary position. To the extent that there can be cooperation in an adversary procedure, yes.

Cooperative arms length relationship; thoroughly professional and in the public interest.

Seems to operate with a minimum of friction. I'm not sure the word is cooperation because they represent different parties and have different responsibilities.

Excellent; they have great respect for each other, at least this is demonstrated in court. Cooperation in the sense of complying with the law as far as adhering to their responsibilities, but never at any time diminishing or ignoring their responsibilities to their respective clients. You know, it is an adversary system.

Judges, then, strongly maintained that the relationship between the opposing attorneys conformed to the ideal adversary relationship. Only one judge even sopke of a possible problem of too much cooperation:

Sometimes there's been criticism because of this, through the idea that you have two large offices constantly doing business together and that the individual case or client could suffer.

Also, one judge specifically mentioned friction over the Career Criminal Unit: 
I'm sure there is strong feeling between them as to this idea of the Career Criminal Unit, that is, the D.A.'s flat denial to negotiate on any of certain cases; there's sharp disagreement in that area. Other than that I don't see them at odd points very often.

Seven judges remarked in their responses to this question that both Offices had very competent, able staffs, and that the legal representation was of the highest quality.

Six public defenders said they did not think there were really any major differences in world views between prosecutors and defense attorneys beyond that inherent in their adversary roles, although three of these six said that there were individual exceptions:

I think that our attitudes are very similar with the exception of some D.A.'s who say that they could never defend someone.

I think there are shared beliefs in general. I think there are some prosecutors and some defense attorneys who have widely divergent views, but there are also some defense attorneys who have widely divergent views.

Eight public defenders said that there were noticeable differences in the belief systems or world views of the prosecutors and defense attorneys, although five of these eight believed that the differences came about as a result of their respective job experiences:

You do get a mind set that fits in with what you're doing, and this is necessary to do it well.

I think it's a question of experience, and how the experience shapes your view of cases.

The comments of two public defenders suggested that public defenders saw themselves as fighting for the underdog (both of these respondents said that they could never be prosecutors):

I think maybe it's kind of the underdog mentality that we have here. You know, it's hard to be a public defender in that you never have the marbles in your pocket; you're 
always fighting an uphill battle and filing motions which you know you have a 28 chance of winning . .

I enjoy having the state on the other side of wherever I am because there is a certain anarchistic romance to that . . My ego satisfaction would not be as great if I were on the side of all the odds.

Among those public defenders who believed that there were basic

differences in world views, the comments held to a similar theme:

I think a prosecutor is more inclined to be law and order oriented, and a defense attorney is more liberal in terms of getting at what are the causes that caused this person to commit crime.

People in our office at least start out dedicated to the idea of trying to do something to help out people who really had a bad shake from the beginning; D.A.S see themselves as protecting society from criminals.

I think there is a feeling that the public defender has a more sympathetic, human point of view.

None of the prosecutors felt that there were widely divergent belief systems beyond what was inherent in the adversary system:

Generally there are shared beliefs and goals. Most of the public defenders would make good prosecutors.

There's a shared belief about criminal justice although we come at it from different sides. Both view crime as something negative; both believe that the criminal justice system ought to be administered by the rules.

One prosecutor did say that prosecutors, like judges, may tend to become more conservative over time as a result of their job experience. Another said that the nature of the public defender's job was such that a pro-client orientation was paramount, leaving little time for a concern with overall criminal justice goals. Judges agreed with prosecutors that generally the only difference in belief systems was that which was inherent in the adversary system: 
In general, no; both are comitted to the same legal system. In a specific case, of course, because they are adversaries, they do take a contrary position, a contrary point of view on the specific case.

No, I don't think it's very dramatic. There are some differences in orientation, but most could switch from one office to the other and be just as effective.

Question Number Nine: What Do You See as the Main Advantages and Disadvantages of Plea Bargaining?

All respondents were asked what they saw as the main advantages and disadvantages of plea bargaining. Probing further, the interviewer also asked them who they thought were the major beneficiaries of plea bargaining. Although there were some within-group differences, the most notable differences in opinions were between the three groups or respondents. Prosecutors were inclined to think that there were few advantages to plea bargaining, but were able to state a number of disadvantages. Public defenders, on the other hand, felt that plea bargaining was a positive and essential part of the criminal justice system, citing the individualization of justice as a major advantage. Judges generally stated that plea bargaining was an inevitable part of the present criminal justice system and that the major advantage was the reduction of court overload.

Although none of the prosecutors felt that there were any major advantages of plea bargaining, two did say that it was useful when there was a case in which a victim didn't want to have to testify at trial. Another said that in a case in which the defendant was guilty but would be difficult to convict because of loopholes in the case, it was probably "better to get him for something than nothing." A fourth said: 
If there is an advantage, I guess its expediency-unclogging of the courts. But I don't think there are any real advantages. I guess it does give us a lot of leverage to get a conviction.

The fifth prosecutor said that plea bargaining didn't really make any difference one way or the other, either in terms of court needs or in terms of the eventual outcome of the case. This prosecutor refrained from giving an opinion about the advantages or disadvantages of plea bargaining, simply stating that it was a long-time tradition which had become routinized. The four prosecutors who did express an opinion said that a major disadvantage was that plea bargaining led to dispositions which didn't really reflect reality--didn't reflect what kind of a person the defendant really was or what he or she really had done. Two said that with plea bargaining the defendant learned to manipulate the system and that thus the integrity of the system was reduced. One said that it was a waste of time, that more time was spent on negotiating than on preparing for a trial. Another said that the state gave up too much of its case. A final negative comment was that the victims usually didn't understand and were unhappy about it.

All public defenders expressed the belief that plea bargaining was a positive part of the system in that it individualized justice and gave defendants a chance of having theix exposure to the criminal justice system reduced. Four public defenders did say that sometimes the benefits for defendants were illusory in that they ended up with the same sentence that they would have without the bargain. However, it was emphasized that a reduction from a felony to a misdemeanor did have the advantage of allowing for record expungement even if the sentence was the same. 
Public defenders often referred to justice goals when citing

the advantages of plea bargaining:

-. it would be impossible to see that justice was

done if cases couldn't be individualized, if modifications couldn't be made in the law, which requires equality regardless of circumstances, situations.

I think oftentimes a more just and certain result occurs with the benefit of plea negotiation than would otherwise occur without it. I can almost liken it to any kind of arbitration in a labor union dispute or a contract dispute; you have attorneys representing the interests of whoever's involved. You negotiate, and out of that comes the best result.

The system is fine in general, but it provides very broad justice. And when it gets down to the individual, it can provide some very definite injustices. And that's where plea negotiation, along with the charging discretion of the D.A. and the judges' sentencing discretion--all of these help to humanize the system.

Twelve public defenders mentioned as an advantage that plea bargaining served functional needs in that it conserved resources and allowed for an efficient processing of a large number of cases. Four of the defense attorneys pointed out that speedy disposition was not merely an advantage for the courts but that it was also a fairness to defendants.

There was also consistency in the responses of the public defenders concerning the disadvantages of plea bargaining. Disadvantages were primarily seen in terms of injustices to the defendants that could result from a poorly or improperly administered negotiation system. Among injustices to defendants, seven public defenders said that plea bargaining could put undue pressure on defendants to plead guilty in exchange for the certainty of a reasonable disposition, even though the individual might not be guilty of the charge and/or might have a good chance of getting an acquittal or dismissal. 
It strikes me that the worst thing about negotiating is that people end up pleading to things that they didn't do and/or they plead to things that couldn't be proven.

- . the real possibility that when a person's charged with a very serious crime, and he is not guilty, but there's a lot of evidence against him, circumstantial or whatever, there's strong pressure to enter a guilty plea to a lesser charge when the D.A. offers a plea bargain.

Two noted that the plea negotiation option in this sytem was discretionary in that certain types of offenders who were charged with certain types of offenses were not given this option. Again the Career Criminal Unit was used as a primary example of such unfair discretion. Another two remarked that plea bargaining did violate due process rights by circumventing the trial process. However, most of the public defenders expressed the belief that going to trial was a difficult and trying experience for the defendant, and that it carried with it higher risks than did disposition through negotiation. One public defender pointed out that an admission of guilt and an expression of remorse with the entry of a guilty plea were valuable in obtaining a lighter sentence from the judge:

If the purpose of sentencing is rehabilitation, and you have a defendant that won't even admit that he's guilty, and he compounds that by getting on the stand and lying about his guilt, then you're more likely to treat him more severely than a person who comes and says, "I've made a mistake; I'm pleading guilty. Please deal with me leniently."

Three defense attorneys said that a potential disadvantage of plea bargaining was that it could lead to a situation in which defense attorneys tended to anticipate and accept routinized bargains without carefully considering possible defenses for individual cases: 
I think that I have perceived, especially if you have a case which you know will fall into a typical plea negotiation pattern, it will make you less apt to really search the case, and prepare the case, do the legal research ${ }_{\text {. }}$ and so discover possible defenses.

- . a potential danger is that the needs of the court system take priority and that cases would not be seen on their individual basis.

All but one of the judges talked about the advantages of plea bargaining in terms of court and criminal justice system needs. For example:

. . without it, the system would be in turmoil; it allows us to streamline the system.

It's practical; there are not enough resources to try all cases.

- . cutting down on the number of cases that go to trial. The whole criminal justice system is overcrowded.

Without it, the costs would simply be staggering.

I think it's absolutely essential in order to dispose of cases.

The one dissenting judge said that "there was a mistaken belief that the system would be bankrupted without plea bargaining." The elimination of plea bargaining, in the opinion of this judge, would increase the integrity of the system without increasing court overload because prosecutors would be forced to consider carefully the charging decision and guilty offenders would thus be likely to plead to the charge. One judge supported the contention of one of the public defenders by saying:

If a person is guilty, an acknowledgement of guilt is an essential precondition to any kind of rehabilitation. Insofar as rehabilitation is one of the goals of the criminal justice syste, it is to that extent facilitated by plea negotiation. 
The responses of the judges to the question about disadvantages of plea bargaining varied. Three said that it was misunderstood by the public, who often saw it as a way in which criminal justice goals were compromised. Four stated that a negative aspect was that the reality of the crime was not accurately reflected as a result of plea bargaining. Two believed that a potential danger was that defendants could be pressured into pleading guilty, and three mentioned the possibility of prosecutorial overcharging in anticipation of bargaining. Finally, two said that because of a bargain, offenders might be given lighter sentences than they deserve.

Of the 11 judges interviewed, 5 did not either strongly support or oppose the plea bargaining process, but rather claimed that it was essential to meet functional needs. Three did not approve of plea bargaining, and three thought that properly administered, plea bargaining was a positive component of the criminal justice system.

It can be fundamentally fair if it's structured and under the supervision of the court.

Plea negotiation carefully controlled, using recognized standards published by the prosecutor's office and available to defense counsel and closely supervised by the court is, in my judgment, a legitimate, effective and necessary component of the criminal justice system. without such controls, it would pose a serious hazard to the integrity of the system.

There must be standard, open procedures. I'm very much in favor of it; properly administered, it benefits all.

And on the other side: 
I don't like it; I'm uncomfortable with it. We should try people on what we think they're guilty of. Society and the whole judicial system suffer because of the acceptance of it.

I don't believe in it... You either stand trial or the case is dismissed. Individuals ought to be tried for what they're indicted for.

While judges agreed that the plea negotiation process should be structured and supervised by the court, no judge expressed the belief that judges ought to take part in the actual plea negotiation process. Three specifically stated (although they were not asked this question) that judges should definitely not play a role in the actual negotiation.

Responses to the question of who were the major beneficiaries of plea bargaining indicated that the way in which major beneficiaries were perceived was related to a general acceptance or rejection of plea bargaining as a positive process. Prosecutors emphasized that the defendant was either the major or sole beneficiary of plea bargaining (although one said that whether or not the defendant . actually benefited depended on individual cases). One prosecutor expressed the opinion that no one benefited. Public defenders consistently stated that everybody benefited from plea bargaining, i.e., the court system, the attorneys, the public and the defendant. Those judges in favor of plea negotiation were inclined to believe that it benefited all, and those opposed that it benefited the defendant or no one. The judges who were neutral in their assessment of plea bargaining emphasized the public as a major beneficiary due to the cost benefits for the taxpayer. 
CONCLUDING REMARKS

Data from the interviews indicated that there was overall agreement among key court actors regarding the reality of the case disposition process in this urban court system. Additionally, their responses about factors given the most consideration in disposition decisions, about what kinds of offenses were typically bargained, and about the power of the prosecutor in the bargaining exchange were consistent with the objective data. Each group of attorneys, however, perceived their own offices in a more favorable light in terms of working toward ideal goals. Judges showed some tendency to idealize the system's operations in general.

The data resulting from the conversational part of the interview offered clear evidence of the between-group variations in attitudes toward the plea bargaining process and exchange. These differences undeniably reflect the system status of prosecutors, public defenders and judges in the court system.

Judges, the group farthest removed from the actual plea negotiation process, viewed this process as a well-structured, open examination and discussion of the facts of a case. They did not talk about the existence of game plans, strategy calculations, tradeoffs, etc. in their descriptions of plea bargaining. They expressed the opinion that, ideal or not, plea negotiation was necessary to meet functional needs. They believed that the relationship between the P.D.'s and D.A.'s Offices was professional and cordial, but cooperative only within the limits of the adversary system. 
Prosecutors, on the other hand, held negative attitudes toward plea bargaining in general. They believed that plea bargaining distorted the reality of the crime (or the criminal), presenting a less negative picture than was actually the case. Like judges, they did not refer to the existence of game plans, strategy calculations or trade-offs. Also like judges, they expressed the opinion that the relationship between the two sets of attorneys was professional and friendly, but cooperative only to the extent that the rules of the adversary system allowed.

Public defenders strongly advocated case disposition through a negotiation process in which individual adversary attorneys were responsible for making decisions about individual cases. They believed that plea negotiation benefited all, and could think of few disadvantages in an open, above-board plea bargaining process in which all parties were committed to obtaining justice on an individualized basis. They believed, however, that the present policies of the D.A.'s Office left little room for individual decision-making and therefore curbed the individualization of justice. Although prosecutors were confined by a strict set of rules regarding plea negotiation, plea bargaining, in the view of public defenders, still included an element of game-playing. An example often given by the defense attorneys was that good deals were offered on cases which differed from non-reducible cases on only one variable, i.e., strength of case. Concerned about not getting a conviction, the prosecutor offered good deals on those very cases which the public defender felt stood a good chance at trial. Since public defenders felt that they had little to offer the state in 
the bargaining process, their need to calculate, anticjpate, and weighi costs and benefits to their client was continual. Public defenders indicated that at the staff level, the relationships between the two sets of attorneys was generally good. They, too, noted that cooperation was of a professional nature and that the adveraary orientation was maintained. Strains were most apparent when the public defenders worked on cases which were totally non-negotiable within D.A. policy.

The interviews, then, fulfilled the research endeavor to include the perceptions of key court actors regarding the case disposition process in the system in which they worked. The next chapter presents the findings from observations of the case disposition process in action. The two activities for which a standard set of observations were recorded were the pre-trial conference (in which plea bargaining took place) and the Chief Criminal Court hearings (in which guilty pleas were entered, accepted and sentenced). 
CHAPTER VII

\section{FELONY CASE DISPOSITION IN ACTION: OBSERVATIONS OF THE PROCESS}

\section{INTRODUCTION}

The findings from the final data source--observations of case process--are presented in this chapter. An observational methodology is obviously extremely useful in uncovering the behavioral reality of the case disposition process. Additionally, it yields information on the attitudes of the individuals participating in the process. It also allows for an assessment of the setting in which the activity takes place. Finally, by combining the observations of all these components--behaviors, attitudes and setting--the researcher is better able to form a picture of the whole.

Two of the several activities in the case disposition process were selected for standardized observations. The first was the pretrial conference, which was the formal setting for plea bargaining. This conference did appear to be the setting in which most of the plea bargaining actually (not just ideally) took place. Thus, its relevance to the research topic is paramount. The second was the plea and sentence hearings in Chief Criminal Court--the setting in which the great majority of felony cases were adjudicated. since all guilty pleas were entered and accepted or rejected in Chief Criminal Court, the relevance of this activity is also obvious. 
THE PRE-TRIAL CONFERENCE

With the agreement of the participating attorneys and the defendant, the researcher was able to observe five pre-trial conferences from beginning to end. The conferences took place in one of two locations in the courthouse. Two rooms separated from one another by a divider and located adjacent to the courtroom of the Chief Criminal Judge (the only entrance to these rooms was through the courtroom) were designated as the pre-trial conference rooms. However, since there were more scheduled conferences than could be handled by these spaces, a number of conferences took place in private offices in the D.A. Office complex. One of the observed conferences was in the former designated rooms, and four took place in the D.A. Offices. The shortest of the observed conferences took ten minutes, the longest thirty minutes. Following is a summary of the conversations carried on during the conferences.

\section{Conference 1}

Initial charge: UUV/DWS/Failure Yield Right-of-Way.

\section{Conversation summary.}

Prosecutor explained what would take place in conference.

Prosecutor presented his case.

Prosecutor and public defender exchanged police and investigative reports.

Prosecutor talked about strength of his case.

Prosecutor questioned defendant about prior record. Defendant responded about prior record.

Prosecutor talked about strength of his case. 
Prosecutor asked defendant if he had questions about the purpose of the conference. Defendant responded that he had no questions.

Public defenders asked defendant if there were witnesses. Defendant answered that there were no witnesses.

Public defender explained what would take place in conference. Public defender talked about strength of case.

Prosecutor asked defendant if he had opinion as to sentence. Defendant answered he did not.

Prosecutor asked defendant if he committed the crime. Defendant answered he was guilty of UUV.

Public defender asked defendant about prior record. Defendant responded about prior record.

Prosecutor asked defendant for information about himself. Defendant responded.

Prosecutor offered to dismiss the DwS count, but said he was hesitant to dismiss the Failure to Yield count.

Prosecutor asked defendant about employment situation. Defendant responded.

Public defender, prosecutor and defendant discussed the nature of the offense.

Public defender asked prosecutor if he would dismiss the Failure to Yield count if there were no civil problem.

Defendant said he would be willing to pay damages and that he didn't want to have to go to jail.

Prosecutor said he would dismiss Failure to Yield count if the victim would agree to this.

Prosecutor set time limit on the plea offer.

Prosecutor said sentence recommendation would be made after the pre-sentence investigation.

Public defender asked prosecutor if state would recommend misdemeanor treatment.

Prosecutor said that state would oppose immediate misdemeanor treatment. 
Public defender told prosecutor deferred misdemeanor recommendation was no bargain since this would probably occur anyway.

Prosecutor again asked defendant if he had any questions. Defendant responded he did not.

Public defender again questioned the prosecutor about sentence recommendation.

Prosecutor and public defender discussed restitution for the victim.

All participants in Conference 1 contributed to the discussion. The prosecutor spoke slightly more often (22 comments) than did the public defender (18 comments) or the defendant ( 15 comments). The prosecutor, however, directed the conversation. He opened the conference by explaining what was to take place, and he opened each new topic of conversation. Both prosecutor and public defender made statements to and asked questions of the defendant, who as a result was not excluded from the conversation. This conference took place in the D.A. Offices and lasted for fifteen minutes.

\section{Conference 2}

Initial Charge: Manslaughter II.

Conversation Summary.

Prosecutor explained what would take place in conference.

Prosecutor presented his case.

Prosecutor questioned defendant about her alcohol status at the time when the crime took place. Defendant responded with uncertainty.

Public defenter gave information about nature of the offense. Prosecutor asked defendant about prior record. Defendant responded that she had no prior record.

Prosecutor again questioned defendant about her alcohol status at the time of the crime. Defendant again responded with uncertainty. 
Prosecutor talked about strength of his case.

Prosecutor and public defender discussed strength of case.

Prosecutor and public defender exchangea police and

investigative reports.

Public defender gave prosecutor information about defendant's family.

Defendant gave prosecutor information about her family.

Prosecutor offered to reduce charge from Manslaughter II to Criminally Negligent Homicide.

Prosecutor said state would recommend confinement, but would not oppose work release.

Prosecutor and public defender explained state's offer to the defendant.

Prosecutor asked defendant for more information about the offense. Defendant gave information.

Public defender asked prosecutor about strength of his case. Prosecutor responded.

Prosecutor asked defendant if she had any questions. Defendant said she did not have questions.

Prosecutor and public defender again discussed strength of case.

Defendant commented about strength of case.

Public defender asked for further information about state's offer. Prosecutor repeated earlier statements regarding the offer.

Defendant asked about retrieving her car and its contents. Prosecutor, public defender and defendant discussed such retrieval.

Prosecutor asked defendant if she har other questions. Defendant responded that she had no other questions.

In Conference 2, the prosecutor was the most prolific speaker, making 24 comments as opposed to 14 comments by the public defender and only 7 comments by the defendant. Much of this conversation 
focused on the strength of the case. Other than asking about the retrieval of her car, the defendant's only comments were responses to questions directed to her. Again, the prosecutor opened and directed the conversation. This conference took place in the designated pre-trial conference room and lasted ten minutes.

\section{Conference 3}

Initial Charge: Burglary II.

Conversation Summary.

Public defender explained what would take place in conference. Prosecutor and public defender exchanged police and investigative reports.

Public defender made comment about strength of case.

Public defender made comment about nature of offense.

Prosecutor asked defendant about nature of offense. Defendant gave information about nature of offense.

Prosecutor questioned defendant about his residential status. Defendant gave information about residential status.

Public defender gave opinion that initial charge did not fit offense. Public defender and prosecutor discussed this issue.

Prosecutor offered sentence recommendation of immediate misdemeanor treatment.

Prosecutor set time limit (48 hours) for acceptance of the offer.

Prosecutor commented on strength of his case.

Public defender questioned strength of prosecutor's case. Prosecutor reiterated his belief that case was strong.

Prosecutor and public defender discussed time limit on offer.

Prosecutor and public defender again discussed strength of case. 
Prosecutor asked defendant about prior record. Defendant responded about prior record.

Prosecutor and public defender discussed legal issues of case.

Public defender raised issue of testing the legal issues without harming defendant.

Prosecutor and public defender discussed legal issues of case.

Conference 3 seemed to be directed more by the public defender than the prosecutor even though the number of comments was about the same ( 31 for the prosecutor and 29 for the public defender). The public defender went into this conference feeling that this was one of the few cases for which he had good bargaining leverage. He was convinced that a legal issue (the nature of the offense did not coincide with the legal description of the charge) weakened the state's case. Indeed, most of the conference centered around a discussion of this legal issue. The defendant was neither asked for or offered many comments. This conference took place in the D.A. Offices and was the longest of the five observed conferences (30 minutes).

\section{Conference 4}

Initial Charge: Burglary I.

Conversation Summary.

Prosecutor explained what would take place in conference.

Prosecutor presented his case, expressing the opinion that the defendant was lucky the charge was Burg rather than Rob.

Prosecutor and public defender exchanged police and investigative reports.

Prosecutor asked defendant about prjor record. Defendant and public defender responded about prior record. 
Prosecutor asked defendant about employment and education statuses. Defendant responded about his employment and education statuses.

Prosecutor asked defendant about his relationship with co-defendant. Defendant responded about this relationship.

Defendant expressed remorse for crime, intention not to repeat.

Prosecutor advised defendant of his right to trial.

Prosecutor commented that his decision not to charge Rob was a good deal.

Prosecutor said state would recommend one year in jail with work release and would also ask for restitution.

Prosecutor and defendant discussed victim's needs and restitution.

Defendant's mother commented on unfaimess of disparate offers for defendant and co-defendant.

Public defender gave legal explanation of disparate offers.

Defendant and defendant's mother again commented on unfairness of severity with which defendant was to be treated.

Public defender and prosecutor gave further descriptions of court processes.

Prosecutor commented that sentence recommendation was light in view of potential severity for the offense.

Prosecutor advised defendant of his right to trial.

Defendant expressed opinion that his chances at trial were slim.

Prosecutor spoke to defendant about "evils" of crime, consequences of participating in crime, and criminal justice goals.

Prosecutor said sentence recommendation might be better if pre-sentence report turned out to be favorable.

Defendant's mother asked for explanation of pre-sentence report. Public defender gave such explanation. 
Defendant gave explanations of why he participated in the crime.

Prosecutor set time limit for acceptance of the offer. Public defender commented on more favorable offer given co-defendant.

Conference 4 had a fourth participant, i.e., the defendant's mother. She provided considerable support for the defendant, possibly accounting in part for the earnest participation of the defendant in this conference. While the prosecutor opened and directed the conversation in the first part of the conference, the defendant and his mother directed the conversation in the latter half of the conference. The prosecutor was still the most prolific speaker, making 28 comments as opposed to 13 comments by the defendant and 10 comments by the public defender. This conference took place in the D.A. Offices and lasted 15 minutes.

\section{Conference 5}

Initial Charge: Theft I (nine counts)/UUV

Conversation Summary.

Public defender explained what would take place in conference.

Prosecutor asked defendant if he had questions about conference. Defendant responded he had no questions.

Public defender asked prosecutor why defendant was arrested when agreement had been made that defendant would turn himself in. Prosecutor and public defender discussed this situation, with prosecutor saying that the police had taken charge.

Public defender gave defendant explanation of the arrest. Prosecutor and public defender exchanged police and investigative reports. 
Prosecutor questioned defendant about prior record. Defendant responded with ambiguity. Prosecutor, public defender and defendant tried to clarify prior record situation.

Prosecutor and public defender again referred to police reports.

Prosecutor expressed hope that case could be settled during the conference.

Prosecutor said state willing to drop all but one count of Theft $I$ in exchange for guilty plea to Theft $I$.

Prosecutor pointed out that a great deal of money was involved in the theft.

Prosecutor expressed opinion that charges would not merge. Public defender expressed opinion that there was a good chance they would merge.

Prosecutor commented on strength of state's case.

Prosecutor questioned defendant about employment status. Defendant responded about employment status.

Public defender raised the possibility of an illegal search issue. Prosecutor expressed opinion that this was not viable issue.

Prosecutor asked how offer of PG to one count of Theft I sounded.

Public defender pointed out that defendant had no prior record for last six years. Defendant confirmed this point.

Prosecutor pointed out possibility of severe punishment if offer was not accepted. Public defender commented that defendant was concerned about this possibility.

Prosecutor commented on particular judge who would sentence.

Public defender asked about restitution recommendation, saying that defendant was not totally responsible for restitution (a co-defendant was involved).

Prosecutor expressed opinion about sentencing judge's strict view of individual responsibility. 
Prosecutor commented that state didn't have evidence to ask for total restitution of all reported missing, but that further evidence could appear making state less willing to negotiate if case had to be re-indicted.

Prosecutor reiterated offer, adding state would not object to five years probation and restitution.

Prosecutor set short time limit on offer, again pointing to possibility of re-indictment if offer were not accepted.

Prosecutor again asked what they thought of offer. Public defender said he would have to discuss it with defendant.

Public defender said offer sounded reasonable if judge would actually give probation sentence.

Prosecutor commented that if case were settled immediately, sentencing would be by less severe judge (who was about to end his turn as Chief Criminal Judge).

Public defender asked prosecutor how co-defendant's case was being handled. Prosecutor said they were waiting to see what took place there. Defendant commented about co-defendant.

As in the other conferences, the prosecutor made the most comments (40) in Conference 5 , followed by the public defender (17 comments) and then by the defendant ( 7 comments). Again, the prosecutor directed the course of the conversation. The public defender, however, did point to several possible weaknesses in the state's case. The defendant's comments were responses to direct questions. In this conference, anticipation of sentence was a prime topic of conversation. In particular, the sentencing judge appeared to be used as a leverage to encourage acceptance of the plea offer (it appeared that the judge who was about to leave the position of Chief Criminal Judge was considered a less severe sentencer than the judge who was about to assume the role of Chief 
Criminal Judge). In addition, the prosecutor used the possibility of re-indictment as a reason why the defense should accept the present offer. This conference took place in the D.A. Offices and lasted 25 minutes.

\section{Concluding Remarks}

Although it was recognized that the very small number of observed conferences made it unwise to offer unequivocal conclusions about the pre-trial conference in general in this jurisdiction, there was no reason to suspect that the conferences observed were not typical of the conferences in general. What these observations did suggest was that the pre-trial conference was (1) routinized in terms of procedure; (2) an open exchange of the facts of the case; (3) an exchange of strategic moves with each side trying to get the best bargain possible; (4) prosecutor-dominated. The routinized procedure began with an explanation to the defendant of the conference and was usually followed by the prosecutor presenting his or her case against the defendant. At some point in the first part of the conference, the prosecutor and public defender exchanged police and investigative reports. Also at various points, the prosecutor directed questions to the defendant regarding the nature of the offense and the nature of the defendant. All defendants were questioned about their prior record. The prosecutor then explained what offers the state would make in exchange for a guilty plea. In all cases observed, an assumption of guilt was standard. Defendants were told that nothing they said in the pre-trial conference could be used against them at any other point in the disposition process. 
While an admission of guilt was thus a protected piece of information, it would seem to give the prosecutor additional leverage. None of the defendants in the observed cases denied that they had been involved in the criminal incident in some way. The question, then, centered around what would be done with the accused offender, with the public defender arguing for the least severe punishment possible. Many of the comments of the public defenders were either (a) questions to the prosecutor regarding strength of case or the plea offer or (b) explanations and clarifications to the defendant. The public defender, however, was not completely without bargaining leverage. In most cases, he or she was able to point to weaknesses in the state's case. In Conference 3, where the public defender felt that he had a strong legal issue in his client's favor, the public defender played an aggressive role in the conference and was more inclined to direct the course of the conversation than in the other conferences. While the defendant was not excluded from the conversation, his or her input was minor in comparison to that of the attorneys.

The researcher was struck throughout the observations by the business-like but almost jovial attitude of the attorneys as the atmosphere for the conference was set. The attorneys initially greeted one another; the defendant was then introduced to the prosecutor if they had not met before, and the defendant was referred to as Mr. or Mrs. ------. Pleasantries were likely to be exchanged, and notes of humor were injected by the attorneys. The conference was explained as though it were to be a business 
transaction in which the three people were going to take care of a routine pending matter. The severity of the situation remained in the background. Such an atmosphere might be introduced by the attorneys in order to attempt to put the defendant at ease. But the defendants did not seem to be at ease and were certainly not "lighthearted." Many appeared to be confused as to what demeanor they should take. They were in the presence of authority figures who had a great deal of power in determining their fate, and yet they were being treated initially as one of three individuals who were going to sit down and mutually decide a matter to the satisfaction of all. As the conference proceeded, however, it became clear that this was not really the situation. The definitive statements of the prosecutor as the conference progressed, indicated that the defendant's fate was not going to be mutually decided to the satisfaction of all.

\section{HEARINGS IN CHIEF CRIMINAL COJRT}

For the judge sitting on the bench in Chief criminal Court the work day is best described as continually busy. Beginning at 9:30 each morning, the judge must make decisions throughout the day which may drastically affect the lives of a number of individuals. Although the number of cases on the daily docket varied, two or three dozen cases were usually heard each day. Since the daily docket was so large, time was of the essence. Most cases were presented and concluded within five minutes. No observed cases were in front of the bench for more than fifteen minutes, and some were settled in two or three minutes. The judge in Chief criminal Court 
was not hearing trials. Rather he was hearing guilty pleas, and making judgments on a variety of other kinds of hearings (e.g., parole or probation revocation, bail or recognizance requests, change of attorney requests, motions for setovers).

Since the majority of cases were settled by guilty pleas, Chief Criminal Judge had the major responsibility for accepting these pleas and sentencing the defendant. Over a two month period, the researcher sat in the spectator section of Chief Criminal court and recorded observations of this part of the court process. Twenty-five cases were recorded in detail (the entire conversation was written down as it took place). While most of the observed cases were either the hearing or sentencing of guilty pleas, a few arraignments and other hearings were also observed.

Defendants who had decided to plead guilty filled out a petition to enter a guilty plea which had to be accepted by the judge of Chief Criminal court. The first business of the judge hearing the guilty plea was to ask the defendant if he or she had read and understood the petition. The judge might or might not question the defendant further about an understanding of the meaning of pleading guilty, e.g., that the right to trial had been waived, that an admissison of guilt had been made. The judge then accepted or rejected the guilty plea (in only one observed case did the judge reject the guilty plea). If the defendant was pleading guilty to a misdemeanor, he or she could either waive postponement of sentence and be sentenced on the spot or ask for a separate sentencing date. In all observed cases, the defendant asked to be sentenced immediately. 
The judge then informed the defendant of his or her right to appeal the sentence and the right to have a court-appointed attorney for such an appeal should he or she be indigent. If the defendant was pleading guilty to a felony, a pre-sentence investigation was required by law prior to sentencing. Such an investigation was taking, at the time of the research, from four to six weeks. Following are some typical examples of the daily business in Chief Criminal Court.

Case 1

The prosecutor introduced the case: defendant was initially charged with CAID but had agreed to plead guilty to Att CAID.

The judge questioned the defendant about pleading guilty and advised him of his rights. The judge accepted the plea and granted immediate misdemeanor treatment.

The defense attorney (a public defender) told the judge that the defendant was very young (had just turned 18), and that although he didn't have a job at present, he was seriously looking for employment. The actual offense, reported the attorney, involved the existence of a marijuana plant in the defendant's garden. The plant was not being cultivated.

The prosecutor told the judge that the defendant had an extensive juvenile record, but that he had no record of drug offenses.

The judge asked the defendant why he didn't go back to school.

The defendant responded that he had been thinking of going to the local community college.

The judge said that he thought that this would be a good idea, telling the defendant that "you're going to have to learn to do something sometime. You have to be able to support yourself." 
The defendant waived sentence postponement and was sentenced to three years on probation.

The hearing was completed in four minutes.

Case 2

The prosecutor introduced the case: defendant was initially charged with one count of Assault II and one count of Criminal Mischief II but had agreed to plead guilty to one count of Assault IV.

The judge questioned the defendant about pleading guilty and advised him of his rights. The judge accepted the plea.

The defense attorney (a public defender) told the judge that the defendant was 23 years old, that he was presently employed, and that he had no prior record. The attorney also told the judge that the crime was a result of a lovers' quarrel and that the defendant and the complainant were Iiving together at the time of the crime. Since arrested, the defendant had been kept by court order from the shared residence and thus had been without his personal possessions.

The judge asked the defendant if he had anything to say.

The defendant responded that it was a lovers' quarrel, and that he had hit the complainant with his hand-not with a weapon as the complainant had reported. The defendant pointed out that the complainant showed no evidence of any injury inflicted with a weapon.

The judge said to the defendant:

If that's the way you love someone, I'd sure hate to have you mad at me. Let me give you some advice; never fight with a woman. If you win, you're a bully. If she whips you, you're a bum.

The judge paused, then continued with:

You had an argument with the person you love so you belted her (comment followed by the judge's disapproving head shake). 
The defendant waived sentence postponement and was sentenced to two years on probation.

The hearing was closed in six minutes.

\section{Case 3}

The prosecutor introduced the case: defendant was initially charged with Forg $I$ and had agreed to plead no contest to Forg I.

The judge questioned the defendant about his understanding of the no contest plea and advised him of his rights. The judge accepted the plea.

The judge asked the prosecutor for the state's position on sentencing.

The prosecutor responded that the state recommended immediate misdemeanor treatment, probation and restitution.

The judge told the defense attorney (a public defender) that he was prepared to accept the state's recommendation and thus the attorney need not say anything on his client's behalf.

The defendant waived sentence postponement and was sentenced to two years on probation and restitution of the amount received through the forgery (\$55).

The judge asked the defendant if he had the money to pay the restitution.

The defendant responded that he had just been laid off his job and that he had to go and see about getting his job back.

The judge asked the defendant how much he made on this job. The respondent responded. After considering the defendant's salary, the judge told the defendant that he had two months to pay the restitution. The judge added that if the defendant couldn't pay back the money in this time, he was to inform the court.

The hearing was completed in six minutes. 
The prosecutor introduced the case: defendant was initially charged with two counts of CAID, but had agreed to plead guilty to one count of Criminal Drug Promotion.

The prosecutor said that the state took no position on sentencing.

The judge questioned the defendant about pleading guilty and advised her of her rights.

The defense attorney (court-appointed from the private bar) told the judge that this was the defendant's first contact with the criminal justice system. He added that the offense occurred through her involvement with a boyfriend who was presently an ex-boyfriend. The defendant, continued the attorney, was living with her parents. She was presently being treated for injuries resulting from a recent automobile accident. The attorney told the judge that this experience had been an awakening for the defendant, and that, in his opinion, she wouldn't be back (re-involved in crime).

The judge asked the defendant if she had anything to say.

The defendant responded that she had learned her lesson and that she was not involved in drugs. She also said that she had epilepsy, for which she was presently under treatment.

The judge told the defendant that he understood that treatment for the epilepsy was necessary, but that that other stuff (street drugs) was not going to help her.

The defendant waived sentence postponement and was sentenced to two years on probation. The judge told the defendant that probation involved no rules which were too difficult to keep.

The judge advised the defendant not to "get messed up in something like this again."

The hearing was completed in five minutes.

The prosecutor introduced the case: defendant was initially charged with Burg I and had agreed to plead guilty to Burg I. 
The judge questioned the defendant about pleading guilty and advised him of his rights. The judge accepted the plea.

The judge informed the defendant that since the plea was to a felony, a pre-sentence investigation which would take from four to five weeks was necessary.

The judge asked if the defendant was presently out on his own recognizance and was informed that he was.

The judge asked if this was the defendant's first time in the criminal justice system and was informed that it was.

The defense attorney (a public defender) told the judge that the defendant had been a reliable, trustworthy client.

The judge asked about the defendant's living situation and was informed that the defendant was living with his brother, who had said that he would be responsible for him.

The judge asked about the defendant's employment status and was informed that the defendant was working with his brother, but that he was going to start a new job recycling tires.

The judge stated that he would continue the recog release until sentencing.

The hearing was completed in three minutes.

\section{Case 6}

The prosecutor introduced the case: defendant had been initially charged with two counts of Theft $I$ and had agreed to plead guilty to one count of Theft $I$.

The prosecutor said that the state would not oppose probation.

The judge questioned the defendant about pleading guilty and advised him of his rights. The judge accepted the plea.

The defense attorney (court-appointed from the private bar) told the judge that the defendant was recently married and had a young child. The attorney added that the defendant had been looking for a job, that he had found a 
job as a cook which he could have, but that he hadn't decided whether to take this job or to keep looking for a better one.

The judge pointed out that the defendant originally had two theft counts listed and asked the defendant if he was sure he only got $\$ 25$ from the thefts. The defendant responded that he only got $\$ 25$.

The defendant waived sentence postponement and was sentenced to three years on probation, the only condition being that the defendant get employment. The judge advised the defendant to "take the job that you were offered."

The defendant asked the judge where he should go to check in for probation. The judge responded that his attorney would tell him what to do.

The hearing was completed in five minutes.

\section{Case 7}

The prosecutor introduced the case: defendant had been initially charged with Rape I but had agreed to plead guilty to Attempted Rape I.

The judge questioned the defendant about pleading guilty and advised him of his rights. The judge accepted the plea.

The judge informed the defendant that since the plea was to a felony, a pre-sentence investigation which would take from four to five weeks was necessary.

The judge said that he was rescinding bail release and that the defendant was to be in jail custody pending sentencing.

The defense attorney (privately retained) expressed the belief that this was a good case for pre-sentence release. The attorney added that the psychological report on the defendant was good, and that the defendant had held a job for 11 years.

The judge reiterated his decision to have the defendant held in pre-sentence custody.

The hearing was completed in four minutes. 


\section{Case 8}

The prosecutor introduced the case: defendant had been initially charged with Burg I and had agreed to plead guilty to Burg I.

The judge questioned the defendant about pleading guilty and advised him of his rights. The judge accepted the plea.

The judge informed the defendant that since the plea was to a felony, a pre-sentence investigation which would take from four to five weeks was necessary.

The judge asked the defendant if he would be able to retain his position in the military police under the circumstances.

The defendant informed the judge that he was still in and that he thought they would let him stay in. He added, however, that he realized that this would depend on what happened at sentencing.

The judge asked the defendant about the length of his enlistment, and the defendant responded that it was a three year enlistment.

The judge advised the defendant to tell his commanding officer that he would be contacted during the pre-sentence investigation.

The hearing was completed in four minutes.

The prosecutor introduced the case: defendant had been initially charged with CAID (possession of over an ounce of marijuana) but had agreed to plead guilty to CAID (possession of less than an ounce of marijuana).

The judge questioned the defendant about pleading guilty and advised him of his rights. The judge accepted the plea.

The defense attorney (privately retained) explained to the judge that the defendant was stopped for a traffic violation at which time his car was searched and the marijuana found. The attorney added that the defendant had not put the marijuana in the car but was aware that it was there. The defendant, reported the attorney, was employed, but had just begun his job and therefore a fine would be a hariship on him. 
The defendant waived sentence postponement. The judge suspended the imposition of sentence and ordered the defendant to pay his attorney, saying:

You pay your lawyer. A man who retains and pays his attorney is not all bad. When you pay your attorney, stop and remember that you were lucky to get out of what is a serious charge.

The hearing was completed in five minutes.

Case 10

The prosecutor introduced the case: defendant had plead quilty to Attempted CAID but had not been granted misdemeanor status. The pre-sentence investigation had been completed, and this hearing was for sentencing.

The prosecutor told the judge that the state recommended deferred misdemeanor status, three years on probation, and a $\$ 200$ fine.

The judge informed the defendant of his post-sentence rights.

The defense attorney (a public defender) asked the judge for immediate misdemeanor treatment. He reported that the defendant had a minimal prior record (one theft in 1975). He explained that the defendant was found with a small amount of cocaine, which was obviously for personal use. The defendant, according to the attorney, was not a drug pusher or anything like that. The defendant was presently living with his aunt and uncle and was working for his uncle. These relatives were considering a move to another state and would like to be able to take the defendant with them.

The judge asked the defendant if he had anything to say, and the defendant responded that he did not.

The judge stated that he was not going to treat the case as a misdemeanor at that time. If the defendant successfully completed a three year probation sentence, misdemeanor status would then be granted.

The judge asked the defendant if he would agree to a waiver of his fourth amendment rights as a condition of probation. The defendant responded that he would agree to this condition, adding: 
You can search me anytime, every day, because I've quit using drugs. Drugs are no good; they've caused me a lot of trouble. $I$ ' $m$ off them completely.

The judge responded:

I'm glad to hear that. I want to help insure that this is true. That's the reason for the waiver of the right not to be searched. You're not a bad guy, not a bad record. But listen to this (judge read a statement written by the defendant admitting to the use of a variety of drugs). I just want you to quit.

The hearing was completed in six minutes.

\section{Concluding Remarks}

All of the preceding cases were heard by one judge. While the researcher did sit in on a few hearings and trials heard by other judges, standardized recordings were not made of these observations. One impression, however, was that there were definite variations in the style in which judges addressed the defendants. The Chief Criminal Judge presiding over the example cases was comparatively informal in his approach to the defendants. He often gave the defendants advice about how to behave; he was at times stern in his reprimands and admonishments; yet his manner with the defendants was extremely personalized. There was no question, however, regarding his authority status. The judge was the "boss" (a standard observation of all court processes in which any judge was involved), and he was deferred to by everyone in the courtroom. His dominant position was expected and accepted by all (defendants, attorneys, other court personnel, and the judge himself), for it is the judge who makes the ultimate decisjon on the outcome of the case. 
The findings from the observations of guilty plea hearings and sentencings indicated that this part of the court process was routinized and swift. Although a certain amount of time and effort had been spent on each case prior to these hearings (e.g., preliminary hearings, investigative reports, pre-trial conferences), the final decisions of the judge to accept or reject guilty pleas and to sentence the guilty were made within a few minutes. As several judges stated in the interviews, efficiency needs severely limit the time and effort they can put into any one case. Guilty pleas were rarely rejected by the judge; it was apparently assumed in most cases that the issue of guilt had been satisfactorily decided by the defendant and attorneys. Defendant characteristics, e.g., prior record, age, employment, family ties, residential status, were used by attorneys to influence the judge's sentencing decision. Although these variables appeared to influence sentencing and thus to some extent individualize justice, it was quite apparent that there was a fair amount of routinization in the way in which individual judges related defendant profiles to sentencing. Attorneys must learn the particular relationships which particular judges make.

In general, then, the observations of guilty plea and sentencing hearings supported prior research contentions (Blumberg, 1967) that the great majority of criminal cases in the American system are subjected to assembly-line justice. In the court system under study, however, although ultimate decisions were made routinely and swiftly, the formal structure did provide some 
mechanisms which mitigated the assembly-line picture of the final steps in the disposition process. The mandated pre-trial conference and pre-sentence investigation were two such mechanisms. This chapter on the findings from observations of felony case dispositions in action concludes the presentations of the data collected for this research project. In the final chapter, the findings from all data sources are used to construct a model of felony case disposition without trial in one urban court system. 
CHAPTER VIII

\section{FELONY CASE DISPOSITION THROUGH NEGOTIATION:}

A MODEL OF ONE URBAN COURT SYSTEM

At the beginning of this study, the research problem was delineated in the form of four propositions and eight exploratory areas. The ultimate goal was to present a model of the social reality of case disposition without trial in one urban court system which could be analyzed in terms of its theoretical relevance as well as its relationship to previous studies.

It was anticipated that the findings would yield support for the four propositions in a very general way. However, exploration was deemed necessary to determine the specific nature of case disposition without trial in the court system under study. In regard to the propositions, exploration included an examination of

(a) the way in which bargains were related to punishment reduction;

(b) the way in which case disposition through negotiation was routinized; (c) the way in which the negotiation process involved cooperation among key court actors; (d) the way in which the negutiation process provided for the needs of key court actors. Additionally, an examination was made of relationships between the formal and informal organization, the behaviors and beliefs within the organization, and functional needs and ideal goals. Finally, policy changes in the District Attorney's Office of the 
court system under study provided an opportunity for the examination of the effects of attempts to limit plea bargaining.

The above areas, then, set the framework for the development of the analytical model which follows.

NEGOTIATING THE GUILTY PLEA AS THE DOMINANT METHOD OF CASE SETTLEMENT

Both the Criminal Court population and sample statistics indicated that the great majority of cases which resulted in formal charges were settled by guilty pleas. Of those cases which ended in convictions, over 80 percent were settled by guilty pleas. Of guilty plea dispositions, about 70 percent involved bargains in the form of charge reduction or charge/count dismissal. Data from the Public Defender files indicated that a third type of bargain, i.e., agreement not to file on other known charges, was also quite common. Sentence recommendations--an integral part of the formal bargaining procedure--were made in the overwhelming majority of guilty plea dispositions. The plea bargaining process was given formal recognition both in the policy and procedural rules of the court system. A pre-trial conference in which the facts of a case were to be mutually examined and negotiations were to take place was mandatory for all felony cases. The interviewed public defenders agreed that it was very important to them that their clients get some kind of a bargain in exchange for a guilty plea. The evidence, then, strongly supported the argument that negotiating for a guilty plea was the dominant method of case settlement in the court system under study. 


\section{ROUTINIZATION THROUGH FORMALIZATION}

The plea negotiation process was given open and formal recognition by the court system as was specified in state procedural law and in the policy manual of the District Attorney's Office. The policy of the District Attorney's Office, which restricted bargaining on certain offenses (and was more restrictive than statutory policy), dominated the decision-making process. The formal delineation of both the procedures for the exchange and the substance of bargains might account for the fact that an informal bargaining process separate from the formal process was not indicated by the data. As would be expected in any organization, individual exchanges between opposing attorneys regarding a given case suggested attitudinal differences from those expressed in formal policy. However, the negotiation outcome usually followed the dictates of the District Attorney's office policy. If an exception was to be made (and exceptions were given formal recognition in the policy manual), it required the approval of top-level staff in the D.A.'s office. The Public Defender's Office had no formal plea bargaining policy; however, the defense attorneys were compelled to negotiate within the confines of the District Attorney's policy. The formal and adhered-to policy also contributed to the fact that the key actors in the bargaining process were extremely familiar with the negotiation process. Public defenders indicated that they usually knew, after an initial look at an assigned case, whether or not it was a bargainable case, and that they were more likely than not to know what the substance of the bargain would be. 
Observations of the pre-trial conference indicated that the negotiation process was highly routinized in terms of procedure. The procedure did include a mutual examination of police and other investigative reports regarding the case. The conference also included a bargaining format in which the prosecutor and defense attorneys attempted to negotiate with one another to get the best deal for their respective sides. Generally, however, it was the prosecutor who dominated the conference--questioning the defendant about himself/herself and about the offense, and describing the state's offer should the defendant be willing to plead guilty. The offer, decided in advance by the prosecutor, appeared not to be modified much as a result of the conference.

\section{CONTAINED COOPERATION WITHIN AN ADVERSARY FRAMEWORK}

The social reality of plea bargaining in this court system was notable in its emphasis on formalization, rigidity and restriction. Formalization reduced the need for key actors to cooperate in the development of an informal system to guide the negotiation process. Rigidity also inhibited the responsibility of key actors for decisionmaking. Restrictions on bargaining reduced the power of the defense attorney in the exchange relationship. In addition, both the formal structure and the philosophies of the District Attorney's Office and the Public Defender's Office were at odds. The D.A.'s office was characterized by hierarchy, specialization and equality of justice. The P. D.'s Office was characterized by lack of hierarchy, generalization and individualization of justice. A careful analysis 
of the findings, however, indicated that the negotiation process operated quite smoothly, with the prosecutors and public defenders behaviorally cooperating and complying with the system. On the other hand, a commitment to the ideal adversary roles was supported by the findings from the observations of and interviews with prosecutors and public defenders. It is the author's contention that certain features of the court system under study encouraged a disposition process characterized by functional cooperation within an adversary framework.

While formalization of the negotiation process did reduce the need for key actors to cooperate in the development of an informal system, it also enhanced functional cooperation by (a) allowing the attorney to focus on the effectiveness rather than the efficiency of the system and (b) providing the attorneys with a clear understanding of the process. The formalized structure of the negotiation process provided in great part for the efficiency need of the system. Indeed, attorneys agreed that a consideration of efficiency needs was built into the formalized structure and that they shared with the opposing attorneys a commitment to the effectiveness of the overall system. Additionally, they reported a clear understanding of the process and expressed the belief that the formal process coincided with the informal process.

Although generally formalized and rigidified, the negotiation process with its mandatory conference did allow for active participation of the attorneys. Data from interviews and observations indicated that in handling a given case, attorneys were necessarily 
involved in a process of mapping out strategies, anticipating actions and attitudes of the opposing sides, and calculating the strengths and weaknesses of both sides in terms of potential bargains. However, the nature of the D.A.'s policy left but one across-the-board negotiable commodity--the strength of case factor. The D.A.'s policy, which outlined which offenses were bargainable as well as the substance of the bargain permissible for different offenses, forced the defense attorney to turn to the legal issues of the case in search of a commodity with bargaining power. In turn, the prosecutor was also attentive to the strength of case factor. This focus on legal issues also strengthened the attorneys' commitment to their professional roles as legal representatives of their respective clients. Observations of the pre-trial conferences supported this emphasis on the strength of case factor. Also, attorneys agreed in the interviews that strength of case was of primary importance in deciding how to handle a given case. The other two factors which were consistently reported as important in bargaining decisions were the policy of the District Attorney's Office and the seriousness of the offense, both of which were based on a legalistic referent. Finally, when asked what their main role or responsibility was, both sets of attorneys consistently referred to their professional role as legal representatives of their respective clients, i.e., the state and the defendant.

A further example of this legalistic framework was found in the data on the nature of charge reduction bargains. Charge reductions were overwhelmingly made to lower levels of the initial 
charge. Although statutory law in the state declared that charge reductions need be only "reasonably related" to the original charge, in fact most reduced charges were necessarily included in the original charge.

The findings from this study, then, led to the conclusion that prosecutors and public defenders in this felony court maintained the adversary roles and that cooperation existed only within the limits of the adversary system. The attorneys did interact frequently in their professional capacities; they knew one another and had formed certain opinions about each other which made anticipation of exchanges more certain. However, an awareness that they represented different sides was reflected in a certain distance and lack of spontaneity observed in their interactions. Interactions among public defenders and among prosecutors appeared to be much more casual and personal. Certain factors facilitated this separateness: prosecutors and public defenders maintained offices in different buildings; technically the Public Defender's Office was independent of the public court system; plea negotiation interactions were formally structured; bargaining focused on legalistic factors. While both sets of attorneys believed that they had a commitment to see that the adjudication process worked within the law, they recognized that the immediate interests of the opposing sides were at odds. Prosecutors worked toward convictions, and public defenders worked toward limiting the exposure of their clients in terms of punishment. 
BENEFITS AND COSTS IN THE EXCHANGE PROCESS

The findings from this research suggested that the plea negotiation process was prosecutor-dominated. Throughout the case disposition process, the balance of power was highly in favor of the prosecutor. The prosecutor had command of the charging decision as well as the bargain offer. The rigidity of the District Attorney's bargaining policies left the public defender with little leverage in the bargaining process. Prosecutors could and did respond to public defenders' counter offers simply by referring to policy restrictions. Beyond formal policy, prosecutors had other bargaining comodities. For example, if the defense did not accept an offer, they could threaten re-indictment on a new charge uncovered by subsequent investigation; they might also rescind an offer if the defense would not accept it within a certain time period (possibly a day or two). The only real baragining power of the public defender came when he or she was able to find a legal loophole in the prosecutor's case. Prosecutors, however, were aware of the importance of settling the majority of cases by guilty pleas. In all observed conferences, the prosecutor made some kind of an offer with at least a suggestion that the potential severity of the sentence coula be reduced. However, because maximum sentences were uncommon, some bargain offers did not actually benefit the defendant. Nevertheless, in that the data indicated a positive relationship between sentence recommendation and actual sentence, the prosecutor's sentence recommendation was another commodity reflecting his or her power. Although all groups indicated agreement with the 
statement that "the prosecutor has the upper hand in the plea negotiation process," public defenders were the most adamant in their agreement with this statement. This is to be expected, as it is the defense attorneys (and of course their clients) who bear the brunt of this power imbalance.

Public defenders expressed the belief that getting convictions was the major concern of the District Attorney's Office. Indeed, prosecutors interviewed said that one of their major goals was to convict the guilty. This appeared to present a definite dilemma for the public defenders. A common lament of the public defenders was that when the prosecutor had a weak case, he or she was more likely to offer the defendant an extremely "good deal." The defense attorney, while seeing a good chance of getting a not guilty verdict should the case go to trial, had to weigh the risks of going to trial against the good deal offered by the prosecutor. In these cases, the responsibilities of the public defender proved incompatible. On the one hand, he or she felt it was his or her duty to subject a weak case to a legal test through a trial; on the other hand, it was also his or her duty to settle the case with the most favorable outcome for the client. The other side of the coin was that on very strong cases, the prosecutor was not, according to public defenders, likely to offer any bargain of substance. Without some benefit, the public defender was not anxious to see his or her client enter a guilty plea. Thus, in the words of one public defender, "we end up going to trial on the losers." Indeed, the risks of going to trial are high; only a very small number of 
defendants were acquitted at trial. In addition, the sentencing of offenders convicted at trial was harsher than of those who were convicted by guilty pleas.

From the preceding discussions, it appears that the exchange process provides rewards for the prosecutor but not for the defense attorney. Yet there were compensations for the defense attorney. The pressure to "win" was not so great due to the perceived (and actual) power imbalance. Also, the public defenders got satisfaction from small achievements, i.e., obtaining benefits for their clients short of acquittal, since they were accomplished in spite of perceived adversity. Public defenders expressed the greatest dissatisfaction with the prosecutors' Career Criminal Unit, as cases placed in this unit were generally not open for any kind of bargaining. Finally, the public defenders' commitment to and belief in the importance of their adversary role provided them with a source of satisfaction. The fact that they were a part of the system--that they were there providing legal counsel to poor defendants who were up against the state--was seen as an essential safeguard against dishonesty and injustice developing in the system.

Thus, the freedom to bargain and at least have a chance to obtain some benefit for their client which explicitly or implicitly involved punishment reduction was functional in terms of meeting the needs of public defense attorneys. Fortified by a belief in the importance of their role and a recognition that they were "fighting for the underdog" as well as fighting from an underdog position, the public defenders appeared to be able to accept the inequality of the exchange relationship as long as some exchange was at least possible. 
PERCEPTIONS OF KEY COJRT ACTORS: AGREEMENT AND DISAGREEMENT REGARDING THE SOCIAL REALITY OF THE DISPOSITION PROCESS

Overall, prosecutors, public defenders and judges agreed that the reality of case disposition through negotiation coincided with the formally-outlined process. The informal and formal structure and procedures were seen as consistent. Regarding the nature of bargains, all groups of actors agreed that generally the policy of the District Attorney's Office was in fact followed. Specifically, all agreed that the strength of case factor was very important in deciding how to handle a given case (this factor was also stated as important in the policy manual of the District Attorney's Office). However, whereas prosecutors tended to limit their descriptions of important factors to those included in formal policy, public defenders were likely to refer additionally to strategical game plans required in the decision-making process. Compared to the prosecutors and public defenders, judges tended to be slightly more idealistic in their assessments of important factors in the attorney's decision regarding the handling of a case.

Prosecutors expressed the opinion that the charging decision was generally not problematic for them, as it was delineated quite specifically in substantive law. It was mentioned, however, that a charging decision could be problematic on cases in which the mental state of the defendant was questionable. The observational data indicated that more discretion was used by prosecutors in the charging decision than the interviewees suggested. For example, a decision to charge a defendant with one of several degrees of Burglary, 
or a decision to charge Burglary rather than a more serious Robbery or less serious Criminal Trespass required discretion. The impression of the observer was that these decisions were based in large part on the prosecutor's perception of the strength of the case. Generally, interviewees did not believe that overcharging was a common activity in this court system.

Moreso than public defenders, prosecutors and judges were inclined to think that standard charge reductions did not exist in this court system. However, all respondents did believe that standard reductions were more common for Drug cases (particularly marijuana possession) and for non-premeditated Assaults and Homicides than for other offenses. Also, it was suggested that Homicides resulting from traffic accidents were commonly reduced from Manslaughter to Criminally Negligent Homicide. The statistical data were consistent with these opinions about common charge reductions. The relationship between the prosecutors and public defenders was generally characterized by all groups of respondents as amicable, professional and cooperative within role restraints. The relationship between attorneys at the staff level was often described as better than between the Offices per se. Respondents in all groups did point out that there were occasions of conflicts and tensions between particular individual attorneys. Public defenders expressed some dissatisfaction with the structure and policies of the District Attorney's office. They believed that the D.A.'s Office was structured in a way that limited the decision-making responsibility of the staff prosecutors. Policies intended to curb plea bargaining 
were viewed by the public defenders as particularly destructive to the working relationship of the offices and the attorneys within them. The interviewees supported the contention that prosecutors and public defenders worked toward settling cases in a functionally cooperative manner while maintaining an adversary perspective.

PERCEPTIONS OF KEY COURT ACTORS REGARDING PLEA BARGAINING AND SYSTEM NEEDS AND GOALS

Public defenders believed that plea bargaining satisfied system needs and advanced the achievement of ideal goals. They suggested that everybody--defendants, attorneys, the court, and the public--benefited from above-board plea negotiation. Defendants benefited by having their cases settled in an individualized manner and by having the severity of punishment reduced. Perceiving individualized justice as an ideal goal of the system, public defenders viewed plea negotiation as furthering the justice goal. Prosecutors benefited by getting convictions, and public defenders benefited by being able to reduce the exposure of their clients to the criminal justice system. Both sets of attorneys benefited from active participation in the case disposition process. The public defenders expressed the belief that restrictions on plea bargaining implemented by the District Attorney's Office limited the extent to which the attorneys could play an active role in case disposition and reduced the decision-making responsibility on a case by case basis. The major disadvantage of plea bargaining, in the opinion of the public defenders, had to do with possible injustices to the defendant should the process not be properly 
administered. For example, plea bargaining could put pressure on a defendant to plead guilty even though he or she was not guilty or was unsure of his or her guilt. Several public defenders also mentioned the potential danger of a situation in which defense attorneys began thinking in terms of routinized bargains rather than possible defenses for the client. Overall, however, public defenders were inclined to think that the advantages of properly administered plea bargaining outweighed the potential disadvantages. Prosecutors, on the other hand, were considerably less inclined to view plea bargaining in a positive light. None of those prosecutors interviewed felt that there were any major advantages to plea bargaining. They expressed the opinion that plea bargaining worked against criminal justice goals in that cases were compromised, and dispositions did not reflect the reality of what the defendant had actually done. Prosecutors did suggest that plea bargaining could be useful for getting a conviction on a case in which a victim had been traumatically involved and felt unable to testify. It should be noted that the five prosecutors interviewed represented only a small proportion of the prosecutorial staff. In addition, they were all top-level deputies and therefore close to the policymaking process. Since current policy in the District Attorney's Office was aimed at limiting plea bargaining, it might be expected that these prosecutors would take a negative view of the bargaining concept.

Overall, judges tended to take a more neutral position on plea bargaining than did public defenders or prosecutors. Most 
judges believed that it was a necessary part of the system in that it did meet functional court needs for efficient production. They also emphasized that it provided benefits for the taxpayer. While there was high within-group agreement among both prosecutors and public defenders regarding the advantages and disadvantages of plea bargaining, the responses of judges varied considerably. Some judges believed that properly-administered plea bargaining did not work against the achievement of ideal goals and could be beneficial to all involved. Others were more inclined to share the opinion of prosecutors that plea bargaining resulted in an inaccurate picture of what the defendant had actually done and thus worked against the achievement of justice and crime control. These findings, then, further indicated that prosecutors and public defenders were not a single-minded body reflecting shared views as a result of their shared membership in the public court organization. Since their definitions of justice were at odds (with prosecutors emphasizing equality and public defenders emphasizing individualization), their opinions regarding whether or not plea bargaining worked toward the achievement of ideal goals were also at odds. Also, each set of attorneys was inclined to think that their own offices gave greater consideration to the achievement of ideal goals and less consideration to functional needs. Judges, on the other hand, chose to emphasize their belief that plea bargaining did attend to functional court needs, thus eschewing the issue of ideal goals. 
PLEA NEGOTIATION AND EFFICIENT PRODUCTION

The data strongly supported the contention that case disposition through guilty pleas advances efficient production within the court system. The findings further suggested that efficient production is an essential requirement for the stability and viability of the court system. Finally, the case disposition process had been formally structured in this court system with an eye toward meeting the efficient production need.

The data on total disposition time indicated that disposition by trial was unequivocably the most time-consuming of all closing types. While straight guilty plea closings had the highest proportion of cases settled within 30 days, very few bargained or non-bargained guilty plea cases took over 60 days. Although closing with a straight guilty plea might be slightly more efficient than closing with a bargained guilty plea, the findings also suggested that on cases in which bargaining was prohibited from the outset, the likelihood of going to trial was greater. For example, of the non-negotiable Career Criminal cases settled in 1977,60 percent were closed by trial. Also, while charge reductions were effectively curbed on certain offenses in 1977, these same offenses showed an increase in the proportion of trial closings from 1976 to 1977 . However, overall proportions of closing types showed little variation (with only a very slight increase in trials) prior and subsequent to the institution of policies which rigidified and expanded the "curb plea bargaining" position. A balancing factor appeared to be at work according to the data on cases closed following the policy 
changes in 1977. Whereas charge bargaining decreased for the nonreducible offenses, it increased for a number of offenses not included in the non-reducible category. Similarly, while trials increased for the non-reducible offenses, they decreased for other offenses. Thus, overall stability in terms of the proportion of guilty plea dispositions to trial dispositions was maintained.

The case disposition process was formally structured to promote efficient production. The newly-instituted Speedy Trial Act which requires that barring unusual circumstances, cases must be settled within 60 days or dismissed appeared to be effective. Between 1976 and 1977, there was a significant decrease in the number of cases which took over 60 days to settle. Likewise, the number of setovers decreased from 1976 to 1977. Additionally, the formalization of plea bargaining, i.e., the designation of a time and place for a negotiation conference, as well as a statement of produces and guidelines, removed the responsibility for organizing the negotiation process from the attorneys. The formalized system was highly routinized in terms of procedure and substance.

The negotiation conferences were notably brief (those observed took less than a half hour to complete). Guilty plea hearings and sentencings were even briefer (few took over five minutes to complete). Large numbers of cases (both in terms of absolute numbers and in terms of the ratio of cases to attorneys and judges) were run through the felony court system on a daily basis. The need to move along quickly was compelling due to the rapid timing of events (attorneys often had several negotiation conferences and 
several plea or sentence hearings in one day). Functional cooperation between the key actors in the process was obviously essential for the completion of tasks within time constraints. The above description certainly fits the picture of assembly line justice set forth in previous research on the American court process in large organizations. However, in the court system under study, case disposition was formally and carefully structured to include both a consideration of functional needs and ideal goals. Emphasizing a legalistic framework, disposition without trial in this court system appeared to be judicially proper in comparison with characterizations of assembly line processes in other court systems.

\section{PLEA NEGOTIATION AND IDEAL GOALS}

An assessment of the way in which disposition through negotiation does or does not work toward the achievement of the larger criminal justice system goals of crime of crime control, protection of the public and maintenance of rule by law was not possible from the present research findings. However, key court actors interviewed did express a commitment to these larger goals. The way in which disposition through negotiation works toward the achievement of justice and due process (ideal goals of both the overall system and the court subsystem) could be assessed on the basis of the present research.

A common criticism of disposition by guilty plea (with or without negotiation) is that it violates the due process rights of the defendant. One such right is the right to presumed 
innocence until guilt has been proven. Indeed, the findings from this study supported the contention that an assumption of guilt precluded the settlement process. All interviewed prosecutors and judges expressed the opinion that over 80 percent of accused felons were guilty either of the formal charge or of some related charge. Twelve of the fifteen interviewed public defenders also agreed with the over 80 percent figure. Generally, the issue at hand in the pre-trial conferences was punishment rather than guilt/innocence. Additionally, several interviewees stated that guilty plea convictions were functional in a rehabilitative sense in that an admission of guilt on the part of the offender was an essential initial step toward rehabilitation.

Another criticism of disposition by negotiation is that defendants may be coerced into forfeiting rights to presumed innocence, to trial, to face accusers and to not self-incriminate by the offering of reduced punishment for pleading guilty and by the threat of severe punishment for not pleading guilty. The present research did not uncover any incidences of formal or explicit coercion aimed at getting defendants to plead guilty. At the beginning of each guilty plea hearing, the juage asked for written and verbal assurances from the defendant that he or she (a) was pleading guilty willingly and without coercion and (b) understood the consequences of the guilty plea. Additionally, all bargains regarding the charge were presented to the defendant and the court in written form. Sentence recommendations (also presented in writing) were not, the judge informed the defendant, binding on 
the court, and if the defendant had been led to believe otherwise, he or she could retract the guilty plea. These formal safeguards, however, cannot insure against implicit coercion. An admission of guilt as well as a description of the defendant's involvement in the offense was sought (and often received) in the pre-trial conference. While such admissions and descriptions could not be used should the defendant decide to go to trial, the very fact that the attorneys who would be trying the case had this information was likely to be perceived by the defendant as working against his or her chances at trial. In fact, the risks of going to trial were indeed high for the defendant. An extremely small percentage of cases (4 percent) ended in trial acquittal. Also, according to the defense attorneys, the ordeal of trial was a perceived and real concern of defendants when making a plea decision. Finally, statistics showed that sentencing was more severe following trial convictions than guilty plea convictions. According to public defenders, inducements in the form of "good deals" were offered by prosecutors when the state's case was weak; thus, rewards for pleading guilty were increased when the risk of trial was decreased. On the other hand, the emphasis placed by the public defender on his or her role as a legal representative of the defendant did appear to be an important safeguard in terms of the rights of the accused to a fair and just disposition process. While admittedly the guilty plea disposition requires that the defendant surrender some due process rights, the public defender system in this county appeared to work toward the preservation of defendants' rights which were not circumvented by the inherent nature of the guilty plea disposition. 
Whether or not a given case disposition process works toward the achievement of justice depends initially on one's definition of justice. The present research uncovered differences in the meaning of justice from the perspectives of prosecutors versus public defenders. Prosecutors tended to believe justice was being achieved when guilty offenders were convicted of the same offense with which they were charged and when similarly-charged offenders were given equal treatment. Public defenders, on the other hand, emphasized the importance of individualizing justice through a consideration of all aspects of a given case. Public defenders maintained that similarly-charged offenders were not necessarily deserving of equal treatment. In line with their respective roles, prosecutors held to a hard line on punishing offenders in the interests of justice for the state, whereas public defenders believed that severe punishment was often unjust in view of mitigating circumstances. There was also a tendency toward a prosecutorial view of punishment severity as facilitating crime control and a defense view of the reduction of punishment severity as facilitating crime control. Regarding charge and bargain decisions, the data indicated that the prosecutorial position of equal treatment was favored. That is, charges appeared to be made based upon the legal facts of the case, and bargains appeared to be offered in accordance with the offense classification scheme set up by the Office of the District Attorney. Characteristics of the offender, e.g., age, sex, employment, education, did not appear to be influential in the prosecutors' charging and bargaining decisions. On the other hand, one could 
argue (as public defenders often did) that the classification of offenses as negotiable, non-reducible or non-negotiable in any way was arbitrary and therefore unjust. The classification scheme was not based on seriousness of offense (some Class $C$ felonies were nonreducible and some Class $\mathrm{A}$ felonies were fully negotiable). A distinction was made between Property offenses and Crimes against the Person, all of the latter being fully negotiable. The most arbitrary, however, was the Career Criminal classification which was not based either on the nature of the offense or the seriousness of the offense. The single shared characteristic of cases placed in this category was the recidivism of the defendant. All of these cases were non-negotiable. The overall result of the classification scheme was that defendants charged with Crimes against the Person or Drug offenses were those most likely to be offered the chance to plead guilty to a lesser charge. In fact, the majority of charge reduction pleas were in the Crimes against Person or Drug offense categories. An additional influential factor in the decision to offer or not offer a bargain was, according to the interview and observational data, the strength of the state's case. Thus, unequal treatment of similarly-charged offenders could result from the state's perception of the strength of the case.

The data on sentencing indicated that punishment decision, relative to charge and bargain decisions, reflect a concern with the individualization of justice. While type offense and type closing were related to sentencing severity, characteristics of offenders were also influential factors. 
Overall, punishment was less severe than its legal potential. Only about half of those convicted received an incarceration sentence in either 1976 or 1977. Additionally, a large proportion of those initially charged with a felony plead guilty to a misdemeanor. Convictions on Homicides, Kidnaps, Robbery I, Escape and Ex-Con in Possession of Firearm had the highest proportions of incarceration sentences. In contrast, those convicted of reducible Drug and Property offenses were the least likely to receive incarceration sentences. While the above findings indicated that sentence severity was related to seriousness of offense, other findings indicated that this relationship was not clear-cut. First, changes in sentence severity for certain offenses occurred between 1976 and the latter half of 1977. Incarceration sentences for Burg I convictions ( a Class A felony), while common in both years, decreased in 1977. On the other hand, incarceration for Theft I and Forg I convictions (both Class C felonies) increased considerably in 1977. All three of these offenses were Impact offenses classified as non-reducible, the governing policies of which were strengthened as of June, 1977. Still another difference occurred for CAID convictions (a Class B felony); while the number of incarceration sentences for CAID was not high in either year, the incarceration percentage decreased considerably in 1977.

Second, the findings showed a clear relationship between type closing and sentencing. The great majority of those defendants who plead guilty to a lesser charge were not incarcerated upon sentencing. 
Pleading guilty to a lesser plus having counts and/or charges dismissed was the next most advantageous closing in terms of the likelihood of incarceration. There was almost no variation in the proportion of straight guilty pleas and guilty pleas to the original charge with a dismissal of counts and/or charges which resulted in incarceration sentences. Both of the above were less advantageous than either PGTL or PGTL + Dis, but were more advantageous than conviction by trial, the latter having the highest proportion of incarcerations of all closing types. Since the offenses which were most likely to close with PG + Dis were not the offenses with high likelihood of incarceration, it appeared that $P G+D i s$ was not a good bargain in terms of sentencing. Being charged with multiple counts--whether or not they were dismissed-worked against the defendant at the time of sentencing. The relationship between type closing and sentencing was examined controlling on four offense types--Burg I, Forg I, Theft I and CAID. The findings from this examination showed the same patterns described above; additionally, these statistics offered evidence that a relationship existed between type closing and sentencing independent of offense type.

Finally, the statistical data offered some support for interview and observation findings that characteristics of defendants were influential variables in sentencing. Having a prior felony record worked against a convicted offender in terms of sentence leniency. There were also indications that offenders who were older, female, undereducated and unemployed were at a disadvantage in terms of light sentencing. 


\section{A RE-EVALUATION OF THE THEORETICAL FRAMEWORK AND THE PROPOSITIONS RESULTING FROM THAT FRAMEWORK}

The theoretical framework on which the present study was based was functional in nature. It was suggested that the court be viewed as a formal organization dedicated to the achievement of ideal criminal justice goals and to the achievement of functional needs to maintain organizational stability and viability. The argument was that case disposition through a routinized and cooperative process of obtaining guilty pleas worked toward the satisfaction of the functional need for efficient production while allowing for a consideration of ideal goals. Exchange theory was used to explain the ways in which negotiating for the guilty plea contributed to the stability and viability of the court organization by attending to the needs of key court actors involved in the disposition process.

Based on this theoretical framework as well as previous research, four general propositions were set forth. The findings from this study unequivocably supported the first two propositions, which read as follows:

PROPOSITION I.

The majority of felony cases which result in formal charges are settled by guilty pleas, and the majority of guilty plea dispositions are the result of some kind of bargain which explicitly or implicitly involves punishment reduction. 
PROPOSITION II.

Case disposition through negotiation is routinized, i.e., there are identifiable patterns both in the substance of the bargain and in the procedures for the exchange which are known to and accepted by key court actors.

The model which emerged from the research offered a picture of a court organization in which case disposition through negotiation for guilty pleas was the dominant method of case settlement, was formally structured, routininzed and well-known to key court actors. The data indicated that case disposition without trial met the efficiency needs of the court system and thus helped maintain the stability and viability of the functional organization. Key court actors generally agreed that settlement prior to trial worked toward the achievement of efficiency needs of the court. Further support for the argument that settling the great majority of cases through guilty pleas is necessary for efficient production came from a comparison of percentages of closing types in 1976 and 1977. Although trials increased for certain offenses on which bargaining was more severely restricted in 1977, trials decreased for other offenses in 1977. Thus, overall the trial versus non-trial rates remained stable in both years.

Based upon the theoretical assumption that cooperation of key actors was necessary for organizational stability and on prior research which suggested that case disposition through negotiation promoted cooperation between key actors, Proposition III was constructed as follows: 
PROPOSITION III.

Key actors in the negotiation process, the prosecutor and the defense attorney, work in cooperation with one another and interact frequently.

The findings from the present study called for some modification of this proposition. The negotiation process in this court system was characterized by formalization both procedurally and substantively. The mandatory pre-trial negotiation conference--with a designated time and setting--removed the need for attorneys to cooperate in constructing an informal system. It also limited the need for frequent interaction of attorneys beyond that which was formalized (although this one formalized interaction was mandatory for every felony case). The rapid timing of events also reduced the possibility for attorneys to engage in informal negotiation exchanges on any one case. Other factors helped maintain the adversary as opposed to the cooperative nature of the attorneys' relationship. Relevant factors appeared to be: the structural independence of the office of the Public Defender; the differences in both the structure and philosophy of the Offices of the District Attorney and the Public Defender; the rigidity and restrictiveness of the plea negotiation policies of the District Attorney's office; the emphasis on legal factors in the bargaining exchange. The data indicated that prosecutors and public defenders shared an attitudinal commitment to the adversary system which was generally reflected in their behaviors. While dissatisfactions were expressed by all groups of key actors with certain aspects of the case disposition process, all expressed a commitment 
to the efficient and effective operation of the overall system. Compliance was facilitated by this commitment, but also appeared to be facilitated by a commitment to the adversary system.

Case disposition through negotiation, then, was carried out in formalized interactions between attorneys in an atmosphere of contained cooperation, with attorneys perceiving themselves as representing opposing sides while working toward a shared goal of case resolution. Although professional cooperation between prosecutors and public defenders existed, the adversary framework remained intact.

The research findings also showed some support but some need for modification of the fourth proposition:

PROPOSITION IV.

The negotiation process provides for the needs of key actors to be active participants, to work toward ideal goals, and to receive rewards for their work.

The data indicated that an open exchange process in which the key court actors were allowed to be active participants helped provide for the actors' needs. Public defenders expressed the greatest dissatisfaction with the handling of cases designated by the District Attorney's Office as non-negotiable. Although the prosecutorial bargaining policies were rigid, public defenders continually searched cases for some commodity (usually a legal factor) which would give them the power to be active participants in the negotiation process.

Another theoretical assumption was that the negotiation provided rewards both for the prosecutor and the defense attorney 
through an exchange in which benefits and costs were not zero-sum. However, the findings from this study indicated that the balance of power in the exchange process was highly-tipped in favor of the prosecutor. Although public defenders reported that it was important to them that their clients receive some benefit in exchange for a guilty plea, benefits were not always easy to come by. One result of this dilema was that public defenders tended to broaden the definition of benefits. Small gains and achievements, perceived as accomplished in spite of adversity, provided satisfaction. Also, public defenders gained satisfaction from their belief that they were playing an essential role as legal representatives of defendants in need of public aid. Fighting for the underdog from an underdog position can provide psychological rewards regardless of the outcome. While they stated that the "ultimate" in rewards was winning an acquittal, public defenders gained satisfaction from winning any benefit for their client through the negotiation process. Although a failure to achieve benefits was mitigated by their role and system perceptions, a chance to achieve benefits through negotiation worked toward the achievement of public defenders' needs.

A final theoretical assumption was that the routinized process of case disposition through negotiation would allow key actors to consider ideal criminal justice goals as they worked toward case settlement. The data did indeed indicate that the case disposition process allowed court actors to work toward ideal goals. However, prosecutors and public defenders had different perceptions of the 
ideal goals and thus different perceptions of the impact of plea bargaining on ideal goals. In line with prosecutorial policy aimed at curbing plea bargaining, prosecutors were not inclined to view plea negotiation as working toward justice or crime control. Justice was perceived by prosecutors as treating similarly-charged defendants equally and convicting the guilty as they were charged. Additionally, they believed that crime control was undermined by allowing defendants to "cop a plea." Thus, they believed that the policies of their Office (which were in fact adhered to in bargaining decisions) to restrict and equalize bargaining offers worked toward ideal goals. Public defenders, on the other hand, generally believed that plea negotiation advanced ideal goals by allowing for individualized justice and offering deserving defendants a chance at sentence leniency. Bargaining policies which closed off active decisionmaking on a case-by-case basis and which used only type offense and strength of case as bases for bargaining decisions were seen by public defenders as working against the justice goal.

The findings from the present research generally supported the theoretical argument that case disposition without trial attends to the functional needs of the court while allowing for a consideration of ideal goals. Negotiating for the guilty plea, however, appears to be more functional in meeting defense attorney than prosecutor needs. However, if the public defender can get no benefits for his or her client in exchange for the guilty plea, his dissatisfaction may work against the prosecutors' need to get convictions in an efficient manner. Thus, professional cooperation is necessary. 


\section{PREVIOUS RESEARCH AND THE PRESENT STUDY: \\ A COMPARISON OF FINDINGS}

The research findings from the present study supported some findings from previous research on case disposition through negotiation. However, there were findings which refuted some of the claims of other researchers. In this section, these similarities and differences are discussed.

Data from the present study were consistent with previous studies in which it was found that plea bargaining is the dominant method of criminal case disposition in American court systems. The present research also supported previous studies which found that the strength of case factor was extremely influential in determining the way in which a case would be handled (McIntyre, 1967; Alshuler, 1968; Mulkey, 1974). Seriousness of the offense was also found in this study and others (Mulkey, 1974) to be an influential factor in the negotiation process. The suggestion that plea bargaining is prosecutor-dominated (Newman, 1956; Mulkey, 1974; Neubauer, 1974) was also strongly supported by this research. While a highly-routinized plea negotiation process was indicated by the present research, some findings differed from those previous studies regarding the nature of the routinized process. Obviously, plea bargaining is structured differently in different court systems. While the present findings cannot be generalized beyond the court system under study, the data did suggest that as plea bargaining gains formal status and open. recognition, it may undergo certain changes. 
In this court system, the plea negotiation process was given formal recognition. Plea negotiation in reality deviated very little from formal procedure and policy. In addition, plea bargaining did not appear to conflict with substantive law. The findings of Sudnow indicating that offenses were often reduced to lesser crimes which were not necessarily or situationally included in the initial charge were not supported in the present study. Sudnow suggested that social rather than statutory referents were used when deciding what a given case would be reduced to. In the present study, the majority of charge reductions were found to be to lower levels of the initial offense. Although statutory law in the state declared that charge reductions need be only "reasonably related" to the original charge, in fact most reduced charges were necessarily included in the original charge.

The present research did support the contention of other researchers (Heumann, 1975; Rosett and Cressey, 1976) that the plea neogtiators were likely to assume some guilt at the outset, and that thus their focal concern was on the punishment issue. Thus, when the state's case was strong and the punishment not severe (Mather's dead-bang cases), disposition by guilty plea was common. However, defnese attorneys interviewed in this study indicated that it was important to them that their client receive some kind of benefit in exchange for a guilty plea. In fact, the number of trials increased for those offenses which became nonreducible in 1977. Although the majoirty of these offenses were still settled by guilty pleas, it does appear that the likelihood of trial increases when defendants are offered no benefits in 
exchange for guilty pleas. The fact that offenses placed in the non-reducible category in 1977 showed an increase in dispositions with other kinds of bargains over the previous year suggested that prosecutors were aware that some bargain offer may be helpful in obtaining a guilty plea.

The data provided some support for previous research indicating that court actors perceived of plea bargaining as fulfilling the efficiency needs of the court (Mulkey, 1974; Rosett and Cressey, 1976). However, this court system was so-structured that efficiency needs were provided for within the formal structure. Thus, it appeared that the court actors themselves felt less pressured to consider efficiency needs in the day-to-day handling of cases. Prosecutors, working in line with office policies to curb plea bargaining, were less inclined than suggested by previous research to believe that plea bargaining was essential to the stability and viability of the court system.

Previous research indicates that there are conflicting opinions regarding the extent to which plea bargaining serves ideal criminal justice goals (Neubauer, 1974). In the present study, conflicting opinions were found regarding this issue between prosecutors and public defenders. Public defenders believed (similar to the conclusions of Rosett and Cressey) that plea bargaining helped achieve justice on an individualized basis by allowing for a personalized :approach to the treatment of offenders. On the other hand, prosecutors believed that plea bargaining distorted the reality of the crime and thus worked against criminal justice goals. 
Attributes of the offender have been suggested to be important in charge, plea and bargain decisions (Newman, 1956; Sudnow, 1965). In the present study, offender characteristics, e.g., prior record, sex, age, education, employment, were not strongly related to whether or not a case was closed.with a bargained plea. However, defendant characteristics did appear to be influential in the type of sentence recommendation as well as in the actual sentence. Being a repeater, over age 21, under-educated, and unemployed seemed to work against a defendant in terms of sentence severity. In previous research it has been suggested that plea bargaining works against the ideal adversary concept of forcing opposing attorneys to work as cooperative members of the same formal organization (Sudnow, 1965; Blumberg, 1967; Rosett and Cressey, 1976). In the present study, both an attitudinal and a behavioral commitment to the adversary system were indicated. While the need for a good working relationship was recognized, the attorneys in the study maintained their adversary roles. Again, the fact that the negotiation process was formalized in this court system (with a required time and setting designated for exchanges) reduced the need for attorneys to engage in informal exchanges outside of the formal structure. Additionally, the adherence of prosecutors to formal office policy inhibited the growth of prosecutor/defense attorney relationships in which cases were handled on a personal level. Overall, then, the formal structure of plea negotiation in this court system facilitated the maintenance of the adversary system. 
The role of the judge in the plea negotiation process has also been researched by social scientists. In his study, Church (1976) found that when bargains on the charge were not allowed, bargains on punishment occurred in which the judge became a focal actor in the exchange process. Others have suggested that the judge must necessarily cooperate with attorneys if the guilty plea system is to work (Cole, 1970; Rosett and Cressey, 1976). In the court system under study, the judge was not a participant in the actual negotiation of guilty pleas on felony cases. In addition, formal policy was adhered to by the judge in his statement to the defendant that sentence recommendations are not binding on the court. If a defendant plead guilty because he/she was led to believe that he/she would be given a certain sentence in exchange for a guilty plea, he/she was informed of the right to rescind this plea. However, the data strongly indicated a positive relationship between sentence recommendations and actual sentences. Attorneys expressed the opinion that certain judges were more likely than others to follow the sentence recommendations of the District Attorney's Office, and thus the tendencies of individual judges were considered by attorneys in planning their prosecution and defense strategies (all respondent groups believed that tendencies of judges were more important to defense attorneys than to prosecutors). Yet, overall, the data did indicate that the judges tended to go along with the state's recommendations for punishment more often than not. The present study has been primarily exploratory in nature. The findings were consistent with theory and with previous research in many major areas. However, some findings suggested a need for 
theoretical modification and for further research to clarify inconsistencies between the present study and previous literature. In the concluding section, suggestions for further research are offered.

\section{SUGGESTIONS FOR FUTURE RESEARCH}

The researcher believes that a court system in which the plea negotiation process is given formal recognition and formal structure operates differently than one in which participants must develop informal processes for disposition by negotiation. Since it is only recently that plea bargaining has been given formal status, the need for further studies of court systems in which plea bargaining has been formally structured is imperative in order to assess the generalizability of the findings from the present study. Of particular interest would be comparisons of court systems in which the informal process conformed to the formal process (as was the case in this study) with court systems in which the informal process deviated from the formal process.

Another research problem which calls for further study has to do with the unsettled question of the cooperative versus adversary models of the plea negotiation process. This study suggested that the adversary system can be maintained within a case disposition process in which negotiation plays a dominant role. On the other hand, several defense attorneys interviewed in this study warned of the danger that, over time, a negotiated guilty plea system may lead to a reduction in the adversary concerns of the 
opposing attorneys. Over-time studies of the same court system would be useful to assess this possibility.

Further information is also needed on the way in which changes in bargaining policies produce changes in (a) the substance of bargains and (b) the outcome of bargains. The policy of the District Attorney's Office in the present study was aimed at reducing (and for certain offenses eliminating) charge reduction bargaining. The data indicated that this policy has been effective. However, a negotiation conference was mandatory for all felony cases, and most often the state offered something in exchange for a guilty plea. An increase in other kinds of bargains, e.g., count dismissals, agreements not to file--was concomitant with a decrease in charge reduction bargains. However, agreements to dismiss counts and/or not file on other known charges did not appear to be good bargains in terms of sentencing. A follow-up study on the actual time served by defendants whose cases were settled with different kinds of bargains would shed some further light on the extent to which various bargains resulted in actual punishment reduction. Although difficult to assess, an important research question concerns the way in which the plea negotiation process does or does not work toward the achievement of ideal criminal justice goals. In this study, prosecutors and defense attorneys expressed conflicting opinions regarding this question. In part, this appeared to be due to their respective roles, in which emphases were placed on different aspects of criminal justice. A case study approach to this research question would be useful in order to obtain objective information on plea negotiation and criminal justice goals. 
The present study began with a broad format, attempting to examine a number of specific research questions along with presenting a model of the total field of study. It is the researcher's opinion that one of the major contributions of this kind of study is in its empirically-based suggestions for future research. Through this exploration of a relatively new field of study, the researcher has identified patterns which might be usefully subjected to refined testing. 
REFERENCES

Alschuler, Albert 1968. "The Prosecutor's Role in Plea Bargaining," The University of Chicago Law Review, 36, pp. 50-112.

Banton, Michael 1964. The Policeman in the Community, New York: Basic Books.

Barber, Bernard 1973. "Research on Research on Human Subjects: Problems of Access to a Powerful Profession," Social Problems, 21 (Summer), pp. 103-112.

Becker, Howard S. 1970. Sociological Work: Method and Substance. Chicago: Aldine Publishing Co.

Blalock, Hubert M. 1970. An Introduction to Social Research, Englewood Cliffs, N.J.: Prentice-Hall.

Blumberg, Abraham S. 1967. "The Practice of Law as Confidence Game: Organizational Cooptation of a Profession," Law and Society Review, 15, pp. 15-39.

Cavan, Sherri 1966. Iiquor License: An Ethnography of Bar Behavior, Chicago: Aldine Publishing Co.

1972. Hippies of the Haight, St. Louis: New Critics Press.

Chambliss, William and Robert Seidman 1971. Law, Order and Power, Reading, Mass.: Addison-Wesley Publishing Co.

Chiricos, Theodore G. and Gordon P. Waldo 1970. "Punishment and Crime: An Examination of Some Empirical Evidence," Social Problems, 18 (Fall), pp. 200-217.

Church, Thomas 1976. "Plea Bargains, Concessions and the Courts: Analysis of a Quasi-Experiment," Law and Society Review, $10: 3$ (Spring), pp. 377-401.

Cole, George F. 1970. "The Decision to Prosecute," Law and Society Review, 4 (February), pp. 331-334.

Deutscher, Irwin 1966. "Words and Deeds: Social Science and Social Policy," Social Problems, 13 (Winter), pp. 235-254. 
Douglas, Jack D. 1976. Investigative Social Research: Individual and Team Field Research, Beverly Hills: Sage Publications.

Etzioni, Amitai 1961. A Comparative Analysis of Complex Organizations: On Power, Involvement, and Their Correlates, New York: The Free Press.

Feeley, Malcolm M. 1973. "Two Models of the Criminal Justice System: An Organizational Perspective," Law and Society Review, 7, pp. 407-424.

Gans, Herbert 1962. Urban Villagers, New York: The Free Press.

Gibbons, Don C. 1977. Society, Crime, and Criminal Careers: An Introduction to Criminology, 3rd ed., Englewood Cliffs, N.J.: Prentice-Hall.

Glaser, Barney G. and Anselm Strauss 1967. The Discovery of Grounded Theory, Chicago: Aldine Publishing Co.

Glazer, Myron 1972. The Research Adventure: Promise and Problems of Field Work, New York: Random House.

Gouldner, Alvin w. 1960. "The Norm of Reciprocity: A Preliminary Statement," American Sociological Review, 25 (April), pp. 170.

Heumann, Milton 1975. "A Note on Plea Bargaining and Case Pressure," Law and Society Review, 9, pp. 515-528.

Johnson, John M. 1975 Doing Field Research, New York: The Free Press.

Kaplan, Abraham 1964. The Conduct of Inquiry: Methodology for Behavioral Science, Scranton, Penn.: Chandler Publishing co.

LaPiere, Richard T. 1934. "Attitudes vs. Actions," Social Forces, 13 (March), pp. 230-237.

Mannheim, Karl 1952. Essays on the Sociology of Knowledge, New York: Oxford University Press.

March, James G. and Herbert A. Simon 1958. "The Theory of Organizational Equilibrium," from March and Simon, eds., Organizations, New York: Wiley, pp. 77-86.

Mather, Lynn 1973. "Some Determinants of the Method of Case Disposition: Decision-Making by Public Defenders in Los Angeles, Law and Society Review, 8, pp. 187-216.

Matza, David 1961. Becoming Deviant, Englewood Cliffs, N.J.: Prentice-Hall. 
McIntyre, Donald M. 1968. "A Study of the Judicial Dominance of the Charging Process," Journal of Criminal Law, Criminology and Police Science, 59 (December), pp. 463-490.

Merton, Robert K. 1957. "Bureaucratic Structure and Personality," from Merton, R. K., Social Theory and Social Structure, New York: Macmillan Co.

Merton, Robert K. and Patricia L. Kendall 1946. "The Focused Interview," American Journal of Sociology, 59 (May), pp. 541-557.

Mulkey, Michael E. 1974. "The Role of the Prosecution and Defense in Plea Bargaining," Policy Studies Journal, 54:3, pp. $54-60$.

Nash, Manning 1966. Primitive and Peasant Economic Systems, San Francisco: Chandler Publishing Co.

Neubauer, David W. 1974. Criminal Justice in Middle America, Morristown, N.J.: General Learning Press.

Newman, Donald J. 1956. "Pleading Guilty for Considerations: A Study of Bargain Justice," Journal of Criminal Law, Criminology and Police Science, 46, pp. 780-790.

1966. Conviction: The Determination of Guilt or Innocence Without Trial, Boston: Little, Brown and Co.

Olson, Sheldon R. 1976. Ideas and Data: The Process and Practice of Social Research, Homewood, Ill.: Dorsey Press.

Parsons, Talcott 1956. "Suggestions for a Sociological Approach to Theory of Organizations," Administrative Science Quarterly, 1, pp. 63-85.

President's Commission on Law Enforcement and Administration of Justice 1968. The Challenge of Crime in a Free Society, New York: Avon Books.

Quinney, Richard 1975. Criminology: Analysis and Critique of Crime in America, Boston: Little, Brown and Co.

Reiss, Albert J. 1968. "Stuff and Nonsense About Social Surveys and Observation," from Becker, Howard S. et al., eds., Institutions and the Person, Chicago: Aldine Publishing Co., pp. 351-367.

Rosett, Arthur and Donald R. Cressey 1976. Justice by Consent: Plea Bargains in the American Courthouse, New York: J. B. Lippincott. 
Rovner-Pieczenik, Roberta 1976. "Another Kind of Education: Researching Urban Justice," from Golden, Patricia, ed., The Research Experience, Itasca, Ill.: F. E. Peacock Publishers, pp. 465-473.

Samuels, Frank G. 1976. The Negro Tavern: A Microcosm of Slum Life, San Francisco: $R$ and $E$ Research Associates.

Sanders, William B. (ed.) 1974. The Sociologist as Detective: An Introduction to Research Methods, New York: Praeger Publishers.

Seeley, John R. 1961. "We Hidden Persuaders: Social Thought and Politics," an address to the National Federation of Canadian University Students, McMaster University, mimeographed.

Selznick, Philip 1948. "Foundations of the Theory of Organization," American Sociological Review, 13, pp. 25-35.

Skolnick, Jerome H. 1966. Justice Without Trial, New York: John Wiley \& Sons.

1967. "Social Control in the Adversary System," Journal of Conflict Resolution, 11:1 (March, pp. 52-70.

Subin, H. G. 1966. Criminal Justice in a Metropolitan Court, Washington: U.S. Government Printing Office.

Sudnow, David 1965. "Normal Crimes: Sociological Features of the Penal Code in a Public Defender Office," Social Problems, 12 (Winter), pp. 255-276.

Webb, Eugene J., Donald T. Campbell, Richard D. Schwartz, Lee Sechrest 1971. Unobtrusive Measures: Nonreactive Research in the Social Sciences, 2nd ed., Chicago: Rand McNally and Co.

Wicker, Allan W. 1969. "Attitudes Versus Actions: The Relationship of Verbal and Overt Behavioral Responses to Attitude Objects," Journal of Social Issues, 25:4, pp. 41-79.

Wilson, James Q. 1968. Varieties of Police Behavior, Cambridge, Mass.: Harvard University Press.

Wiseman, Jacqueline P. 1970. Stations of the Lost: The Treatment of Skid Row Alcoholics, Englewood Cliffs, N.J.: Prentice-Hall.

Wiseman, Jacqueline and Marcia S. Aron 1970. Field Projects for Sociology Students, Cambridge, Mass.: Schenkman Publishing Co. 
APPENDIX A

COMMENTS ON THE FIELD RESEARCH MODEL

Previous discussions of the field research model and the specific methodology for this study (see Chapter II) indicated that this type of research was no small undertaking. It is not surprising, therefore, that a number of criticisms have been leveled against this methodological model. In this appendix, criticisms are confronted, and advantages of the field research methodology for this kind of study are discussed.

MULTIPLE TECHNIQUES FOR DATA COLLECTION

The use of multiple techniques of data collection furthers the field research goal of examining the totality of the field of study. In the present study, in which formal and informal attitudes and activities were examined, different techniques were required to retrieve different kinds of information. Also, by using independent measures, both validity and reliability are strengthened. The comments of two methodologists are appropriate:

Once a proposition has been confirmed by two or more independent measurement processes, the certainty of its interpretation is greatly reduced. The most persuasive evidence comes through a triangulation of measurement processes. If a proposition can survive the onslaught of a series of imperfect measures, with all their irrelevant error, confidence should be placed in it (Webb, 1971: 3). 
In short, the very large number of observations and kinds of data an observer can collect, and the resulting possibility of experimenting with a variety of procedures for collecting them, means that his final conclusions can be tested more often and in more ways than is common in other forms (Becker, 1970: 52).

The use of the data sources selected for the present study has been common in other similar studies. Sudnow used observations, interviews and case records to examine the way in which cases were judged to be typical of given classes of offenses and treated in routinized ways based upon theix typicality or normalcy (Sudnow, 1965). Rovner-Pieczenik used these same sources to uncover the way in which ielony cases were adjudicated in an urban court by a labeling process which regularized the adjudication process (Rovner-Pieczenik, 1976). Several other studies used observations, interviews and case records to identify and analyze important factors in decisions to charge, plea and bargain (Cole, 1970; Mather, 1973; Neubauer, 1974).

Observations and interviews complement one another and act upon one another in a "check and balance" fashion. According to Olson:

Interviews and what might more correctly be called conversations are interlocked with observations. They provide access to information that would be otherwise unavailable. They also provide the chance for elaboration and validation of your observations and interpretations of events. In a similar manner, observations supplement and guide material gained through interviews and conversations (Olson, 1976: 51).

Formal records provide another independent check on the validity and reliability of field research. Formal records may be used to corroborate the findings from observations and interviews; additionally, 
they may be used to ascertain the way in which the perspectives of key actors do or do not coincide with the statistical facts of case disposition. In her field research on the adjudication process in an urban court, Rovner-Pieczenik found the use of court records to be helpful:

Although I could observe "bargain justice" on a case-by-case basis, quantitative data concerning the outcome of the bargaining sessions was not available in either the legal or the sociological literature. I concluded that the statistics on dispositions and sentences actually represent the outcome of bargainings, since the majority of cases was resolved by a plea of guilty. It was at this point in my observational experience that I decided to collect statistical information about the processing and outcome of a large number of individual cases. These statistics collectively would represent what was too difficult to observe directly; how, in fact, different case types were adjudicated by the courts (Rovner-Pieczenik, 1976: 470).

It was the conclusion of this researcher that the use of multiple methods of data collection leads to a more accurate depiction of the case disposition process and strengthens both the validity and reliability of the research. It is also a partial response to the critics of field research who express a concern about the lack of objectivity in such research.

\section{MULTIPLE TECHNIQUES FOR DATA ANALYSIS}

The controversy over the use of quantitative versus qualitative methods for data analysis is indeed an old one. Proponents of quantitative methods have argued strongly that numerical representation provides the objectivity necessary for reliability. Without quantification, they continue, findings cannot be standardized, and 
they therefore rely heavily on the judgment of the researcher. Further, critics suggest that only through a statistical analysis can relationships be assessed in terms of their significance. Those who support qualitative analysis argue that for certain kinds of research, e.g., in-depth, exploratory, ethnographic-the meaning of social relationships can best be understood through a qualitative analysis of the findings. They also point out that the benefits of quantification, e.g., standardization, precision, comparability, statistical probability, may be outweighed by the costs of losing important information.
- . qualitative analysis is more likely to explain relationships in terms of social meanings, social realities, social norms, and definitions of the situation. Such understandings are not readily quantified (transformed into numbers), and, if they were, they might lose their sense and complexity (Sanders, 1974: 164).

Others have argued that quantitative analysis requires judgmental decisions initially, as qualitative data must be transformed into numerical codings in much research (Cavan, 1972). Kaplan states that "certain things are necessarily omitted in the numerical description, for this is always based on a determinate set of properties and relations to the exclusion of others" (Kaplan, 1964: 207). Kaplan further suggests that the argument over qualitative versus quantitative methods of analysis may be a false one in that the two methods per se are not antithetical:

The point is that both quality and quantity are misconceived when they are taken to be antithetical or even alternative. Quantities are of qualities, and a measured quality has just the magnitude expressed in its measure. In a less metaphysical idiom, we could say that whether 
something is identified as a quality or as a quantity depends on how we choose to represent it in our symbolism (Kaplan, 1964: 207).

Even if one believes that qualitative and quantitative analyses are not as easily fused as Kaplan suggests, it would be difficult to argue against incorporating both methods into a data analysis model for this particular type of study. Like the use of multiple methods for acquiring data, the use of multiple methods for analyzing data can only strengthen the validity and reliability of the research.

THEORY AND HYPOTHESIS-TESTING

The theoretically-based propositions provided the conceptual framework within which the phenomena under study were to be explored. Within this focal framework, flexibility was allowed as the research process progressed. Since the purpose was to explore a particular social reality, the testing of well-formulated hypotheses was inappropriate. Becker has pointed out that having well-formulated hypotheses in advance may bias or limit the field researcher's attempt to examine social reality as it actually exists:

[Field researchers] attempt to make their research theoretically meaningful, but they assume that they do not know enough about the organization a priori to identify relevant problems and hypotheses and that they must discover these in the course of the research (Becker, 1970: 26).

While in the present study general problems were identified, the precise nature of these problems was not clearly understood prior to the research undertaking. Thus, the research process itself led to further development of and modifications in the theoretical framework. This process has been referred to as the discovery of grounded 
theory (Glaser and Strauss, 1967). The purpose of the research was not merely descriptive; rather, it was to make theoretical sense of the circumstances. However, the descriptive data could not be ignored when they did not fit into the initial theoretical perspective. According to Nash:

The theory strives for a nomological form--it attempts to state laws, but it must account for the facts gathered. That is, it is an uneasy mixture between deductive and inductive nomological theories (Nash, 1966: 10).

Becker's description of the field research process reflects the analytical approach taken in the present study:

- . the observer characteristically begins by constructing models of parts of the organization as he comes in contact with them, discovers concepts and problems, and the frequency and distribution of the phenomena these call to his attention. After constructing a model specifying the relationships among various elements of this part of the organization, the observer seeks greater accuracy by successively refining the model to take account of evidence which does not fit his previous formulation (Becker, 1970: 34).

The final stage of analysis consists of "incorporating individual findings into a generalized model of the social system or organization under study or some part of that organization" (Becker, 1970: 33). A number of studies are illustrative of the research process described above. Sudnow used this process to generate a model of the classification scheme which guided charge, plea and bargain decisions in case disposition. Sudnow examined individual cases to describe the way in which classes of offenses were categorized according to their "typical features." From this description, he moved to an analysis of the total bargaining phenomenon (Sudnow, 1965). 
In her study of skid row alcoholics, wiseman sought to understand the social world of a particular deviant community by examining the perspectives of those involved in the social world of the skid row alcoholics. Wiseman reported that as the study progressed, important concepts and constructs emerged (Wiseman, 1970). In two separate studies, Cavan attempted to apprehend the social world of specific groups by observing them in their natural settings. In her ethnographic study of bar behavior, Cavan focused on activities in the bar setting which gave meaning to the total social reality of the social system. The descriptive data focused on three categories of activities: seating and spatial distribution, internal movement, and face-to-face interaction. After identifying the frequency and distribution of regular behavior patterns, Cavan moved to the analytic stage, suggesting that the data indicated the existence of a well-defined social system in which rules for behavior were informally established and consequences of particular actions and attitudes were readily anticipated by participants (Cavan, 1966). In her study of hippies in San Francisco, Cavan used a similar research process--describing everyday life, social exchange, social trouble and social control as relevant phenomena in the hippie subculture (Cavan, 1972). These studies covered a variety of topics and differed in their conceptual frameworks; however, they all were directed toward the exploration of the social reality of a social system by examining the way in which the parts gave meaning to the whole. 


\section{OBJECTIVITY}

One of the basic concerns of methodologists is how to insure that the findings from a research undertaking are objective. This problem is compounded by the fact that a variety of meanings have been attached to the term objectivity.

While objectivity is certainly not synonymous with validity or reliability, issues regarding validity and reliability are often raised in discussions of the objectivity of a given research project. A carefully constructed field research design is every bit as capable of attending to validity (the study measures what it purports to measure) as any other kind of research design. In the present study, content and construct validity were checked by referring to previous similar studies and consulting with experts regarding the construction of the measurements. Although controls required to insure internal validity after the instruments have been constructed are not as easily applied in field research as in experimental research, the field researcher compensates by continually assessing and reassessing internal validity throughout the research process (Johnson, 1975). Field research is especially strong in external validity (generalizability of the findings) since the research takes place in a natural rather than contrived setting. The reliability issue is more problematic. In order to insure reliability (the study can be repeated under the same circumstances with the same results), controls can be introduced in a true experiment which cannot be introduced in field research. In a true experiment, variables are manipulated, and attempts are made 
to insure that all variables extraneous to the hypothesis being measured are controlled. In field research, however, the purpose is to consider all variables as they occur in the natural setting. Admittedly, there are fewer guarantees that a field study can be replicated in the same way that an experimental study can be replicated. Becker suggests that we should not expect identical results from different field studies of the same organization but only that the findings be compatible (Becker, 1970).

The present study had to contend with another reliability problem. Due to the fact that the data were collected by a single researcher, reliability could not be checked by making interobserver comparisons. There were, however, compensations. Observation and interview schedules were structureed with standardized lists of activities and attitudes to be measured. Experts were consulted throughout the research process regarding data collection and analysis. Finally, the use of multiple data sources provided for a variety of measurements of the same phenomena.

A specific criticism of field research focuses on lack of objectivity due to the obvious intrusion of the researcher into the research process (reactivity). The field researcher, who is often a participant in or at least a direct observer of the phenomenon under study must deal with the possibility that 1) his or her presence is influencing the way in which respondents react and/or 2) his or her involvement is leading him or her to be judgmental or biased in the collection and analysis of the data. Field researchers have had much to say on these issues. 
First, it is generally accepted that reactivity can be a problem in all research in which people are the objects of study. Becker argues that field research may actually reduce respondents' inclinations to respond "falsely" since they are being observed in a natural setting in which "business must go on as usual."

Experimenters neutralize external constraints by isolating the subjects of their experiments from their usual surroundings, by experimenting on topics unconnected with any strong beliefs held by the subject, and by assuring the subject that his behavior in the experiment, however, he performs, will have no influence on his life outside the experimental laboratory. To. precisely the degree that these aims are achieved, subjects are free to shape their words and deeds in accordance with cues unwittingly given off by a biased experimenter (Becker, 1970: 45-46).

In the present study, lack of objectivity in terms of respondent bias was checked through the use of multiple data sources. However, because of the research goal to understand the total social reality, the researcher was interested in attitudes and opinions of respondents regardless of whether or not they coincided with "objective" truth. If only actions are considered to constitute objective truth, field research does have an objectivity problem, for it is well-documented that words and deeds are not necessarily consistent with one another (LaPiere, 1934; Wicker, 1969; Deutscher, 1973). However, objectivity does not have this meaning for most field researchers. Rather, it means an accurate description of an entire phenomenon--including both words and deeds. It is, of course, recognized that attitudes and actions constitute two classes of data which must be separated analytically. Although one purpose of the present study was to make comparisons between 
attitudes and actions, the central focus was on the way in which both fit into the social reality of the case disposition process within the court setting.

Although respondent bias is recognized as an objectivity problem in all types of research, researcher bias has been claimed to be a more serious problem for field research than for other types of research. Observation methods, it is alleged, lead to descriptions and interpretations which depend on subjective judgments of the field researcher. Field researchers deny these claims, pointing out that the use of structured schedules, the recording of specific events, and the use of multiple data sources all work toward observer objectivity.

On the other hand, it has been recognized that the notion of science as a totally objective, value-free enterprise is a myth. Based upon the seminal work of Karl Mannheim (1952), the realization that knowledge itself is socially-constructed and subjectivelybased calls for a reassessment of the meaning of objectivity. If the arguments of Mannheim and others are accpeted, it follows that the perceptions of researchers are biased in the sense that they are influenced by subjective experiences and world views which are a part of their life history. The fact that subjectivity cannot be entirely eliminated does not mean that the objectivity criterion must be abandoned. The research design can incorporate techniques previously referred to which strengthen objectivity. Additionally, an awareness of the possible intrusion of subjectivity leads to a more careful consideration of biases and judgments which may be influencing the findings. 
Another perspective is that subjectivity and objectivity are

both useful in arriving at scientific truth in field research.

In uncovering the social reality of a given phenomenon, it is

suggested that the subjective experiences of the researcher may

actually enhance the research endeavor. In his discussion of

naturalistic observation as a research methodology, Matza concludes:

Naturalism must choose the subjective view, and consequently it must combine the scientific method with the distincitve tools of humanism--experience, intuition, and empathy. Naturalism has no other choice because its philosophical commitment is neither to objectivity nor subjectivity, neither to scientific method, nor humanist sensibility. Its only commitment is fidelity to the phenomenon under consideration (Matza, 1961: 8).

Finally, a comment on subject-object dualism seems

appropriate. The traditional scientific view is that bias can

be eliminated (or at least reduced) by maintaining a strict

separation between the subject and object of study. Recently,

social scientists have rejected this dualism and argued that

subject and object must be considered in terms of their relation-

ship to one another (Johnson, 1975). To consider the subject and

object as interdependent parts of a total phenomenon does not in

itself reduce objectivity. Kaplan states:

All measurement yields, not a property intrinsic to the object being measured taken in isolation, but a relation between that object and the others serving as standards of measurement. When the relation is to other human beings, or even to the observer himself, it is not therefore a subjective one (Kaplan, 1964: 212). 
SAMPLING

In an exploratory study, traditional sampling techniques are not always appropriate as "it is difficult to know in advance just what the sample should be representative of" (Wiseman, 1970: 282). Yet representativeness is exactly what is being pursued in examining the frequency and distribution of phenomena under study. To satisfy the exploratory purpose, some sampling flexibility must be allowed during the course of the collection of data. However, an initial description of units to be sampled along with procedures for sampling is necessary to strengthen reliability and to reduce the possibility of mistaking idiosyncratic findings for representative ones. In this study, there were three levels of sampling units which corresponded with the sources of data: events observed; respondents interviewed; felony cases recorded in criminal files.

Two specific events (pre-trial conferences and plea hearings) were selected for observation. These events were selected due to their direct relevance to the phenomenon under study. It was not possible to take a random or representative sample of pre-trial conferences. Since access to these conferences was not readily available, the researcher had to take whatever she could get. Conclusions from this set of observations, therefore, had to be described as tenuous and only suggestive. The researcher sat in on plea hearings on a number of different days. On these days, all hearings which took place were recorded. Thus, there is no reason to suspect that the observed hearings did not constitute a representative sample. However, observations of hearings took 
place during a time period in which only two different judges were on the bench in Chief Criminal court. In this respect, the findings are limited.

Since the entire verbal content of these two events was recorded, bias which may result from recording only selected aspects of events was non-existent. More casual observations were made of other events in the case disposition process (trials, other hearings, meetings). Data from these latter observations were used to corroborate or expand upon the findings from other data sources.

The populations to be interviewed were selected for the purpose of 1) examining the perspectives of key actors in the case disposition process who were members of the same public court system; and 2) comparing the perspectives of groups who played different roles in the case disposition process. The original intent was to interview the total populations of these groups. This was accomplished for the public defender group, and fell only slightly short of the mark for the felony judge group. As indicated earlier, however, the prosecutor group consisted only of individuals selected by the District Attorney's office. Only about half of the total population of felony prosecutors was represented in the questionnaire responses, and less than one fifth was represented in the open-ended part of the interview. Traditional random samples were taken of all felony cases settled in the time periods under study. There is no reason to suspect, therefore, that error contained in the data from these 
samples was not random. Sumary statistics on type closing of the total populations from which these samples were drawn indicated that, on this one important variable, the samples were representative of the total populations.

\section{ETHICAL ISSUES}

When doing a field study, the researcher must take into consideration the implications and consequences that the research might have on those being studied. There are several ethical issues which are relevant for this particular study.

The first issue has to do with disclosure. Members of an organization are likely to be wary of outside investigators; such potential participants are increasingly seeking an answer to the question of whose side the researcher is on (Becker, 1970; Glazer, 1972). The researcher may answer this question by referring to the tenet of scientific objectivity. However, regardless of techniques for objective data collection and analysis built into the research design, the selection and conceptualization of the problem reflects a political point of view.

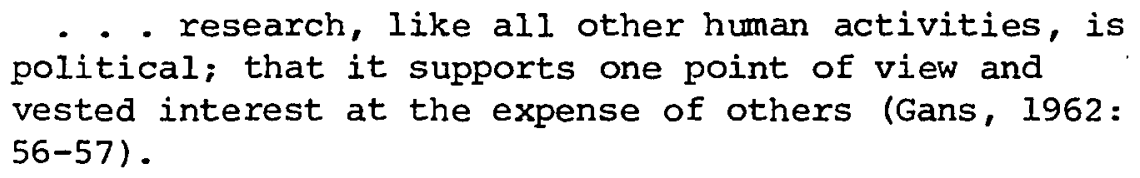

Increasingly, social scientists are openly advocating that research be used to bring about social change in programs and policies. Not only is a commitment to social "progress" seen as an appropriate part of the researcher role, but further, a neutral stance is seen as fostering the myth of value-free research (Seeley, 1961). 
Obviously, the political perspective of the research/researcher has implications for the object of study. Political perspectives aside, the "exposing" or "unmasking" nature of the exploratory field study may have political or professional consequences for the organization and/or its members. While ethics demand that the researcher explain to those being studied the general nature of the research, as well as its possible implications, there are several factors which work against full disclosure.

First, in order to gain access to the organization and thus to the desired data, it is essential to gain the trust and cooperation of the organization members (Becker, 1970; Wiseman, 1970; Glazer, 1972; Sanders, 1974; Johnson, 1975). Trust and cooperation are facilitated by developing rapport.

Generally, rapport is a matter of being noncritical, interested in what the subjects do and say, and, most important, genuinely open to an understanding of how they see and experience their social world (Sanders, 1974: 159).

However, rapport may not be easily established if full disclosure suggests to the participants that their organization may be described in ways which work against their interests. The researcher, then, may be tempted to withhold information which he or she feels may inhibit cooperation. When the participants are individuals or organizations with power and influence (as was the case in this study), the researcher may be even more likely to lose accessibility by full disclosure (Glaser, 1972; Barber, 1973).

Administrators in government, business, and the unions who pass on requests for research funds or who must acquiesce before field workers can study their own organizations are reluctant to assist those who might expose their decisions in an unfavorable light (Glazer, 1972: 150). 
In addition to the researcher's own vested interest in gaining accessibility in order to complete a research project, the researcher should have a commitment to uncovering the reality of all aspects of society--especially those aspects in which great power to influence social decisions and activities is vested.

Those in power, whether in public or private positions, have been defined as fair game by social scientists. This is as it should be. Their position often includes the expectation of accountability. Social scientists, among others, have and should continue to strive to ensure that those who control vast administrative organizations are not shielded from the appropriate limelight (Glazer, 1972: 172).

The approach in the present study was to attempt to develop a relationship of trust, cooperation and rapport with the participants in the study by reassuring them that there was a genuine interest in their perspectives and in depicting their organization accurately and objectively. Participants in the study were in fact extremely cooperative. All public defenders of whom an interview was requested agreed to be interviewed. Of the judges who were approached, only one declined to be interviewed (this judge offered time constraints as an explanation of his refusal). Three judges, however, declined to fill out the questionnaire form, commenting on their lack of trust in data obtained from questionnaire forms. The District Attorney's office proved to be the least accessible (the District Attorney stated that time constraints were responsible for this inaccessibility). However, all of the public defenders and prosecutors who were eventually interviewed were cooperative and willing to take the time to respond to all questions (the interviews ranged in time from a half hour to an 
hour and a half). Overall, the interviewed judges were cooperat . personable and open in their responses. Yet, as a group, the judges were the most difficult to interview. The authority status of the judges was reflected in their demeanor and in their actual verbal responses. Additionally, the judges' offices (in which the interviews took place) confirmed by their spaciousness, opulence and formal decor the powerful and authoritative position of the occupant. Finally, compared to attorneys, judges were more inclined to confine their comments to descriptions of the ideal, formal system and less inclined to comment on informal processes in which they were not directly involved. Overall, the respondents seemed to be satisfied with the brief explanation given them of the nature and purpose of the study. They did not express concern about the consequences or implications of the research project either for themselves or for the system. When interviewees did ask for further explanations of the nature or purpose of the study, an elaboration of the initial introduction was given. Care was taken, however, not to bias responses by indicating what the researcher expected to find by asking a particular question. The validity and reliability of the findings depends upon something less than full disclosure of what particular observations or interview questions are attempting to explain (Blalock, 1970; Glazer, 1972). Another ethical issue has to do with the protection of the rights of individual respondents to privacy. In this study, these rights were protected by guaranteeing anonymity to the interviewees and observed. Respondents were referred to only by the label 
which designates their status in the court system, e.g., prosecutor, public defender, judge. In addition, care was taken not to include information which would reveal identities of respondents. The study was concemed with attitudes and actions of individuals only as they were representative of a group or of a system. Likewise, names or other imformation which might reveal identities of defendants whose cases were researched were carefully excluded. Finally, since information on formal structure and procedure of the court process is open to the public, the use of such information was not believed to be an invasion of privacy.

It should be noted that while anonymity of individual participants can be guaranteed, confidentiality regarding responses cannot really be provided. To insure total confidentiality would require that the research findings not be released. Viewing confidentiality in this light, it appears that social scientists talk somewhat erroneously about providing confidentiality of research findings. Samuels comments:

Where the research findings to applied goals would be rendered useless if true confidentiality is maintained, the researcher must assume the responsibility of either entirely withholding the findings from publication or releasing them at a time when the informants can no longer be harmed by such disclosures (Samuels, 1976: 22).

The ethical issues in social research are not easily resolved. However, these issues must be carefully considered as the researchers weigh commitments to the scientific endeavor on the one hand and to those being studied on the other. 
Perhaps most significantly, field workers have to confront one of the most pressing issues of social science research; how to resolve the profound tension between exposure of what is beyond the facade of social conduct and avoidance of harm to those we study (Glazer, 1972: 150). 
APPENDIX B

VARIABLE CODINGS: CRIMINAL COURT FELONY CASE SAMPLE DATA

\section{Variable}

1. Initial most serious charge

2. Initial charge: 2nd count

3. Initial charge: 3ra count

4. Initial charge: 4 th count

5. Settled most serious charge

6. Settled charge: 2nd count

7. Settled charge: 3rd count

8. Settled charge: 4 th count

9. \# initial counts

10. \# initial felony counts

11. \# settled counts

12. \# settled felony counts

13. No contest plea

14. Type closing

15. \# setovers

16. Type attorney

17. Judge

18. Pre-trial custody status

19. Sentence: incarceration
Coding

Offense by name and level, e.g., Forgery I, Attempted Assault II.

Actual number counts, e.g., $1,2,3$.

Yes/No.

PG/PGTL/PGTL+Dis/PG+Dis/CBJ/ $\mathrm{CBC} / \mathrm{ABJ} / \mathrm{ABC} / \mathrm{DIS}$

Actual number setovers, e.g., $1,2,3$

Public defender/court-appointed from private bar/privately retained.

Number substituted for name, e.g., Judge $A$, Judge $B$.

Recognizance/bail/jail.

Penitentiary 5 years or more/ Pen less than 5 years/Jail

and probation/Jail only/No jail and probation/ No jail and no probation. 
Variable

20. Fine

21. Drug or alcohol program

22. Mental health program

23. Restitution

24. Community service

25. Month arrest

26. Total disposition time

27. Sex of defendant

28. Age of defendant

29. Prior record of defendant

30. Education of defendant

31. Employment of defendant

32. Residence of defendant

33. DA unit

\section{Coding}

Yes/No.

Actual month, e.g., January, February.

1-30 days/31-60 days/61-90

days/over 90 days.

Male/Female.

$17-20 / 21-30 / 31-40 /$ over 40 .

Felony record/No felony record/ No record.

No high school/Less than 4 years high school/4 years high school/Some college/College graduate.

Unemployed/Employed less than 6 months/Employed over 6 months.

N.E./S.E./N./N.W./S.W./Out city/ Out state/Transient

Actual unit, i.e., A, B, C, D, E, U. 


\begin{abstract}
APPENDIX C
VARIABLE CODINGS:

PUBLIC DEFENDER FORGERY I AND BURGLARY I DATA
\end{abstract}

Variable

Coding

1. Most serious settled charge

Offense by name and level, e.g., Burglary II.

2. \# initial counts

3. \# initial felony counts

Actual number counts, e.g.,

4. \# settled counts

5. \# settled felony counts

6. Type Closing

PG/PGTL/PGTL+Dis/PG+Dis/ PGTL+Not file/PG+Not file/ PGTL+Dis+Not file/PG+Dis+Not file/CBJ/CBC/ABJ/ABC/DIS.

7. Judge

Number substituted for name, e.g., Judge 1 , Judge 2 .

8. Sentence recommendation by prosecutor: incarceration

Penitentiary 5 years or more/ Penitentiary less than 5 years/ Jail and probation/Jail only/ No jail and probation/No jail/ No position or not oppose/ After conviction/Confinement.

9. Sentence recommendation by prosecutor: Other conditions

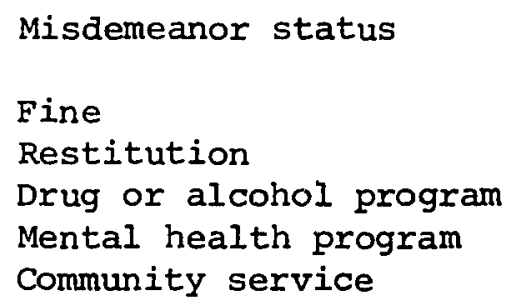

10. Sentence: incarceration

Immediate/deferred/no.

Yes/No.

Penitentiary 5 years or more/ Penitentiary less than 5 years/ Jail and probation/Jail only/ No jail and probation/No jail. 
Variable

11. Sentence: other conditions

12. Sex of defendant

13. Age of defendant

14. Prior record of defendant

15. Education of defendant

16. Employment of defendant

17. Race of defendant

18. Defendant arug or alcohol problem

19. Dismissal reason

20. Offense in dwelling (Burglary only)

Coding

Immediate/deferred/no.

Yes/No.

Male/Female.

$17-20 / 21-30 / 31-40 /$ over 40 .

Prior felony record/No felony record.

No high school/Less than 4 years high school/4 years high school/Some college/College graduate.

Unemployed/Employed less than 6 months/Employed part time or off and on/Employed less than 6 months and part time or off and on/Employed over 6 months and full time.

White/black/other.

Yes/No.

PG to other charge/State unable sustain burden of proof/Civil compromise/Speedy trial violation/Remand juvenile/ other.

Yes/No. 
APPENDIX D

QUESTIONNAIRE FORM

For the following questions, please circle the number which most closely approximates your opinion.

1. In deciding how to handle a give case, how much consideration do you think the following factors are given by

a) the Public Defender's Office;

b) the District Attorney's Office:

Very

Much Some None

Strength of prosecutor's case

a) Public Defender's Office

b) District Attorney's Office

$\begin{array}{lllll}5 & 4 & 3 & 2 & 1\end{array}$

Seriousness of offense

a) Public Defender's Office

b) District Attorney's Office

$\begin{array}{lllll}5 & 4 & 3 & 2 & 1\end{array}$

$\begin{array}{lllll}5 & 4 & 3 & 2 & 1\end{array}$

Prior record of defendant

a) Public Defender's Office

b) District Attorney's Office

$\begin{array}{lllll}5 & 4 & 3 & 2 & 1\end{array}$

$\begin{array}{lllll}5 & 4 & 3 & 2 & 1\end{array}$

Actual guilt of the defendant

a) Public Defender's Office

b) District Attorney's Office

$\begin{array}{lllll}5 & 4 & 3 & 2 & 1 \\ 5 & 4 & 3 & 2 & 1\end{array}$

Typicality of the offense

a) Public Defender's Office

b) District Attorney's Office

$\begin{array}{lllll}5 & 4 & 3 & 2 & 1\end{array}$

$\begin{array}{lllll}5 & 4 & 3 & 2 & 1\end{array}$

General character of the defendant

a) Public Defender's Office

b) District Attorney's Office

$\begin{array}{lllll}5 & 4 & 3 & 2 & 1\end{array}$

$\begin{array}{lllll}5 & 4 & 3 & 2 & 1\end{array}$ 
Attitude of the defendant

a) Public Defender's Office

b) District Attorney's Office

Defendant's wishes regarding handling of case

a) Public Defender's Office

b) District Attorney's Office

Report of arresting officer

a) Public Defender's Office

b) District Attorney's Office

Tendencies of juries

a) Public Defender's Office

b) District Attorney's Office

Tendencies of presiding judge

a) Public Defender's Office

b) District Attorney's Office

Community attitudes

a) Public Defender's Office

b) District Attorney's Office

Victim needs

a) Public Defender's Office

b) District Attorney's Office

Office policy

a) Public Defender's Office

b) District Attorney's Office

Political concerns

a) Public Defender's Office

b) District Attorney's Office

Career advancement concerns

a) Public Defender's office

b) District Attorney's office $\begin{array}{lllll}5 & 4 & 3 & 2 & 1\end{array}$

$\begin{array}{lllll}5 & 4 & 3 & 2 & 1\end{array}$

$\begin{array}{lllll}5 & 4 & 3 & 2 & 1\end{array}$

$\begin{array}{lllll}5 & 4 & 3 & 2 & 1\end{array}$

$\begin{array}{lllll}5 & 4 & 3 & 2 & 1\end{array}$

$\begin{array}{lllll}5 & 4 & 3 & 2 & 1 \\ 5 & 4 & 3 & 2 & 1\end{array}$

$\begin{array}{lllll}5 & 4 & 3 & 2 & 1 \\ 5 & 4 & 3 & 2 & 1\end{array}$

$\begin{array}{lllll}5 & 4 & 3 & 2 & 1\end{array}$

$\begin{array}{lllll}5 & 4 & 3 & 2 & 1\end{array}$

$\begin{array}{lllll}5 & 4 & 3 & 2 & 1\end{array}$

$\begin{array}{lllll}5 & 4 & 3 & 2 & 1\end{array}$

$\begin{array}{lllll}5 & 4 & 3 & 2 & 1 \\ 5 & 4 & 3 & 2 & 1\end{array}$

$\begin{array}{lllll}5 & 4 & 3 & 2 & 1\end{array}$

$\begin{array}{lllll}5 & 4 & 3 & 2 & 1\end{array}$

$\begin{array}{lllll}5 & 4 & 3 & 2 & 1\end{array}$

$\begin{array}{lllll}5 & 4 & 3 & 2 & 1\end{array}$ 
Demands of special interest groups

a) Public Defender's Office

b) District Attorney's Office

$\begin{array}{lllll}5 & 4 & 3 & 2 & 1 \\ 5 & 4 & 3 & 2 & 1\end{array}$

Relationship with particular attorney handling other side of the case

a) Public Defender's Office

b) District Attorney's Office

$\begin{array}{lllll}5 & 4 & 3 & 2 & 1\end{array}$

$\begin{array}{lllll}5 & 4 & 3 & 2 & 1\end{array}$

Need to maintain good relations with others in the court system

a) Public Defender's Office

b) District Attorney's Office

$\begin{array}{lllll}5 & 4 & 3 & 2 & 1 \\ 5 & 4 & 3 & 2 & 1\end{array}$

Avoiding court overload

a) Public Defender's Office

b) District Attorney's Office

$\begin{array}{lllll}5 & 4 & 3 & 2 & 1 \\ 5 & 4 & 3 & 2 & 1\end{array}$

Conserving staff resources

a) Public Defender's Office

b) District Attorney's Office

$\begin{array}{lllll}5 & 4 & 3 & 2 & 1\end{array}$

Speedy case settlement

a) Public Defender's Office

b) District Attorney's Office

$\begin{array}{lllll}5 & 4 & 3 & 2 & 1 \\ 5 & 4 & 3 & 2 & 1\end{array}$

Due process

a) Public Defender's Office

b) District Attorney's office

$\begin{array}{lllll}5 & 4 & 3 & 2 & 1 \\ 5 & 4 & 3 & 2 & 1\end{array}$

Crime control

a) Public Defender's office

b) District Attorney's Office

$\begin{array}{lllll}5 & 4 & 3 & 2 & 1\end{array}$

For the following questions, please circle the response which most closely reflects your opinion.

2. If your client decides to plead quilty, how important is it to you that he/she receive some benefit in exchange for a guilty plea?

$\begin{array}{clll}\text { Very } & \text { Somewhat } & \text { Not Very } & \text { Not At All } \\ \text { Important } & \text { Important } & \text { Important } & \text { Important Important }\end{array}$


3. After having studied a case assigned to you, how often do you feel that you can reasonably anticipate

a) whether or not the case will be plea negotiated?

Always Usually Sometimes Not Usually Never

b) what kind of a bargain will be made?

Always Usually Sometimes Not Usually Never

4. How often would you say you are satisfied with the disposition outcome of cases you handle?

Always Usually Sometimes Not Usually Never

5. Approximately how many accused felons do you think are actually guilty, either of the formal charge or of some related charge?

Over $80 \% \quad 80 \%-60 \% \quad 60 \%-40 \% \quad 40 \%-20 \%$ Less Than $20 \%$

6. Approximately how many accused felons assigned to the Public Defender's office do you think are actually guilty, either of the formal charge or of some related charge?

Over $80 \% \quad 808-60 \% \quad 608-408 \quad 408-20 \%$ Less Than 208

7. Of cases which are settled by guilty pleas, how many do you think involve some kind of bargain, however minimal?

Over 808 80\%-60\% 608-40\% 408-20\% Less Than 208

8. The district attorney has the "upper hand" in the plea negotiation process.

Strongly Agree
Agree Neutral
Strongly

Disagree 


\section{APPENDIX E}

\section{OBSERVATION SCHEDULE: PRE-TRIAL CONFERENCE}

Following is a sample form of the observation schedule used to record data from the pre-trial conferences in felony court. The data in the cells are ficticious but resemble data in the actual completed forms. Unlike this sample form, the actual forms provided space for an unlimited number of comments. The letters in the cells indicate the speaker $(A=$ Prosecutor; $B=$ Public Defender; $C=$ Defendant). The headings at the top of each column (with the exception of the first column) indicate the subject matter of the comment. A question mark in a cell indicates that the verbalization was a question. The column labeled "Researcher Comments" allows for elaboration on the subject matter. 


\begin{tabular}{|c|c|c|c|c|c|c|c|c|}
\hline$\infty$ & $\checkmark$ & $\sigma$ & $G$ & $\rightarrow$ & $\omega$ & $N$ & $r$ & $\begin{array}{l}\text { Sequence order } \\
\text { of comments }\end{array}$ \\
\hline & & & & & & & $\nabla$ & $\begin{array}{l}\text { Pre-Trial } \\
\text { Conference }\end{array}$ \\
\hline & & & & & $\infty$ & $\triangleright$ & & $\begin{array}{l}\text { Nature of } \\
\text { Offense }\end{array}$ \\
\hline \multirow[t]{10}{*}{$\Omega$} & ? & & & & & & & $\begin{array}{l}\text { Nature of } \\
\text { Defendant }\end{array}$ \\
\hline & & & & $>$ & & & & $\begin{array}{l}\text { Strength } \\
\text { of Case }\end{array}$ \\
\hline & & & & & & & & $\begin{array}{l}\text { Guilt } \\
\text { Issue }\end{array}$ \\
\hline & & $\varpi$ & $\nabla$ & & & & & $\begin{array}{l}\text { Police \&/Or } \\
\text { Investigative } \\
\text { Reports }\end{array}$ \\
\hline & & & & & & & & $\begin{array}{l}\text { Needs/Goals } \\
\text { of CJ System }\end{array}$ \\
\hline & & & & & & & & $\begin{array}{l}\text { Victim } \\
\text { Concerns }\end{array}$ \\
\hline & & & & & & & & $\begin{array}{l}\text { Charge } \\
\text { Reduction }\end{array}$ \\
\hline & & & & & & & & $\begin{array}{l}\text { Charge/ } \\
\text { Count } \\
\text { Dismiss }\end{array}$ \\
\hline & & & & & & & & $\begin{array}{l}\text { Charge/ } \\
\text { Count } \\
\text { Not File }\end{array}$ \\
\hline & & & & & & & & $\begin{array}{l}\text { Offer } \\
\text { Time } \\
\text { Limit }\end{array}$ \\
\hline 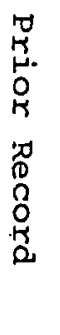 & 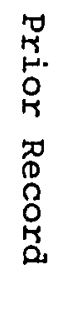 & 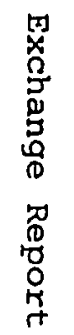 & 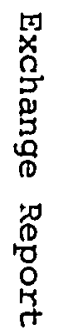 & 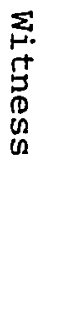 & $\begin{array}{l}0 \\
0 \\
1 \\
0 \\
\mathbb{D} \\
1 \\
\mathbb{1} \\
0 \\
0 \\
0 \\
5 \\
0\end{array}$ & $\begin{array}{l}0 \\
0 \\
1 \\
0 \\
0 \\
1 \\
0 \\
0 \\
0 \\
0 \\
5 \\
4\end{array}$ & & $\begin{array}{l}\text { Researcher } \\
\text { Comments }\end{array}$ \\
\hline
\end{tabular}

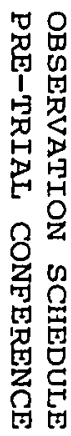




\author{
APPENDIX F \\ OREGON CRIMINAL PROCEDURE CODE \\ FINAL DRAFT AND REPORT \\ CRIMINAL LAW REVISION COMMISSION \\ NOVEMBER, 1972
}

The present Oregon criminal procedure code gives formal

recognition to plea bargaining as a method of case disposition.

The Commission which drafted the present code viewed plea bargaining

as necessary and useful in terms of the needs of the criminal

justice system. Due to its common use for case disposition, the

Commission felt that plea bargaining should be given legal status.

In its final report, it stated:

In Oregon criminal justice administration, as elsewhere in this country, the practice known as "plea negotiation," "plea bargaining," "cop out" and "deal" is regularly engaged in by prosecutors and defense lawyers. The oregon Criminal Law Handbook recognizes that the negotiated plea serves a useful public purpose and suggests that the terms employed in connection with the practice should be stripped of their anti-social implications. (158)

The Commission also quoted in its report a statement made by the President's Commission on Law Enforcement and Administration of Justice which lends support to the philosophy behind the procedure code drafted by the oregon Commission. This statement reads as follows:

The negotiated guilty plea serves important functions. As a practical matter, many courts could not sustain the burden of having to try all cases coming before them. The quality of justice in all cases would suffer if overloaded courts were faced with a great increase in the number of trials. Tremendous investments of time, talent, and money, all of which are in short supply and can be better 
used elsewhere, would be necessary if all cases were tried. It would be a serious mistake, however, to assume that the guilty plea is no more than a means of disposing of criminal cases at minimal cost. It relieves both the defendant and the prosecution of the inevitable risks and uncertainties of trial. It imports a degree of certainty and flexibility into a rigid, yet frequently erratic system. (158) (Challenge of Crime in a Free Society, 135:1967,)

The following four sections of the criminal procedure code give plea bargaining legal status and set out procedural guidelines for its use. The sections are quoted in full below.

Section 263. Plea discussions and plea agreements.

1) In cases in which it appears that the interest of the public in the effective administration of criminal justice would thereby be served, and in accordance with the criteria set forth in section 264 of this Act, the district attorney may engage in plea discussions for the purpose of reaching a plea agreement.

2) The district attorney shall engage in plea discussions or reach a plea agreement with the defendant only through defense counsel, except when, as a matter of record, the defendant has effectively waived his right to counsel or, if the defendant is not eligible for court-appointed counsel, has not retained counsel.

3) The district attorney in reaching a plea agreement may agree to, but is not limited to, one or more of the following, as required by the circumstances of the individual case.

a) To make or not to oppose favorable recommendations as to sentence which should be imposed if the defendant enters a plea of guilty or no contest to the offense charged;

b) To seek or not to oppose dismissal of the offense charged if the defendant enters a plea of guilty or no contest to another offense reasonably related to the defendant's conduct; or

c) To seek or not to oppose dismissal of other charges or to refrain from bringing potential charges if the defendant enters a plea of guilty or no contest to the offense charged. 
4) Similarly situated defendants should be afforded equal plea agreement opportunities.

Section 264. Criteria to be considered in plea discussions and plea agreements.

In determining whether to engage in plea discussions for the purpose of reaching a plea agreement, the district attorney may take into account, but is not limited to, any of the following considerations.

1) The defendant by his plea has aided in ensuring the prompt and certain applications of correctional measures to him.

2) The defendant has acknowledged his guilt and shown a willingness to assume responsibility for his conduct.

3) The concessions made by the state will make possible alternative correctional measures which are better adapted to achieving rehabilitative, protective, deterrent or other purposes of correctional treatment, or will prevent undue harm to the defendant from the form of conviction.

4) The defendant has made public trial unnecessary when there are good reasons for not having the case dealt with in a public trial.

5) The defendant has given or offered cooperation when the cooperation has resulted or may result in the successful prosecution of other offenders engaged in equally serious or more serious criminal conduct.

6) The defendant by his plea has aided in avoiding delay in the disposition of other cases and thereby has increased the probability of prompt and certain application of correctional measures to other offenders.

These criteria seem to suggest that the defendant who cooperates and thus enhances criminal justice goals and system needs should be rewarded with a reasonable bargain. In the commentary following this section of the code, the Commission offers the rationale behind each criterion. The rationale behind subsection 1 ) is:

Promptness and certainty in punishment are both important in accomplishing the goals of the criminal justice system. The swift and certain punishment of a given defendant aids in the deterrence of others and 
in accomplishing rehabilitation of that defendant. A defendant who pleads guilty may substantially contribute to both the promptness and the certainty of his punishment. (160)

The rationale behind subsection 2) emphasizes the importance of the attitude of the defendant concerning his or her criminal conduct:

This factor recognizes the defendant's acknowledgement of guilt and willingness to assume responsibility for his conduct as a valid consideration in dealing with the guilty plea defendant. It is consistent with prevailing and accepted sentencing criteria, which emphasizes the relevance of the "attitudes of the defendant" and his willingness to assume responsibility for his actions.

In Subsection 3), the Commission seems to be advocating the reduction of severity of punishment:

In view of the wide range of sentencing options that oregon judges have for most crimes, the main purpose in including this standard is to recognize that in many cases a plea to a reduced charge is to avoid a felony conviction, or conviction of a crime that carries a particularly reprehensible label. (160)

The rational behind Subsection 4) has to do with protection of victims in certain offenses, e.g., sex offenses where it might be traumatic for the victim to have to appear in court; theft by extortion in which public exposure of the victim might be best avoided. Subsection 5) is said to be in line with the recommendations of the American Bar Association ( $A B A$ ) which suggest that "whatever is lost by the reduced punishment of one offender is gained by the resulting conviction of one or more other offenders" (160). The rationale behind Subsection 6) may be the most far-reaching in its willingness to reward defendants for co-operating by pleading guilty. It is said that guilty plea defendants as a class make a "meaningful contribution toward the attainment of the objectives of the criminal justice system" by reducing court congestion and enhancing speedy 
case settlement. This, in turn, is said to further the goal of prompt and certain punishment for all guilty defendants. The Commission refers to an $A B A$ commentary which states that

- . it is not inappropriate to grant concessions to those defendants who by their plea increase both the proximity and probability of punishment for other guilty defendants. (161) (Commentary 1.8.)

The Commission also makes reference to a study of plea bargaining in Oregon in which it was found that "when asked how the administration of justice is aided by the plea bargaining process, over half of the responding district attorneys indicated that it saved time, money and reduced the caseload of the courts (Klonoski Study. 50 Or L Rev supra at 131). The Commission then concludes that:

The standard set out in this subsection (6) is consistent with the above observations and recognizes that avoiding delay in the disposition of other cases is a proper matter to be taken into account by a district attorney or trial judge in determining whether to agree to a "barq̧ained for" plea.

The policy of the Office of the District Attorney of Miltnomah County appears to conflict with the intent of the law as outlined above, for Office policy states that plea negotiations shall never be used to reduce case backlogs or reallocate manpower. The office considers such considerations to be a "flagrant abuse of the process."

Section 265. Responsibilities of defense counsel.

1) Defense counsel shall conclude a plea agreement only with the consent of the defendant, and shall ensure that the decision whether to enter a plea of guilty or no contest is ultimately made by the defendant.

2) To aid the defendant in reaching a decision, defense counsel, after appropriate investigation, shall advise the defendant of the alternatives available and of factors considered important by him or the defendart in reaching a decision. 
In their commentary on Section 265, the Commission elaborates on

the kinds of information that are important for counsel to give the defendant. Among these are: the probability of being convicted should the defendant stand trial; consequences which would follow a plea of guilty as opposed to conviction by trial; concessions

offered by or agreeable to the district attorney. Section 266. Responsibilities of trial judge.

1) The trial judge shall not participate in plea discussions.

2) If a tentative plea agreement has been reached which contemplates entry of a plea of guilty or no contest in the expectation that charge or sentence consessions will be granted, the trial judge, upon request of the parties, may permit the disclosure to him of the tentative agreement and the reasons therefore in advance of the time for tender of the plea. The trial judge may then advise the district attorney and defense counsel whether he will concur in the proposed disposition of the information in the presentence report or other information available at the time for sentencing is consistent with the representations made to him.

3) If the trial judge concurs, but later decides that the final disposition of the case should not include the sentence concessions contemplated by the plea agreement, he shall so advise the defendant and allow the defendant a reasonable period of time in which to either affirm or withdraw his plea of guilty or no contest.

4) When a plea of guilty or no contest is tendered or received as a result of a prior plea agreement, the trial judge shall give the agreement due consideration, but notwithstanding its existence, he is not bound by it, and may reach an independent decision on whether to grant sentence concessions under the criteria set forth in section 264 of this Act.

Subsection 2) of Section 266 is a new provision in the criminal procedural code. It recognizes that a bargain agreed upon by the 
prosecuting and defense attorneys which includes sentence recommendation requires cooperation from the judge. The Commission comments :

It recognizes that it is proper for the judge, when requested by the parties, to permit certain procedures that will allow a greater degree of certainty when the proposed concessions involved the sentence or the dismissal of other charges before the court. (163)

Subsection 3) allows the defendant a further safeguard in the event that the trial judge changes his or her mind regarding the proposed concessions.

The criminal procedure code of Oregon devotes three sections to the due process rights of defendants who plead guilty. The first section outlines the court's responsibilities in advising the defendant of the implications of his or her plea. The second states that the court must be satisfied of the voluntariness of the plea, and the third states that the court must be satisfied of the accuracy of the plea. These three sections are given in full below, along with commentary of the Criminal Law Revision Commission.

Section 260. Defendant to be advised by court.

1) The court shall not accept a plea of guilty or no contest to a felony or other charge on which the defendant appears in person without first addressing the defendant personally and determining that he understands the nature of the charge.

2) The court shall inform the defendant:

a) That by his plea of guilty or no contest he waives his right:

To trial by jury;

of confrontation; and Again self-incrimination. 
b) Of the maximum possible sentence on the charge, including the maximum possible sentence from consecutive sentences.

c) When the offense charged is one for which a different or additional penalty is authorized by reason of the fact that the defendant may be adjudged a dangerous offender, that this fact may be established after his plea in the present action, thereby subjecting him to different or additional penalty.

Section 260 is based on previous court rulings (both federal and state) in which opinions have been expressed that due process has been violated if defendants have not been advised of the above (Boykin v. Alabama, 395 US 238:1969; McCarthy v. United States, 394 US 459:1968; Lay v. Cupp, I Or App 296, 462 P2d 443:1969; Nealy

v. Cupp, 2 or App 240, 467 P2d 649:1970).

Section 261. Determining voluntariness of plea.

1) The court shall not accept a plea of guilty or no contest without first determining that the plea is voluntarily and intelligently made.

2) The court shall determine whether the plea is the result of prior plea discussions and a plea agreement. If the plea is the result of a plea agreement, the court shall determine the nature of the agreement.

3) If the district attorney has agreed to seek charge or sentence concessions which must be approved by the court, the court shall advise the defendant personally that the recommendations of the district attorney are not binding on the court.

Subsection 1) of Section 261 is based upon the ruling of the

U.S. Supreme Court in Boykin vs. Alabama in which it was said that

- . it was error, plain on the face of the record, for the trial judge to accept petitioner's guilty plea without an affirmative showing that it was intelligent and voluntary. (156) 
Subsections 2) and 3) are in line with $A B A$ recommendations which suggest that plea negotiations be given "visibility" by court inquiry. It appears that knowledge of plea negotiations is also perceived of as useful in determining voluntariness of plea.

Section 262. Determining accuracy of plea.

After accepting a plea of guilty or no contest, the court shall not enter a judgment without making such inquiry as may satisfy the court that there is a factual basis for the plea.

Section 262 is a new provision in oregon law. Commentary by the Commission states that procedures for determining accuracy of plea may vary:

The court would be free to use any appropriate procedure which seems best suited to the court and for the kind of case involved. (157)

In the Commission report there is also a reference regarding this section to $A B A$ commentary. $A B A$ comments that although inquiry into plea accuracy may reduce some of the efficiency of the guilty plea process, the benefits of such investigation for the defendant and for the system outweigh efficiency reduction.

Primarily, inquiry ensures that the defendant actually committed a crime at least as serious as the one to which he is willing to plead. Furthermore, investigation into the factual basis of guilty pleas helps to increase the visibility of charge reduction practices, a common form of plea agreement. Also, inquiries provide a more adequate record of the conviction process and minimize the chances of a defendant successfully challenging his conviction later. Finally, increased knowledge about the circumstances of the defendant's crime allows the court to better evaluate his competency, his willingness to plead guilty, and his understanding of the charges against him. (157) 
FELONY AND MISDEMEANOR LEVELS: STATUTORY CLASSIFICATIONS FOR CRIMINAL OFFENSES*

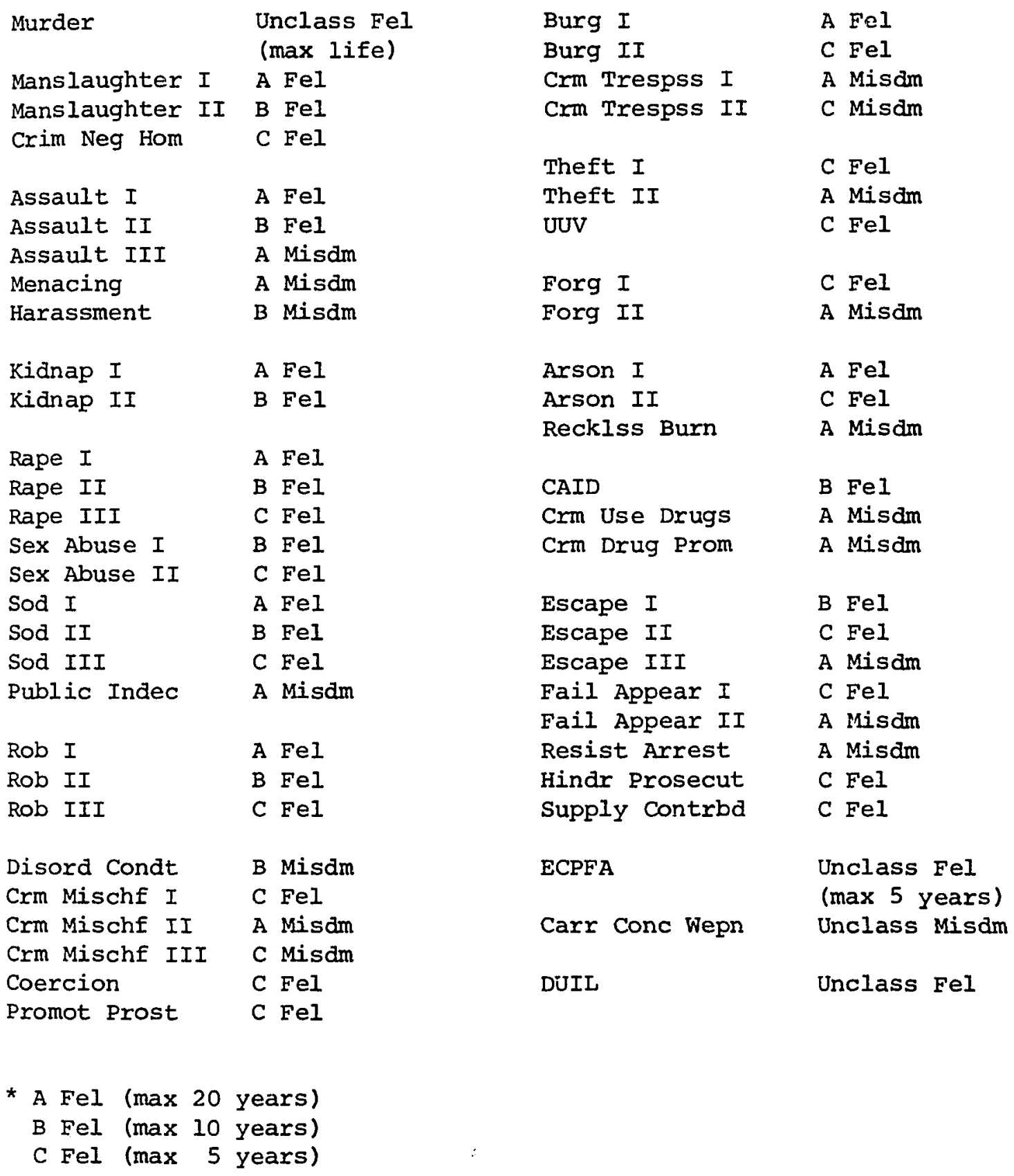


APPENDIX H

JOB DESCRIPTIONS OF EMPLOYED DEFENDANTS

An attempt was made to get some idea of the nature of jobs held by those offenders who were employed. Many of the case files only gave the name of the defendant's employer, and thus it was not possible to ascertain the nature of the job. However, job descriptions were obtained for 72 defendants from the 1976 sample. The great majority of these defendants either had "bl.ue collar" jobs (skilled or semi-skilled labor) or had low-level service jobs. It should be remembered that defendants are relatively young, and therefore it would not be expected that they would have high-level employment. Nevertheless, the data do suggest that accused felons have jobs which social scientists would cateogrize at the lower end of the social class scale.

Nineteen defendants were skilled or semi-skilled laborers. Of these, three were construction workers, two were truck drivers, two were machinists, and two did automobile body work. The others worked as: auto mechanic, caxpenter, freight loader, painter, printer, roofing contractor, tree service employee, meat company employee, livestock market employee, and railroad worker.

Eleven people did some kind of building maintenance work. Seven of these described their positions as janitor, two as maintenance workers in care centers, one as hotel maintenance, and one as housekeeper. 
Nine defendants did some kind of restaurant, tavern or bar work. Positions included waiter/waitress, bartender, busboy, dishwasher, cook.

Another nine people worked in retail sales. Of these, seven were store clerks. One described his position as sales manager of a bakery, one sold produce at an outside stand. Six defendants described themselves as self-employed. Of these, the three who gave further information were a junk dealer, a craftsman and a mechanic.

Five people worked at various jobs assigned to them either through a government-funded poverty program or through a temporary work agency, e.g., Manpower.

Three were gas station attendants, and three were field laborers. One was a cashier in an amusement park; one was a theater concession stand worker, and one worked in a massage parlor. Another was a security guard.

Only three could be considered to be "white-collar" workers. Two of these held positions in state agencies, and one was a businessman.

Admittedly, the data are not complete, and thus it is possible that those employed defendants for whom there was no job description held higher-level jobs. The available data, however, strongly indicate that people who get into trouble with the law tend to be either unemployed or have employment which this society characterizes as working or lower class. 


\section{APPENDIX I}

SUMMARY PROFILE OF SELECTED OFFENSE TYPES: 1976 AND JULY THROUGH DECEMBER OF 1977

Following is a summary profile of six offenses: Burg I; Other Burg; Theft I; Other Property; CAID; Other Drugs. The variables on which the summary data are given are listed in the first column. Under the column labeled Hi 8 , the category of the variable with the highest percentage of cases for the particular offense is given. Under the column labeled Variation Tot 8 , the pluses and minuses symbolize the following. Four pluses $(++++)$ means that the $\mathrm{Hi}$ \% variable category is over $35 \%$ higher than the total percentage (for all offenses) of that variable category; three pluses $(+++)$ indicates that it is from 258 to 348 higher; two pluses (t+) refers to a percentage that is from $15 \%$ to $24 \%$ higher than the total; one plus $(+)$ means that it is from 58 to $14 \%$ higher. Minuses have the same meaning in the opposite direction, e.g., one minus (-) indicates that the $\mathrm{Hi}$ \&ariable category is from 58 to 148 lower than the total percentage of that category. Where the variable category was less than $5 \%$ higher or less than $5 \%$ lower, the word "same" has been used. Thus, for example, the highest percentage of Burg I in 1976 was closed by PG, and this percentage was ovex $35 \%$ higher than the total percentage of PG closings in 1976. Similarly, the highest percentage of Burg I defendants had public attorneys, but this percentage was only from 
$5 \%$ to 148 higher than the total percentage of cases handled by public attorneys. For easier interpretation of these summary profiles, the plus and minus codings are given below in concise form.

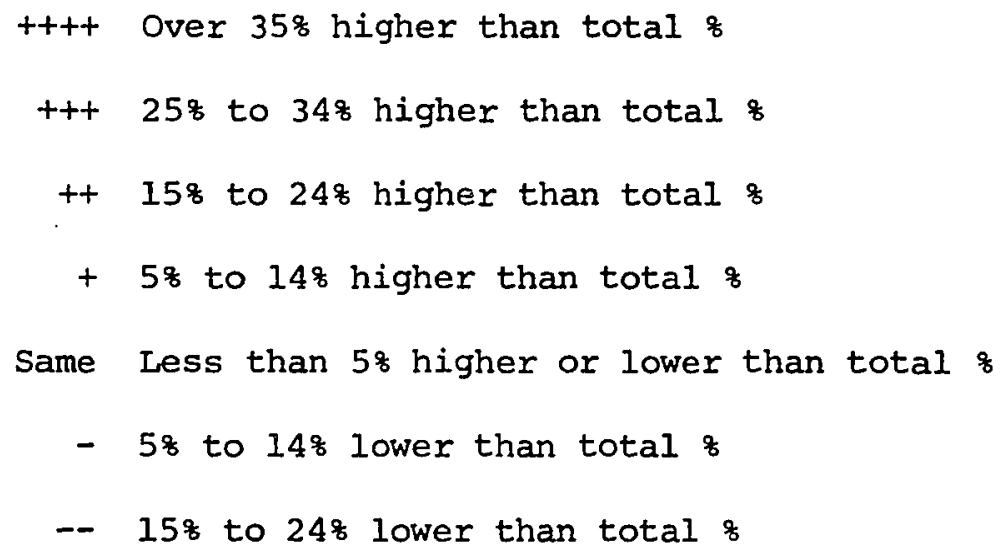


Burg I

$$
\begin{gathered}
1976 \\
(N=14)
\end{gathered}
$$

\begin{tabular}{|c|c|c|c|c|}
\hline \multirow[b]{2}{*}{ Variables } & \multicolumn{2}{|c|}{$\begin{array}{c}1976 \\
(N=14)\end{array}$} & \multicolumn{2}{|c|}{$(N=11)$} \\
\hline & $\underline{\mathrm{Hi}} \mathrm{z}$ & $\begin{array}{c}\text { Variation } \\
\text { Tot } 8 \\
\end{array}$ & $\underline{\mathrm{Hi}}$ & $\begin{array}{c}\text { Variation } \\
\text { Tot } 8 \\
\end{array}$ \\
\hline Type Clos & PG & ++++ & PG & ++++ \\
\hline Attorney & Public & + & Public & ++ \\
\hline Custody & Jail & +++ & Jail & ++ \\
\hline Sentence & Incarc & ++++ & Incarc & same \\
\hline Prior Record & Felony & ++ & Felony & - \\
\hline Education & Less HS & +++ & HS & + \\
\hline Employment & Unempl & + & Unempl & same \\
\hline Age & $17-20$ & $+++t$ & $17-20$ & ++++ \\
\hline
\end{tabular}

Other Burg

$$
\begin{gathered}
1976 \\
(N=22)
\end{gathered}
$$

\begin{tabular}{llr} 
Variables & Hi \& & $\begin{array}{r}\text { Variation } \\
\text { Tot } \&\end{array}$ \\
\cline { 3 - 3 } Type Clos & PG & same \\
Attorney & Public & - \\
Custody & No Jail & same \\
Sentence & Incarc & ++ \\
Prior Record & Felony & + \\
Education & HS & same \\
Employment & Unempl & - \\
Age & $2 l-30$ & -
\end{tabular}

$21-30$
1977

$(\mathrm{N}=11)$$$
(\mathrm{N}=8)
$$

Hi 8

Trial

Public

Jail

No Incarc

Felony

Less HS

Unemp1

$21-30$
Variation

Tot 8

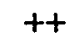

$++$

$++$

$++$

same

$++$

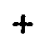


Theft I

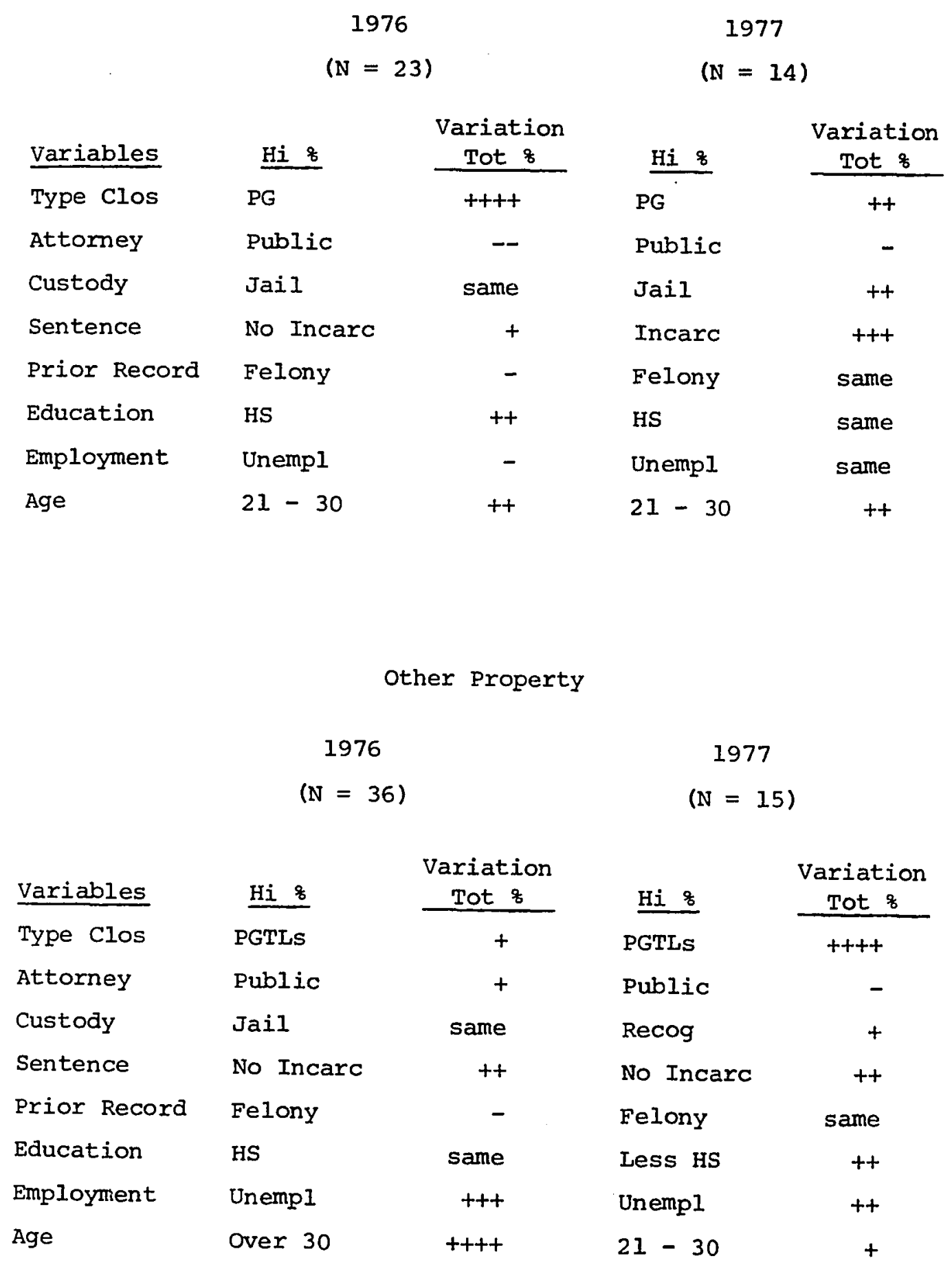


CAID

1976

$(\mathrm{N}=17)$
1977

$(\mathrm{N}=15)$

\begin{tabular}{|c|c|c|c|c|}
\hline Variables & $\underline{\mathrm{Hi}} 8$ & $\begin{array}{c}\text { Variation } \\
\text { Tot } 8 \\
\end{array}$ & Hi \& & $\begin{array}{c}\text { Variation } \\
\text { Tot } 8 \\
\end{array}$ \\
\hline Type Clos & $P G+D i s$ & $+t$ & PGTLS & + \\
\hline Attorney & Public & - & Public & + \\
\hline Custody & Recog & ++ & Recog & $++t$ \\
\hline Sentence & Incarc & + & No Incarc & ++ \\
\hline Prior Record & Felony & same & Felony & -- \\
\hline Education & HS & same & HS & $++t$ \\
\hline Employment & Unempl & + & Unempl & same \\
\hline Age & $21-30$ & same & $21-30$ & ++ \\
\hline
\end{tabular}

1976

$(\mathrm{N}=29)$
1977

$(\mathrm{N}=13)$

\begin{tabular}{llcllr} 
Variables & Hi \& & $\begin{array}{c}\text { Variation } \\
\text { Tot } 8\end{array}$ & & Hi \& & $\begin{array}{r}\text { Variation } \\
\text { Tot \& }\end{array}$ \\
\cline { 2 - 3 } Type Clos & PGTLs & ++++ & & PGTLS & ++++ \\
Attorney & Public & same & & Public & - \\
Custody & Recog & +++ & & Recog & ++ \\
Sentence & No Incarc & ++ & No Incarc & ++ \\
Prior Record & Felony & - & & Felony & same \\
Education & HS & + & & HS & + \\
Employment & Unempl & + & & Unempl & + \\
Age & $21-30$ & ++ & $21-30$ & same
\end{tabular}


APPENDIX J

\begin{abstract}
DESCRIPTIVE STATISTICS ON QUESTION ONE FROM INTERVIEWS WITH KEY COURT ACTORS
\end{abstract}

In Question One respondents were asked to rate the amount of consideration on a five-point scale (from five meaning very much consideration to one meaning no consideration) given each of 26 factors by the Public Defender's Office and by the District Attorney's Office. The means, modes, ranges and standard deviations of these ratings are given below. The order in which respondent groups are listed was determined by ranking means from high to low.

\title{
Mean Mode Range $\begin{aligned} & \text { Standard } \\ & \text { Deviation }\end{aligned}$
}

Strength of Prosecutor's

Case

$\begin{array}{llllll}\text { P.D.'s office: } & \text { Judges } & 5.0 & 5 & 0 & .0 \\ & \text { Prosecutors } & 4.7 & 5 & 1 & .5 \\ & \text { Pub Defenders } & 4.5 & 5 & 2 & .7 \\ \text { D.A.'s Office: } & \text { Judges } & 5.0 & 5 & 0 & .0 \\ & \text { Pub Defenders } & 4.5 & 5 & 2 & .6 \\ & \text { Prosecutors } & 4.4 & 5 & 2 & .8\end{array}$

Report of Arresting Officer

$\begin{array}{llcccr}\text { P.D.'s office: } & \text { Judges } & 3.6 & 3 & 2 & .9 \\ & \text { Pub Defenders } & 3.4 & 4 / 3 / 2 & 3 & 1.1 \\ \text { Prosecutors } & 3.3 & 3 & 4 & .9 \\ \text { D.A.'s Office: } & \text { Pub Defenders } & 4.3 & 5 & 3 & 1.0 \\ & \text { Judges } & 4.0 & 4 & 2 & .8 \\ & \text { Prosecutors } & 3.5 & 3 & 3 & .9\end{array}$


Mean Mode Range Deviation

Seriousness of offense

$\begin{aligned} \text { P.D.'s Office: } & \text { Pub Defenders } \\ & \text { Judges } \\ & \text { Prosecutors }\end{aligned}$

$4.2 \quad 5 / 4 \quad 2$

.8

$4.1 \quad 4 \quad 2$

.6

3.7

1.0

D.A.'s Office

Pub Defenders

4.7

4

3

5

Prosecutors

4.7

5

1

.5

Judges

4.5

$5 / 4$

.5

Prior Record of Defendant

$\begin{array}{lllllr}\text { P.D.'s Office: } & \text { Pub Defenders } & 3.5 & 4 & 3 & .9 \\ & \text { Prosecutors } & 3.4 & 3 & 3 & .9 \\ & \text { Judges } & 3.1 & 3 & 4 & 1.2 \\ \text { D.A.'s Office: } & \text { Prosecutors } & 4.5 & 5 & 2 & .7 \\ & \text { Pub Defenders } & 4.3 & 5 & 2 & .7 \\ & \text { Judges } & 3.8 & 4 & 3 & 1.0\end{array}$

Actual Guilt of Defendant

$\begin{array}{llcccr}\text { P.D.'s Office: } & \text { Judges } & 4.3 & 5 & 3 & 1.0 \\ & \text { Pub Defenders } & 2.9 & 5 / 1 & 4 & 1.8 \\ & \text { Prosecutors } & 2.8 & 3 & 4 & 1.2 \\ \text { D.A.'s Office: } & \text { Prosecutors } & 4.5 & 5 & 3 & .9 \\ & \text { Judges } & 4.4 & 5 & 3 & 1.1 \\ & \text { Pub Defenders } & 2.7 & 2 & 3 & 1.0\end{array}$

General Character of Defendant

$\begin{array}{lllllr}\text { P.D.'s Office: } & \text { Pub Defenders } & 3.3 & 3 & 3 & 1.0 \\ & \text { Prosecutors } & 3.2 & 3 & 4 & 1.4 \\ \text { Judges } & 2.3 & 3 & 2 & .9 \\ \text { D.A.'s Office: } & \text { Pub Defenders } & 3.0 & 3 & 2 & .7 \\ & \text { Judges } & 2.5 & 2 & 2 & .8 \\ & \text { Prosecutors } & 2.2 & 2 & 3 & 2.0\end{array}$

Attitudes of Defendant

$\begin{array}{lllllr}\text { P.D.'s Office: } & \text { Pub Defenders } & 3.4 & 4 & 4 & 1.2 \\ & \text { Prosecutors } & 3.1 & 3 & 3 & 1.0 \\ & \text { Judges } & 2.4 & 2 & 3 & .9 \\ \text { D.A.'s Office: } & \text { Pub Defenders } & 3.0 & 3 & 4 & 1.0 \\ & \text { Prosecutors } & 2.8 & 3 & 3 & .9 \\ & \text { Judges } & 2.5 & 2 & 2 & .8\end{array}$




\section{Mean Mode Range Deviation}

Defendant's Wishes

$\begin{array}{llcccr}\text { P.D.'s Office: } & \text { Pub Defenders } & 4.7 & 5 & 1 & .5 \\ & \text { Prosecutors } & 4.3 & 5 & 3 & .9 \\ & \text { Judges } & 4.3 & 5 & 4 & 1.4 \\ \text { D.A.'s Office: } & \text { Prosecutors } & 1.9 & 2 / 1 & 2 & .8 \\ & \text { Judges } & 1.5 & 1 & 2 & .8 \\ & \text { Pub Defenders } & 1.5 & 1 & 1 & .5\end{array}$

Tendencies of Juries

$\begin{array}{llcccr}\text { P.D.'s office: } & \text { Pub Defenders } & 4.1 & 4 & 2 & .6 \\ & \text { Judges } & 4.0 & 5 / 4 & 3 & 1.1 \\ & \text { Prosecutors } & 3.5 & 3 & 3 & .8 \\ \text { D.A.'s Office: } & \text { Judges } & 3.9 & 4 & 3 & .7 \\ & \text { Pub Defenders } & 3.8 & 4 / 3 & 2 & .8 \\ & \text { Prosecutors } & 3.2 & 3 & 2 & 1.0\end{array}$

Tendencies of Judges

P.D.'s Office: Pub Defenders

4.34

.6

Judges

$3.6 \quad 3$

.9

Prosecutors

3.34

1.3

D.A.'s Office: Judges

$3.8 \quad 3$

.9

Pub Defenders

Prosecutors

3.53

1.1

2.21

1.0

Community Attitudes

$\begin{array}{llcccr}\text { P.D.'s Office: } & \text { Pub Defenders } & 2.1 & 2 & 2 & .7 \\ & \text { Judges } & 2.1 & 2 / 1 & 4 & 1.4 \\ & \text { Prosecutors } & 1.8 & 2 & 1 & .4 \\ \text { D.A.'s office: } & & 4.0 & 5 & 3 & 1.0 \\ & \text { Pub Defenders } & 3.8 & 5 & 3 & 1.3 \\ & \text { Judges } & 3.6 & 4 & 2 & .6\end{array}$

Victim Needs

$\begin{array}{llcccr}\text { P.D.'s office: } & \text { Prosecutors } & 2.2 & 2 & 4 & 1.2 \\ & \text { Pub Defenders } & 2.0 & 1 & 3 & 1.0 \\ & \text { Judges } & 1.6 & 1 & 1 & .5 \\ \text { D.A.'s Office: } & \text { Prosecutors } & 4.2 & 4 & 2 & .6 \\ & \text { Pub Defenders } & 3.4 & 4 / 3 & 2 & .6 \\ & \text { Judges } & 3.3 & 4 & 2 & .9\end{array}$


Mean Mode Range Deviation

Office Policy

$\begin{array}{llccrr}\text { P.D.'s office: } & \text { Judges } & 4.0 & 5 / 4 & 3 & 1.1 \\ & \text { Prosecutors } & 2.6 & 3 / 1 & 4 & 1.4 \\ & \text { Pub Defenders } & 1.2 & 1 & 1 & .4 \\ \text { D.A.'s office: } & \text { Pub Defenders } & 4.6 & 5 & 1 & .5 \\ & \text { Judges } & 4.4 & 5 & 2 & .7 \\ & \text { Prosecutors } & 4.1 & 4 & 2 & .7\end{array}$

Political Concerns

$\begin{array}{llcccc}\text { P.D.'s office: } & \text { Prosecutors } & 1.6 & 2 / 1 & 1 & .7 \\ & \text { Judges } & 1.1 & 1 & 1 & .4 \\ \text { Pub Defenders } & 1.1 & 1 & 2 & .3 \\ \text { D.A.'s Office: } & \text { Pub Defenders } & 4.2 & 5 & 3 & .9 \\ & \text { Judges } & 3.6 & 4 & 3 & .9 \\ & \text { Prosecutors } & 2.1 & 3 & 2 & .9\end{array}$

Career Advancement Concerns

$\begin{array}{llcccr}\text { P.D.'s Office: } & \text { Judges } & 2.0 & 3 / 1 & 2 & .9 \\ & \text { Prosecutors } & 1.5 & 1 & 1 & .5 \\ & \text { Pub Defenders } & 1.3 & 1 & 1 & .5 \\ \text { D.A.'s Office: } & \text { Pub Defenders } & 3.4 & 3 & 4 & 1.0 \\ & \text { Judges } & 2.9 & 5 / 2 / 1 & 4 & 1.6 \\ & \text { Prosecutors } & 1.4 & 1 & 1 & .5\end{array}$

Special Interest Groups

$\begin{array}{llcccr}\text { P.D.'s Office: } & \text { Judges } & 2.0 & 2 & 2 & .8 \\ & \text { Prosecutors } & 1.8 & 1 & 3 & .9 \\ & \text { Pub Defenders } & 1.1 & 1 & 1 & .3 \\ \text { D.A.'s Office: } & \text { Pub Defenders } & 3.7 & 4 & 4 & 1.2 \\ & \text { Judges } & 3.3 & 4 / 3 / 2 & 3 & 1.1 \\ & \text { Prosecutors } & 1.6 & 2 & 2 & .6\end{array}$

Relationship with Adversary Attorney

$\begin{array}{lllllr}\text { P.D. 's Office: } & \text { Pub Defenders } & 2.8 & 3 & 3 & .8 \\ & \text { Judges } & 2.8 & 3 & 4 & 1.2 \\ & \text { Prosecutors } & 2.2 & 2 & 3 & .9 \\ \text { D.A.'s Office: } & \text { Judges } & 3.0 & 3 & 4 & 1.4 \\ & \text { Pub Defenders } & 2.9 & 3 & 3 & .7 \\ & \text { Prosecutors } & 2.1 & 1 & 3 & 1.0\end{array}$


Mean Mode $\underline{\text { Range }} \begin{aligned} & \text { Standard } \\ & \text { Deviation }\end{aligned}$

Maintenance of Good Relations With Others in Court System

$\begin{array}{lllllr}\text { P.D.'s Office: } & \text { Judges } & 2.8 & 3 & 2 & .7 \\ & \text { Prosecutors } & 2.5 & 2 & 3 & .9 \\ & \text { Pub Defenders } & 2.1 & 2 & 4 & 1.1 \\ \text { D.A.'s Office: } & \text { Pub Defenders } & 3.0 & 2 & 4 & 1.2 \\ & \text { Judges } & 2.9 & 3 & 2 & .6 \\ & \text { Prosecutors } & 2.6 & 3 & 3 & .8\end{array}$

Avoiding Court Overload

$\begin{array}{llcccr}\text { P.D.'s Office: } & \text { Judges } & 2.4 & 1 & 4 & 1.5 \\ & \text { Prosecutors } & 1.5 & 1 & 2 & .9 \\ & \text { Pub Defenders } & 1.4 & 1 & 2 & .6 \\ \text { D.A.'s Office: } & \text { Judges } & 3.3 & 5 / 4 / 3 / 1 & 4 & 1.6 \\ & \text { Pub Defenders } & 2.1 & 3 & 2 & .8 \\ & \text { Prosecutors } & 1.6 & 1 & 2 & .8\end{array}$

Conserving Staff Resources

$\begin{array}{llcccr}\text { P.D.'s Office: } & \text { Judges } & 3.3 & 5 / 3 & 4 & 1.5 \\ & \text { Pub Defenders } & 2.1 & 2 & 4 & 1.1 \\ & \text { Prosecutors } & 2.1 & 3 & 2 & .9 \\ \text { D.A.'s Office: } & \text { Judges } & 3.4 & 3 & 3 & 1.1 \\ & \text { Prosecutors } & 2.4 & 3 & 2 & .8 \\ & \text { Pub Defenders } & 2.3 & 2 & 3 & .9\end{array}$

Speedy Case Settlement

$\begin{array}{llcccr}\text { P.D.'s office: } & \text { Judges } & 3.1 & 3 & 4 & 1.1 \\ & \text { Prosecutors } & 2.5 & 3 / 2 & 3 & .8 \\ & \text { Pub Defenders } & 2.4 & 3 / 2 & 3 & 1.0 \\ \text { D.A.'s Office: } & \text { Judges } & 3.9 & 3 & 2 & 1.0 \\ & \text { Pub Defenders } & 2.9 & 2 & 3 & 1.0 \\ & \text { Prosecutors } & 2.5 & 3 & 3 & 1.0\end{array}$

Due Process

$\begin{array}{lllcrr}\text { P.D.'s office: } & \text { Pub Defenders } & 4.5 & 5 & 2 & .8 \\ & \text { Judges } & 4.5 & 5 & 2 & .8 \\ & \text { Prosecutors } & 4.2 & 5 & 3 & 1.1 \\ \text { D.A.'s Office: } & \text { Judges } & 4.4 & 5 & 2 & .7 \\ & \text { Prosecutors } & 3.8 & 5 / 3 & 3 & 1.1 \\ & \text { Pub Defenders } & 2.9 & 4 / 2 & 3 & 1.0\end{array}$


Mean Mode $\quad$ Range $\quad \begin{aligned} & \text { Standard } \\ & \text { Deviation }\end{aligned}$

Crime Control

\begin{tabular}{|c|c|c|c|c|c|}
\hline P.D.'s Office: & Pub Defenders & 2.0 & 1 & 4 & 1.3 \\
\hline & Prosecutors & 1.9 & 2 & 2 & .8 \\
\hline & Judges & 1.8 & 1 & 2 & .9 \\
\hline D.A.'s Office: & Prosecutors & 4.3 & 5 & 2 & .8 \\
\hline & Judges & 4.1 & 5 & 2 & .6 \\
\hline & Pub Defenders & 3.9 & 4 & 3 & 1.0 \\
\hline
\end{tabular}

